\title{
The modern enterprise and the stock market : exploring the effects of uncertainty on the valuation and on the financing of innovation and intangibles
}

Citation for published version (APA):

Pacher, S. (2012). The modern enterprise and the stock market : exploring the effects of uncertainty on the valuation and on the financing of innovation and intangibles. [Doctoral Thesis, Maastricht University]. Datawyse / Universitaire Pers Maastricht. https://doi.org/10.26481/dis.20121206sp

Document status and date:

Published: 01/01/2012

DOI:

10.26481/dis.20121206sp

Document Version:

Publisher's PDF, also known as Version of record

Please check the document version of this publication:

- A submitted manuscript is the version of the article upon submission and before peer-review. There can be important differences between the submitted version and the official published version of record.

People interested in the research are advised to contact the author for the final version of the publication, or visit the DOI to the publisher's website.

- The final author version and the galley proof are versions of the publication after peer review.

- The final published version features the final layout of the paper including the volume, issue and page numbers.

Link to publication

\footnotetext{
General rights rights.

- You may freely distribute the URL identifying the publication in the public portal. please follow below link for the End User Agreement:

www.umlib.nl/taverne-license

Take down policy

If you believe that this document breaches copyright please contact us at:

repository@maastrichtuniversity.nl

providing details and we will investigate your claim.
}

Copyright and moral rights for the publications made accessible in the public portal are retained by the authors and/or other copyright owners and it is a condition of accessing publications that users recognise and abide by the legal requirements associated with these

- Users may download and print one copy of any publication from the public portal for the purpose of private study or research.

- You may not further distribute the material or use it for any profit-making activity or commercial gain

If the publication is distributed under the terms of Article 25fa of the Dutch Copyright Act, indicated by the "Taverne" license above, 
THE MODERN ENTERPRISE AND THE STOCK MARKET:

EXPLORING THE EFFECTS OF UNCERTAINTY ON THE VALUATION AND FINANCING OF INNOVATION AND INTANGIBLES 
The Modern Enterprise and the Stock Market: Exploring the Effects of Uncertainty on the Valuation and Financing of Innovation and Intangibles

(C) Sebastian Pacher

All rights reserved. No part of this publication may be reproduced, stored in a retrieval system, or transmitted, in any form, or by any means, electronic, mechanical, photocopying, recording or otherwise, without the prior permission of the writing author.

ISBN: 9789461592002 


\title{
THE MODERN ENTERPRISE AND THE STOCK MARKET:
}

EXPLORING THE EFFECTS OF UNCERTAINTY ON THE VALUATION AND FINANCING OF INNOVATION AND INTANGIBLES

\author{
PROEFSCHRIFT
}

TER VERKRIJGING VAN DE GRAAD VAN DOCTOR

AAN DE UNIVERSITEIT MAASTRICHT, OP GEZAG VAN DE RECTOR MAGNIFICUS,

PROF. DR. L.L.G. SOETE

VOLGENS HET BESLUIT VAN HET COLLEGE VAN DECANEN,

IN HET OPENBAAR TE VERDEDIGEN

OP DONDERDAG 6 DECEMBER 2012 OM 10.00 UUR

DOOR

Sebastian Pacher

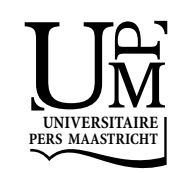




\section{Promotor:}

Prof. dr. John Hagedoorn

\section{Beoordelingscommissie:}

Prof. dr. Franz C. Palm (voorzitter)

Prof. dr. Bronwyn H. Hall

Dr. Katrin Hussinger

Dit onderzoek werd financieel mogelijk gemaakt door Maastricht Research School of Economics of Technology and Organizations (METEOR). 


\section{Table of Contents}

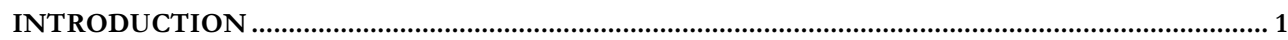

1.1. R\&D AND THE STOCK MARKET IN THE 'CHANDLERIAN’ INDUSTRIAL ENTERPRISE ............................................

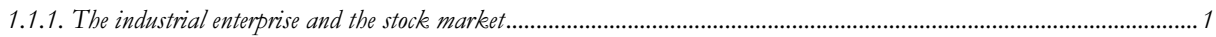

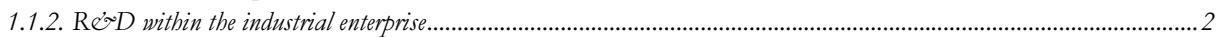

1.2. PRESSURES FOR CHANGE: THE INCREASING IMPORTANCE OF KNOWLEDGE AND INTERFIRM ALLIANCES3

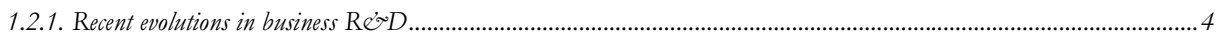

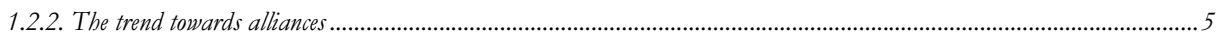

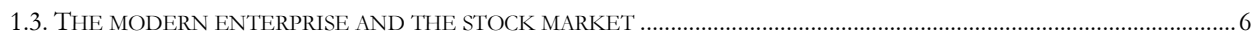

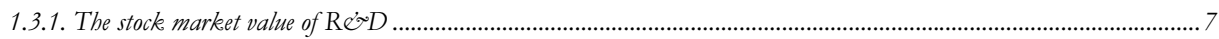

1.3.2. The changing role of the stock market for $R \& \dot{D}$ financing....................................................................................... 7

1.3.3. The stock market value of alliances and alliance portfolios............................................................................................ 8

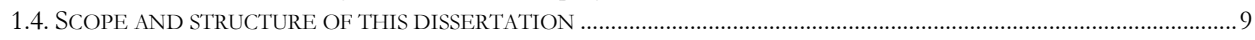

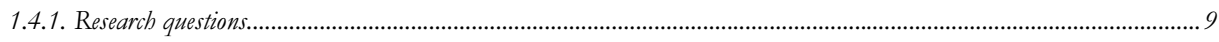

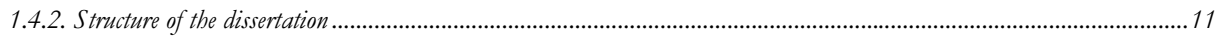

THE EFFECTS OF R\&D AND PATENTS ON ANALYST DISAGREEMENT AND THE MARKET

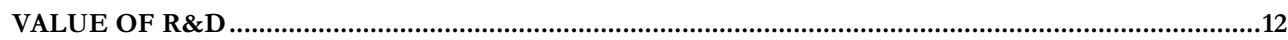

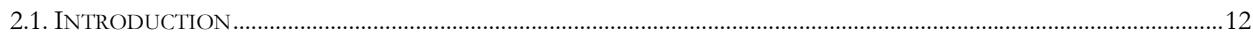

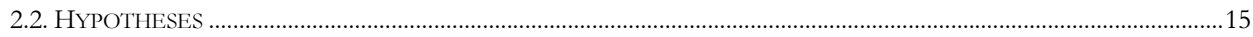

2.2.1. The link between R\&D investments, uncertainty, and analyst forecast dispersion .....................................................15

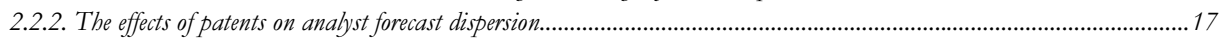

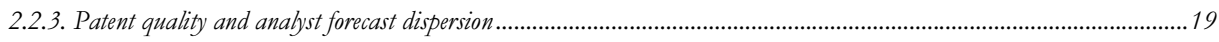

2.2.4. Analyst forecast dispersion and the relationship between $\mathrm{R} \& \mathrm{D}$ and firm value ......................................................21

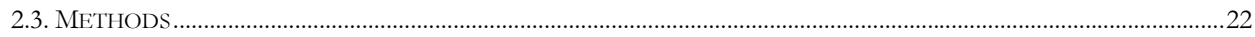

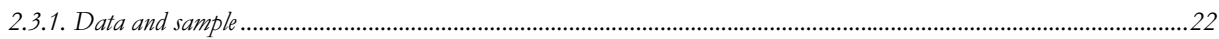

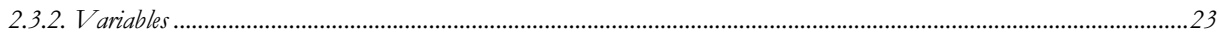

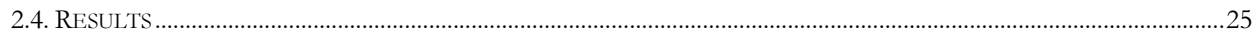

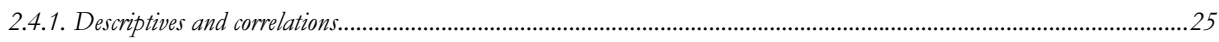

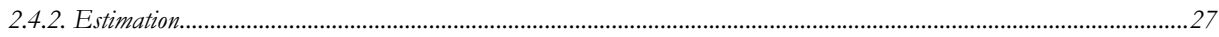

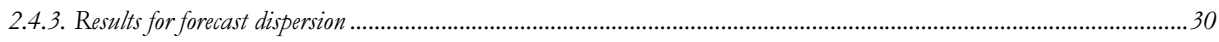

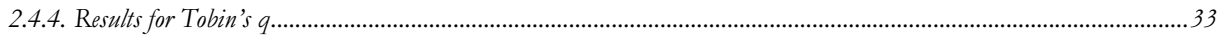

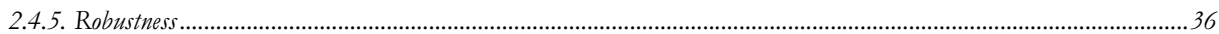

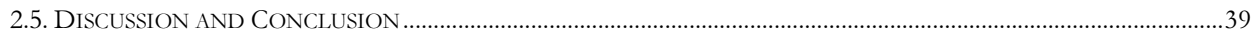

ANALYST DISAGREEMENT, INVESTOR RECOGNITION, AND CORPORATE INVESTMENT EVIDENCE FROM A PANEL OF MANUFACTURING FIRMS BETWEEN 1984 AND 2006 ............. 42

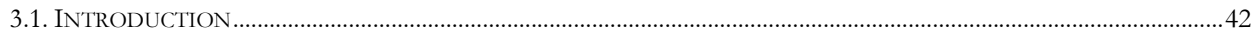

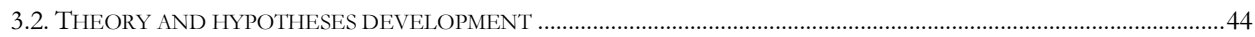

3.2.1. Disagreement and firm investment: Competing bypotheses....................................................................................4

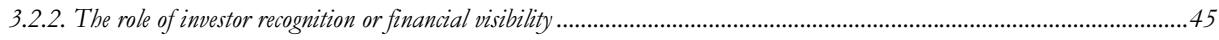

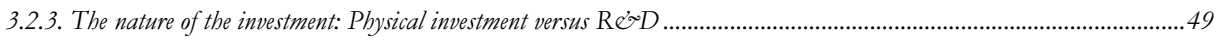

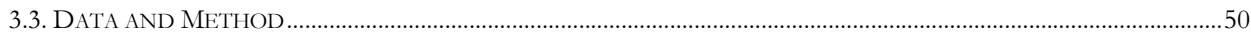




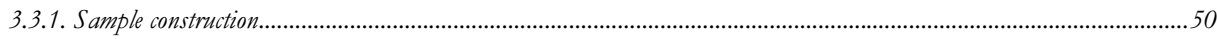

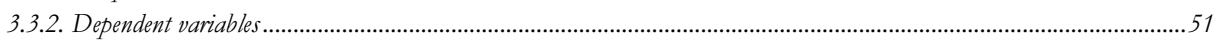

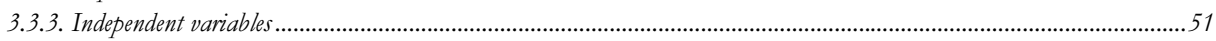

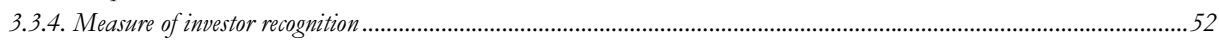

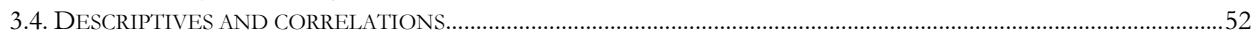

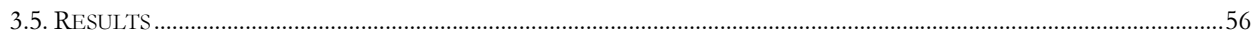

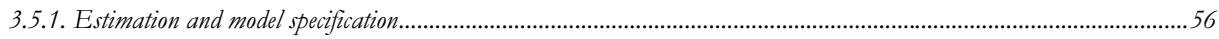

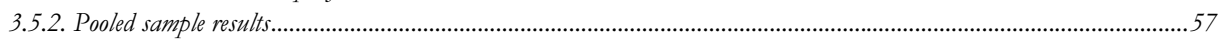

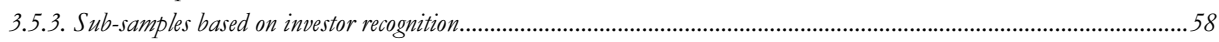

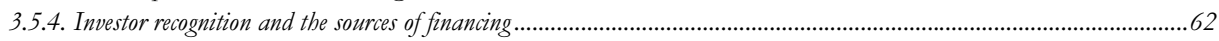

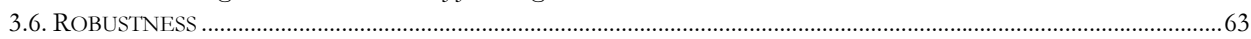

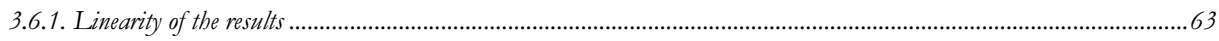

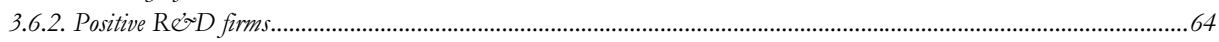

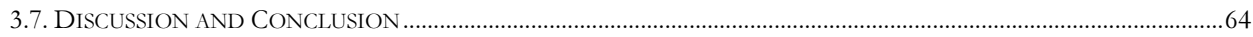

\section{UNCERTAINTY AND THE MARKET VALUE OF EXPLORATORY AND EXPLOITATIVE}

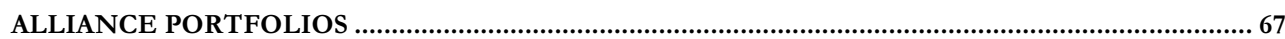

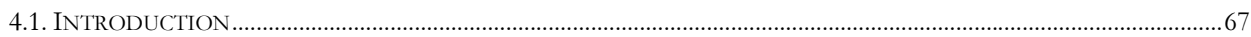

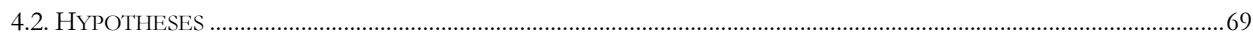

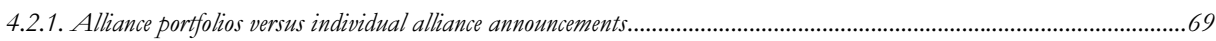

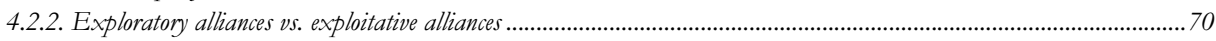

4.2.3. Uncertainty and the market value of exploratory alliance portfolios ..........................................................................72

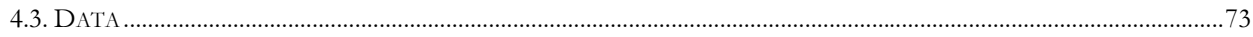

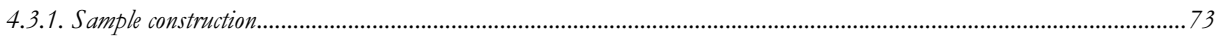

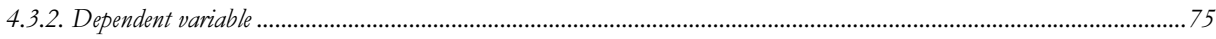

4.3.3. Measuring exploratory and exploitative alliance portfolios ....................................................................................75

4.3.4. Measuring uncertainty about firm value......................................................................................................... 76

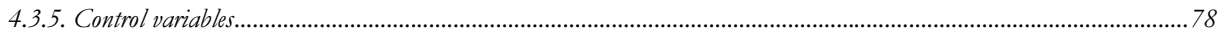

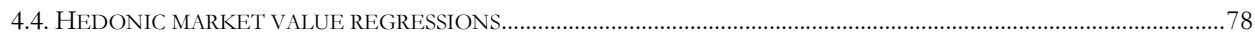

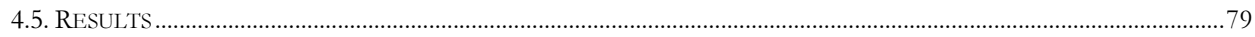

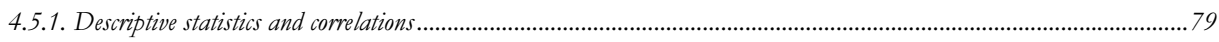

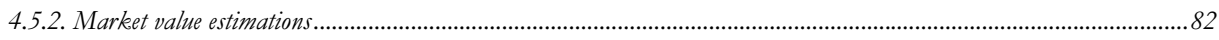

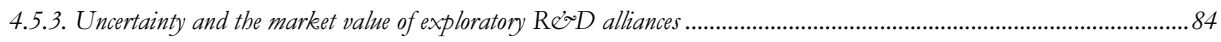

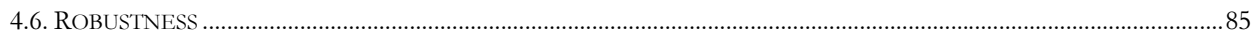

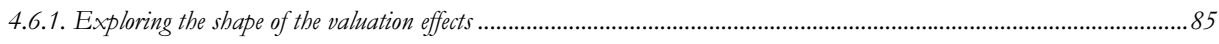

4.6.2. The valuation of exploratory alliances and the burst of the late 1990's technology bubble..............................................86

4.6.3. Fundamental risk and the market value of $\mathrm{R} \& D$, patents, and forward citations ....................................................87

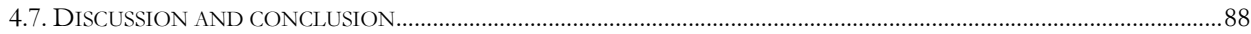

\section{WHEN DOES THE MARKET PERCEIVE ALLIANCES TO BE (NOT) RISKY? EVIDENCE FROM ALLIANCE PORTFOLIOS AROUND THE BURST OF THE LATE 1990'S TECHNOLOGY BUBBLE}

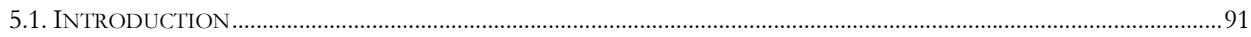

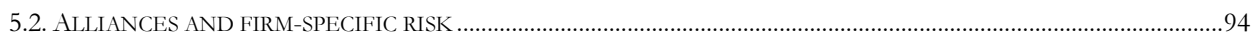

5.2.1. An alliance portfolio perspective on firm-specific risk ........................................................................................96

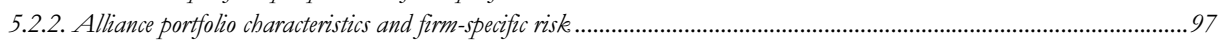

5.3. UNCERTAINTY SHOCKS AND THE EFFECTS OF ALLIANCE PORTFOLIOS ON FIRM-SPECIFIC RISK ......................101

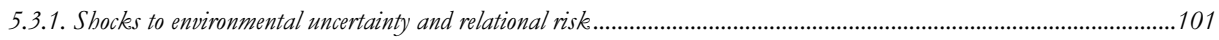

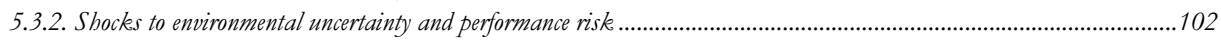

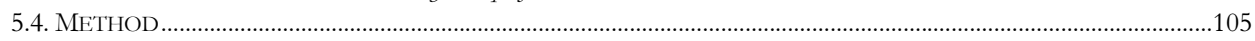

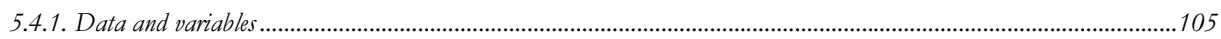

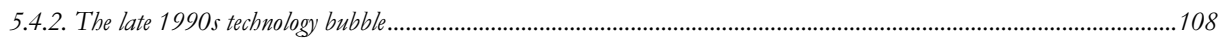

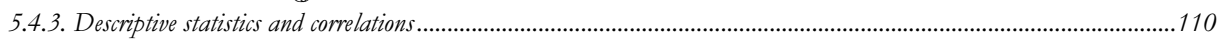




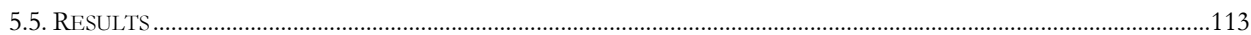

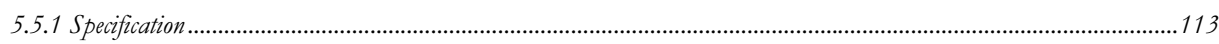

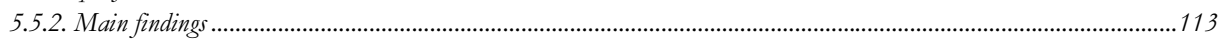

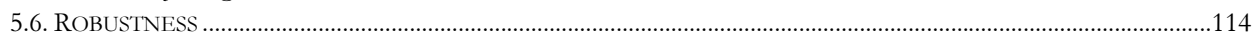

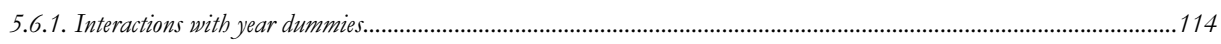

5.6.2. Fixing the alliance portfolio variables at their initial conditions ..............................................................................117

5.6.3 Accounting for the correlation between alliance portfolio size and firm size...........................................................118

5.6.4. Testing for potential biases in the alliance data ................................................................................................118

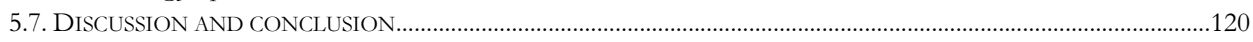

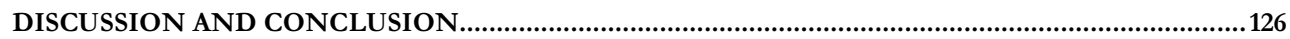

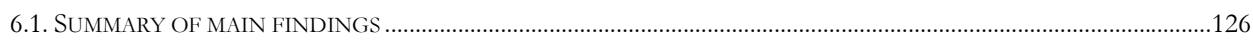

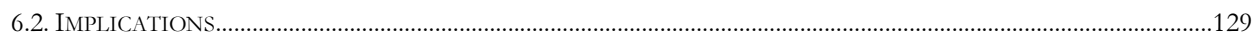

6.3. LIMITATIONS AND SUGGESTIONS FOR FUTURE RESEARCH ..........................................................................130

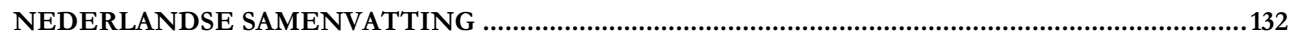

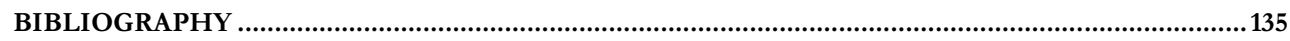

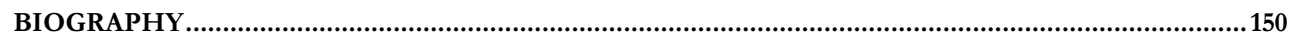




\section{List of Tables}

TABLE 2.1: DESCRIPTIVE STATISTICS

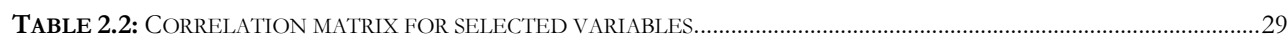

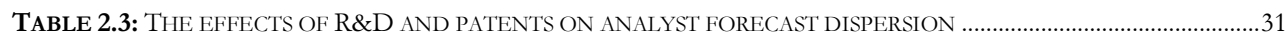

TABLE 2.4: SEMI ELASTICITIES FOR R\&D STOCK AND PATENT STOCK MEASURES ...........................................................33

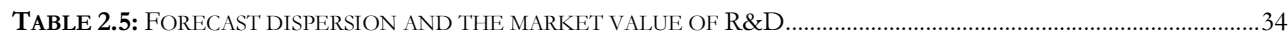

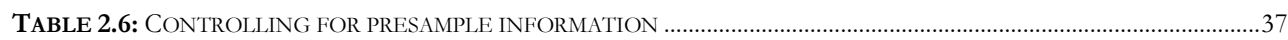

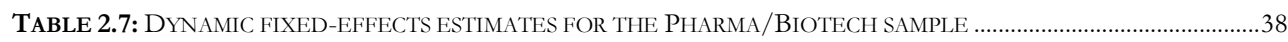

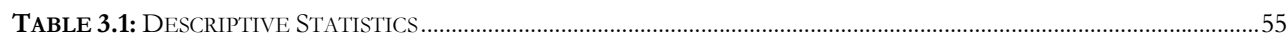

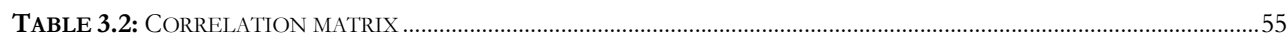

TABLE 3.3: DESCRIPTIVES FOR SAMPLE QUARTILES OF HIGH AND LOW INVESTOR RECOGNITION ..............................56

TABLE 3.4: POOLED ESTIMATES OF FORECAST DISPERSION ON FIRM INVESTMENT …………….................................59

TABLE 3.5: FORECAST DISPERSION AND CORPORATE INVESTMENT - UPPER AND LOWER QUARTILE OF INVESTOR

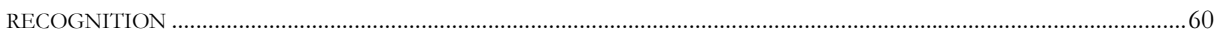

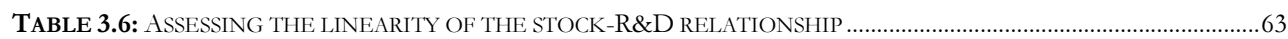

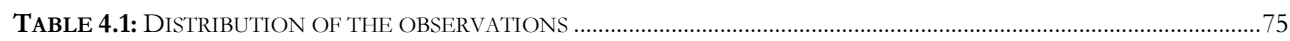

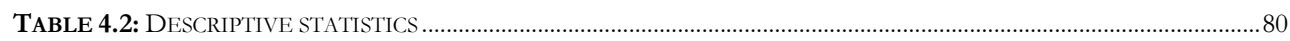

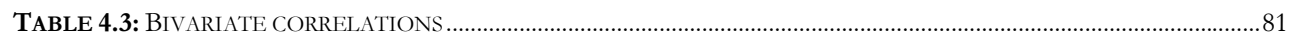

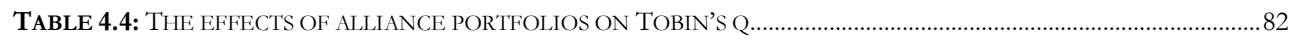

TABLE 4.5: ALLIANCE PORTFOLIOS, TOBIN'S Q, AND THE EFFECTS OF FIRM-SPECIFIC RISK AND UNCERTAINTY........83

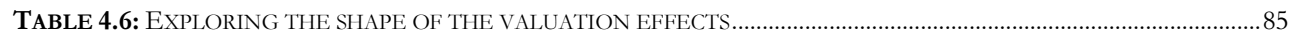

TABLE 4.7: EXPLORATORY ALLIANCES AND MARKET VALUE: DIFF-IN-DIFF ESTIMATES .............................................86

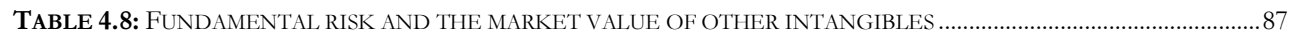

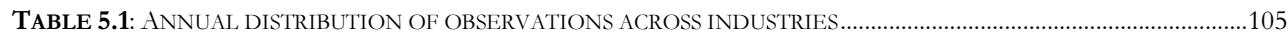

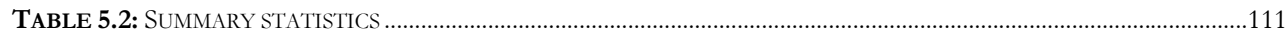

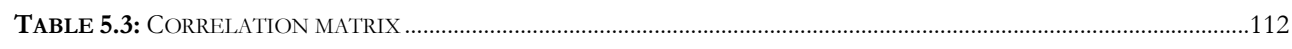

TABLE 5.4: THE EFFECTS OF ALLIANCE PORTFOLIOS ON FIRM-SPECIFIC RISK ……...............................................115

TABLE 5.5: THE EFFECTS OF ALLIANCE PORTFOLIOS ON FIRM-SPECIFIC RISK ……...............................................116

TABLE 5.6: THE EFFECTS OF (INITIAL) ALLIANCE PORTFOLIOS ON FIRM-SPECIFIC RISK ………………………..........119

TABLE 5.7: USING THE MERIT-CATI DATABASE TO CONSTRUCT R\&D ALLIANCE PORTFOLIO SIZE ........................121 


\section{List of Figures}

FIGURE 1.1: INDUSTRY FINANCED GERD IN ABSOLUTE TERMS AND AS PERCENTAGE OF GDP IN THE UNITED STATES

FIGURE 2.2: PATENT QUALITY INDICATORS OVER THE SAMPLE PERIOD 26

FIGURE 2.3: RENEWED PATENTS AND TRIADIC PATENTS AS PERCENTAGE OF THE PATENT STOCK 26

FigURE 2.4: MARGINAL EFFECT OF R\&D ON TOBIN'S Q FOR DIFFERENT VALUES OF FORECAST DISPERSION 36

FigurE 3.1: ILLUSTRATION OF HYPOTHESES 1A TO 2B

FIGURE 3.2: FORECAST DISPERSION AND RESIDUAL ANALYST COVERAGE (1984-2006) 53

FigURE 3.3: EVOLUTION OF CAPITAL EXPENDITURES AND R\&D (1984-2006) 53

FigurE 3.4: THE SOURCES OF FINANCING OVER TIME (1984-2006)

FigURE 3.5: TOTAL SALES AND PURCHASES OF COMMON AND PREFERRED STOCK IN LOGS OF THOUSAND US\$ (1984-2006)

FIGURE 3.6: MARGINAL EFFECT OF STK ON R\&D FOR DIFFERENT VALUES OF FORECAST DISPERSION 62

FIGURE 3.7: SUMMARY OF MAIN FINDINGS

FIGURE 4.1: CLASSIFICATION OF ALLIANCE PORTFOLIOS

Figure 4.2: MARGINAL EFFECT OF EXPLORATORY ALLIANCES ON TOBIN'S Q FOR DIFFERENT VALUES OF FIRMSPECIFIC RISK $\quad 84$

FIGURE 5.1: DEVELOPMENT OF STOCK PRICE INDICES OVER THE SAMPLE PERIOD 109

FIGURE 5.2: AGGREGATE RISK BY YEAR AND INDUSTRY 111

FIGURE 5.3: COEFFICIENT ESTIMATES ALLIANCE PORTFOLIOS AND FIRM-SPECIFIC RISK 117 



\section{Preface}

About four and a half years ago, at the last day of one of my internships in the so called 'real world', a colleague of mine told me: Don't study too long or you will become an old lonesome nerd. I thought back about these words a couple of times and every now and then - especially when I was frustrated by the misbehavior of data or by hypotheses that simply refused to be written down in an understandable manner - I really wondered whether my colleague's prophecy has already come true.

Her statement essentially predicts a positive effect of the years of education on a person's nerdiness or loneliness as perceived by other members of the society. The two little words too long probably suggest that the expected relationships are non-linear. From my experience as a $\mathrm{PhD}$ student, I know that it is always good to assume that they might look like something close to an inverted u-shape. This also makes intuitive sense (note that this sentence is often extremely helpful in the absence of a well developed theory). Studying for a couple of years - let's say 4 to 6 - transforms the raw material (i.e., students) into eloquent young adults with excellent social skills and with a large number of social connections. Unfortunately, the marginal effects of education inevitably decline for those who can't get enough and may even become negative. After about 10 years of studying, the once so polished social skills might degenerate to levels only comparable to those of the weirdest computer geek.

So what was the effect of studying too long on me? Have I really become an old lonesome nerd in the end? I have to admit that it was not always easy to write this dissertation. In retrospect it seems to have been an incredibly long journey. A main reason for why I found it so difficult to complete this work is the fact that my papers often touch upon a diversity of different streams of literature such as financial economics, the economics of innovation, corporate strategy, or the management of alliances and alliance portfolios. When I started working on my dissertation I was quite unfamiliar with many of these literatures. My way of dealing with this issue was to increase my reading efforts. This worked quite well but it was also extremely time consuming.

An even more severe problem for me was the tendency of scholars from different disciplines to often hold completely different believes about the nature of firms or about the question why firms exist in the first place. Rajan and Zingales (2000) and Zingales (2000) point out that many if not most studies in finance presume a firm to be a nexus of explicit contracts. In this research, neoclassical theory and agency theory are the dominant theories of the firm. In contrast, researchers in the field of innovation, management, and alliance research tend to draw heavily from evolutionary economics (Nelson and Winter, 1982), the resource-based view (Barney, 1991; Wernerfelt, 1984), or the dynamic capabilities' perspective (Teece, Pisano, and Shuen, 1997). Unfortunately, the basic assumptions regarding the nature of the firm fundamentally influence the questions that researchers deem to be interesting and worthwhile studying. And to make things even worse, accepted research methods also differ substantially across disciplines. To quote O'Sullivan (2006: 260): 
"If the only barrier to intellectual integration was lack of familiarity with each other's work then it would be relatively easy to overcome. In addition to theoretical differences (...), methodological differences pose a formidable barrier to the integration of research on finance and innovation."

All in all, writing this dissertation was quite time and attention consuming. Time for social activities was scarce, especially in the first two years of being a $\mathrm{PhD}$ student. The threat of becoming a lonesome nerd was therefore a real one. ${ }^{1}$ It is up to the people who know me to judge in how far I am a lonesome nerd. From my perspective I am certainly not! The credits for this are not entirely my own, however. There are a number of people to whom I am deeply indebted. First, I would like to thank my promoter, John Hagedoorn, for his patience and especially for his trust in my work. Thank you also for enabling me to spend almost a quarter of my time as your $\mathrm{PhD}$ student in the United States. It was an invaluable experience for me! Thanks also to David Teece and Josh Lerner for being my faculty sponsors.

I also wish to thank my reading committee Franz Palm and Bronwyn Hall. I believe that your comments have contributed a lot to the quality of this dissertation. I am thankful for the continuous support of Katrin Hussinger (who is also part of my reading committee). Without Katrin and Wim Swaan, I would probably not have considered enrolling in a PhD program in the first place.

Further, I am thankful to Luc Soete and Pierre Mohnen for giving me the opportunity to continue my academic work at UNU-MERIT in Maastricht. Dirk Czarnitzki always had an open ear for econometric questions. Thanks a lot for this!

Special thanks go to Myrhte Frenk who accompanied me from the very first to the very last day of my PhD. Thanks for all the Take Five and Tribunal evenings and for sharing the long hours in the office. Thanks to Johannes Dick, Antonio della Malva, and Franz Schwiebacher for the good times we had in Maastricht, Toulouse, Turunç, and Mannheim. I also wish to thank all colleagues with whom I have enjoyed the last years at O\&S. In somewhat random order these are Bart, Nico, Gabri, Andrea, Daniela, Jia, Ann-Kristin, Désirée, Kristin, Tom, Roy, Maarten, Sjir, and Harold. I also thank an anonymous rootkit, which forced me to write the final version of this dissertation on an apple computer and I thank myself for having saved all important data on an external hard drive.

Mein größter Dank gilt meinen Eltern, die mich in allem was ich tue unterstützen und die mir bei allen wichtigen Entscheidungen mit Hilfe und mit Rat zur Seite stehen. Gleiches gilt für Grantl, Tina, Tom, Jona und Mika. Auch wenn es für Euch bestimmt nicht immer leicht nachzuvollziehen war, was ich so genau in Maastricht, Cambridge, oder Berkeley gemacht habe, hätte ich es ohne Euch nicht geschafft. Danke! Außerdem danke ich Bo, Dele, Jo, Kiste, Ritze, Tommy und all den Anderen, die in den letzten Jahren meine Launen ertragen mussten. Thanks also go to Claire and Ed Rousseau for their hospitality in the last year and to Martine for sharing her dreams with me.

\footnotetext{
1 According to the Oxford Dictionary (2012), a nerd is "a foolish or contemptible person who lacks social skills or is boringly studious." As a practical example for a nerd, the dictionary suggests a nerd is someone who has never asked a girl to dance, which I actually never did.
} 


\section{Chapter 1}

"In no technology is 'what works best and why' perfectly understood. This is why inventive work is inherently uncertain."

Richard R. Nelson (1990: 197)

\section{Introduction}

\section{1. $R \& D$ and the stock market in the 'Chandlerian' industrial enterprise}

The last decades have seen some dramatic changes in the nature of the firm. Not so long ago, a firm's value - at least that of manufacturing firms - was largely determined by specialized and mostly physical assets such as machinery, furnaces, stills or other production facilities that were owned by the firm. The typical industrial enterprise could increase its output “ $\ldots$ by adding more machines and workers to operate them" (Chandler, 1990: 21). The legal and economic boundaries of the firm were clearly defined on the basis of tangible asset ownership (Rajan and Zingales, 2000: 31). More often than not, high capital and scale intensities of production technologies provided sizeable first mover advantages, because potential new entrants into an industry faced high entry costs. Firms typically achieved a competitive advantage through the exploitation of economies of scale and scope and through the efficient managerial planning, coordination, and control of production, marketing, and distribution processes (Chandler, 1990). Most manufacturing industries in the US but also in other industrialized economies, such as Britain or Germany, used to be dominated by a few very large and highly vertically integrated industrial enterprises. These firms were controlled by a strong central management at the top of the corporate hierarchy (Chandler, 1990; Mowery, 2009). ${ }^{2}$

\subsubsection{The industrial enterprise and the stock market}

The industrial enterprises that emerged in the 19th century were the first firms to use public stock markets for investment financing. The first initial public offerings (IPOs) were those of the large American railway companies in the first half of the nineteenth century. These firms were also the first to employ thousands of people, the first to develop modern methods of business administration, and the first to have a cadre of professional managers who specialized in administration, developed standards of performance measurement, and published their ideas in journals such as the American Railroad Journal (Brands, 2010). Due to the enormous capital demands and the due to the riskiness of future returns, these firms started to explore new ways of financing. Whereas these firms traditionally used to rely on bank financing, “... their business

\footnotetext{
${ }^{2}$ An exception might have been the postwar IT industry in the United States, where small firms played an important role in the commercialization of new technologies (Mowery, 2009: 10).
} 
plans were too risky, their collateral assets to meager, or the banks too cautious to cover all the roads' investment needs" (Brands, 2010: 24).

As bank financing was not well suited for their capital demands, railway companies began to sell partial ownership (i.e., stock) to public investors, which - for the first time in American economic history - lead to a separation of ownership and management (or control). This separation became a defining feature of the industrial enterprise, especially in the United States but also in other industrialized countries in Western Europe (Chandler, 1990: 140: Lazonick, 2006: 38). Initially, the outside investors used to be wealthy individuals who had long-term interests in the firms in which they invested. This changed substantially after World War II, when pension and mutual funds became important investors. The managers of these funds typically focused on rather short-term returns (Chandler, 1990: 625).

Several characteristics of the industrial enterprise facilitated the financing of investments through a dispersed set of outside investors. First, strong vertical integration enabled the planning and scheduling of cash flows. Uniform accounting and auditing procedures could be set up “... to provide information concerning performance and resource allocation” (Chandler, 1990: 33). This information was quantifiable and could easily be communicated to shareholders and other stock market participants. Zingales (2000: 1642) describes this in the following way:

"[T] he size and the asset intensity of the traditional firm required more investment and more risk taking than were within the capacity of the management. The control conferred by the ownership of crucial assets, however, made outside ownership feasible. Therefore the traditional firm came to be owned by disperse investors."

Further, due to the strong concentration of control over critical assets at the top of the managerial hierarchy, the alignment of interests of shareholders and managers was relatively easy, for instance, by tying the salary of top managers to stock price developments (Rajan and Zingales, 2000).

\subsection{2. $R \& D$ within the industrial enterprise}

Research and development (R\&D) quickly became one of the most important functions within the industrial enterprise. Especially in the aftermath of World War II, the importance of R\&D increased substantially (Chandler, 1990: 619). R\&D was typically performed within a firm's boundaries in large, centralized $R \& D$ departments. These $R \& D$ departments performed the entire continuum from basic research to development (Mowery, 2009). ${ }^{3}$ The closed and centralized organization of $R \& D$ was a reasonable choice, as critical scientific resources and expertise were not widely dispersed (both geographically and across firms) and were often held by the firms themselves or could be monitored by the in-house $R \& D$ department with relative ease.

Despite their public ownership, firms mainly used internal funds such as retained profits or cash flow for the financing of R\&D (Himmelberg and Petersen, 1994; Kamien and Schwartz, 1978). One of the prime reasons for this preference for internal funds over external funds for

\footnotetext{
${ }^{3}$ Mowery (2009: 11) points out that the strong concentration of US firms on in-house research and development, especially in the time after the end of World War II until the mid 1980s might also be explained by stringent antitrust policy in the United States. In that time, government funded $R \& D$ accounted for over $50 \%$ of national $R \& D$ expenditures. This share declined to less than $30 \%$ at the beginning of this millennium.
} 
R\&D financing are severe information asymmetries between investors (i.e., firms) on the one hands, and external suppliers of funds on the other hand (Himmelberg and Petersen, 1994: 39). Information asymmetries arise as firms are reluctant to disclose R\&D related information to the public. As noted by Arrow (1962) and Bhattacharya and Ritter (1983: 331), R\&D investments essentially create information, which is inherently difficult to appropriate and which may spill over to competitors once it is disclosed to the public. Hall (2002: 38) points out that due asymmetric information, the market for the external financing of $\mathrm{R} \& \mathrm{D}$ might resemble a market for 'lemons'. Due to asymmetric information, investors are unable to distinguish good from and bad R\&D projects they price all projects at an average value. Due to the 'lemons' premium, some firms face excessively high costs of external R\&D financing. Hence, the role of the stock market for R\&D financing used to be negligible (Brown and Petersen, 2009). ${ }^{4}$

Another and probably more fundamental problem for the financing of R\&D projects through external capital markets is the inherent uncertainty about their outcomes. According to O'Sullivan (2006), the challenge is not that some persons know something that others do not. It is rather that nobody knows anything. Drawing on Knight's (1921/2006) distinction between risk and uncertainty, she argues that in the case of innovation, “... economic agents are uncertain not just about which possible state will obtain but about which ones are even possible” (O'Sullivan, 2006: 257). Decision makers within companies but also external analysts learn about the prospects of R\&D projects over time and alter their perceptions about potential outcomes accordingly. This does, however, not imply that perceptions converge to an underlying truth.

Thus, while uncertainty should be highest at the beginning of an R\&D project, uncertainty remains fundamental throughout the innovation process (Hall, 2002). Some researchers in financial economics posit that investors dislike this type of fundamental uncertainty and therefore treat investments with uncertain outcomes as if they had a lower mean payoff. In other words, due to the inherent uncertainty about the returns to $R \& D$, investors may charge an 'ambiguity premium,' which increases firms' cost of external financing (Epstein and Schneider, 2008). In summary, both information asymmetry and uncertainty of future returns make R\&D financing through external sources costly.

\subsection{Pressures for change: the increasing importance of knowledge and interfirm alliances}

A number of structural changes in the competitive and technological environment have put tremendous pressure on the industrial enterprise. First, the process of globalization and the associated opening of new markets have lead to the emergence of new competitors and to more intense competition on a worldwide scale. At the same time, external capital markets have improved and the availability of venture capital has increased. Advances in information and communication technology (ICT) have dramatically increased the pace by which new knowledge is created and have generally facilitated the access to the scientific knowledge base. Whereas the speed of innovation and technological change has increased, the life-cycles of many products and technologies have become much shorter (Grant, 1996). Finally, the progress in ICT has also reduced the transaction and coordination costs across firm boundaries.

In response to these pressures, the nature of the firm has changed in the last three to four decades. The large conglomerates have mostly disintegrated through spinning off non-core activities and forming new firms, which tend to focus on a narrowly defined set of core

\footnotetext{
${ }^{4}$ Hall (2002) provides a more comprehensive review for why R\&D is difficult to finance with external funds.
} 
competences (Lazonick, 2007: 988; Mowery, 2009; Teece, 1993). Firms have also relaxed their tight control over suppliers what has lead to more competition but also to more innovation in intermediate markets (Zingales, 2000). Further, firms have moved towards looser forms of collaboration and tend to have much less distinctive boundaries (Zingales, 2000: 1624). Chandler (1990: 627) notes that as a result of the intensified global competition firms began to rely more on joint ventures and other 'interfirm cooperative arrangements'.

Moreover, physical and financial assets have become less unique over time. On the one hand, more efficient capital markets have enabled also smaller firms to finance relatively large investments via external funding (Brown, Fazzari, and Petersen, 2009). On the other hand, and maybe more important, firms are now in a better position to access some of the advantages associated to economies of scale and scope, which once were unique to large firms through contracts and other forms of interfirm cooperation (Teece, 1993: 218). Consequently, the modern firm is much less defined by the ownership of physical or financial assets. Due to the decreasing importance of these assets and due to the increasing pace of innovation, knowledge and the ability to learn have become the most crucial assets for firms across many industries (Rajan and Zingales, 2000; Zingales, 2000). ${ }^{5}$ Inkpen (1996: 123) points out that the creation of new knowledge is becoming a priority for managers and that failure to create knowledge can lead to the deterioration of a firm's competitive advantage. According to Baumol (2002: 2-4), innovation has become "... a life-and-death matter for the firm" and "has replaced price as the name of the game in a number of important industries."

\subsubsection{Recent evolutions in business $R \& D$}

Increasing $\mathrm{R} \& \mathrm{D}$ spending is but one indicator for the rising importance of knowledge and innovation. Figure 1.1 illustrates the development of business financed R\&D expenditures in the United States. In absolute terms but also in relation to the gross domestic product (GDP), the aggregate R\&D intensity of US firms has increased substantially over time. The 1990s, and in particular the years between 1994 and 2000, have seen a boom in corporate R\&D spending. During this time, the ratio of business financed R\&D to US GDP rose from about $1.40 \%$ to almost $1.90 \%$. The aggregate R\&D intensity declined somewhat in the aftermath of the burst of the technology bubble in March 2000 and the following recession in 2001. Nevertheless, business financed $R \& D$ continued to increase substantially in absolute terms. Comparable patterns are observable for other countries and regions such as Japan or the European Union (OECD, 2012).

Consistent with figure 1.1, the aggregate R\&D intensity of publicly listed firms in the United States has also increased. Brown and Petersen (2009: 971) observe that the structure of publicly listed firms' investment has changed over time. They argue that “... there has been a dramatic change in the composition of firms' investments: the absolute and the relative importance of physical investment has declined substantially and $R \& D$ intensity has risen dramatically for the typically traded manufacturing firm." This finding is in line with the above proposition that the importance of $\mathrm{R} \& \mathrm{D}$ and knowledge has increased in particular in relation to the importance of physical assets. ${ }^{6}$

\footnotetext{
5 The increasing importance of knowledge as an economic resource is also eminent in the emergence of the knowledge based view of the firm (Demsetz, 1988; Grant, 1996; Kogut and Zander, 1992).

${ }^{6}$ One reason for the increasing R\&D intensity of publicly listed firms is that the typical public firm today tends to differ from the typical public firm in the past. Bates et al. (2009) and Hall (1993b: 297-298) show that new firms that became publicly listed during the 1980 s were predominately firms from high tech sectors. These firms tend to be
} 
Figure 1.1: Industry financed GERD in absolute terms and as percentage of GDP in the United States

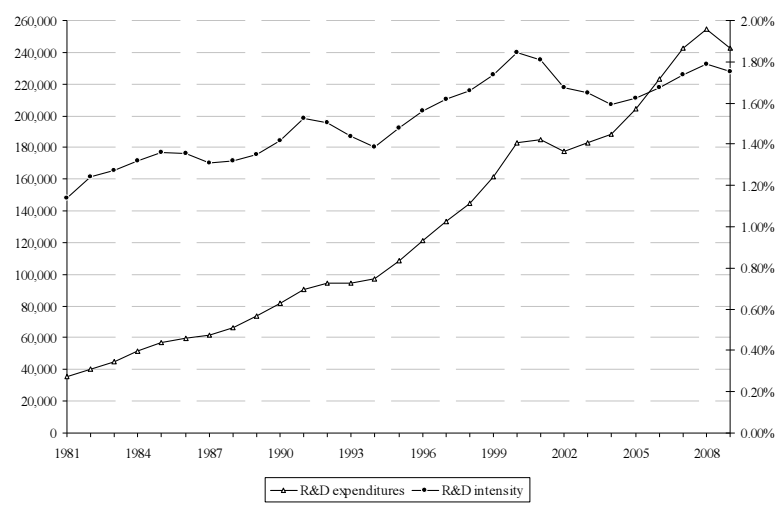

Notes: Date retrieved from the OECD; R\&D intensity is annual business R\&D deflated by GDP

\title{
1.2.2. The trend towards alliances
}

Not only the R\&D intensity but also the organization of business $R \& D$ has changed fundamentally. A quote from The Economist (2007) illustrates these developments:

\begin{abstract}
"Modern technology firms are much less vertically integrated. They use networks of outsourced suppliers and assemblers, which has lead to the splintering of research divisions. Even though big American firms still spend billions of dollars on R\&D, none has any intention of filling the shoes left empty by Bell Labs or Xerox PARC."
\end{abstract}

In other words, changes in the nature of the firm have not only increased the need to invest into knowledge creation and R\&D but have also caused an increase in the number of interfirm alliances. Alliances are voluntary agreements between two or more firms, in which the alliance partners agree to share or co-develop certain resources, capabilities, or knowledge (Gulati, 1995). In a survey, Hagedoorn (2002) shows that that number of alliances undertaking some form of joint $R \& D$ has increased substantially since the 1970s, in particular in high tech sectors.

Hagedoorn (1993) presents a comprehensive review of firms' motives for entering (technology) alliances. I will not review all these motives in detail here. Rather, the intention of this section is to illustrate that the trend towards alliances is due to the same structural changes in the environment that lead to the disintegration of the industrial enterprise and to the rise in R\&D. For instance, the opening of new geographic markets brought new opportunities for many firms. For entering these markets firms frequently use alliances or joint ventures with local partners who have profound knowledge about the foreign market or who have established distribution systems in these regions (Cloodt, Hagedoorn, and van Kranenburg, 2005).

The rise in alliances is also related to the increasing importance of knowledge in the economy. Demsetz (1988: 157) recognized that firms can only reap economic benefits from knowledge when this knowledge is specialized. Due to specialization, the type of knowledge that an

R\&D intensive. At the same time, firms that were taken private were typically firms from mature industries that were downsizing in response to excess capacities and increased competition. These firms were typically not (very) $R \& D$ intensive. 
individual or a firm holds will differ at least to a certain extent from the knowledge held by other actors. Whereas specialization is necessary in the process of knowledge acquisition (i.e., learning) it hinders the transfer of knowledge to other firms or individuals who are less specialized in a particular field. Demsetz (1988: 157) theory about how individuals or firms transfer specialized knowledge is compelling. In his words:

"There must be a low-cost method of communicating between specialists and the large number of persons who either are non-specialists or who are specialists in other fields. Since this communication cannot consist of extensive education in this knowledge without losing the benefits of specialized learning, and since the bare facts contained in this knowledge are often uninterpretable, much communication must consist in the giving of directions. (...). Firms and industries must form a pattern of economic organization that takes account of the need for acquiring knowledge in a more specialized fashion than the manner in which it will be used. Those who are to produce on the basis of this knowledge, but not be possessed of it themselves, must have their activities directed by those who possess (more of) the knowledge."

Consistent with Demsetz (1988), an important reason for the rise in the number of interfirm alliances and partnerships is the increasing vertical specialization that can be observed in several (high tech) industries (Hagedoorn, 2002; Mowery, 2009: 22). In vertically specialized industries, different firms specialize in distinct elements of the value chain and develop a strong expertise in these rather narrow areas. For instance, in the pharmaceuticals industry, mostly small biotechnology firms specialize in drug discovery and early-stage development. These firms typically form alliances with established pharmaceutical firms, which have the expertise for managing the process of drug development and the obligatory and increasingly costly clinical trials (Mowery, 2009: 20). In vertically specialized industries, alliances have become an alternative to vertical integration.

Due to vertical specialization, the emergence of new competitors, but also due to the increasing speed by which new discoveries in science and technology occur, knowledge is now much more dispersed among different actors than it used to be in the past (Powell et al., 1996). In an interview with The Economist (2007), Charles Giancarlo of Cisco Systems states:

"If you go back to that period of AT\&T, there wasn't the same kind of engineering going on at universities, and Bell Labs could not rely on an external cadre of engineers for their research — they really had to do it internally."

Alliances represent one mechanism through which firms can access and monitor widely dispersed knowledge (Mowery, 2009: 13). Finally, alliances are also a response to the increasing costs and risks associated with R\&D and innovation (Hagedoorn, 1993). In fact, alliances may enable firms to take on projects that would be too risky or costly for each individual firm alone.

\subsection{The modern enterprise and the stock market}

The type of firm that emerged from the 'third industrial revolution' (Jensen, 1993) is quite distinct from the Chandlerian industrial enterprise. The importance of scientific and technological 
knowledge has increased (especially in relation to the importance of physical assets). Further, the boundaries of these firms are less clear cut and are 'in constant flux' (Zingales, 2000: 1624). Rajan and Zingales (2000) describe this type of firm as the 'modern enterprise.' As R\&D and interfirm alliances have become much more important elements of firms' business strategies, understanding how these activities affect the relationship between firms and external capital markets has become much more relevant. This dissertation draws on the findings of three broad streams of literature, which analyze (1) the effects of R\&D on firm value, (2) the sources of financing for $\mathrm{R} \& \mathrm{D}$, and (3) the effects of alliances on firm value. The following sections provide a brief review of some of the main findings of these literatures.

\subsubsection{The stock market value of $R \& D$}

$\mathrm{R} \& \mathrm{D}$ is an input factor into the knowledge creation process. More than half of what firms invest into R\&D represents wages and salaries for highly trained employees, scientists, and engineers (Hall, 2002: 36). The efforts of these people create an intangible asset, which can be described as the firm's knowledge capital. A firm's knowledge capital is essentially a repository of technical or scientific knowledge and know-how, which the firm uses to create new products and services and from which it derives financial returns in the future.

Probably starting with Griliches (1981) a stream of literature has evolved, which attempts to measure the stock market's valuation of the knowledge capital, which is created by $R \& D$ (Cockburn and Griliches, 1988; Hall, 1993a; Hall, Jaffe, and Trajtenberg, 2005). Assuming that stock markets are efficient, the aim of this literature is to make inferences about the future expected returns that are to be expected from $\mathrm{R} \& \mathrm{D}$ and other measures of knowledge capital such as patents. Czarnitzki, Hall, and Oriani (2006: 8) provide a review of the main findings of this literature. Their paper suggests that stock markets in the US but also in Europe (i.e., France, Germany, and Italy) seem to evaluate R\&D expenditures positively. However, the US data suggests that “... market valuation of R\&D has progressively decreased over time from the 1970s to the present time." The study by Hall (1993a) examines the changing stock market valuation of R\&D for the US manufacturing sector between 1973 and 1991. She finds that the market valuation of R\&D literally collapsed after 1983 and remains at a very low level throughout her sample. Cockburn and Griliches (1988) find that the stock market valuation of knowledge capital also differs across industries.

\subsubsection{The changing role of the stock market for $R \& D$ financing}

Traditionally, firms used internal financing such as current cash flow or retained earnings for R\&D financing. Himmelberg and Petersen (1994) confirm this hypothesis based on a sample of 179 small firms in high tech industries on which they have data from 1983 to 1987. They find a large and significant effect of cash flow on R\&D investments. More recent studies confirm the pivotal role of cash flow as the primary source of financing for R\&D projects.

However, these studies also suggest that the role of the stock market in this process has changed quite substantially over time. Brown et al. (2009) examine the elasticity of R\&D investment to firms' issuance of public equity during the years 1994 to 2004, focusing on firms in seven high tech sectors in the United States (drugs, office and computing equipment, communications equipment, electronic components, scientific instruments, medical instruments, 
and software). ${ }^{7}$ The results of their study are interesting for two reasons. On the one hand, they establish that the 'R\&D boom' that occurred in the latter half of the 1990s was mainly driven by relatively young firms that were publicly listed for less than 15 years. On the other hand, they find that especially these young firms have extensively used external equity capital for R\&D financing. They find that these firms invested roughly $15 \%$ of their external equity funds into R\&D.

A companion paper by Brown and Petersen (2009) investigates how the sensitivity of R\&D investments and capital expenditures to external equity financing has changed over time. Focusing on manufacturing firms (SIC classes 20-39) over the period from 1970 to 2006, they find that the elasticity of $R \& D$ (but not that of physical investments) to external equity financing has increased substantially over time, especially for young firms. Even for mature firms, which are publicly listed for more than 15 years, public equity seems to have become a more popular source of R\&D financing. ${ }^{8}$ Their empirical results reveal that the use of external equity for R\&D financing is a relatively recent phenomenon. Even for young firms, they do not find significant effects of external equity on R\&D investment prior to the 1980 s.

\subsubsection{The stock market value of alliances and alliance portfolios}

Early contributions on the association between alliances and the stock market value of firms typically employ the event study method. These studies examine the abnormal stock returns following individual alliance or (mostly) joint venture announcements in order to make inferences about the future profits that firms create through alliances (Anand and Khanna, 2000a; Chan et al., 1997; Das, Sen, and Sengupta, 1998; Kale, Dyer, and Singh, 2002; Koh and Venkatraman, 1991; Merchant and Schendel, 2000; Reuer and Koza, 2000). These studies typically find that individual alliance or joint venture announcements are positively received by the stock markets and create significant abnormal stock returns. Several contingencies underlying this relationship have been identified. For instance, interfirm cooperations tend to invoke larger stock market reactions when their focus is on $\mathrm{R} \& \mathrm{D}$ or joint technology development rather than on marketing, licensing, or supply. Investors also tend to be more positive about alliances when the partnering firms have accumulated experience in managing alliances or when they have created a dedicated alliance function.

The event study literature has been criticized more recently. In the words of Lavie (2007: 1190), this literature “... neglects the simultaneous and interdependent effects of other alliances in the focal firm's portfolio." Based on this criticism, several more recent studies investigate the stock market valuation of alliance portfolios, where alliance portfolios are defined as the total number of alliances that firms operate simultaneously at a given point in time. Two studies examine the market valuation of alliance portfolios in the US software industry (Lavie, 2007; Lavie, Kang, and Rosenkopf, 2011). Whereas Lavie (2007) does not find a significant effect of alliance portfolio size, Lavie et al. (2011) document a positive and significant effect of alliance portfolio size on firm value. ${ }^{9}$

\footnotetext{
${ }^{7}$ These firms' primary activities fall into one of the following SIC classes: $28,35,36,37,38$, and 73 . The empirical analyses to be presented in this thesis will mainly consider these or a sub-set of these industries.

${ }^{8}$ Note that for mature firms, Brown and Petersen (2009: 980) find significant effect of external equity on R\&D investments only for positive cash flow firms in the period between 1994 and 2006.

${ }^{9}$ Note that both studies do not explicitly study the relationship between alliance portfolio size and firm value, but use measures for alliance portfolio size as control variables.
} 


\subsection{Scope and structure of this dissertation}

\subsubsection{Research questions}

The results of these studies are interesting for several reasons. First, only looking at the R\&D related literature (sections 1.3.1 and 1.3.2) there seem to be important connections between the stock market, innovation, and growth. Interestingly, the stock market valuation of R\&D and also the extent to which firms can use public equity markets for the financing of $R \& D$ are changing over time. The main focus of the literature examining the changing stock market valuation of $\mathrm{R} \& \mathrm{D}$ is to document these changes as careful as possible (Hall, 1993a: 259) and to identify conditions at the aggregate level (such as aggregate changes in demand and supply of finance) which can explain these changes (Hall, 1993b). By and large this also holds true for the literature investigating changes of the role of the stock markets for $\mathrm{R} \& \mathrm{D}$ financing. ${ }^{10}$ Due to the focus on aggregate, economy-wide changes, firm-level factors are largely excluded from the analyses. Firms are treated as homogeneous and passive entities that simply react to exogenous changes in the environment.

In a comment on the paper of Hall (1993b: 331-332), Mansfield points out that more emphasis should be placed on firm-specific capabilities - such as the ability to exploit R\&D efforts - and on how such firm-specific factors affect the stock market valuation of R\&D. Similar points have been raised with regard to a firm's ability to use the stock market for R\&D financing. According to Lazonick (2006: 50), it is possible that some 'well-positioned firms' are able to use the stock markets for the financing of $\mathrm{R} \& \mathrm{D}$ while other, less-well positioned firms are not. However, what does it mean to be well positioned in the above sense? Is a firm a rather passive entity that treats stock market conditions as exogenous or can the firm actively influence the market's perception about the returns to $R \& D$ or about the quality of its $R \& D$ projects? If yes, which means can the firms use for that purpose? Against the background of an increasing importance of $\mathrm{R} \& \mathrm{D}$ in many industries, questions like these are becoming increasingly relevant. In the words of O'Sullivan (2006: 259):

" $[\mathrm{R}]$ esearch on finance and innovation must devote greater attention to the role that contextual factors play in shaping financial relationships. Who gets financial resources, when they get them, how they use them and other factors that can only be identified by making qualitative distinctions among enterprises, time periods, and investments, are likely to be more important than the overall quantity of financial resources that is invested in an industry"

This dissertation contributes to this research agenda. It starts from the observation that the unique challenge that sets $R \& D$ investments apart from other types of investments is the inherent uncertainty about future outcomes (O'Sullivan, 2006: 257). In the first part, this dissertation addresses the following questions:

- All else equal, do investors perceive the future returns of $R \& D$ intensive firms to be more uncertain compared to less $\mathrm{R} \& \mathrm{D}$ intensive firms?

\footnotetext{
${ }^{10}$ Note that this latter stream distinguishes between mature and young firms.
} 
- (How) can firms influence the extent to which investors perceive the returns to their R\&D projects as uncertain?

- How do investors' perceptions of uncertainty affect (1) the stock market value of a firm's knowledge capital, and (2) a firm's ability to use the stock market for R\&D financing?

In the second part, the focus of the dissertation will shift to interfirm alliances. I argue above that alliances represent an alternative way to organize the innovation process. Whereas the industrial enterprise used to perform R\&D within its clearly defined boundaries, modern firms have become much more likely to form alliances. Powell et al. (1996) even posit that the network, rather than the firm itself may have become the 'locus of innovation' in several industries. Alliances, at least those that focus on $\mathrm{R} \& \mathrm{D}$, have clearly become an important input factor into the knowledge creation process. However, alliances are typically not considered in the literature studying the stock market valuation of a firm's knowledge capital. This leads to the following question:

- Do alliance portfolios contribute to a firm's knowledge capital as measured by the stock market?

- Do investor perceptions of uncertainty moderate the relationship between alliance portfolios and the stock market value of firms?

The trend towards alliances is largely a response to pressures in the external environment. For instance, firms engage in alliances to share the increasing costs and risks of R\&D. At the same time, however, alliances create additional risks that are absent in vertically integrated organizations. The trend towards alliances implies that power and control over critical resources today often reside outside the legal boundaries of firms (Powell, Koput, Smith-Doerr, 1996; Zingales, 2000: 1648). This is a fundamental difference to the Chandlerian industrial organization, where power and control were concentrated within the boundaries of the firm. Firms that access these critical resources through alliances face relational risk due to potential opportunistic behavior or hold-up problems (Das and Teng, 1996). Surprisingly, very few studies investigate how alliances affect stock market investors' perceptions about the riskiness of a firm's future returns.

- What is the relationship between alliances and investors' perceptions of firm-specific risk?

The concepts of firm-specific or idiosyncratic risk or uncertainty clearly have important roles to play in all empirical chapters of this dissertation. My understanding of these concepts is broadly consistent with the theorizing of Knight (1921/2006). According to Knight, risk and uncertainty are the manifestation of imperfect knowledge about the future, which may arise from change (or variability) or from a lack of information. In the words of Knight (1921/2006: 199):

"If all changes were to take place in accordance with invariable and universally known laws, they could be foreseen for an indefinite period in advance of their occurrence (...). Hence it is our imperfect knowledge of the future, a consequence of change, not change as such, which is crucial for the understanding of our problem.'” 
While there are important differences between the concepts of risk and uncertainty, ${ }^{11}$ both concepts are thus inherently connected to the predictability of the future. The higher the amount of risk and uncertainty about a firm's future performance, the lower the predictability of future returns. Variance in stock returns, analyst disagreement, or analyst forecast errors - which I use as proxys for firm-specific risk and uncertainty in the following - are essentially proxies for the predictability of a firm's future performance.

Finally note that what I am referring to as risk or uncertainty in this dissertation should be understood as perceptions of risk and uncertainty by stock market participants about future returns. Again, Knight (1921/2006) provides a good starting point for understanding the difference between perceived and true risk and uncertainty. What sets human consciousness apart from animals is the ability of humans to react to a situation before the situation actually materializes. In other words, we make decisions based on anticipation of future events or, as in the words of Knight, based on 'images of future states of affairs.' These images are the result of our perceptions about the world and our response is based on the inferences that we make from these perceptions. Obviously, neither perceptions nor inferences necessarily coincide with the true risk and uncertainty. In the context of this dissertation, this implies that a firm can actually alter perceptions of risk and uncertainty among market participants without altering the true risk or uncertainty of its assets or its technology.

\subsubsection{Structure of the dissertation}

Each of the following chapters addresses one or more of the research questions described above. Chapter 2 investigates the relationship between R\&D intensity and firm-level uncertainty, which I approximate by the dispersion in sell-side analysts' earnings forecasts. In a second step, this chapter will explore whether patents have an effect of firm-level uncertainty. If patents provide signals about the quality of a firm's R\&D projects to market participants, forecast dispersion should decline as the number of patents relative to R\&D increases. The chapter will also examine the role of several measures of patent quality in this process. Finally, the chapter analyzes the question how (whether) forecast dispersion moderates the relationship between a firm's stock market value and its knowledge assets. Chapter 3 provides new insights to the question which firm characteristics affect firms' abilities to use the stock market for $\mathrm{R} \& \mathrm{D}$ financing. Drawing on the seminal work of Miller (1977) and Merton (1986), the chapter highlights the role of disagreement among stock market participants and financial visibility. Chapter 4 examines the role of alliance portfolios in a market value context. Equivalent to chapter 2 , chapter 4 also analyzes whether analyst forecast dispersion moderates the relationship between alliance portfolios of firms and a firm's stock market value. Chapter 5 explores the effects of alliance portfolios of firms on firm-specific risk. Special attention is given to the moderating role of shocks to environmental uncertainty in this process. Finally, Chapter 6 summarizes the findings of this dissertation, highlights some of its implications, and gives directions for future research.

\footnotetext{
${ }^{11}$ Knight (1921) distinguishes risk and uncertainty based on the degree of measurability. He defines risk as 'measurable uncertainty' where the probability distribution of a future outcome is known. Uncertainty, in turn is 'unmeasurable' and the probability distribution by which a particular outcome will occur in the future is unknown.
} 


\section{Chapter 2}

\section{THE EFFECTS OF R\&D AND PATENTS ON ANALYST DISAGREEMENT AND THE MARKET VALUE OF R\&D"2}

This paper investigates how firms' investments into research and development (R\&D) and patents affect firm level information uncertainty, as measured by the dispersion of analysts' earnings forecasts. Further, the paper explores how information uncertainty affects the market valuation of $R \& D$. The empirical findings of this study show that forecast dispersion increases with $R \& D$ intensity and decreases with the extent to which firms invest into patents. This latter effect is restricted to patents of high quality as measured by forward citations, the number of claims, and the number of non-patent references, patent renewals, and triadic patent families. Further, this study finds that forecast dispersion has a negative effect on the market value of R\&D. My results are consistent with the view that firms can use patents as signals for the quality of their R\&D projects. Further, as patents reduce the informational uncertainty about the future returns to $R \& D$, they may reduce the misevaluation of $R \& D$ in the stock market, which may affect managerial incentives to invest into $R \& D$ in the first place.

\subsection{Introduction}

Investment into research and development $(R \& D)$ is considered one of the most important decisions to be taken by firms (Nelson and Winter, 1982). According to Schumpeter (1942/2008) and Nelson (1990), R\&D is at the heart of the capitalist system and the main source of economic growth. Further, corporate R\&D is a prerequisite for competitiveness in many if not all industries. There is evidence that the importance and the magnitude of corporate $\mathrm{R} \& \mathrm{D}$ spending has increased in the last decades (Bates, Kahle, and Stulz, 2009; Brown, Fazzari, and Petersen, 2009; OECD, 2012). The declining share of government financed R\&D in the United States may partly explain this trend (see Mowery, 2009). Disregarding the underlying reasons, the composition of firms' investments is clearly changing, in that the magnitude of $\mathrm{R} \& \mathrm{D}$ investments increases relative to investments into physical assets (Brown et al., 2009; Brown and Petersen, 2009).13

\footnotetext{
${ }^{12}$ I thank Katrin Hussinger and Antonio della Malva for their valuable support and for the many fruitful discussions about this paper. Further I would like to thank Bronwyn Hall, David Mowery, and seminar participants at the innovation seminar at the University of California, Berkeley. Parts of this paper were completed when the author was a visiting researcher at the University of California at Berkeley.

${ }^{13}$ Like R\&D investments, the number of patent applications and patent grants increased substantially throughout the last decades (Jaffe, 2000; Kortum and Lerner, 1999; Kim and Marschke, 2004). Jaffe (2000, p. 536) points out that one reason for the increase of patenting activity is a strengthening of patent protection during the 1980s in the United States. However, he acknowledges that at least part of this increase reflects the output of rising R\&D expenditures.
} 
A fundamental choice to be mad by innovative firms is the decision to become publicly listed or to remain privately owned. The extant literature suggests that a firm confronted with this decision has to consider at least two important factors. On the one hand, a public listing would enable the firm to access new funds. In particular against the background of ever increasing R\&D expenditures, accessing these sources of financing may be crucial for sustained investment into R\&D. Further, a more dispersed ownership structure may also enable the firm to take on higher risks. In a recent paper, Brown et al. (2009) show that during the 1990's R\&D boom, especially young firms in high tech sectors excessively used external equity for investing for financing R\&D. In other words, access to public equity markets might be an important source of funds for R\&D financing, increasing the firm's ability to innovate.

On the other hand, a growing body of literature suggests that a public listing and dispersed ownership adversely affects managerial incentives to invest into innovation (Aghion, Van Reenen and Zingales, 2009; Asker, Farre-Mensa and Ljungqvist, 2001; Bernstein, 2012; Ferreira, Manso and Silva, 2012). Recent findings within this literature suggest that the decision to go public may decrease the quality of the firm's inventions quite dramatically. Bernstein (2012) uses patentbased measures for innovation quality to show that going public decreases a firm's invention quality by roughly $50 \%$ relative to firms that remained private. Asker et al. (2011) find that private firms are significantly more responsive to new investment opportunities than public firms suggesting that public firms face disincentives to innovate.

What are the reasons underlying the negative relationship between public ownership and firm-level innovativeness? In essence, innovation requires firms to take on risks and to forgo current or short-term returns in the hope for future returns (Aghion et al., 2009; Griliches, 1981). One factor explaining the decline in innovativeness in response to going public is the fact that innovation outcomes are typically highly uncertain and that the information about these projects is difficult to access and to process for equity market participants. Consequently, managers within firms tend to have information advantages over outside investors (Aboody and Lev, 2000; Chang, Lakonishok and Sougiannis, 2001).

Stein (1988: 62) demonstrates that when there is asymmetric information implying that market participants “... cannot observe all the inner workings of the firm," takeover pressures and public market pressures reduce managerial incentives to invest into long run R\&D projects with uncertain payoffs. ${ }^{14}$ In other words, managerial agency problems may reduce the innovativeness of public firms, as these firms face incentives to invest into rather incremental innovations that are less complex and thus easier to communicate to equity market participants (Aghion et al., 2001; Bernstein, 2012; Ferreira et al., 2012). The difficulty of explaining and justifying complex R\&D projects to equity market participants has important implications for a public firm's ability to innovate: if market participants fail to understand the future returns to an innovative project, managers of public firms face incentives to forgo the project disregarding potentially positive future returns.

Surprisingly, few studies analyze whether or through which mechanisms public firms can influence market participants' perceptions about the outcomes of R\&D. A notable exception is a recent study by Cohen, Diether and Malloy (2012), in which the authors show that heterogeneity

\footnotetext{
${ }^{14}$ Consider the example of The Technology Partnership (TTP) - a leading independent technology development and licensing firms. Von Stamm (2003) addresses a key factor for the TTP's success: the firm's ownership structure. At the time the case was prepared, $76 \%$ of the firm's capital was held by its employees. According to TTP's founder Gerald Avison, this structure is preferable over public ownership, as the “... financial market has difficulties to understand what TTP does" (von Stamm, 2003: 372).
} 
in information provision across firms may enhance market participants' ability to decipher the information contained in $R \& D$.

This study contributes to this literature by exploring how R\&D, patents, and several measures of patent quality affect the dispersion in sell-side analysts' earnings forecasts. Analyst data is particularly attractive in this context, as analysts' career prospects are partly determined by the accuracy of their earnings forecasts (see Hong and Kubik, 2003 for evidence). Whereas the average investor may neither have the resources nor the ability to access and to process the detailed highly firm-specific information about $\mathrm{R} \& \mathrm{D}$, analysts make considerable investments into uncovering and understanding the implications of such information for a firm's prospects. Palmon and Yezegel (2012) find, for instance, that the value of analysts' recommendations is higher for R\&D intensive firms. Their study suggests that analysts uncover valuable private information about firms' $\mathrm{R} \& \mathrm{D}$ projects, which they disseminate in the financial community. Consequently, analysts are important intermediaries through which information about R\&D becomes impounded into firms' stock prices.

The dispersion or the variance in analysts' earnings forecasts is a measure for the uncertainty underlying a firm's current market value. Johnson (2004: 1960) posits that the total uncertainty facing an investor comprises two components. The first component captures the variance of future returns or the firm's fundamental risk. The second component, parameter risk, is purely determined by the information setting of the firm. Johnson concludes that analyst forecast dispersion is a measure for this second component of the overall uncertainty characterizing a firm. If forecast dispersion is high, market participants are likely to perceive a firm's information environment to be unfamiliar, complex, or opaque. If forecast dispersion is low, a firm's information environment is probably perceived to be predictable, simple, and transparent. ${ }^{15}$

Consistent with this interpretation, I argue below that the uncertainty driving analyst forecast dispersion stems from a lack of information about a firm's future returns (Knight, 1921/2006). As market participants typically lack information about R\&D, I expect forecast dispersion to increase with the R\&D intensity of firms. Patents should reduce this effect through the provision of novel information about the technical details of an invention and by signalling a firm's own beliefs about an invention's future profitability. In the second part of this study, I examine whether forecast dispersion has implications for the market valuation of firm-level R\&D. If forecast dispersion is a proxy for uncertainty, one may expect a negative effect on the value of $R \& D$ assets, because investors are particularly inclined to underestimate the future returns to $\mathrm{R} \& \mathrm{D}$ when parameter risk - or the opacity of a firm's information environment - is high (Cohen et al., 2012: 20).

My analysis is based on a rich and novel panel dataset covering 299 manufacturing firms listed at the NYSE and NASDAQ in the years 1997 to 2007. My findings reveal a robust positive association between R\&D intensity and analyst forecast dispersion. Surprisingly, the patent yield or the extent to which R\&D expenditures are covered by patents seems to have no effect on forecast dispersion. Once I adjust for measures of patent quality, the expected negative effect of patents on forecast dispersion occurs. Also consistent with my expectations, my results suggest a negative association between forecast dispersion and the market value of $\mathrm{R} \& \mathrm{D}$. Overall, my findings imply that patents can increase the stock market valuation of $R \& D$ assets by reducing

\footnotetext{
${ }^{15}$ Note that forecast dispersion is not a proxy for the confidence of each individual analyst about her estimate. In fact, all analysts may agree upon a particular mean, each of them being highly uncertain about a firm's underlying value (Johnson, 2004).
} 
market participants' perceptions of uncertainty about these assets. My results are robust to the inclusion of fixed-effects in the regressions and also hold in a dynamic panel data setting in which I account for the potential endogeneity of regressors.

My results contribute to a growing literature on the inability of stock markets to accurately value firms' future returns to R\&D (Chen et al., 2001; Cohen et al., 2012; Eberhart et al., 2004; Lev and Sougiannis, 1996). In particular, the results of this study suggest that high-quality patents enhance market participants' ability to understand a firm's R\&D projects. As market participants' perceptions of uncertainty about R\&D outcomes are likely to affect managerial incentives and the selection of R\&D projects within firms, the informational value of patents may be quite high for public firms. Having a portfolio of high-quality patents may, in fact, serve as a credible signal for innovative competence and for a firm's ability to create or appropriate profit from R\&D.

This study also contributes to the discussion on the functions of the patent system and the mechanisms by which patents promote investment into innovation. This paper suggests that the patent system represents an important channel through which innovative firms can communicate R\&D related information to capital market participants. This is consistent with Bhattacharya and Ritter (1983), who argue that patents may reduce informational imperfections by facilitating investors' understanding of the nature of an invention and of the quality of a firm's R\&D projects. By reducing the uncertainty about R\&D in capital markets, patents might lower a firm's cost of external financing and increase the firm's incentives to invest into R\&D.

\subsection{Hypotheses}

2.2.1. The link between $R \& D$ investments, uncertainty, and analyst forecast dispersion

I define uncertainty as the extent to which future outcomes are predictable from current inputs (Arrow, 1962). ${ }^{16}$ The higher the uncertainty surrounding future returns to any kind of investment, the lower will be the predictability of future returns and vice versa. I follow Knight (1921/2006: 199) when arguing that uncertainty is a manifestation of imperfect knowledge about the future. Let the equilibrium return $\left(\widetilde{R}_{k}\right)$ from investing into a firm's security $k$ be explained by:

$$
\widetilde{R}_{k}=\bar{R}_{k}+b_{k} \widetilde{Y}+\sigma_{k}^{2} \varepsilon_{k}
$$

where $\bar{R}_{k}, b_{k}, \sigma_{k}^{2}$ are respectively the estimates about a firm's future returns, the parameter of a random variable, and the variance about expected returns. A market participant's information set about the returns to security $k$ is complete if he knows all parameters in equation 2.1 (Merton, 1987). Following this definition, uncertainty or parameter risk will be absent only in the specific case where all parameters are known to investors and other market participants. In this case, equity market participants will be able to perfectly foresee a security's future returns for an indefinite period in advance of their occurrence (Knight, 1921/2006: 199).

In reality, market participants' information set about the future returns to $R \& D$ is nearly always incomplete for at least two reasons. On the one hand, as pointed out by Arrow (1962) inventive activity and R\&D aim at the production of new knowledge. This knowledge creates economic value by increasing the future profits of its owner. However, if the owner would sell or

${ }^{16}$ This interpretation of uncertainty is quite common in the innovation literature (see Rosenberg, 1994; Pavitt, 2002). 
disclose this knowledge, "any one purchaser can destroy the owner's monopoly, since he can reproduce the information at little or no cost" (Arrow, 1962: 615). Public disclosure may therefore drive an inventor's economic returns towards zero in the absence of special legal protection and an inventor may prefer to keep his invention secret and to extract as much economic value as possible through the exploitation of first-mover advantages (Nelson, 1990). Firms may even attempt to actively maintain information asymmetries, in order to keep valuable information from spreading over to their competitors (Anton and Yao, 2004; Bhattacharya and Ritter, 1983).

Because firms have incentives to keep R\&D related information secret, $R \& D$ intensive firms tend to be plagued by severe information asymmetries between inventors (in this paper firms) and investors (in this paper stock market participants) (Hall, 2002). ${ }^{17}$ In fact, it is often claimed that it is insufficient disclosure or insufficient information about $\mathrm{R} \& \mathrm{D}$, which makes the returns to innovative activities extremely difficult to predict (Aboody and Lev, 2000; Chan, Lakonishok, and Sougiannis, 2001: 2431; Lev and Sougiannis, 1996).

On the other hand, it is certainly not a simply lack of information, which sets $R \& D$ apart from other investment types. According to Arrow (1962: 610), the returns to R\&D depend not only upon inputs - which firms may or may not disclose to the market - but also upon a future 'state of nature.' The probability by which a particular state of the nature will occur is unknown to inventors and firms alike, at the time at which the initial $\mathrm{R} \& \mathrm{D}$ outlays are made. In theory, there may be an infinite number of possible states of the nature that may all reasonably be expected. The occurrence of each particular state of the nature has important implications for the returns to $\mathrm{R} \& \mathrm{D}$.

The unpredictability of the state of the nature weighs particularly heavy in the case of R\&D, as the time-span between the initial investment and the time at which a firm incurs the returns to this investment is typically quite long for $R \& D$ investments. ${ }^{18}$ The unpredictability of $R \& D$, especially with reference to the confounding effects of changes in the environment, was described by Schumpeter (1942/2008: 88):

"Long range investing under rapidly changing conditions, especially under conditions that change or may change at any moment under the impact of new commodities and technologies, is like shooting a at a target that is not only indistinct but also moving and moving jerkily at that."

Following O'Sullivan (2006: 257), the uncertainty inherent in R\&D is not adequately described by asymmetric information, where some persons know something that others do not. It is rather that nobody knows anything. This is because in the case of innovation, “... economic agents are uncertain not just about the possible state that will obtain but about which ones are even possible."

\footnotetext{
${ }^{17}$ In fact, Aboody and Lev (2000) use the R\&D intensity of firms as a proxy for asymmetric information. They find that insider gains in $R \& D$ intensive firms are substantially larger than insider gains in firms that do not perform $R \& D$ Boone and Raman (2001) analyze the adverse selection component of bid-ask spreads and find that R\&D intensity correlates positively with the amount of asymmetric information.

${ }^{18}$ Pakes and Schankerman (1984) suggest that the average gestation lag ranges somewhere between 1.2 to 2.5 years. Ravenscraft and Scherer (1982) find that around 45\% of the firms responding to their survey reported a lag of one to two years between an R\&D investment and the introduction of a new product, around $40 \%$ of the firms reported a time lag of two to five years, and roughly $5 \%$ indicated a lag of more than five years. Their econometric analysis suggests a bell-shaped lag structure with a mean lag of four to six years.
} 
To summarize, I assume that the uncertainty or the parameter risk of $R \& D$ varies across firms for two reasons:

- The amount of knowledge or information about the nature of the technology that is available to market participants.

- The extent to which the future state of the nature is predictable.

The nature of the technology might be known by the inventor but is probably not fully evident to equity market participants due to firms' disincentives to publicly disclose R\&D related information. Market participants' lack of technical information about an invention may be adequately described as asymmetric information. The other source of uncertainty - the future state of the nature - can be known by neither inventors (i.e., firms) nor market participants $e x$ ante. This factor might be best described as true uncertainty. For market participants who want to predict a firm's future returns to $R \& D$, the effects of both factors are very similar. Both reduce the predictability of a firm's underlying value.

Recent advances in the field of industrial economics and corporate finance support the view that R\&D leads to uncertainty about a firm's future returns. For instance, Mazzucato and Tancioni (2008) establish a positive relationship between firm-specific risk, which they define as the degree to which a firm's stock returns are more volatile than aggregate market returns, and firm level $R \& D$ intensity. Their study suggests that firm-level $R \& D$ intensity increases equity market participants' perceptions of uncertainty about firms' future returns. Similarly, Barron et al. (2002) find that analyst forecast dispersion is significantly higher in $R \& D$ intensive industries as compared to less R\&D intensive industries. My first hypothesis therefore reads as follows:

H1: There will be a positive relationship between a firm's $R \& D$ intensity and analyst forecasts dispersion.

\subsubsection{The effects of patents on analyst forecast dispersion}

A firm's internal forecasts of the future returns to $R \& D$ tend to become more accurate over time, as the firm gathers knowledge through experimentation as well as through developing, implementing, and refining a new technology or product (Beardsley and Mansfield, 1978; Levinthal and March, 1981). Through experimentation and development, the firm can continually update its expectations about an invention's future returns, whereas market participants receive only highly aggregated information at discrete points in time. Hence, in the specific case of R\&D, firms typically enjoy an information advantage over market participants (Aboody and Lev, 2000: 2749; Myers and Majluf, 1984). ${ }^{19}$

Communicating their private information about $R \& D$ to equity market participants is a fundamental problem for innovative firms. Even though voluntary disclosure about R\&D may reduce the uncertainty among equity market participants (Lev, 2001), the revelation of R\&D

\footnotetext{
${ }^{19} \mathrm{R} \& \mathrm{D}$ investments can be extremely important for explaining a firm's future performance. Hence, investors and other market participants often make substantial investments in the acquisition of private information about $\mathrm{R} \& \mathrm{D}$ outcomes (Aboody and Lev, 2000; Brown and Hillegeist, 2007). However, the acquisition and the evaluation of such information is costly and requires among other things significant 'set-up' or 'receiver' costs, without which investors would be unable to process the detailed firm-specific information about R\&D (Merton, 1987). In the light of these costs, Aboody and Lev (2000: 2752) point out that even if information acquisition by outsiders is optimal, it will generally fall short of the firm's own information.
} 
related information can be costly, as it increases the risk of imitation (Arrow, 1962; Hall, 2002). Further, voluntary disclosure about R\&D is usually not audited, deterring its credibility for equity market participants (Palmon and Yezegel, 2012). In other words, even if a firm would voluntarily disclose supplementary information about $R \& D$, it is not clear whether this information would reduce the uncertainty about $\mathrm{R} \& \mathrm{D}$ outcomes among stock market participants.

Patents are especially attractive in such situations. A patent grants an inventor a temporary monopoly right in return to the public disclosure of detailed information about an invention. Thus, patents offer at least some protection from imitation through competitors (Arora, Fosfuri and Gambardella, 2001; Scotchmer and Green, 1990). In addition, the examination of a patent application by a patent office and the punishment for misstatement should enhance the credibility of the information contained in patents (Hsu and Ziedonis, 2008). For these reasons, patents might be extremely useful for communicating value relevant information about R\&D to equity market participants (Cohen et al., 2000; Long, 2002).

The information in patents can affect market participants' beliefs about the future returns to $\mathrm{R} \& \mathrm{D}$ in at least three ways. First, it can increase market participants' understanding of a new technology by providing detailed technical information about the invention's nature and its relationships to the prior art (see Long, 2002). However, by definition, patents can only include codifiable information i.e., information that can be put into a written document (Teece, 1981). Large parts of the information that firms obtain through experimentation with new technologies is tacit in nature. Tacit information is intrinsically difficult to codify and there are considerable barriers hindering the transfer of tacit information from one person to another. ${ }^{20}$ As patents only include codified knowledge, the pure information contained in patent documents might not substantially affect information asymmetries among firms and equity market participants.

Second, and probably more important, patents also enable firms to signal their own expectations about the profitability of inventions to equity market participants (Anton and Yao, 2005; Bhattacharya and Ritter, 1983; Penin, 2005). Consequently, signaling goes well beyond the mere disclosure of codified information. According to signalling theory (Spence, 1973), patents can only be effective in reducing uncertainty, if the correlation between the returns to R\&D and the costs of patenting is negative. ${ }^{21}$ In other words, a signal must be costly in a way that only high-quality firms have incentives to actually use it. Prior research suggests that this condition holds in the case of patents. Griliches (1990) posits, for instance, that firms will only apply for patent protection when they expect the future returns of an invention to exceed of the costs of patenting. Similarly, Hall et al. (2005) point out that a successful patent application indicates that a firm does not expect an R\&D project to be a 'dry hole,' from which the firm does not expect to receive any future profits. Assuming that patents provide positive signals about R\&D quality, a larger number of patents relative to $R \& D$ should reduce the extent to which $R \& D$ leads to uncertainty in the stock market.

Finally, patents may also be informative about the past track record or a firm's past R\&D success. Cohen et al. (2012) show that this past track record, for which successful patent applications are but one proxy, represents a simple way of estimating the future returns to R\&D. This finding is consistent with the idea that $R \& D$ success is due to relatively time-constant heterogeneity across firms. Thus, some firms may, for instance, simply have more advanced

\footnotetext{
20 This is captured in Polanyi's (1966/1983: 4) famous expression we can know more than we can tell.

${ }^{21}$ In the words of Spence (1976: p. 592): "[F] or a signal to be effective, it must be unprofitable for sellers of low quality products to imitate it. That is, high quality sellers must have lower costs of signaling activities."
} 
routines for screening and selecting profitable $R \& D$ projects. Such differences in firm-level R\&D or innovation routines are most likely to be quite persistent over time, as discussed in length by Nelson and Winter (1977; 1982).

There is some empirical evidence consistent with the interpretation of patents as means for disclosing and signalling R\&D related information. A growing literature examines, for instance, how patents affect the likelihood of startup firms to secure venture capital financing (Gans, Hsu, and Stern, 2008; Hall and Ziedonis, 2001; Häussler, Harhoff, and Müller, 2010). Hsu and Ziedonis (2008) find that patents have a positive effect on the valuation of semiconductor startups by venture capitalists. This effect appears to be strongest in earlier financing rounds where information asymmetries between inventors and investors and uncertainty about future returns tend to be highest. Hsu and Ziedonis (2008) therefore conclude that patents are useful means to overcome early stage disclosure and information problems for startup firms. These findings extend insights from earlier work by Hall and Ziedonis (2001), who establish that one of the primary roles that patents play for young design firms in the U.S. semiconductor industry is to obtain private financing in the start up phase.

Overall, it appears quite likely that patents - either by signalling unobserved R\&D quality, by giving access to codified technical information, or by providing information about past R\&D track record - enhance market participants' information about the future returns to R\&D. Firms with a higher patent yield, which is the ratio of the patent stock to R\&D stock, should therefore face less uncertainty in equity markets compared to firms with a lower patent yield. Consequently, I expect that a higher patent yield reduces the positive effect of $R \& D$ on analyst forecast dispersion. Hence:

H2: A higher patent yield will reduce the positive relationship between $R \& D$ and analyst forecast dispersion.

\subsubsection{Patent quality and analyst forecast dispersion}

The above discussion suggests that patents provide information about the nature and the quality of $\mathrm{R} \& \mathrm{D}$ and by that reduce the uncertainty or parameter risk in the stock market. However, even after the grant of a patent, there remains some residual uncertainty about the importance and about the commercial value of a patented invention (Trajtenberg, 1990). In fact, several researchers document an extreme skewness of the patent value distribution (Harhoff et al., 1999; Harhoff and Scherer, 2000). In this section, I argue that the extent to which patents reduce the uncertainty about $\mathrm{R} \& \mathrm{D}$ outcomes will vary along several dimensions of average patent quality. My measures for patent quality are: (1) the number of claims, (2) forward citations, (3) and nonpatent references, as well as (4) whether a patent has been renewed, and (5) whether a patent is member of a triadic patent family. I will shortly discuss these indicators in the following.

\subsubsection{Number of Claims}

The number of claims included in a patent document is a frequently used indicator for the bits of information contained in a patent. Claims comprise the novel and non-obvious features of an invention and are informative about a patent's the breadth and the scope. Claims therefore indicate the size of the region of technology space from which a firm can exclude others (Jaffe, 2000, p. 544). While compiled by the inventor, claims can be delimited or rejected by the patent examiner (Cockburn et al., 2003). Claims are thus subject to external validation, which should 
increase their credibility. Further, the number of claims included in a patent can increase a patent's filing costs and the risk of future litigation (Jaffe, 2000; Lanjouw and Schankerman, 2001).22 Several studies suggest a positive relationship between the number of claims and the value of a patent. Harhoff and Reitzig (2004) report a positive effect of the number of claims on the likelihood of opposition in the case European patents. Gambardella et al. (2008) find a positive association between the number of claims and the stock market value of patents.

\subsubsection{Backward citations to non-patent literature}

The front page of a patent contains one or more references to prior art. While serving multiple purposes, backward citations are particularly useful for understanding how a patent relates to earlier or related patented inventions (Alcácer, Gittelman, and Sampat, 2009). A minority of patents includes references to non-patent literature, such as scientific articles, books, or standards. Such non-patent references (NPRs) are informative about the proximity of a patent to the scientific research base (Narin, Hamilton, and Olivastro, 1997).23 Fleming and Sorensen (2004) show that citations to scientific journals predict the number of forward citations that a patent will receive in the future. Harhoff et al. (2003) find that NPRs are valuable in the pharmaceutical and chemical sectors but not in other industries. Hirschey and Richardson (2004) also report a positive effect of NPRs on firm value. These findings suggest that a high number of NPRs is indicative of patent quality or patent value.

\subsubsection{Forward citations}

Forward citations, i.e., the number of references that a patent receives from future patented inventions, are an indicator for the technological impact of a patent and for the contribution of a patent to the state of the art. In the long run, forward citations indicate the extent to which a patent has lead to a successful line of subsequent innovations (Hall et al., 2005; Trajtenberg, 1990). A large number of studies document a positive correlation between forward citations and the social and private value of patents (Trajtenberg, 1990; Harhoff et al., 1999; Gambardella et al., 2008; Bessen, 2008; Serrano, 2010). A recent paper by Czarnitzki, Hussinger, and Schneider (2011) suggests that forward citations are useful for identifying so called wacky patents, which have little or no economic value..$^{24}$

\subsubsection{Patent renewal}

Whether or not a patent holder decides to renew a patent or not is another indicator for the economic value and the quality of patents (Bessen, 2008; Schankerman and Pakes, 1986). In the United States, patent renewal fees are due 3.5, 7.5, and 11.5 years after the grant date of a patent

\footnotetext{
${ }^{22}$ At the time of this study the USPTO fee for each independent claim in excess of three was US\$250 (US\$125) for large (small) entities. The fee for claims in excess of 20 was US\$ 60 (US\$ 30) for large (small) entities.

${ }^{23}$ Clearly not all NPRs relate to scientific publications. Fleming and Sorensen (2004) find that in a sample of all patents granted in May and June of 1990, the majority of the NPRs (67\%) refer to scientific journals. Harhoff et al. (2003) find that about $60 \%$ of the patents in their sample of German patents refer to scientific journals.

${ }^{24}$ Wacky patents typically do not involve a high innovative step and often only marginally fulfill the non-obviousness criterion, which is required to obtain patent protection.
} 
in order to keep patent protection after the fourth, 8th, and 12th year, respectively. ${ }^{25}$ Patent renewals should strongly correlate with a patentee's perception of patent value: a patentee should only renew a patent when she expects the future returns associated to the patent to exceed the patent's renewal fees. If this condition does not hold, the patentee should let the patent expire (Hegde and Sampat, 2009; Bessen, 2008). Consistently, Hegde, and Sampat (2009) as well as Serrano (2010) show that more valuable patents are significantly more likely to be renewed.

\subsubsection{Triadic patent families}

A patent family is a set of patents taken out at different patent offices to protect the same invention. Establishing and maintaining patent protection at several patent offices is costly so that patentees often limit broad international patent protection to their economically most important inventions (Guellec and van Pottelsberghe de la Potterie, 2008). Thus, the membership of a patent to a patent family is a good indicator for the economic importance of a patented invention (Gambardella et al., 2008; Harhoff et al., 2003; Lanjouw, Pakes, and Putnam, 1996). One way to account for the membership of a patent in a patent family is to use triadic patents that are simultaneously filed at the USPTO, the EPO, and the JPO (Dernis and Khan, 2004). De Rassenfosse and Van Pottelsberge de la Potterie (2009) find that variables commonly associated with research productivity significantly increase the number of triadic patents but not the number of domestic patents on the country level. Even though the focus of De Rassenfosse and Van Pottelsberghe de la Potterie (2009) is on cross country variation in patenting, their findings suggest that the number of triadic patents is probably a particularly useful measure for differences in R\&D quality across firms. In summary, these five patent characteristics can influence market participants' expectations about firms' future R\&D related profits by revealing information about the technological and economic importance of a firm's R\&D projects. The number of claims, patent renewals, and triadic patents also increase firms' cost of patenting. My third hypothesis reads as follows:

H3: High quality patents will reduce the positive relationship between R\&D and forecast dispersion even after controlling for the patent yield.

\subsubsection{Analyst forecast dispersion and the relationship between $\mathrm{R} \& \mathrm{D}$ and firm value}

Whereas $\mathrm{R} \& \mathrm{D}$ is costly in the short run, it leads to the accumulation of knowledge from which a firm can derive positive economic returns in the future (Arrow, 1962). Consistently, Eberhart et al. (2004) establish that firms who significantly raise their R\&D expenditures in a given year experience a substantially better operating performance in the years to follow relative to firms that did not increase their R\&D efforts to a similar extent. ${ }^{26}$ Assuming that stock markets are somehow efficient, the expected future returns to R\&D should be reflected in a

\footnotetext{
${ }^{25}$ Renewal fees at the USPTO start at a relatively low level and increase as a patent matures. In general one can say that the renewal fee that is due in the second period is roughly twice the amount of the renewal fee in the first period and the renewal fee in the third period is about twice as high as that in the second period. Fees also differ between large and small entities. At the time this study was conducted, the maintenance fees for large (small) entities were US\$ 980 (US\$ 490), US\$2,480 (US\$ 1,240), and US\$ 4,110 (US\$2,055) for the $4^{\text {th }} 8^{\text {th }}$, and $12^{\text {th }}$ year, respectively.

${ }^{26}$ The study focuses on 'economically significant' and unexpected increases in R\&D intensity. The sample comprises $R \& D$ intensive firms (R\&D intensity $\geq 5 \%$ ) between 1951 and 2001 that increased their $R \& D$ expenditures within one year by at least $5 \%$.
} 
firm's current market value. Indeed, a large body of literature shows that R\&D positively correlates with the market value of firms (Cockburn and Griliches, 1988; Griliches, 1981; Hall, 1993a; Hall et al., 2005; McGahan and Silverman, 2006; Pakes and Schankerman, 1984).

Disregarding this positive association between $R \& D$ and firm value, there is ample evidence suggesting that the stock market underreacts to the information entailed in firms' R\&D investments. Chan et al. (2001) find significant abnormal returns for a sub-sample of R\&D intensive firms with poor historical stock returns. Their findings seem to imply that investors undervalue the stocks of 'beaten down' R\&D intensive firms. In a later study, Eberhart et al. (2004) focus on abnormal returns to unexpected R\&D increases. They report significant longterm abnormal returns to these events and conclude that unexpected $\mathrm{R} \& \mathrm{D}$ increases lead to mispricing that the market takes years to correct. Finally, Daniel and Titman (2006) decompose firms' stock returns into tangible and intangible components. They show that the intangible component explains future stock returns whereas the tangible component does not. ${ }^{27}$

In a recent paper, Cohen et al. (2012) argue that the future returns to current R\&D might be comparably easy to predict by analyzing a firm's past R\&D track record. Specifically, they identify a group of high ability $\mathrm{R} \& \mathrm{D}$ performers with a proven capacity to transform $\mathrm{R} \& \mathrm{D}$ into tangible outcomes such as patents, patent citations, or new product innovations. Interestingly, their study suggests that investors fail to incorporate the information in past $\mathrm{R} \& \mathrm{D}$ success when valuing a firm's current R\&D. Further, firm-level information opacity seems to play an important role in explaining the misevaluation of past $R \& D$ success. Thus, investors' underreaction to the information in a firm's R\&D track record appears to be significantly less pronounced for firms that are more forthcoming in information provision. These results suggest that the undervaluation of R\&D should be stronger for firm's whose information environment is opaque and intransparent or, to put it differently, when parameter risk is high. My final hypothesis therefore predicts a negative effect of forecast dispersion on the stock market value of R\&D.

H4: The positive relationship between firms' R\&D intensity and market value will decline as forecast dispersion increases.

\subsection{Methods}

\subsubsection{Data and sample}

I assemble a rich panel of firm-level data from a variety of sources. My starting point is the Compustat database, which provides accounting data for the years 1997 to 2007. To this initial dataset, I match data on patent applications later granted, as well as information on claims, forward citations, backward citations, non-patent references (NPRs), and patent renewal events from the United States Patent and Trademark Office (USPTO). Data on patent families are obtained from the OECD Triadic Patent Families (TPF) database (OECD, 2011).28

Analyst forecast data come from the Institutional Brokers' Estimation System (I/B/E/S). $\mathrm{I} / \mathrm{B} / \mathrm{E} / \mathrm{S}$ provides earnings per share forecasts from sell-side analysts of most US brokerage

\footnotetext{
${ }^{27}$ Whereas the tangible returns are those that are predictable from firms' fundamentals, the intangible comportment of stock returns is orthogonal to these returns. R\&D represents a substantial part of this latter component.

28 Triadic patent families are sets of patents simultaneously taken at the three most important patent offices - the United States Patent Office (USPTO), the Japanese Patent Office (JPO), and the European Patent Office (EPO) to protect the same invention (Dernis and Khan, 2004).
} 
houses (Ljungqvist, Malloy, and Marston, 2009). Following prior research, I use the unadjusted summary dataset (Diether et al., 2002). This file comprises monthly forecast data and includes various summary statistics, such as the mean, the median, and the standard deviation of earnings forecasts. I use forecast data for the current accounting period, as the number of analysts issuing earnings forecasts for this period is considerably larger than for longer horizons (see Bond and Cummins, 2000).

To be included in the sample, firms must be covered by at least three analysts in each year (Diether et al., 2002). Moreover, I require firms to have a minimum of four consecutive years of non-missing data to allow for first differencing and the use of lagged variables as instruments in the regressions (Bond and Cummins, 2000). Following Hall et al. (2005), I confine my dataset to firms in the manufacturing sector. ${ }^{29}$ Firms in this sector are likely to have material R\&D expenditures and are thus more likely to disclose such expenditures in their annual reports. I select firms from four industries at the two-digit SIC level: machinery and computer equipment (SIC 35), electrical and electronic components (SIC 36), transportation equipment (SIC 37), and medical and scientific instruments (SIC 38). I exclude firms whose shares are traded over-thecounter (OTC). ${ }^{30}$ The remaining firms in my sample are listed at NASDAQ or the NYSE. Although the exact number of observations depends on the specific regressions, the final dataset contains 2,012 observations on 305 firms. Figure 2.1 shows how these observations are distributed across industries and across years.

Figure 2.1: Distribution of observations by year and industry

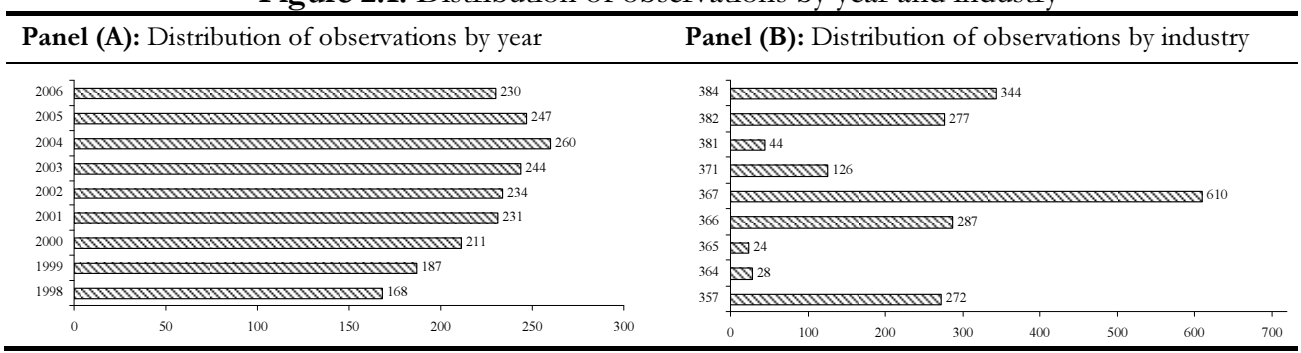

Notes: Industry distribution is based on the three-digit SIC-classification.

\subsubsection{Variables}

\subsubsection{Dependent variables}

I measure analyst forecast dispersion as the standard deviation of analysts' one year-ahead earnings forecasts divided by share price (Eastwood and Nutt, 1999). ${ }^{31}$ Elton, Gruber and Gultekin (1984) show that forecasts made closer to the end of a forecasting period include more firm-specific information and are less affected by macro and/or industry wide effects. Findings by Anderson et al. (2005) also suggest that biases in analysts' (short-term) forecasts tend to

\footnotetext{
${ }^{29}$ Whereas my main dataset is composed of manufacturing firms, I also compiled a second dataset including firms from the Pharma/Biotech sectors. I will elaborate on this data in the robustness section.

${ }^{30}$ Firms whose shares are traded over-the-counter have potentially inferior information environments. Hail and Leuz (2009) establish, for example, that OTC listings require a less rigorous information disclosure than listings at the NYSE, AMEX, or NASDAQ. Note, however, that leaving these observations in the sample does not affect any of the empirical findings that I will describe below.

${ }^{31}$ I experimented with different scaling variables such as forecast dispersion at the industry level, firm size, or the absolute value of analysts' mean forecast. Scaling forecast dispersion by these variables yields very similar results to those reported below.
} 
decline over the fiscal year. For this reason, I use monthly forecast data as close as possible, but preceding the announcement date of actual earnings. Overall, analyst forecast dispersion is a well established measure for information uncertainty, information risk, or for the amount of disagreement among market participants and has been used in quite a number of empirical studies. ${ }^{32}$

In the second part of this study, I use Tobin's q - the ratio of firms' market value to the replacement costs of assets - as the dependent variable. I define Tobin's q or the market to book ratio as:

$$
\frac{P R C_{i t} \times S H R_{i t}+\text { longterm_debt }_{i t}+\text { preferred_stock }_{i t}}{B A_{i t}+\text { inventories }_{i t}+\text { net_short_term_assets }_{i t}}
$$

where PRC is a firm's end of the year stock price, SHR is the number of shares outstanding and $\mathrm{BA}$ is the book value of assets. Chapter 4 provides a more extensive discussion on the usefulness of Tobin's $q$ as a measure for firm value and on the rationale behind using Tobin's $q$ for valuing intangible assets (sees also Hall 1993c).

\subsubsection{Independent variables}

I measure R\&D intensity as the ratio between a firm's R\&D stock and the book value of assets. I calculate firms' R\&D stocks as a perpetual inventory of their past and contemporaneous $\mathrm{R} \& \mathrm{D}$ expenditures. I use a constant annual depreciation rate $(\delta)$ for R\&D of $15 \%$ (Cockburn and Griliches, 1988; Griliches and Mairesse, 1984) and compute R\&D stocks as: ${ }^{33}$

$$
R D_{i t}^{\text {stock }}=(1-\delta) \times R D_{i, t-1}^{\text {stock }}+R D_{i t}^{\text {flow }}
$$

where the flow variable is a firm's current year R\&D expenditure as reported by Compustat. I construct patent stocks using the same perpetual inventory method and depreciation rate as for the R\&D stock (Hall et al., 2005). The flow variables in the patent stock measures are (1) the number of a firm's annual patent applications later granted, (2) the number of claims made in these patents, (3), the number of forward citations received by a firm's patents, (4) the number of non-patent references, (5) the number of renewal events, and (6) the number of triadic patents. The data used for constructing the R\&D stock and patent stock measures go back to the year 1981..$^{34}$ Thus, the effect of missing initial conditions is likely to be negligible and a correction is not required.

\subsubsection{Control variables}

All regressions control for firm size, which I measure as the natural logarithm of sales, and a dummy indicating whether a firm reports $R \& D$ expenditures in a given year. It is possible that the future earnings of those firms who do not disclose $R \& D$ in their financial reports are particularly difficult to forecast. Hence, I expect a positive effect of the latter variable on forecast

\footnotetext{
32 Some recent examples are Anderson et al. (2005), Diether et al. (2002), Güntay and Hackbarth (2010), Johnson (2004), Kumar et al. (2008), Moeller et al. (2007), Sadka and Scherbina (2007), Thomas (2002).

${ }^{33}$ See also Hall (2005) for a discussion on the appropriate depreciation rate for R\&D.

${ }^{34} \mathrm{I}$ use the year 1981 as the starting year for the patent and R\&D data, as renewal fees for US patents were not required for patents granted before December 12, 1980.
} 
dispersion. I also include measures for firm profitability, in form of the ratio of operating income to assets (ROA), and firm age measured as the number of years since a firm's first appearance in Compustat (see Brown et al., 2009). I include these two latter variables in the analyst forecast dispersion regressions but not in the Tobin's q regressions. Regarding the specification of the hedonic Tobin's q regressions, I follow prior literature and control for the log of sales and the R\&D dummy (Hall et al., 2005). ${ }^{35}$ I further add a full set of year dummies in each model to capture changes in the macroeconomic environment that have a common influence on all firms. When possible, I control for industry fixed-effects at the 4-digit SIC level and for stock-exchange dummies (i.e., whether a firm is listed at the NYSE or the NASDAQ). Industry and stock exchange dummies can neither be identified in the within transformed nor in the first-differenced data, as they do not vary over time. Finally, I include one or more lags of the dependent variables on the right-hand side of the regression equations to account for the persistence of Tobin's q and forecast dispersion. This approach has some caveats especially as it may bias some of my estimates. I will discuss this issue in more detail below.

\subsection{Results}

\subsubsection{Descriptives and correlations}

Table 2.1 gives descriptive statistics for the main variables used in this study. As forecast dispersion is skewed, I take the natural logarithm of this variable. ${ }^{36} \mathrm{I}$ follow the hedonic pricing literature on the stock market valuation of knowledge assets and compute the natural logarithm of Tobin's q. The average patent in my sample receives roughly 4 forward citations over the sample period. Figure 2.2 shows that this number drops from 7.40 in 1997 to about 2.70 in 2006 . The reason for this pattern is most likely the truncation of forward citations in my data. Whereas citations take time to accumulate, I only observe forward citations until the end of 2007 . Hence, forward citations are measured with error especially in the later years of my sample.

Claims are not subject to this truncation problem. The average number of claims in my data is about 23.3.37 The figure also shows that in my sample, the average number of claims per patent has increased over time. The average number of NPRs per patent is rather small ( .33.), which might be due to the focus of my study on manufacturing industries. In contrast, the share of patents renewed in the $4^{\text {th }}$ year after the grant date is very high in my data. On average, about $92 \%$ of the patents are renewed at this point in time. This is comparable to findings by Bessen (2008), who shows that publicly listed US firms allow only about $14 \%$ of their patents to expire in the $4^{\text {th }}$ year after the grant date.

Figure 2.3 illustrates the shares of patents held by the firms in my sample that were renewed in the $4^{\text {th }}, 8^{\text {th }}$, or $12^{\text {th }}$ year over the sample period. The average share of triadic patents in firms'

\footnotetext{
${ }^{35}$ It is not obvious why ROA should be included in the Tobin's q regressions. In principle, a firm's income is generated by the tangible and intangible assets of the firm so including ROA on the right-hand side of the equation would essentially be double counting, unless one expects that some assets are mismeasured by the market. I would like to thank Bronwyn Hall for this comment.

${ }^{36}$ Note that forecast dispersion is zero for roughly $4 \%$ of the observations in the sample. For these observations, I replace the variable by .001 before the log transformation. This choice does not affect any of the results reported below.

${ }^{37}$ This is comparable to prior studies. For instance, Cockburn and MacGarvie (2009) find an average of 21 claims per patent for firms in the software industry. De Rassenfosse and van Pottelsberghe de la Potterie (2009) report an average of 23 claims per USPTO patent for the year 2003.
} 
patent stocks is about 31\%. This number is lower than the $50 \%$ that van Zeebroeck (2011) finds for EPO patents. Figure 2.3 shows that the share of triadic patents decreased slightly from about $29.91 \%$ in 1997 to $28.17 \%$ in 2002 and then increased to $34.68 \%$ in 2006 .

Figure 2.2: Patent quality indicators over the sample period

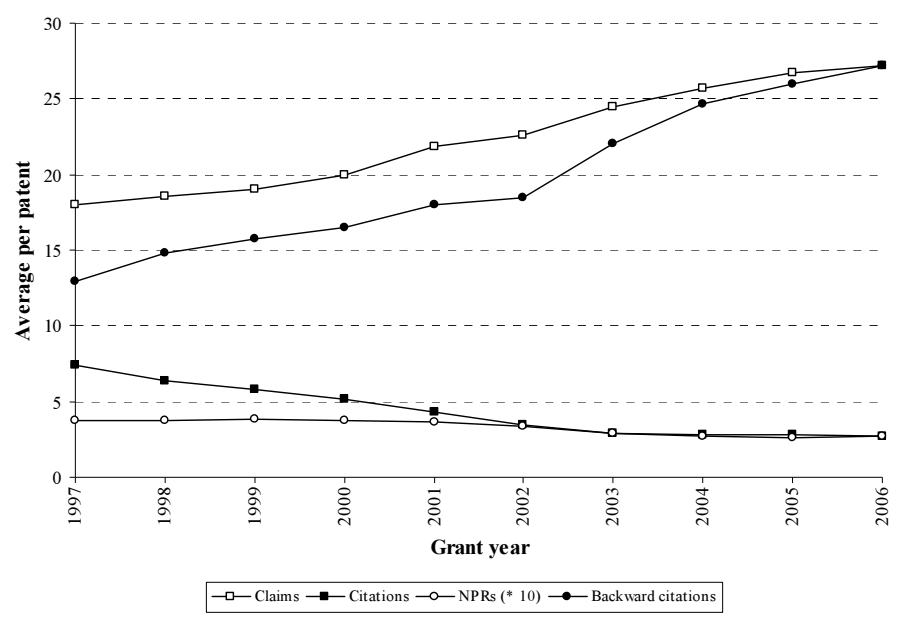

Figure 2.3: Renewed patents and triadic patents as percentage of the patent stock ${ }^{38}$

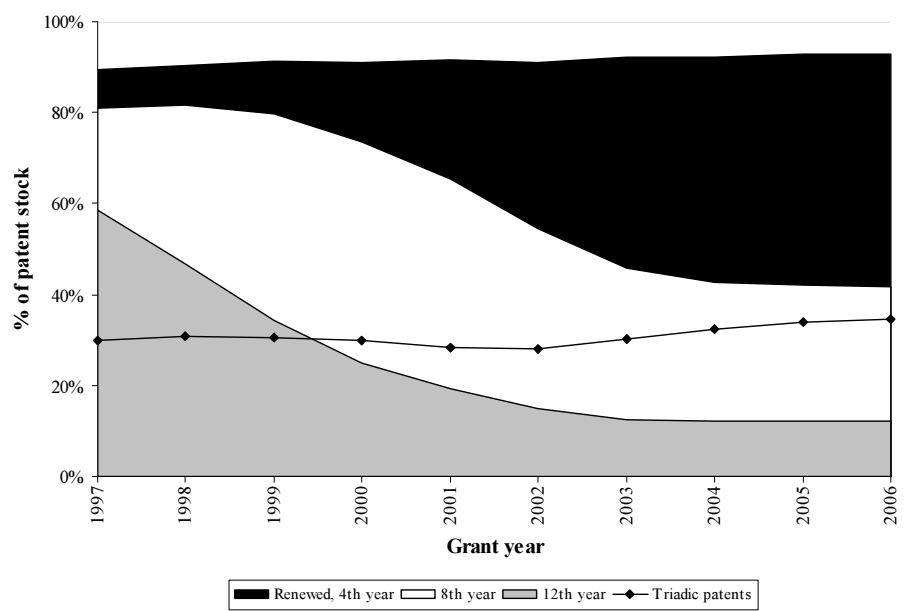

The panel structure of my data enables me to identify relationships based on two sources of variation: across firms (between variation) and within firms over time (within variation). Table 2 also decomposes these sources of the variation. The percentages in the last column give the ratio of the within variation relative to the overall variation (the sum of the within variation and the

\footnotetext{
38 The data on patent renewal and maintenance fees come from the U.S. Patent Grant Maintenance Fee Events File and cover the period between 1981 and 2011. The file contains information on a variety of patent maintenance events. Following the patent maintenance schedule published by the USPTO, I use the event codes M1551 (for small entities M2551) for maintenance fees due at 3.5 years, M1552 (for small entities M2552) for maintenance fees due at 7.5 years, M1553 (for small entities M2553) for maintenance fees due at 11.5 years.
} 
between variation) in my data. Values below $50 \%$ suggest that a variable varies relatively more across firms than within firms over time. Clearly, a larger part of the variation comes from the cross-sectional dimension of the data for all R\&D and patent measures.

\subsubsection{Estimation}

I use three different estimators to test my hypotheses: pooled OLS, fixed-effects, and system GMM. The pooled OLS estimates exploit both, variation across firms and within firm variation over time. In the light of the limited within firm variation that most variables of interest exhibit, the pooled regression might be preferable over fixed-effects estimates in the particular setting of this study. In the Tobin's q regressions, the pooled OLS estimates are also superior for theoretical reasons, as the hedonic market value regressions essentially measure conditional expectations of equilibrium relationships that are constantly changing. The inclusion of a permanent firm fixed-effect justify is therefore difficult to justify, as the shadow price of the fixed-effect would change over time as the equilibrium shifts, which is obviously not plausible. For these reasons, I will choose pooled OLS models as baseline regressions against which the results of the other estimators will be compared.

The pooled estimates have a number of limitations. In particular, they might be affected by unobserved heterogeneity across firms, which can arise from omitted variables in the regression equations. It might, for instance, be important to control for differences in managerial quality or differences in patenting behavior across firms (Gittelman, 2008). I therefore also report the results of fixed-effects regressions, which account for time-constant unobserved firm effects. The fixed-effects models have been found to be preferable over the more efficient random-effects models using Hausman tests. Note, that the fixed-effects estimates only exploit the within-firm variation in my data, which is sometimes limited.

The pooled OLS estimates and the fixed-effects estimates are biased if a lagged value of the dependent variable is included on the right-hand side of the regression equation. ${ }^{39}$ For this and for other reasons to be discussed below, I also present the results of GMM regressions. Two frequently used GMM estimators are the difference GMM estimator (Arellano and Bond, 1991; Holtz-Eakin, Newey and Rosen, 1988) and the system GMM estimator (Arellano and Bover, 1995; Blundell and Bond, 1998). The difference GMM estimator transforms the equation into first differences to eliminate time-invariant unobserved firm effects:

$$
\left(y_{i t}-y_{i, t-1}\right)=\delta\left(y_{i, t-1}-y_{i, t-2}\right)+\left(x_{i t}-x_{i, t-1}\right)^{\prime} \beta+\varepsilon_{i t}-\varepsilon_{i, t-1}
$$

where $y_{i, t-1}$ is the first lag of the dependent variable and $x_{i t}$ is a vector of exogenous and potentially endogenous regressors. By construction, first differencing in the presence of lagged dependent variables induces endogeneity in the model, because the correlation between $\Delta y_{i, t-1}$ and $\Delta \varepsilon_{i t}$ is nonzero. Assuming that the error terms are serially uncorrelated, lagged levels of the endogenous variables are valid instruments in the first differenced equation. The Arellano and

\footnotetext{
${ }^{39}$ The within-firm transformation on which the fixed-effects estimator is based subtracts each firm's average value of a variable from each observation. Hence, each transformed value of the lagged dependent variable involves all the error terms associated with a firm. The lagged dependent variable is therefore contemporaneously correlated with the transformed error (Kennedy, 2008: 291).
} 
Bond (1991) test for no second-order serial correlation explicitly tests this assumption. I present the results of these tests along the estimates.

For highly time persistent variables, the correlation between an endogenous variable in first differences and its past levels is relatively small. Lagged levels of the endogenous variable are then rather poor instruments and the difference GMM estimator will be biased. To reduce the weak correlation problem and to increase the efficiency of the GMM estimator, Arellano and Bover (1995) and Blundell and Bond (1998) propose an augmented estimator that exploits additional moment conditions. ${ }^{40}$ This estimator is based on a system of equations in first differences and in levels that are estimated simultaneously. Blundell and Bond (1998) show that this system GMM estimator is superior to the difference GMM estimator in small samples. In addition to the instruments of the difference GMM estimator, the system GMM estimator uses the lagged differences of the endogenous variables as further instruments in the levels equation.

Table 2.2 gives bivariate correlations for selected variables. The correlations reveal some interesting patterns in the data. First, R\&D intensity correlates positively with both, forecast dispersion and Tobin's q. Second, most measures of patent quality correlate negatively with log forecast dispersion, whereas almost all patent quality measures show strong positive correlations with Tobin's q.

Table 2.1: Descriptive statistics

\begin{tabular}{lrrrrrr}
\hline \multicolumn{1}{c}{ Variables } & \# Obs. & \multicolumn{1}{c}{ Mean } & Min & Max & SD & $\begin{array}{c}\text { \% within } \\
\text { variation }\end{array}$ \\
\hline Forecast dispersion & 2,012 & 0.195 & 0.000 & 5.750 & 0.387 & $52.87 \%$ \\
$\ln$ (forecast dispersion) & 2,012 & -2.509 & -6.908 & 1.749 & 1.431 & $52.08 \%$ \\
$\ln$ (Tobin's q) & 2,012 & 0.171 & -2.068 & 3.886 & 0.691 & $42.46 \%$ \\
$\ln$ (Sale) & 2,012 & 6.516 & -0.914 & 12.207 & 1.797 & $18.10 \%$ \\
$\ln$ (Age) & 2,012 & 2.636 & 0.693 & 4.025 & 0.770 & $23.66 \%$ \\
ROA & 2,012 & 0.020 & -3.883 & 0.449 & 0.174 & $51.81 \%$ \\
R\&D = 0 (dummy) & 2,012 & 0.027 & 0.000 & 1.000 & 0.163 & $0.00 \%$ \\
R\&D stock & 2,012 & 1342.335 & 0.000 & 44184.190 & 4202.974 & $16.97 \%$ \\
R\&D stock/assets & 2,012 & 0.375 & 0.000 & 4.110 & 0.364 & $24.23 \%$ \\
Patent stock & 2,012 & 355.319 & 0.263 & 8207.987 & 1006.643 & $17.81 \%$ \\
Patent stock/R\&D stock & 2,012 & 0.376 & 0.000 & 4.105 & 0.507 & $27.39 \%$ \\
Claim stock/Patent stock & 2,012 & 23.295 & 3.000 & 161.319 & 9.773 & $33.01 \%$ \\
Forward citations/Patent stock & 2,012 & 3.921 & 0.000 & 22.323 & 3.266 & $32.15 \%$ \\
NPRs/Backward citations & 2,012 & 0.021 & 0.000 & 0.149 & 0.019 & $35.65 \%$ \\
Renewed (4th year)/patent stock & 2,012 & 0.918 & 0.000 & 1.000 & 0.144 & $26.77 \%$ \\
Renewed (8th year)/patent stock & 2,012 & 0.571 & 0.000 & 1.000 & 0.255 & $39.75 \%$ \\
Renewed (12th year)/patent stock & 2,012 & 0.198 & 0.000 & 1.000 & 0.201 & $36.70 \%$ \\
Triadic patents/patent stock & 2,012 & 0.310 & 0.000 & 1.000 & 0.280 & $22.82 \%$ \\
\hline Notes: NPR
\end{tabular}

Notes: NPR = Backward citations to non-patent literature. Industry and year dummies are omitted due to space limitations.

\footnotetext{
${ }^{40}$ In particular, these authors consider the additional condition $E\left(\Delta \mathrm{y}_{\mathrm{i}, \mathrm{t}-1} \varepsilon_{\mathrm{it}}\right)=0$, which implies that lagged differences of endogenous variables are suitable instruments for the equation in levels. The difference-in-Hansen test assesses these additional moment conditions of the system GMM estimator relative to the corresponding GMM estimator in first differences (Blundell and Bond, 1998). This is done by computing the difference-in-Hansen $j$-value when the subset of additional instruments is added to the estimation. Under the null hypothesis of joint validity of the additional instruments the Hansen test is $\chi^{2}$ distributed with degrees of freedom equal to the number of additional instruments. Failure to reject the null hypothesis of this test indicates that the additional instruments in the system GMM estimation are not correlated to the fixed effect.
} 


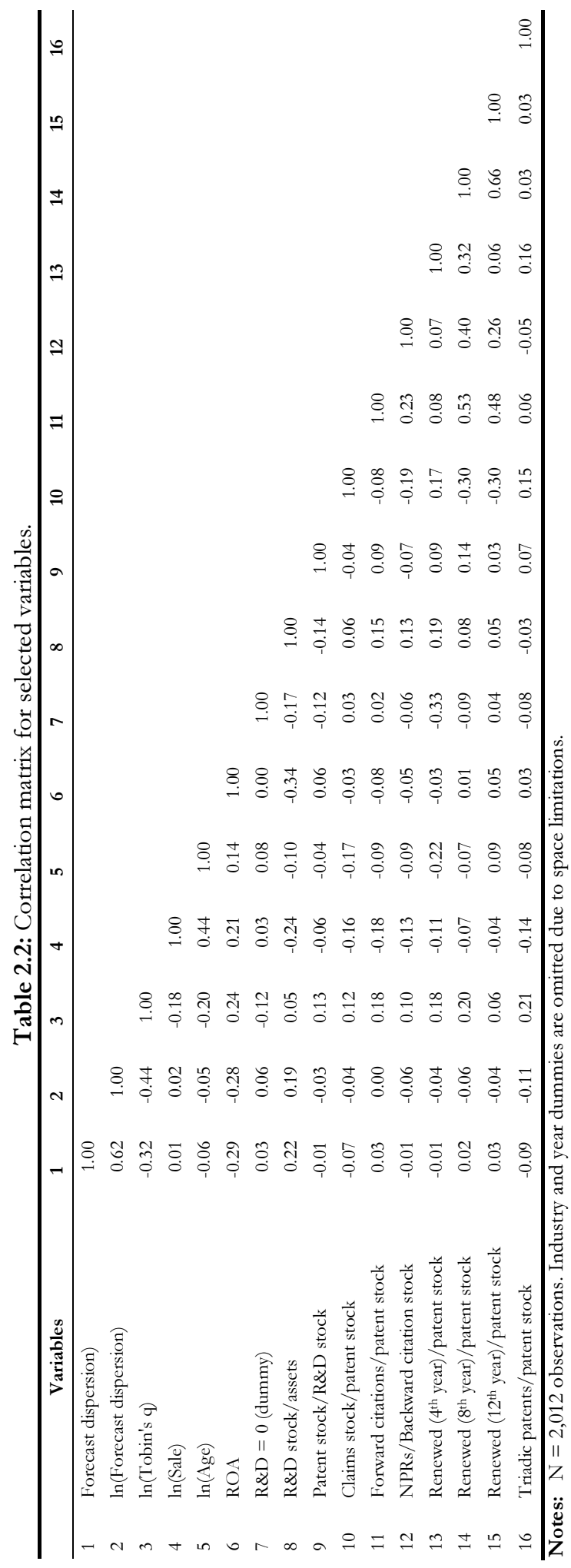




\subsubsection{Results for forecast dispersion}

Table 2.3 presents pooled OLS, fixed-effects, and system GMM estimates. I present the results of Durbin-Wu-Hausman (DWH) tests along the estimates, to assess whether endogeneity of any kind is a concern in my data (Baum, Schaffer and Stillman, 2003). Under the null hypothesis of the DWH test, OLS would be the appropriate estimator and only efficiency would be lost by turning to the GMM estimator. The null hypotheses of the DWH tests are rejected in some of the models underlining the importance of controlling for potential endogeneity of regressors.

Model 1 suggests that more profitable firms and firms that do not report R\&D expenditures face higher forecast dispersion, whereas older firms seem to have lower forecast dispersion. Note, however, that only the negative effect of ROA is significant and negative throughout all models and estimation methods.

Hypothesis 1 predicts a positive effect of $R \& D$ intensity on forecast dispersion. Consistent with this hypothesis, model 1 shows a significant and positive effect of R\&D intensity $(\beta=.345$, p. $<.001)$. This effect even becomes stronger in the fixed-effects and GMM regressions. It therefore seems to be important to control for unobserved firm-effects.

Hypothesis 2 predicts that patents should have a negative effect on forecast dispersion. In contrast, the coefficient of the patent yield is positive and insignificant in model 1. This finding does not change in the fixed-effects and in the GMM regressions, even though the sign of the coefficient is always (sometimes) negative in the fixed-effects (GMM) regressions. Hypothesis 2 is clearly rejected by the data.

My third hypothesis states that forecast dispersion should be lower for firms whose patents are of higher average quality. To test this hypothesis, I include the first three indicators of patent quality (i.e., the average number of claims per patent, the average number of forward citations per patent, and the average number of NPRs per backward citation) in model 2. The coefficients of all three variables are negative. Whereas the coefficient of the average number of forward citations per patent is insignificant in the OLS and in the GMM models it is significant in the fixed-effects regressions. I use Wald tests to assess whether the three coefficients of the patent quality measures are jointly different from zero. The null hypothesis of the test, which states that the three coefficients are jointly not different from zero, is always rejected.

Model 3 includes the other two measures of average patent quality - the share of patents that have been renewed in the 8th year following the grant date and the share of triadic patents in a firm's patent stock. ${ }^{41}$ Both variables have significant and negative effects on forecast dispersion in the pooled models and in the GMM models. In the fixed-effects models only the coefficient of patent renewals is negative. A potential reason for this finding is that the share of triadic patents has particularly little time-series variation. Wald tests again suggest that the coefficients of the two variables are jointly significantly different from zero. Finally, model 4 includes all patent quality measures. Even though not all coefficients of the patent measures are significant, my results provide consistent support for hypothesis 3 .

\footnotetext{
${ }^{41}$ I include patents renewed after eight years in the regressions, because the fraction of patents that are renewed in the fourth year is very high in my sample. In unreported regressions, I also control for the share of patents that have been renewed in the fourth year and for the share of patents that been renewed to the full term. The coefficient of this variable is significant and negative but turns insignificant once the share of patents renewed in the $8^{\text {th }}$ year is included.
} 


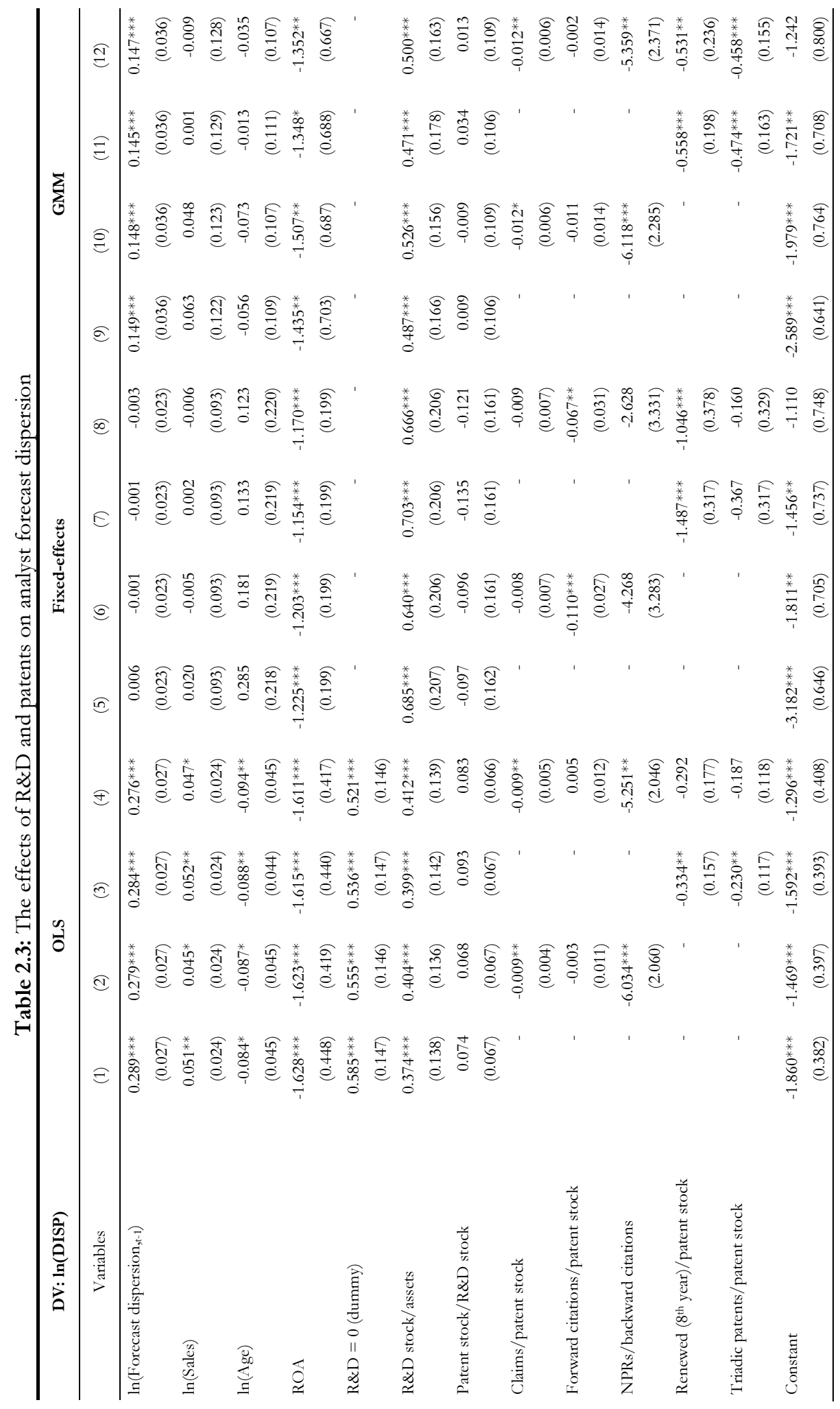




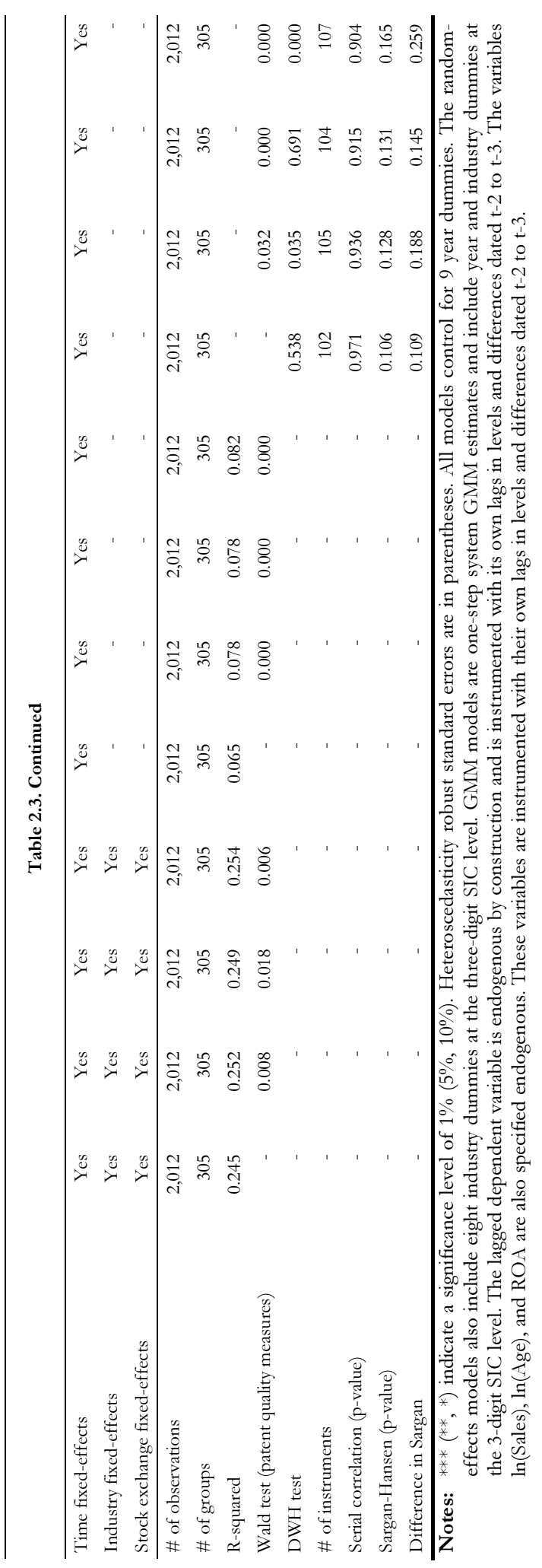


Table 2.4 presents semi-elasticities to assess the magnitude of the estimated effects. Holding all variables at their means, a change in $R \& D$ intensity by one unit, leads to an increase in analyst forecast dispersion by roughly $30 \%$. An increase in R\&D intensity by one standard deviation causes an increase in forecast dispersion by about $9.7 \%$. In contrast, increasing the number of claims per patent by one standard deviation leads to a reduction in forecast dispersion by about $5.4 \%$ and a one standard deviation increase in the number of NPRs per backward citation reduces forecast dispersion by $3.3 \%$. Finally, increasing the share of patents renewed in the 8 th year after the patent grant or increasing the share of triadic patents in a firm's patent stock each by one standard deviation decreases forecast dispersion by roughly $3.8 \%$.

Table 2.4: Semi elasticities for R\&D stock and patent stock measures

\begin{tabular}{|c|c|c|c|c|}
\hline Variables & Mean & SD & $\begin{array}{l}\text { Semi- } \\
\text { elasticity }\end{array}$ & $\begin{array}{c}\text { Effect of one SD } \\
\text { increase }\end{array}$ \\
\hline $\mathrm{R} \& \mathrm{D}$ stock/assets & 0.375 & 0.364 & $\begin{array}{r}.301^{* * *} \\
(.061)\end{array}$ & $9.69 \%$ \\
\hline Patent stock/R\&D stock & 0.376 & 0.507 & $\begin{array}{l}.0412 \\
(.030)\end{array}$ & $2.03 \%$ \\
\hline Claims/patent stock & 23.295 & 9.773 & $\begin{array}{r}-0.005^{* *} \\
(.0018)\end{array}$ & $-5.42 \%$ \\
\hline Forward citations/patent stock & 3.921 & 3.266 & $\begin{array}{r}-.0001 \\
(.005)\end{array}$ & $-0.03 \%$ \\
\hline NPRs/backward citations & 0.021 & 0.019 & $\begin{array}{r}-1.724^{* *} \\
(.772)\end{array}$ & $-3.27 \%$ \\
\hline Renewed ( $8^{\text {th }}$ year) $/$ patent stock & 0.571 & 0.255 & $\begin{array}{r}-0.155^{* *} \\
(.074)\end{array}$ & $-3.79 \%$ \\
\hline Triadic patents/patent stock & 0.310 & 0.280 & $\begin{array}{r}-0.133^{* *} \\
(.0499)\end{array}$ & $-3.82 \%$ \\
\hline
\end{tabular}

Notes: ${ }^{* * *}(* *, *)$ indicate a significance level of $1 \%(5 \%, 10 \%)$. The dependent variable is the log of forecast dispersion. Standard errors obtained by using the delta method are in parentheses.

\subsubsection{Results for Tobin's $\mathrm{q}$}

My final hypothesis states that forecast dispersion is a measure for parameter risk, which should reduce the market value of $R \& D$ assets. I present tests for this hypothesis in table 2.5.42 A look at the control variables in model 1 suggests a positive effect of R\&D intensity on Tobin's q. Conditional on R\&D the patent yield has an additional positive effect. Finally, the coefficients of the share of renewed patents and the share of triadic patents are both positive and significant. I also control for the potential non-linearity in the relationship between forecast dispersion and Tobin's q by including forecast dispersion in both linear and squared form. Whereas the linear term is negative the squared term is positive and comparably small. This suggests a negative effect of forecast dispersion with decreasing marginal effects.

\footnotetext{
${ }^{42}$ Note that the autoregressive coefficient of Tobin's q is large in the OLS models, indicating strong persistence. This persistence complicates the specification of the GMM models, as I need to move further back in time to find suitable instruments for the lagged dependent variable. The specification in table 2.5 includes a second lag of Tobin's q. Further, I select deeper lags in levels and differences from the periods $t_{i, t-5}$ and $t_{i, t-6}$ as instruments for the lagged dependent variable. In this specification, the Hansen test of overidentifying restrictions does not reject the validity of the instruments and there is no evidence for second order serial correlation in the residuals.
} 


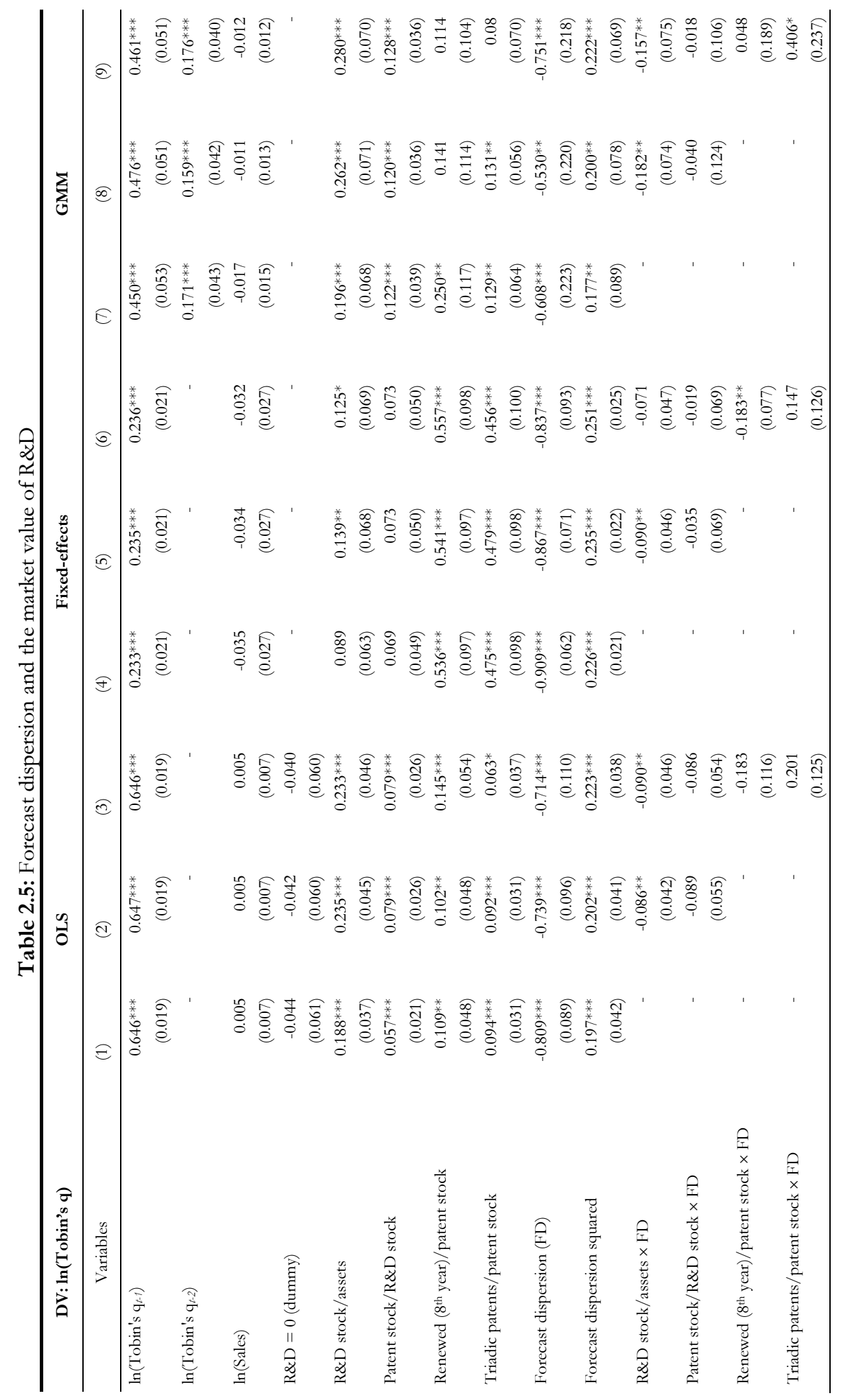




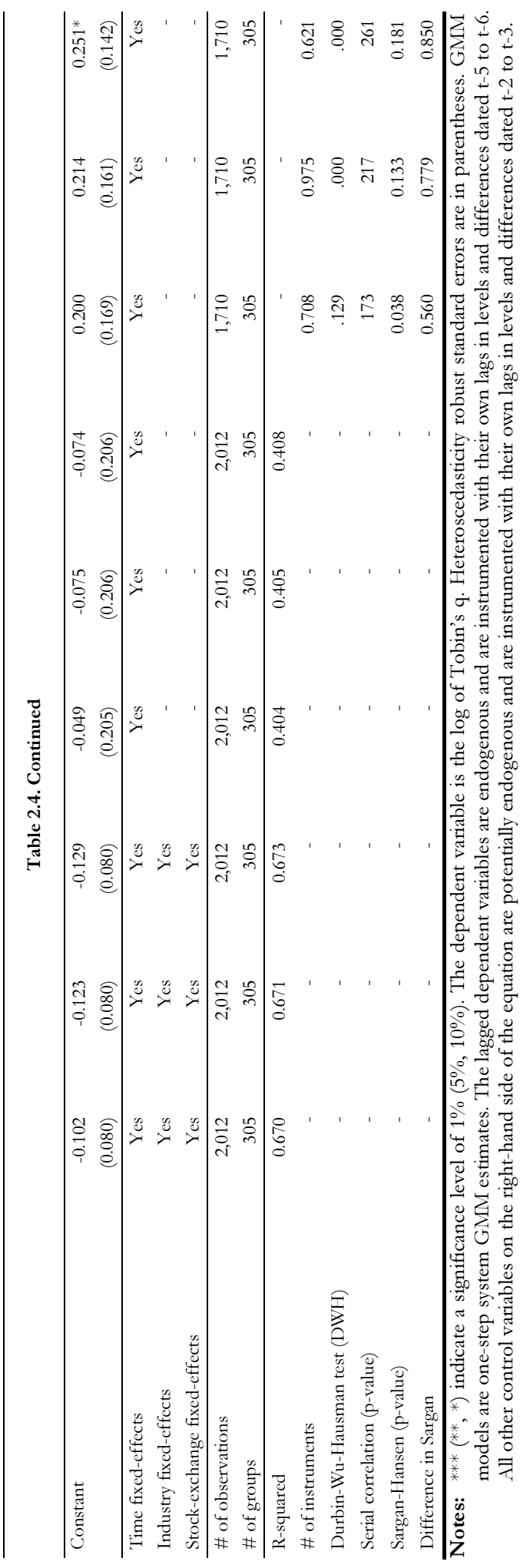


To test hypothesis 4 , I include an interaction term between forecast dispersion and R\&D in model 2. This interaction term turns out to be negative and significant across all regressions. ${ }^{43}$ Thus, the positive effect of R\&D on firm value declines as forecast dispersion increases. Figure 2.4 shows the marginal effect of $R \& D$ intensity on Tobin's $q$ for different values of forecast dispersion. For completeness, I also include interaction terms between forecast dispersion and the patent measures. Patents are (intermediate) output measures of the R\&D process and as such, should not be subject to the same information problems as R\&D. I therefore do not expect an effect of forecast dispersion on the market value of patents. This is exactly what the results in table 2.5 suggest.

Figure 2.4: Marginal effect of R\&D on Tobin's q for different values of forecast dispersion

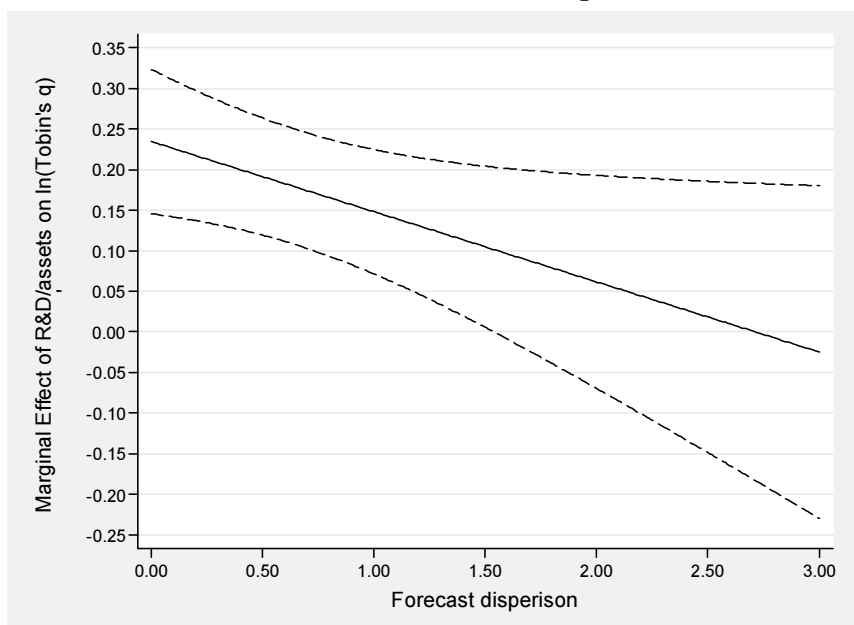

\subsubsection{Robustness}

\subsubsection{Unobserved heterogeneity across firms}

A potential concern in this study relates to the potentially confounding effects of persistent differences in the quality of $\mathrm{R} \& \mathrm{D}$ and in patenting behavior across firms. Therefore, it is important to control for unobserved heterogeneity across firms. So far, I have used fixed-effects and GMM estimators to account for unobserved differences across firms. However, I argue above that especially the fixed-effects estimator is not optimal in the context of this study, as many key variables do not vary substantially within firms over time. Blundell, Griffith, and van Reenen (1999) propose an alternative method to account for unobserved heterogeneity by including the mean of the dependent variable from a long enough pre-estimation period in the regressions. Even though this method was originally developed for the application to count data models, Czarnitzki and Dhaene (2011) show that it is also consistent and efficient for linear least squares regressions.

I include the mean of analyst forecast dispersion from a five-year pre-sample period in table 2.6. As the presample information is frequently missing, my dataset is reduced to 602

\footnotetext{
${ }^{43} \mathrm{My}$ findings are robust to using the log of forecast dispersion in the Tobin'q regressions.
} 
observations related to 94 firms. Note that the coefficient of the pre-sample mean is highly significant in all specifications, which shows that unobserved differences across firms have strong effects on forecast dispersion. Regarding the large drop in sample size, the results are fairly consistent to the main findings of this study.

Table 2.6: Controlling for presample information

\begin{tabular}{|c|c|c|c|c|}
\hline \multirow{2}{*}{$\frac{\text { DV: } \ln (\mathbf{D I S P})}{\text { Variables }}$} & \multicolumn{4}{|c|}{ OLS } \\
\hline & (1) & (2) & (3) & (4) \\
\hline \multirow[t]{2}{*}{ Pre-sample mean } & $0.326^{* * *}$ & $0.324^{* * *}$ & $0.329^{* * *}$ & $0.326^{* * *}$ \\
\hline & $(0.054)$ & $(0.054)$ & $(0.055)$ & $(0.054)$ \\
\hline \multirow[t]{2}{*}{$\ln$ (Sales) } & 0.041 & 0.013 & 0.042 & 0.018 \\
\hline & $(0.034)$ & $(0.034)$ & $(0.034)$ & $(0.035)$ \\
\hline \multirow[t]{2}{*}{$\ln ($ Age $)$} & $-0.165^{*}$ & -0.138 & $-0.210^{* *}$ & $-0.171^{*}$ \\
\hline & $(0.100)$ & $(0.097)$ & $(0.103)$ & $(0.103)$ \\
\hline \multirow[t]{2}{*}{$\mathrm{ROA}$} & $-4.278^{* * *}$ & $-4.229 * * *$ & $-4.307^{* * *}$ & $-4.247^{* * * *}$ \\
\hline & $(0.475)$ & $(0.452)$ & $(0.464)$ & (0.445) \\
\hline \multirow[t]{2}{*}{$\mathrm{R} \& \mathrm{D}=0$ (dummy) } & $0.569^{* * *}$ & $0.724 * * *$ & $0.624 * * *$ & $0.730^{* * *}$ \\
\hline & $(0.208)$ & $(0.200)$ & $(0.202)$ & $(0.199)$ \\
\hline \multirow[t]{2}{*}{ R\&D stock/assets } & $0.544 * *$ & $0.842^{* * *}$ & $0.537^{* *}$ & $0.804^{* * *}$ \\
\hline & $(0.239)$ & $(0.246)$ & $(0.234)$ & $(0.242)$ \\
\hline \multirow[t]{2}{*}{ Patent stock/R\&D stock } & $0.156^{* *}$ & $0.233^{* * *}$ & $0.158^{* *}$ & $0.219 * * *$ \\
\hline & $(0.074)$ & $(0.075)$ & $(0.074)$ & $(0.075)$ \\
\hline \multirow[t]{2}{*}{ Claims/patent stock } & - & $-0.022 * * *$ & - & $-0.022^{* * *}$ \\
\hline & & $(0.006)$ & & $(0.007)$ \\
\hline \multirow[t]{2}{*}{ Forward citations/patent stock } & - & $-0.042 * *$ & - & -0.026 \\
\hline & & $(0.021)$ & & $(0.026)$ \\
\hline \multirow[t]{2}{*}{ NPRs/backward citations } & - & $-7.784^{* *}$ & - & $-7.170^{* *}$ \\
\hline & & $(3.108)$ & & $(3.111)$ \\
\hline \multirow[t]{2}{*}{ Renewed ( $8^{\text {th }}$ year $) /$ patent stock } & - & - & -0.201 & -0.195 \\
\hline & & & $(0.227)$ & $(0.274)$ \\
\hline \multirow[t]{2}{*}{ Triadic patents/patent stock } & - & - & $-0.382^{* *}$ & -0.259 \\
\hline & & & $(0.167)$ & $(0.175)$ \\
\hline \multirow[t]{2}{*}{ Constant } & 0.083 & 0.957 & 0.531 & $1.176^{*}$ \\
\hline & $(0.641)$ & $(0.667)$ & $(0.650)$ & $(0.675)$ \\
\hline Time fixed-effects & Yes & Yes & Yes & Yes \\
\hline Industry fixed-effects & Yes & Yes & Yes & Yes \\
\hline Stock-exchange fixed-effects & Yes & Yes & Yes & Yes \\
\hline R-squared & 0.246 & 0.262 & 0.252 & 0.264 \\
\hline Wald test (patent quality measures) & - & 0.004 & 0.045 & 0.001 \\
\hline
\end{tabular}

Notes: ${ }^{* * *}(* *, *)$ indicate a significance level of $1 \%(5 \%, 10 \%)$. Heteroscedasticity robust standard errors are in parentheses.

\subsubsection{Discrete vs. complex technologies}

One rather surprising finding of this study is the insignificant or sometimes even positive effect of the patent yield on analyst forecast dispersion. A potential explanation for this result might be that the main sample used above comprises firms operating in 'complex' technological fields, in which firms need numerous patents to protect a single invention. Alcácer et al. (2009) find that the quality of the patents issued by firms in complex technologies tends to be rather low. In contrast, one or few patents are usually sufficient to create monopoly rents in discrete technological fields such as chemicals, pharmaceuticals, or Biotech (Cohen, Nelson, and Walsh, 2000). The informational value of simple patent counts might be higher in these latter industries. 
I therefore construct a second dataset for the pharmaceutical-biotech industry (SIC 2834 and 2836). This alternative sample comprises 532 observations related to 78 firms. Further information about the sample and descriptive statistics are available from the author upon request.

Table 2.7: Dynamic fixed-effects estimates for the Pharma/Biotech sample

\begin{tabular}{|c|c|c|c|c|c|c|}
\hline \multirow[b]{2}{*}{ Variables } & \multicolumn{4}{|c|}{ DV: $\ln (\mathrm{DISP})$} & \multicolumn{2}{|c|}{ DV: $\ln$ (Tobin's q) } \\
\hline & (1) & (2) & (3) & (4) & (5) & (6) \\
\hline \multirow[t]{2}{*}{ Dependent variable $t_{t-1}$} & $0.110^{* *}$ & $0.099 *$ & $0.104^{* *}$ & $0.095^{*}$ & $0.271^{* * * *}$ & $0.282 * * *$ \\
\hline & $(0.047)$ & $(0.051)$ & $(0.048)$ & $(0.051)$ & (0.038) & (0.038) \\
\hline \multirow[t]{2}{*}{$\ln$ (Sales) } & -0.027 & -0.017 & -0.033 & -0.018 & $-0.054 * * *$ & $-0.054 * *$ \\
\hline & $(0.066)$ & $(0.072)$ & $(0.067)$ & $(0.073)$ & $(0.021)$ & $(0.021)$ \\
\hline \multirow[t]{2}{*}{$\ln ($ Age $)$} & -0.488 & -0.537 & -0.509 & $-0.558^{*}$ & - & - \\
\hline & $(0.322)$ & $(0.324)$ & $(0.319)$ & $(0.321)$ & & \\
\hline \multirow[t]{2}{*}{$\mathrm{ROA}$} & $-0.854^{* * *}$ & -0.839 *** & $-0.881 * * *$ & $-0.871 * * *$ & - & - \\
\hline & $(0.282)$ & $(0.302)$ & $(0.294)$ & $(0.313)$ & & \\
\hline \multirow[t]{2}{*}{ R\&D stock/assets } & $0.572^{* *}$ & $0.605^{* *}$ & $0.602^{* *}$ & $0.623^{* *}$ & $0.312^{* * *}$ & $0.394 * * *$ \\
\hline & $(0.268)$ & $(0.278)$ & $(0.280)$ & $(0.291)$ & (0.033) & (0.043) \\
\hline \multirow[t]{2}{*}{$\left(\mathrm{R} \& \mathrm{D}\right.$ stock/assets) ${ }^{2}$} & -0.089 & -0.096 & -0.095 & -0.100 & - & - \\
\hline & $(0.061)$ & $(0.064)$ & $(0.062)$ & $(0.066)$ & & \\
\hline \multirow[t]{2}{*}{ Patent stock/R\&D stock } & $-0.926 * *$ & $-0.899 * *$ & $-0.872^{* *}$ & $-0.861 * *$ & 0.141 & 0.123 \\
\hline & $(0.449)$ & $(0.420)$ & $(0.436)$ & $(0.416)$ & $(0.189)$ & $(0.187)$ \\
\hline \multirow[t]{2}{*}{ Claims stock/Patent stock } & - & 0.011 & - & 0.015 & - & - \\
\hline & & $(0.014)$ & & $(0.015)$ & & \\
\hline \multirow[t]{2}{*}{ Forward citation stock/patent stock } & - & $-0.111 *$ & - & -0.101 & - & - \\
\hline & & $(0.065)$ & & $(0.067)$ & & \\
\hline \multirow[t]{2}{*}{ NPR stock/patent stock } & - & 1.641 & - & 1.764 & - & - \\
\hline & & $(1.526)$ & & $(1.627)$ & & \\
\hline \multirow[t]{2}{*}{ Renewed stock (8)/patent stock } & - & - & $-1.478^{*}$ & $-1.565^{*}$ & 0.351 & 0.418 \\
\hline & & & $(0.829)$ & $(0.875)$ & $(0.359)$ & $(0.382)$ \\
\hline \multirow[t]{2}{*}{ Triadic stock/patent stock } & - & - & 0.037 & -0.127 & -0.050 & -0.105 \\
\hline & & & $(0.458)$ & $(0.520)$ & $(0.197)$ & $(0.201)$ \\
\hline \multirow[t]{2}{*}{ FD } & - & - & - & - & $-0.573^{* * *}$ & $-0.723^{* * *}$ \\
\hline & & & & & $(0.073)$ & $(0.184)$ \\
\hline \multirow[t]{2}{*}{$\mathrm{FD}^{\wedge} 2$} & - & - & - & - & $0.113^{* * *}$ & $0.117^{* * *}$ \\
\hline & & & & & $(0.021)$ & $(0.022)$ \\
\hline \multirow[t]{2}{*}{$(\mathrm{R} \& \mathrm{D}$ stock/assets $) \times \mathrm{FD}$} & - & - & - & - & - & $-0.068 * *$ \\
\hline & & & & & & $(0.027)$ \\
\hline \multirow[t]{2}{*}{ (Patent stock $/$ R\&D stock $) \times$ FD } & - & - & - & - & - & $0.240^{*}$ \\
\hline & & & & & & $(0.125)$ \\
\hline \multirow[t]{2}{*}{ (Renewed stock/patent stock $) \times$ FD } & - & - & - & - & - & 0.086 \\
\hline & & & & & & $(0.168)$ \\
\hline \multirow[t]{2}{*}{$($ Triadic stock $/$ patent stock $) \times \mathrm{FD}$} & - & - & - & - & - & 0.109 \\
\hline & & & & & & $(0.152)$ \\
\hline \multirow[t]{2}{*}{ Constant } & -0.762 & -0.719 & 0.633 & 0.733 & 0.501 & 0.419 \\
\hline & $(0.792)$ & $(1.002)$ & $(1.207)$ & $(1.291)$ & $(0.419)$ & $(0.435)$ \\
\hline R-squared & 0.183 & 0.194 & 0.189 & 0.200 & 0.553 & 0.565 \\
\hline Wald test (patent quality measures) & - & 0.138 & 0.183 & 0.120 & - & - \\
\hline
\end{tabular}

Notes: ${ }^{* *}(* *, *)$ indicate a significance level of $1 \%(5 \%, 10 \%)$. The sample comprises firms with the four-digit SIC codes 2834 and 2936. All models control for firm-fixed effects. The dependent variable in models 1 to 4 is the log of forecast dispersion and the dependent variable in models 5 and 6 is the log of Tobin's q. 
Dynamic fixed-effects estimates for this alternative sample are given in table 2.7. My findings based on this sample broadly confirm the main findings of this paper. And yet, there are important differences. Note that the effect of the patent yield on analyst forecast dispersion is negative and significant in model 1 . This finding may suggest that raw patents may indeed provide more information about the value of inventions in discrete technological fields. Whereas the coefficient of the patent yield becomes somewhat weaker after controlling for average patent quality it remains significant in model 2, 3, and 4. Further, even though some of the patent quality measures have the expected negative effects, the coefficients of these measures are jointly never significantly different from zero.

Models 5 and 6 in table 2.7 provide further evidence on the moderating role of forecast dispersion or parameter risk on the market value of $R \& D$. Thus, the interaction term between forecast dispersion and R\&D is negative and significant in model 6. Interestingly, the interaction term between the patent yield and forecast dispersion turns out to be positive, which may even suggest that the information conveyed in patents could become more valuable when parameter risk is high.

\subsection{Discussion and Conclusion}

This paper explores how R\&D and patents affect analyst forecast dispersion - a measure for the parameter risk component of firm-level uncertainty (Johnson, 2004). In a second step, this study analyzes how forecast dispersion affects the market value of R\&D assets.

In the first part, this paper establishes a positive effect of $R \& D$ intensity on analyst forecast dispersion. This finding is fully consistent with recent evidence that $R \& D$ creates uncertainty in public equity markets about a firm's underlying value (Mazzucato and Tancioni, 2008) and that market participants fail to accurately evaluate innovation outcomes (Chan et al., 2001; Cohen et al., 2011; Eberhart et al., 2004).

Market participants' inability to understand the implications of R\&D on a firm's prospects can have important effects on managerial incentives regarding the selection of $R \& D$ projects in public firms. Equity dependent firms may, for instance, select less ambitious or less risky R\&D projects that may be easier to communicate and to justify to market participants (Bernstein, 2012; Ferreira, Manso, and Silva, 2010). As mentioned by Bernstein (2012: 1), managers concerned about how market participant perceive their actions may also prefer the acquisition of existing technologies over internal innovation, as this strategy might appear less risky and more transparent to market participants.

The findings of this paper are relevant, as the role of patents as a means to communicate R\&D related information to investors and market participants has not been studied extensively in prior research. In this context, a first intriguing finding of this paper is the insignificant effect of simple patent counts on analyst forecast dispersion. Potential explanations for this finding may be the high skewness in patent values (e.g., Harhoff et al., 1999) and the large number of low quality patents that have been granted in recent years. My findings may thus support the view that the average informational value of (US) patents is rather low, in particular in complex technological fields (Jaffe, 2000; Jaffe and Lerner, 2004). Once I adjust raw patent stocks by measures of patent quality, I find that patents reduce the positive effect of R\&D intensity on analyst forecast dispersion. In other words, the uncertainty about R\&D outcomes - which is the root cause of disagreement among market participants - is lower for firms with a higher average patent quality. 
This finding may have quite interesting implications. As uncertainty or parameter risk are important drivers of publicly traded firms' incentives to invest into rather low risk R\&D projects, such incentives might be weaker for firms that possess high quality patents. The role of patents as means to disclose private information to equity market participants may be substantial and the structure of a firm's patent portfolio may actually predict which kind of R\&D projects managers can possibly sell to market participants and which R\&D projects a firm will select.

There are a number of potential explanations for my findings. First, it is possible that patents reduce information asymmetries between firms and equity market participants. This explanation is unlikely to be particularly relevant. Patents only include codifiable information, which is not overly important for understanding the prospects of R\&D projects. Second, it is possible that patents are signals for a firm's ability to create tangible returns to R\&D. The effect of high-quality patents on forecast dispersion may be equivalent to a truncation of the left tail of the distribution of market participants' beliefs about R\&D outcomes. To put it differently, market participants might be less likely to expect $R \& D$ projects to fail, if firms possess high innovative competence as illustrated by the share of high quality patents in their patent portfolios. A lower probability of negative R\&D outcomes leads to a reduction in the variance of market participants' beliefs.

It is difficult to judge what patents signal exactly. Do they signal that firms possess valuable knowledge or do they signal that this knowledge is protected by exclusive rights? These questions are difficult to disentangle form the results of this paper and it is possible that patents signal both, valuable knowledge and the protection of this knowledge. In future research, it might be useful to compare the effects of corporate scientific publications - which only include information but no exclusive rights - to the effects of patents. Finally, it is also possible that high quality-patents are informative about a firm's track record of successful past R\&D projects.

The second part of this study examines whether forecast dispersion or parameter risk affects the market value of R\&D. Results by Cohen et al. (2012) may suggest that the information provision by firms has important effects on the market valuation of R\&D. Especially when a firm's information environment is opaque and intransparent, investors' may underreact to the information entailed in corporate R\&D investments. Consistent with this idea, my empirical findings show that forecast dispersion reduces the market value of $R \& D$. One may therefore conclude that patents increase the stock market value of R\&D by reducing the compounding effects of R\&D on the parameter risk component of uncertainty.

Even though the empirical results of this study largely confirm my hypotheses and are robust to a variety of robustness tests, this paper is not without limitations. One important limitation relates to my proxy for parameter risk or uncertainty. Whereas Kumar et al. (2008) and Anderson et al. (2005) argue that forecast dispersion is a good proxy for the information component of uncertainty and for the amount of disagreement among market participants, this variable may be biased by the incentives of analysts (Daniel, Hirshleifer, and Teoh, 2002). Lin and McNichols (1998) find, for instance, that analysts discontinue the coverage of underperforming firms. Analysts also often work for similar institutions and tend to have similar educational backgrounds. Finally, analyst forecast might be biased due to herding behavior, in that analysts align their forecasts with those of other analysts (Trueman, 1994). Forecast dispersion may therefore understate the true amount of disagreement in the stock market. However, the direction of this bias should work against my hypotheses and should - if anything - reduce my ability to find meaningful variation in analyst forecasts. 
Appendix 2.1: Absolute number of patents granted between 1989 and 2006and later renewed

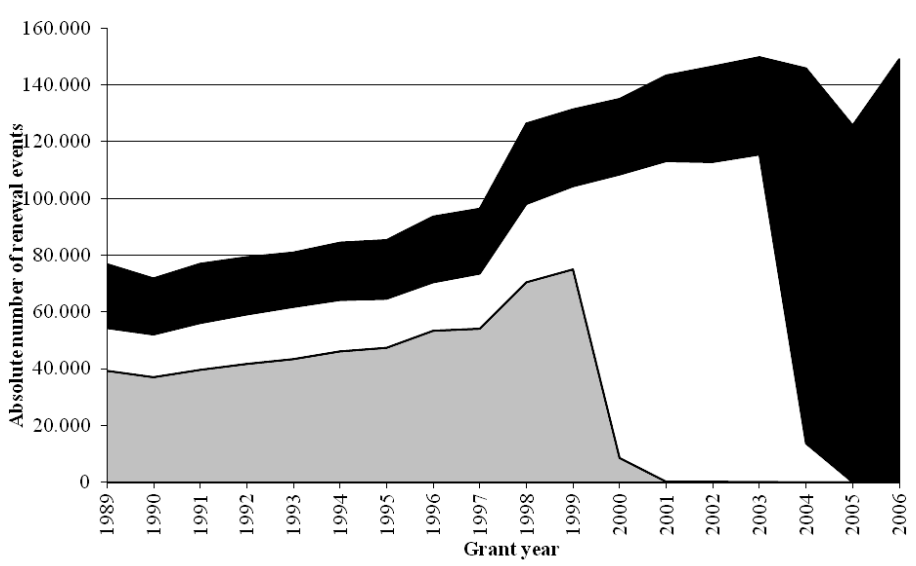

Genewal, 4thyear $\square 8$ thyear $\square 12$ thyear

Notes: The data on patent renewal and maintenance fees come from the U.S. Patent Grant Maintenance Fee Events File and cover the period between 1981 and 2011. The file contains information on a variety of patent maintenance events to which the USPTO assigns an event code. Following the patent maintenance schedule published by the USPTO, I use the event codes M1551 (for small entities M2551) for maintenance fees due at 3.5 years, M1552 (for small entities M2552) for maintenance fees due at 7.5 years, M1553 (for small entities M2553) for maintenance fees due at 11.5 years. 


\section{Chapter 3}

\section{ANALYST DISAGREEMENT, INVESTOR RECOGNITION, AND CORPORATE INVESTMENT - EVIDENCE FROM A PANEL OF MANUFACTURING FIRMS BETWEEN 1984 AND 2006"}

Despite several recent contributions, the effect of disagreement among stock market participants on firm investment is unclear. Some researchers assume that disagreement is a measure for firmspecific risk and thus for costly external financing. Others argue that disagreement causes a temporary overvaluation of stock prices over fundamentals, which essentially implies lower costs of external financing. This paper posits that the dominance of one of these effects over the other will depend on the amount of investor recognition to which a firm's stock is exposed. For firms with low investor recognition, disagreement probably is an indicator of costly external financing. In contrast, disagreement is likely to be a proxy for the overvaluation of stock prices when investor recognition is high. My empirical results support these predictions by showing that highly visible firms use more external equity for investment financing, whereas the opposite holds true for low visibility firms. Finally, this study suggests that the effect of disagreement on corporate investment differs between investments into tangible and intangible assets (R\&D). This latter finding suggests that these two types of investment should be modeled separately.

\subsection{Introduction}

How does disagreement in the stock market - i.e. the extent to which stock market participants disagree about a firm's underlying value - affect firms' investment decisions? A small but growing number of empirical studies investigates this question (Bakke and Whited, 2010; Gilchrist, Himmelberg, and Huberman, 2005; Lyandres, 2007; Thakor and Whited, 2011). This research is challenging in particular because measures of stock market disagreement - such as the dispersion in analyst forecasts - proxy for several related phenomena that affect firms' investment decisions in different ways (Diether, Malloy, and Scherbina, 2002). In his seminal paper, Miller (1977) argues that disagreement can lead to a divergence of stock prices from their fundamental values. More precisely, Miller makes the point that disagreement leads to a temporary overvaluation of stock prices. Papers following this line of reasoning presume that disagreement reduces firms' costs of external equity financing, which implies a positive effect of disagreement on corporate investment (e.g., Gilchrist et al., 2005).

${ }^{44}$ I thank Bettina Peters, Veit Böckers and seminar participants at Maastricht University for helpful comments. 
In stark contrast to this literature, a number of studies in the field of asset pricing suggest that disagreement is a measure for idiosyncratic risk for which investors require additional compensation (e.g., Anderson et al., 2005; Doukas et al., 2006; Kumar et al., 2008). Studies on corporate investment drawing from this latter stream of literature assume that disagreement among market participants is a risk factor, which increases firms' cost of external equity financing and should, for this reason, have a negative effect on corporate investments (Lyandres, 2007; Thakor and Whited, 2011).

This paper deviates from the existing literature examining the relationship between disagreement among stock market actors and corporate investment in several important ways: First, consistent with Miller (1977) and Boehme et al. (2009), this study proposes that the extent to which disagreement leads to the overvaluation of stock prices depends on the amount of investor recognition to which a firm's stock is exposed. When investor recognition is high, the most optimistic investors in the market drive stock prices above fundamentals. This overvaluation effect becomes weaker when only a subset of investors is aware of a stock. When investor recognition is low, there is often substantial uncertainty about the quality of a firm's future earnings. When investor recognition is low, firms also tend to be plagued by asymmetric information, increasing the risk of a lemons problem in the market for external equity financing, especially when opinions among stock market participants diverge (Doukas et al., 2005). This line of reasoning suggests a positive effect of disagreement on the costs of external financing for firms with low investor recognition. Inconsistent findings in prior research might therefore be due to the limited consideration of the role of investor recognition in these studies.

Second, this paper follows the methodology lined out in recent work by Brown, Fazzari, and Petersen (2009) and Brown and Petersen (2009; 2011). According to these researchers, earlier contributions to the corporate investment literature may suffer from an omitted variables bias, as these studies control only for variation in cash flow and ignore the variation in other sources of financing. The investment equations in this paper also include measures for external equity (i.e., new share issues) and external debt (i.e., new long-term debt) financing. Finally, this paper also follows Brown and Petersen $(2009 ; 2011)$ in differentiating between physical investments and R\&D investments. These two investment types differ substantially in that R\&D investments typically (1) face comparably high adjustment costs, (2) are less suitable to be secured by debt, and (3) are subject to considerable uncertainty about future payoffs, whereas the outcomes of physical investments tend to be more predictable (Arrow, 1962; Hall, 2002; Kothari et al., 2002).

The empirical analysis in this paper is based on a large unbalanced panel of manufacturing firms listed at the NYSE or at the NASDAQ in the years 1984 to 2006. In total, the sample comprises 11,100 observations from 1,358 firms. Due to the panel character of my data, I am able to control for unobserved heterogeneity across firms and for the potential endogeneity of variables by using lagged values of these variables as instruments in the regressions. Whereas this methodology is broadly accepted in corporate investment research, the reader should be reminded that due to the strong persistence of the key variables used in this study, the empirical findings are to be interpreted as correlations rather than causal relationships.

My findings suggest that the differentiation between high and low investor recognition is very relevant for corporate investment research. Thus, I find a positive effect of analyst forecast dispersion on investments of firms with presumably high investor recognition and a negative effect on this variable on the investments of firms with low investor recognition.

Consistent with my expectations, these findings also differ across investment types. Whereas the positive effect of disagreement on the investment of high visibility firms seems to be driven 
by increased $R \& D$ expenditures, the negative effect of disagreement on the investment of low visibility firms can be explained by lower capital expenditures. These findings suggest firms' investment decisions with regard to physical investments and $\mathrm{R} \& \mathrm{D}$ are governed by different considerations, so that there is some merit in analyzing these type of investments separately, rather than looking at aggregate investment.

Finally, I also show that firms with high investor recognition are more likely to use external equity financing when disagreement among market participants is strong. I find somewhat weaker evidence for the hypothesis that low visibility firms use less external equity capital for investment financing when disagreement is strong. I find these latter effects only in the R\&D regressions not in the physical investment regressions - and only in dynamic panel models that control for past revelations of the dependent variable on the right-hand side of the regression equation.

The remainder of this paper is structured as follows. Immediately below, I will review relevant theory in order to formulate my hypotheses. Section 3 describes the sample and the variables used in this study. Section 4 presents the main findings. The robustness of these findings is discussed in section 5 . I end with a short conclusion and a discussion of my findings.

\subsection{Theory and hypotheses development}

\subsubsection{Disagreement and firm investment: Competing hypotheses}

Miller (1977) is among the first to describe how disagreement among investors may affect stock prices and firms' cost of external equity financing. Miller (1977) criticizes the traditional capital asset pricing model (CAPM) for its assumption of homothetic expectations. Miller introduces a simple model, in which investors can buy the stock of a single firm and will do so if the expected returns exceed the returns to an alternative risk free investment. A central point in his theory is that uncertainty about future returns will lead investors' to have divergent beliefs about firms' future expected returns. In Miller's words, “... the very concept of uncertainty implies that reasonable men may differ in their forecasts" (p. 1151). Assuming that investor beliefs can diverge due to uncertainty, Miller derives two main conclusions:

- The market value of the firm's shares will be above the mean evaluation of potential investors when there is uncertainty about future returns leading to investor disagreement.

- An increase in disagreement will lead to an increase in share price as long as a minority of investors can absorb the entire supply of a security.

In other words, once one accepts the idea that expectations about future returns are not necessarily homogeneous across investors, Miller's theory predicts that stock prices reflect the opinions of optimists, if investors with pessimistic valuations face binding short-sale constraints or if negative information is not incorporated into stock prices for frictions other than short-sale constraints (Boehme, Danielsen, and Sorescu, 2006; Diether et al., 2002).

A number of studies provide empirical support for Miller's hypotheses. Diether et al. (2002) use the standard deviation of analysts' earnings forecasts (forecast dispersion) as a proxy for the divergence of investor opinion. They find that stocks in the highest quintile of forecast dispersion earn significantly lower future returns than otherwise similar stocks. These findings support the view that high forecast dispersion positively correlates with the overvaluation of stock prices. A 
later study by Boehme et al. (2006) confirms these results. These authors show that disagreement will only lead to the overvaluation of stock prices in the presence of short sale constraints and vice versa. ${ }^{45}$ According to the market-timing hypothesis, managers will exploit the temporary overvaluation of their firms' stock prices by issuing new shares and use the proceedings for investment (Baker and Wurgler, 2002; Merton and Fischer, 1986). If one follows this literature, one would expect that the larger the disagreement among stock market participants, the more a firm's stock will be overvalued, the more a firm will be able to obtain external equity for investment financing. In other words, firms will issue equity when disagreement among market participants is strong. Indeed, Gilchrist et al. (2005) find positive effects of analyst forecast dispersion on Tobin's q, new stock issuance, and corporate investment.

Nevertheless, the interpretation of disagreement as an indicator for the overvaluation of stock prices over fundamental is controversial. Some researchers argue that disagreement among investors is a manifestation of firm-specific risk or uncertainty (Anderson et al., 2005; Doukas et al., 2006; Kumar et al., 2008) and/or poor information quality or low information precision (Zhang, 2006). These researchers posit that disagreement is a priced risk factor. When disagreement is high investors face the risk that the market price will move more in line with the estimates of other investors. Investors will demand additional compensation for bearing this kind of risk (Dittmar and Thakor, 2007).

Empirical evidence for this latter perspective is quite rich. Kumar et al. (2008) develop a conditional CAPM and find that disagreement, which they approximate by analyst forecast dispersion, has a positive effect on investors' expected rates of return and on firms' cost of equity. Doukas et al. (2006) interpret forecast dispersion as a measure for information uncertainty and find a positive effect on future stock returns. Anderson et al. (2005) establish that forecast dispersion is a priced risk factor in traditional asset pricing models. Dittmar and Thakor (2007) find that firms tend to issue new stock in times of low disagreement among market participants, which is consistent with the interpretation of disagreement as measure for costly external equity financing. Güntay and Hackbarth (2011) show that forecast dispersion increases firms' credit spreads and by that the costs of debt financing. Following this literature, Lyandres (2007) interprets forecast dispersion as a measure for costly external financing and finds evidence for a $\mathrm{u}$-shaped relationship between forecast dispersion and the sensitivity of physical investment to variation in cash flow. His findings seem to be consistent with the view that disagreement is a measure for risk and costly external financing.

\subsubsection{The role of investor recognition or financial visibility}

In the light of these supposedly conflicting empirical finings, the relationship between disagreement among market participants, stock prices, and corporate investment is ambiguous. It might be possible that disagreement is a proxy for both idiosyncratic risk - which reduces stock prices and increases firms' cost of external financing - and for the overvaluation of stock prices over fundamentals which should (temporarily) reduce firms' cost of external financing. Bakke and Whited (2010) follow this contingency perspective and interpret analyst forecast dispersion as a proxy for stock market mispricing - an interpretation which is consistent with both interpretations.

\footnotetext{
${ }^{45}$ If disagreement is high in the absence of short-sale constraints, optimists and pessimists will be able to trade so that a firm's stock price will reflect the mean valuation over the cross section of investors. Hence, stocks will not be overvalued on average in the absence of short-sale constraints (Boehme et al., 2006: 456).
} 
However, it is also possible that the relationship between disagreement among market participants, stock prices, and corporate investment is influenced by unobserved variables which prior studies did not consider. Is it possible to identify factors to determine the dominance of one of these two effects over the other? According to Miller (1977) and Merton (1987), investor recognition or the extent to which investors know about a stock might be an important variable in this context. ${ }^{46}$ Merton (1987) derives a modified version of the traditional capital asset pricing model (CAPM), which explicitly addresses the importance of investor recognition and information costs, where information costs as the costs associated with gathering and processing data and the costs of transmitting information from one party to another. ${ }^{47}$ Merton describes the equilibrium return $\left(\widetilde{R}_{k}\right)$ from investing into a firm's security $k$ as:

$$
\widetilde{R}_{k}=\bar{R}_{k}+b_{k} \widetilde{Y}+\sigma_{k}^{2} \varepsilon_{k}
$$

where $\bar{R}_{k}, b_{k}, \sigma_{k}^{2}$ are respectively the estimates about a firm's future returns, the parameter of a random variable, and the variance about expected returns. An investor's information set about security $k$ is complete if the investor knows all parameters in 3.1. Incomplete information about these parameters might be due to information asymmetries between investors and a firm's managers or due to poor information quality, which relates to the precision of the estimates.

Whereas important, Merton does not discuss the effects of information asymmetry and information quality in more detail. Instead, he focuses on his main behavioral assumption that a rational investor can only include the security $k$ in his optimal portfolio, when the investor is aware of the security's existence. The information costs considered by Merton are hence the costs of making investors aware of a firm. Merton assumes that an investor has to expend significant 'set-up' or 'receiver' costs in order to be able to process detailed information about a firm, either disclosed by the firm itself or through intermediaries, such as financial analysts or brokerage houses. As a result of these fixed-costs, investors will only follow a subset of all available securities. This is consistent with Miller (1977), who observes that there are typically more securities available in the market than investors can potentially evaluate. Consequently, securities will differ in the amount of investor recognition to which they are exposed.

Investor recognition may have important implications for the relationship between the amount of disagreement among market participants and stock prices. Assuming that only the most optimistic investors absorb a firm's securities, disagreement among investors should lead to a stronger overvaluation of stocks that are subject to high investor recognition. In the words of Miller (1977: 1164-1165):

"[] $\mathrm{f}$ absorption of a security issue requires that $1 \%$ of the investors hold it, the price will be set by the most optimistic $1 \%$ of the investors, if all investors look at it. However, if only one out of ten investors ever look at it, the price will be set by the

\footnotetext{
${ }^{46}$ In fact, Boehme et al. (2009: 440) also call for a more careful investigation of financial visibility or investor recognition when analyzing the effects of disagreement on stock prices. The arguments put forward in the following are broadly consistent with theirs.

${ }^{47}$ The traditional Sharpe-Lintner capital asset pricing model (CAPM) rests on the assumptions that (1) the diffusion of any type of public information takes place immediately among all investors (2) all investors act upon this information as soon as they receive it. Merton (1987: 485) derives a modified CAPM, which accounts of the fact that the speed of information diffusion as well as the ease of information acquisition through investors can vary across different pieces of information and across firms.
} 
most optimistic $10 \%$. (..).Thus, it is hypothesized that anything that increases investor awareness of a stock will increase its price."

Therefore, the higher the amount of investor recognition the higher will be the extent to which the stock prices are set by the most optimistic investors in the market. On the flipside, this implies that the overvaluation effect is probably less pronounced for stocks with low investor recognition.

Whereas Miller (1977) is most useful for understanding how disagreement affects stock prices when investor recognition is high, Merton (1987) is more informative about the effects of disagreement on the stock prices when investor recognition is low (Boehme et al., 2009: 440). Merton (1987) describes the relationship between investor recognition, investors' ability to optimally diversify their portfolios, and idiosyncratic risk. To be more specific, Merton demonstrates that investors' ability to optimally diversify their portfolios increases in the amount of investor recognition. Due to the set up or receiver costs described above, investors only follow a subset of all available stocks and some stocks will be only held by a subset of investors. Investors holding securities that are only held by a relatively small proportion of investors essentially over weight such stocks in their portfolios, leading to an under-diversification of these investors' portfolios.

Merton refers to the difference between the returns from suboptimally diversified portfolios and the returns predicted by the CAPM as the 'shadow costs of incomplete information' (Boehme et al., 2009; Elliot et al., 2006: 41).48 Merton (1987) derives the following relation between these costs $\left(\lambda_{k}\right)$ and a security's expected returns:

$$
\lambda_{k}=\delta \sigma_{k}^{2} x_{k}\left(1-q_{k}\right) / q_{k}
$$

where $\delta$ is the coefficient of aggregate risk aversion, $\sigma_{k}^{2}$ is the firm-specific component of the stock's return variance or the stock's idiosyncratic risk, $x_{k}$ is the market value of the firm relative to the market value of traded securities, and $q_{k}$ is the proportion of all potential investors who know about a security. In Merton's model $q_{k}$ is the ratio of the firm's shareholder base relative to the total number of potential investors in the market.

It follows from 3.2 that the shadow cost of incomplete information decrease as investor recognition increases. Merton goes on to describe how the shadow cost of incomplete information affect investors' expected rate of return:

$$
E\left(R_{k}\right)-E\left(R_{k}^{*}\right)=\lambda_{k} E\left(R_{k}^{*}\right) R_{f}
$$

where $E\left(R_{k}\right)$ is the actual expected value of the security, $E\left(R_{k}^{*}\right)$ for the expected return on firm $i$ in the complete information case (i.e., when all investors are aware of the stock or when $q_{k}$ is equal to 1), and $R_{f}$ is the riskless return (Bodnaruk and Ostberg, 2009; King and Segal, 2009).

\footnotetext{
48 The CAPM assumes that investors form optimal portfolios, in which securities are included in equal proportions to their weight in the market portfolio. For that reason, investors are able to fully diversify away any idiosyncratic risk (Elliot et al., 2006).
} 
Equation 3.3 shows that all else equal, an increase in investor recognition reduces investors' expected returns by reducing the shadow costs of incomplete information.

Essentially, Merton (1987) demonstrates that investors who are under-diversified due to the shadow costs of incomplete information require compensation for securities' idiosyncratic risk. Given that disagreement among market participants probably reflects more volatile and less predictable earnings streams, investors are likely to require higher compensation for bearing a stock's idiosyncratic risk when disagreement among market participants is strong and when the visibility of a security is low (Boehme et al., 2009: 439; Diether et al., 2002: 2117). Thus, in line with Boehme et al. (2009: 440), I expect that disagreement will only be a priced risk factor for low visibility stocks. Consistent with Miller (1977) I expect highly visible stocks with high investor recognition to be overvalued when disagreement is strong.

A recent study by Bakke and Whited (2010) provides some empirical support for these proposed associations. Bakke and Whited (2010) split their sample into quintiles based on firm size. Firm size tends highly correlated with measures of investor recognition such as analyst coverage. They find a positive and significant effect of analyst forecast dispersion on the investment of large firms, which have presumably high investor recognition, and a negative though insignificant - effect of forecast dispersion on the investment of small firms, which have presumably low investor recognition. This leads to the following hypotheses:

H 1a: There will be a positive association between forecast dispersion and investment for firms with high investor recognition.

H 1b: There will be a negative association between forecast dispersion and investment for firms with low investor recognition.

Based on the literature reviewed above, it is also possible to formulate hypotheses about firms' preferred sources of investment financing. In particular, I argue that disagreement can either increase or decrease the cost of external equity financing depending on the amount of investor recognition to which a firm is exposed. For firms with low investor recognition, Merton (1987) suggests relatively high costs of external equity especially for firms with high idiosyncratic risk. Hence, firms for which these criteria hold are likely to use less external equity (i.e., new stock issues) for their investment. Miller (1977) points out that disagreement leads to the temporary overvaluation of stock-prices over fundamentals for firms with high investor recognition (assuming some kind of short-sale constraints). Firms that fall into this category should therefore face low costs of external equity relative to other sources of financing. Hence, these firms should use more external equity for investment financing. Thus, my next two hypotheses are:

H 2a: Firms with high investor recognition will use more external equity (new stock issues) for investment financing when disagreement is high.

H 2b: Firms with low investor recognition will use less external equity (new stock issues) for investment financing when disagreement is high.

Figure 3.1 summarizes hypotheses $1 \mathrm{a}$ to $2 \mathrm{~b}$. So far, the hypotheses focus on the effects of disagreement and new stock issues on firms' aggregate investments (i.e., CAPX $+\mathrm{R} \& D$ ). However, investments into tangible assets (CAPX) and intangible assets (R\&D) differ 
substantially, which means that it might be preferable to model physical investments and R\&D investments separately, rather than modeling total (aggregate) investment. Whereas firms with low investor recognition are likely to invest less into physical assets in the face of larger disagreement, these firms are less likely to adjust $\mathrm{R} \& \mathrm{D}$ expenditures in response to temporary high cost of external equity financing.

Figure 3.1: Illustration of hypotheses $1 \mathrm{a}$ to $2 \mathrm{~b}$

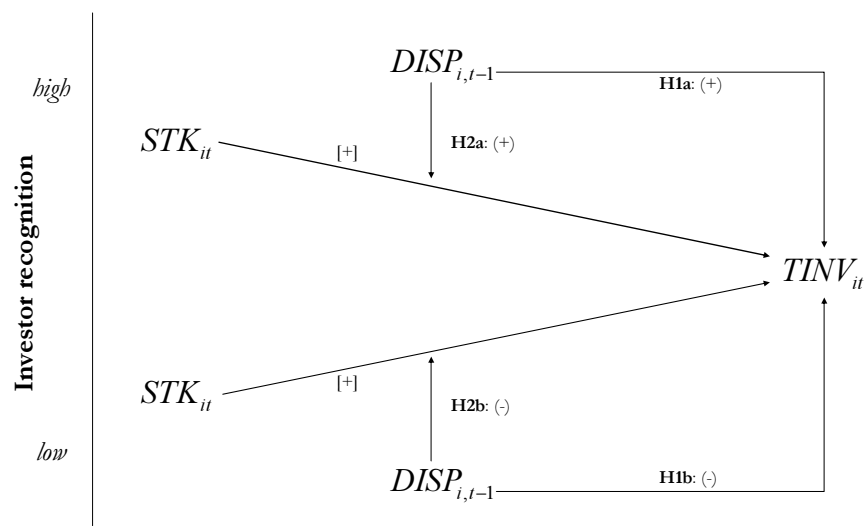

Notes: The four hypotheses are shown in bold. Their expected signs are given in round brackets. Expected signs for correlations for which I have not made specific hypotheses are given in square brackets.

3.2.3. The nature of the investment: Physical investment versus $R \& D$

Compared to physical investments, R\&D investments are typically more costly to adjust (Brown and Petersen, 2011; Hall, 2002; Himmelberg and Petersen, 1994). More than 50\% of firms' R\&D expenditures are made up by wages and salaries to highly educated scientists and engineers. Reducing R\&D is thus often equivalent to releasing knowledge workers. Knowledge workers embody large parts of the tacit knowledge that is derived from past R\&D investments (Hall, 2002). Releasing these workers would therefore lead to a loss of strategically important knowledge. These employees may also transfer sensitive information to competitors. Finally, firms would need to hire and train new workers once the costs of external financing become less excessive leading to high search and training costs (Himmelberg and Petersen, 1994).

Due to these reasons, even firms with low investor recognition are unlikely to reduce their $\mathrm{R} \& \mathrm{D}$ expenditures in response to high levels of forecast dispersion. Consequently, hypothesis 1a is probably weaker in the specific case of $\mathrm{R} \& \mathrm{D}$ investment. Thus:

H 3a: The negative association between forecast dispersion and investment for firms with low investor recognition will be stronger for physical investment than for R\&D.

Furthermore, I argue above that disagreement among market participants stems from uncertainty about a firm's future returns. This kind of uncertainty is typically more pronounced in the case of R\&D than in the case of physical investments. Arrow (1962: 610) argues, for instance, that any inventive activity requires a producer "... to make a decision on inputs at the present moment but the outputs are not completely predictable from the inputs.” Kothari, Laguerre and 
Leone (2002) find empirical support for a positive association between R\&D expenditures and the uncertainty of firms' future profits. They show that R\&D expenditures contribute substantially more to the variability in future earnings than comparable investments into property, plant, and equipment. Mazzucato and Tancioni (2008) find that firm-level R\&D intensity is associated to higher levels of uncertainty as perceived by investors.

Besides the inherent uncertainty about the future returns to $R \& D$ investments, the limited amount and quality of R\&D related information might also affect disagreement. Firms need to expense $R \& D$ expenditures as incurred, so that quantitative information about $R \& D$ - if there is any - is restricted to a single line item in firms' income statements (Chan, Lakonishok and Sougiannis, 2001; Lev, 2001). In particular for R\&D intensive firms, a lack of information provides incentives for market participants to engage in costly private information acquisition (Barth et al., 2001; Diamond, 1985; Verrechia, 1982). This acquisition of private information creates asymmetric information in the stock market as not all investors are willing to invest into information acquisition and processing (Brown and Hillegeist, 2007; Merton, 1987). Information asymmetry among market participants will also be reflected in a higher amount of disagreement among market participants.

Several studies investigate to which extent market participants are able to correctly forecast the future profits that firms will obtain from their R\&D investments. Chan et al. (2001) do not find evidence for significant abnormal returns to R\&D investments, which one would expect if the market would not fully incorporate the information contained in R\&D expenditures into current stock prices. In a later study, Eberhart et al. (2004) focus on abnormal returns to unexpected R\&D increases. They find significant long-term abnormal returns and conclude that R\&D leads to mispricing that the market takes years to correct. A recent study by Daniel and Titman (2006) supports the view that market participants face difficulties in forecasting the value of R\&D investments. ${ }^{49}$ Not surprisingly, Barron et al. (2002) find that the dispersion in analysts' earnings forecasts is substantially larger in $R \& D$ intensive industries. Overall, these studies suggest that $\mathrm{R} \& \mathrm{D}$ investments increase the uncertainty in the information about firms' future returns and therefore the extent to which investors disagree about a firm's future performance. Following Miller (1977), the overvaluation effect of firms with high investor recognition should thus be stronger for $R \& D$ than for physical investments, for which payoffs are typically easier to forecast (Chan et al., 2001). This leads to my final hypothesis:

$\mathrm{H} 3 \mathrm{~b}$ : The positive association between forecast dispersion and investment for firms with high investor recognition will be stronger for $R \& D$ than for physical investment.

\subsection{Data and Method}

\subsubsection{Sample construction}

I assemble annual firm level data from three sources. First, firm level accounting data for the years 1984 to 2006 come from the Compustat database. ${ }^{50}$ To this dataset, I merge data on analyst

\footnotetext{
${ }^{49}$ These authors decompose firms' stock returns into a tangible and an intangible component and find that intangible returns predict future stock returns whereas tangible returns do not.

${ }^{50}$ I also collect data from 1983 for some variables which are included as lags in the empirical models.
} 
coverage and forecast dispersion from the Institutional Brokers Estimates System (I/B/E/S). Following prior investment literature (Brown and Petersen, 2009), I restrict my study to firms in manufacturing industries (SIC 20-39). Even though there has been a shift towards services in recent years, manufacturing firms are still responsible for the bulk of R\&D expenditures (Hall, 1993b: 296). Further, limiting the study to manufacturing firms also ensures that a large share of the firms in my sample has material R\&D expenditures. I delete firm-year observations with annual changes in sales or assets of more than 100\% because such large changes in fundamentals might indicate major corporate events such as mergers or acquisitions or financial distress (Almeida et al., 2004). Further, I require at least two years of consecutive non-missing data for all variables used in the study. Finally, to ensure that the standard deviation of analysts' earnings forecast is a meaningful proxy for disagreement, a firm must be covered by at least three analysts in each year in order to be included in the sample. The final sample is an unbalanced panel covering 10,969 observations related to 1,342 firms.

\subsubsection{Dependent variables}

My main dependent variable is firms' aggregate investment spending (TINV). Similar to Brown and Petersen (2009) I compute this variable as the sum of a firm's physical investments (CAPX) and R\&D expenditures (RD). Following Brown and Petersen (2009), I scale TINV, CAPX, and R\&D by total assets. I argue above that disagreement may have divergent effects on physical investment and R\&D. Hence, I present regression results for all three investment measures throughout the paper.

\subsubsection{Independent variables}

My measure for the amount of disagreement among stock market participants is the dispersion in sell-side analysts' one year-ahead earnings forecast (DISP). This measure is frequently employed as a measure for disagreement and for the divergence of investor opinion (Anderson et al., 2005; Diether et al., 2002; Gilchrist et al., 2005; Lyandres, 2007; Sadka and Scherbina, 2007). I use earnings forecasts as close as possible but preceding the reporting of actual earnings, because forecast made closer to the end of the accounting period are less likely to be affected by macro and industry wide effects (Barth et al., 2001; Mansi et al., 2011; Elton, Gruber and Gultekin, 1984). Following Johnson (2004), I scale forecast dispersion by the beginning of the year total assets (Johnson, 2004).

Consistent with Brown et al. (2009) and Brown and Petersen (2009, 2011), I include three variables to measure the sources of firms' investment financing. These measures are (1) gross cash flow (GCF) defined as after tax income before extraordinary items plus depreciation and amortization plus research and development expenses. (2) Net new long-term debt (DBT) is the amount of long term debt issued minus long term debt reduction. And (3) net cash from new stock issues (STK), which equals the sale of common and preferred stock minus the purchase of common and preferred stock. Again I scale all three financing measures by total assets at the beginning of the fiscal year. Finally, to control for firms' investment opportunities and for future demand, I control for the log of sales - both contemporaneous and lagged by one period. This specification is comparable to that in Brown et al. (2009), only that the models reported below exclude lags of the three financing variables, which are included in Brown et al. (2009). Including 
these variables would not change my findings but would increase the number of instruments in the dynamic panel regressions dramatically.

\subsubsection{Measure of investor recognition}

I use the number of analysts following a firm's stock (NAF) as a proxy for investor recognition (Baker, Nofsinger, and Weaver, 2002; Boehme et al., 2009; Hou and Moskowitz, 2005). Among others, Arbel et al. (1983), Baker et al. (2002: 496), and Marcus and Wallace (1991) argue that analyst reports are the primary source of information for investors and that firms followed by only few analysts face low investor recognition. Analyst coverage is therefore a suitable proxy for investor recognition. Past research suggests a significant positive relationship between analyst coverage and firm size suggesting that analysts are more likely to follow larger firms (Bushan, 1989). Analyst coverage may also differ systematically across industries. For these reasons, I follow Hong et al. (2000) and Doukas et al. (2008: 104) and create a measure of residual analyst coverage (RESCOV). I compute RESCOV as the residual from the following regression, which I estimate separately for each year:

$$
\ln (N A F)_{i}=\alpha+\beta_{1} \ln (T A)_{i}+\sum_{j=1}^{J} \delta_{j i}(I N D)_{j i}+\varepsilon_{i}
$$

where TA is the book value of assets, and IND is a set of 20 industry dummies at the twodigit SIC level. Positive (negative) residual analyst coverage values reflect (strong) weak coverage. More precisely, positive (negative) values of residual analyst coverage show that coverage is higher (lower) than the 'standard coverage' given a firm's size and industry affiliation. Interestingly, these unreported regressions reveal that the positive correlation between analyst coverage and firm size deteriorates over time, at least for the firms in my sample.

Whereas the coefficient estimates for firm size hover somewhere between .30 and .35 between1984 and 1995, these estimates drop considerably in the period after 1999, where the coefficient estimates range somewhere between .30 and .22 . Appendix 3.1 provides an overview of the key variables used in this study and their definitions.

\subsection{Descriptives and correlations}

I present descriptive statistics for the entire sample in table 3.1. Average forecast dispersion across all firms and years is about .023. Figure 3.2 illustrates that forecast dispersion has substantially declined over time. It is not entirely clear what drives this pattern. It is, for instance, possible that advances in ICT enable analysts to compare their estimates more easily with those of others. In any case, figure 3.2 underlines the importance of controlling for time effects in this study. Average residual analyst coverage in my sample is .012. Thus, the average residual analyst coverage in the sample is slightly higher than what one would expect given the firms' size and industry. Residual analyst coverage fluctuates considerably over time, with a marked drop in 2001.

Looking at the investment variables, one can see that firms use around $11.5 \%$ of book assets for investments into physical assets and R\&D. Average investments into physical assets (.066) are somewhat higher than investments into R\&D (.049). These numbers differ somewhat from those reported in Brown et al. (2009) who find higher R\&D ratios. This difference probably reflects the 
fact that their sample includes high tech industries such as software and biotech, which are excluded in this study. Further, note that R\&D is zero for more than one fourth of the observations in the sample, whereas the sample of Brown et al. (2009) only includes R\&D performing firms.

Figure 3.2: Forecast dispersion and residual analyst coverage (1984-2006)

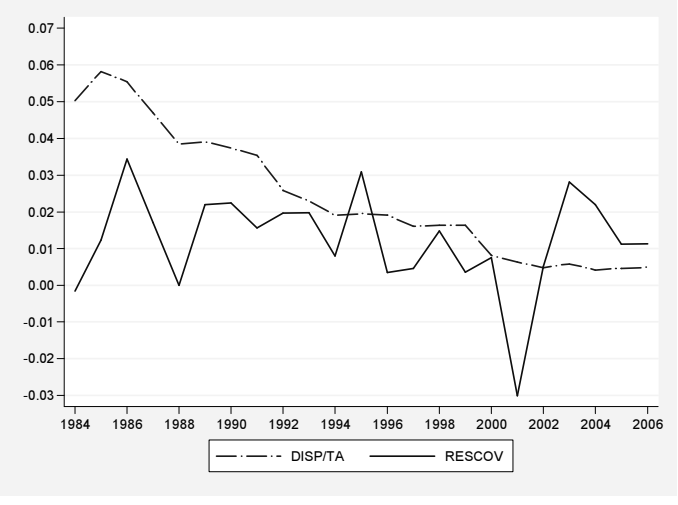

Figure 3.3: Evolution of capital expenditures and R\&D (1984-2006)

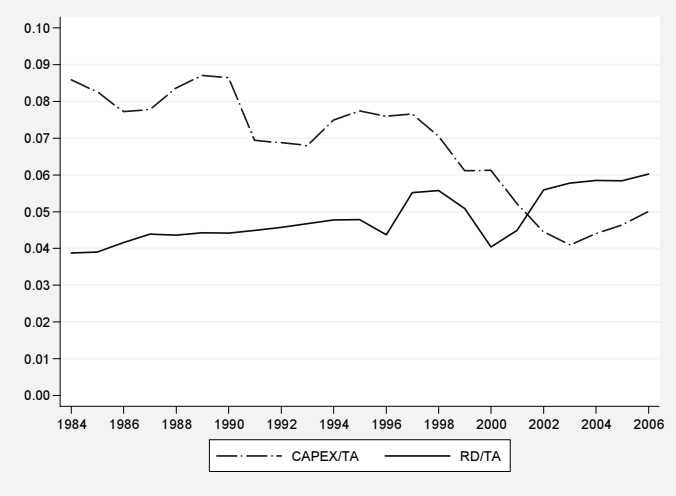

Figure 3.3 depicts the development of physical investments and R\&D investments over time. These patterns are comparable to those documented by Brown and Petersen (2009) and support their observation that the relative importance of $R \& D$ has increased over time, whereas the relative importance of physical investments has declined. The data also show a steep increase in average R\&D intensity in the latter half of the 1990s. This 'R\&D boom' (Brown et al., 2009) is followed by a similar steep drop in average $R \& D$, which probably reflects the burst of the technology bubble in March 2000. In general, R\&D seems to be more persistent in the time series than physical investment. The standard deviations of the time series are .006 and .015 respectively, which may reflect the higher adjustment costs of $R \& D$.

Finally, looking at the three financing variables, it becomes clear that cash flow is by far the most important source of financing, followed by debt and equity. Cash flow is on average $7.5 \%$ of assets and average net new debt about $1.7 \%$ of assets. Average net new equity is close to zero.

Figure 3.4 shows the development of cash flow, net new debt, and net new equity over the sample period. Note that cash flow declines almost consistently over the sample period and 
literally collapses in the years 2001 and 2002 after the burst of the technology bubble and the $9 / 11$ terrorist attacks. Average net new debt and net new equity move in opposing cyclical patterns. Figure 3.5 depicts total sales and total purchases of common and preferred stock (unscaled). Both measures are increasing in the time series but stock repurchases tend to be higher than stock sales, especially after 1994. This probably explains why the ratio of net new stock to assets is so low in my data.

Figure 3.4: The sources of financing over time (1984-2006)

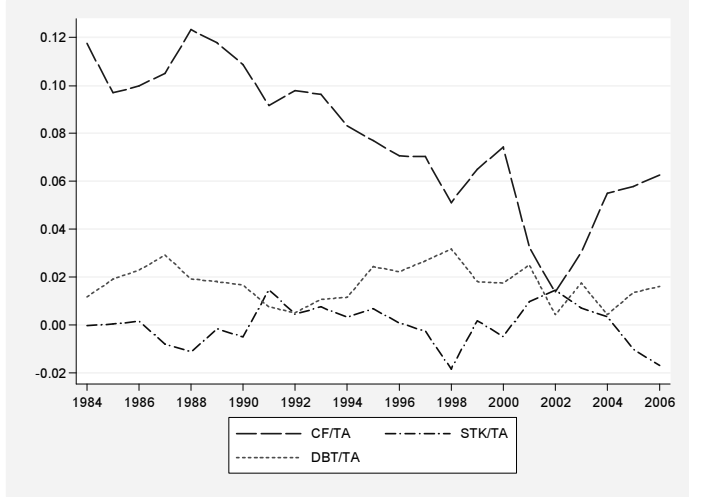

Figure 3.5: Total sales and purchases of common and preferred stock in logs of Thousand US\$ (1984-2006)

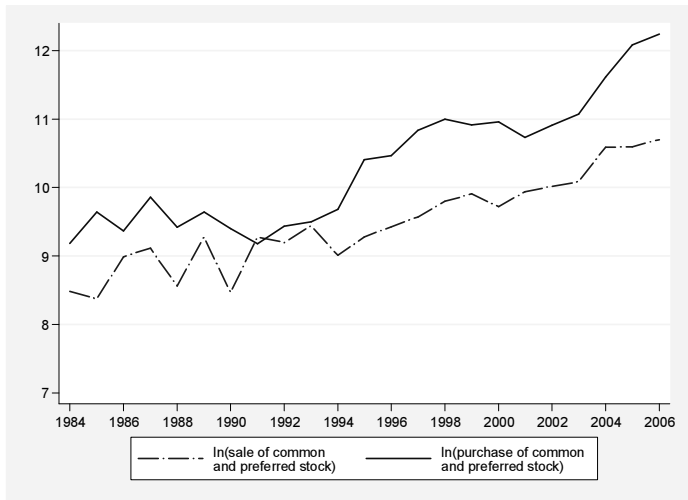

Roughly $68 \%$ of the firms in my sample are listed at the NYSE. On average, a firm's stock is followed by just over 11 analysts. Even though these sample characteristics are comparable to prior investment research (Bakke and Whited, 2010), my sample is clearly a biased towards larger and more mature firms. A likely reason for this is my focus on manufacturing firms that are followed by at least three analysts. Even though there is clearly a selection bias in my data, the direction of this bias should only weaken my ability to find differences between firms with low and high investor recognition, because I exclude a large number of young and small firms. ${ }^{51}$

\footnotetext{
51 This bias is also present in and acknowledged by Bakke and Whited (2010) Thakor and Whited (2011) who also examine analyst forecast dispersion in an investment setting.
} 


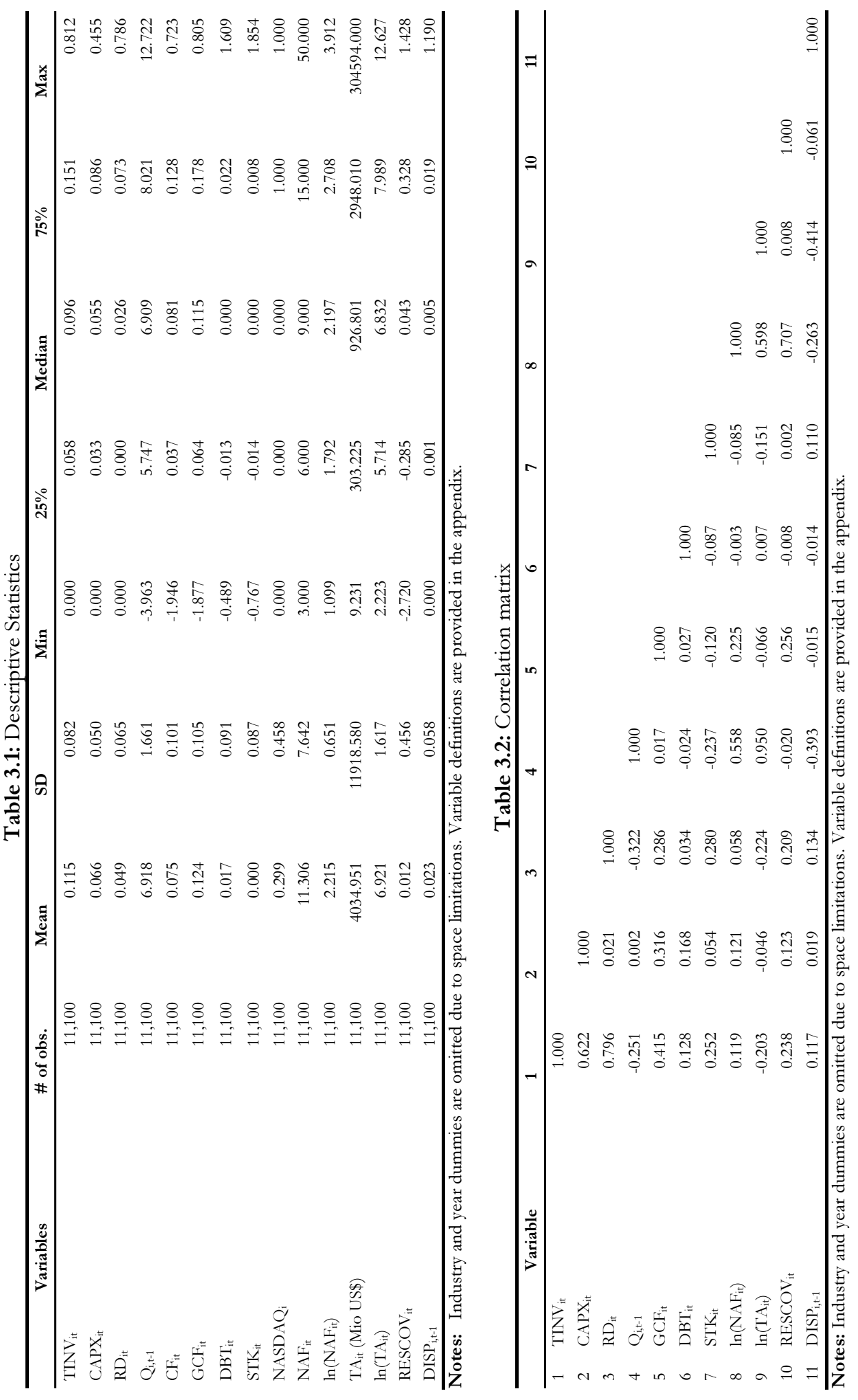


Table 3.3: Descriptives for sample quartiles of high and low investor recognition

\begin{tabular}{|c|c|c|c|c|c|c|}
\hline & \multicolumn{3}{|c|}{ Upper quartile of $\mathrm{RESCOV}_{\text {it }}$} & \multicolumn{3}{|c|}{ Lower quartile of $\mathrm{RESCOV}_{\text {it }}$} \\
\hline & Obs. & Mean & SD & Obs. & Mean & SD \\
\hline $\mathrm{TINV}_{\text {it }}$ & 2,775 & 0.148 & 0.097 & 2,775 & 0.095 & 0.066 \\
\hline CAPX $_{\text {it }}$ & 2,775 & 0.076 & 0.057 & 2,775 & 0.059 & 0.042 \\
\hline $\mathrm{RD}_{\mathrm{it}}$ & 2,775 & 0.072 & 0.077 & 2,775 & 0.037 & 0.049 \\
\hline $\ln (\text { Sales })_{\text {it }}$ & 2,775 & 6.960 & 1.631 & 2,775 & 6.828 & 1.603 \\
\hline $\mathrm{CF}_{\mathrm{it}}$ & 2,775 & 0.093 & 0.119 & 2,775 & 0.061 & 0.089 \\
\hline $\mathrm{GCF}_{\text {it }}$ & 2,775 & 0.165 & 0.121 & 2,775 & 0.098 & 0.092 \\
\hline $\mathrm{DBT}_{\text {it }}$ & 2,775 & 0.017 & 0.091 & 2,775 & 0.018 & 0.096 \\
\hline STK $_{\text {it }}$ & 2,775 & 0.000 & 0.110 & 2,775 & 0.000 & 0.075 \\
\hline $\mathrm{NASDAQ}_{\mathrm{i}}$ & 2,775 & 0.363 & 0.481 & 2,775 & 0.265 & 0.441 \\
\hline $\mathrm{NAF}_{\text {it }}$ & 2,775 & 2.810 & 0.442 & 2,775 & 1.584 & 0.449 \\
\hline $\ln \left(\mathrm{TA}_{\mathrm{it}}\right)$ & 2,775 & 7.047 & 1.512 & 2,775 & 6.784 & 1.614 \\
\hline $\operatorname{DISP}_{i, t-1}$ & 2,775 & 0.016 & 0.041 & 2,775 & 0.029 & 0.071 \\
\hline
\end{tabular}

Notes: Industry and year dummies are omitted due to space limitations. Variable definitions are provided in the appendix.

Table 3.2 gives bivariate correlations for the main variables used in this study. Both, physical and R\&D investments correlate positively with a firm's growth opportunities and with future demand as measured by Tobin's $q$ and sales growth. Overall, the correlations among the variables included in the empirical models tend to be fairly low. Table 3.3 presents descriptive statistics for the upper and the lower quartile of investor recognition. While the firms in the two samples do not differ dramatically in size and sales, it seems that firms in the upper quartile of residual analyst coverage have substantially higher investment expenditures and in particular R\&D investment. Firms in the upper quartile also have higher cash flows and are more likely to be listed at the NASDAQ.

\subsection{Results}

\subsubsection{Estimation and model specification}

I start my analysis with standard OLS estimators that may or may not account for unobserved time-invariant firm-effects. These estimators may be biased (1) when lags of the dependent variable are included on the right-hand side of the regression equation (Nickell, 1981), and (2) in the presence of endogenous or predetermined regressors.

In more recent investment literature, researchers typically report GMM estimates that correct for these biases (Brown et al., 2009; Brown and Petersen, 2009, 2011). The basic idea underlying these estimators is that lagged levels of an endogenous variable are correlated with subsequent realizations of this variable but are uncorrelated to subsequent idiosyncratic errors. If this condition holds, lagged levels of an endogenous variable can be used as instruments in the first differenced equation (Holtz-Eakin, Newey, and Rosen, 1988; Arellano and Bond, 1991).

This difference GMM estimator is likely to be imprecise and biased when the autoregressive parameter approaches unity. ${ }^{52}$ Therefore, Arellano and Bover (1995) and Blundell and Bond

\footnotetext{
52 Problems with the basic difference GMM estimator are, among others, described by Blundell and Bond (1998), who argue that the difference GMM estimator tends to have poor finite sample properties when the lagged levels of
} 
(1998) propose an alternative estimator that exploits additional moment conditions. In particular, these authors consider the additional condition, which implies that lagged differences of the endogenous variable are suitable instruments in the equation in levels.

Almeida, Campello, and Galvao (2010) find that GMM estimators tend to produce robust results for investment equations that are also consistent with theoretical predictions. According to these authors, the GMM estimators have the advantage that they handle firm fixed effects and also allow the estimation of endogenous regressors. Following the lead of prior investment literature (Brown et al., 2009; Brown and Petersen, 2009, 2011), I specify all independent variables to be endogenous. I use lags of these variables (in levels and differences) as instruments. The basic model to be estimated in this study takes the following form:

$$
T I N V_{i t}=\beta_{1} D I S P_{i, t-1}+\beta_{2} G C F_{i t}+\beta_{3} D B T_{i t}+\beta_{4} S T K_{i t}+\sum_{k=1}^{K} \beta_{k} C_{k, i t}+\gamma_{i}+\gamma_{t}+\varepsilon_{i t}
$$

where $C$ is a vector of $k$ control variables including current and lagged sales and when possible a set of industry dummies at the four digit SIC level. The intercept coefficients $\gamma_{i}$ and $\gamma_{t}$ allow for firm and year specific intercepts. The system GMM estimates also include the dependent variable and the square of the dependent variable each lagged by one period (Brown et al., 2009).

\subsubsection{Pooled sample results}

Before testing my hypotheses, I explore the relationship between forecast dispersion and corporate investment using the entire sample. Table 3.4 presents OLS, fixed-effects, and system GMM regressions for all three investment variables. As expected, the coefficients of the financing variables are all positive and significant. Note that the coefficient estimates decrease somewhat after controlling for unobserved heterogeneity in the fixed-effects regressions and even further after controlling for lagged investment and potential endogeneity in the GMM setting. Not too surprisingly, the effect of cash flow is almost always strongest, which is consistent with the predictions of the basic pecking order theory (Myers, 1984; Myers and Majluf, 1984)..$^{53}$

The effects of DBT and STK are smaller and vary across investment types. Whereas the physical investment regressions align rather well with the basic pecking order prediction that firms will prefer external debt over external equity when internal financing sources are exhausted, STK has a stronger effect on $R \& D$ than DBT. These findings are in line with the R\&D financing literature. Firms primarily finance R\&D from current and retained profits (Himmelberg and Petersen, 1994; Kamien and Schwartz, 1978). External equity is the marginal source of R\&D financing when internal financing sources are exhausted. However, firms tend to avoid debt for the financing of R\&D (Brown et al., 2009). Among other reasons, the rationale for this

\footnotetext{
an endogenous variable are weakly correlated with the subsequent first differences. This problem can arise when the data generating process is highly persistent.

${ }^{53}$ Classical investment theory assumes that firms are indifferent with to their financing sources, because firms are assumed to have frictionless access to external capital markets, which implies that the firms' cost of capital depend solely on the business risk facing them (Modigliani and Miller, 1958). The pecking order theory allows for the existence of information asymmetries between managers and investors. As investors' information set regarding a firm's future returns is now incomplete, investors demand compensation for the uncertainty they hold. Uncertainty drives a wedge between the costs of internal and external financing. For this reason, firms will first exhaust internal sources of investment financing. When internal sources are exhausted, firms will prefer external debt over external equity and use external equity as a last resort (Myers and Majluf, 1984: 207).
} 
preference of external equity over debt is the intangible and specialized nature of R\&D assets. Such assets possess little or no collateral value and are therefore not well suited for the securitization of debt (Hall, 2002).

Looking at the OLS estimates, the coefficient of forecast dispersion is positive and significant in the aggregate investment regression. This effect turns negative once I account for unobserved firm-effects and is insignificant in the GMM regression. This latter finding is consistent with findings by Bakke and Whited (2008) and Thakor and Whited (2011). A look at the separate regressions for R\&D and physical investment provides some explanation for these conflicting results. The effect of forecast dispersion on physical investment is negative and significant across all estimators, whereas the effect of forecast dispersion on $\mathrm{R} \& \mathrm{D}$ is always positive. In the aggregate investment regression, these effects cancel out. Whereas these results may be puzzling at first sight, they will become clearer in the following.

\subsubsection{Sub-samples based on investor recognition}

In a next step, I run separate regressions for the upper and lower quartiles of investor recognition. Panel 3.5 (A) presents fixed-effects and system GMM estimates. I do not report simple OLS estimates for space reasons. These estimates are available on request. Consistent with hypothesis $1 \mathrm{a}$, the fixed-effects estimates in column 1 suggest a positive association between forecast dispersion and aggregate investment for firms with high investor recognition $(\beta=.122$; $p$. $<.01)$. Whereas the coefficient does not change very much, the GMM estimates for aggregate investment in column turn insignificant $(\beta=.115$; $\mathrm{p} .=.15)$. Hypothesis $1 \mathrm{~b}$ predicts a negative effect of forecast dispersion on the aggregate investment of firms with low investor recognition. Again, the fixed effects estimates in model 7 provide support for this hypothesis $(\beta=-.040$; $\mathrm{p}$. $<.05)$. The effect turns insignificant in the GMM estimate in model $10(\beta=-.006$; p. $=.82)$. Overall, these results provide rather mixed evidence for hypotheses $1 \mathrm{a}$ and $1 \mathrm{~b}$.

Hypotheses $3 \mathrm{a}$ and $3 \mathrm{~b}$ suggest it is important to split aggregate investment into its components: physical investment and R\&D. Hypothesis 3a posits that the negative correlation between forecast dispersion and physical investment will be stronger than its correlation with $\mathrm{R} \& \mathrm{D}$, essentially due to high adjustment costs for the latter type of investment. In line with this hypothesis the coefficients of forecast dispersion in the physical investment regressions in the low investor recognition quartile are significant and negative in model $8(\beta=-.044 ;$ p. $<.01)$ and model $11(\beta=-.028 ;$ p. <.05). The effects of forecast dispersion on R\&D in models 9 and 12 are insignificant.

Hypothesis $3 \mathrm{~b}$ suggests a stronger positive effect of forecast dispersion on the R\&D investment than on physical investment for firms with high investor recognition. Here the rationale is that the overvaluation effect described in Miller (1977) is essentially an outcome of uncertainty about future returns. Such uncertainty is certainly higher for R\&D. Models 3 ( $\beta$ $=.111 ; \mathrm{p} .<.01)$ and $6(\beta=-.090 ; \mathrm{p} .<.05)$ are indeed positive and significant, whereas the coefficient estimates of forecast dispersion in models 2 and 5 are insignificant. Based on these results, I accept hypothesis $3 \mathrm{~b}$. 


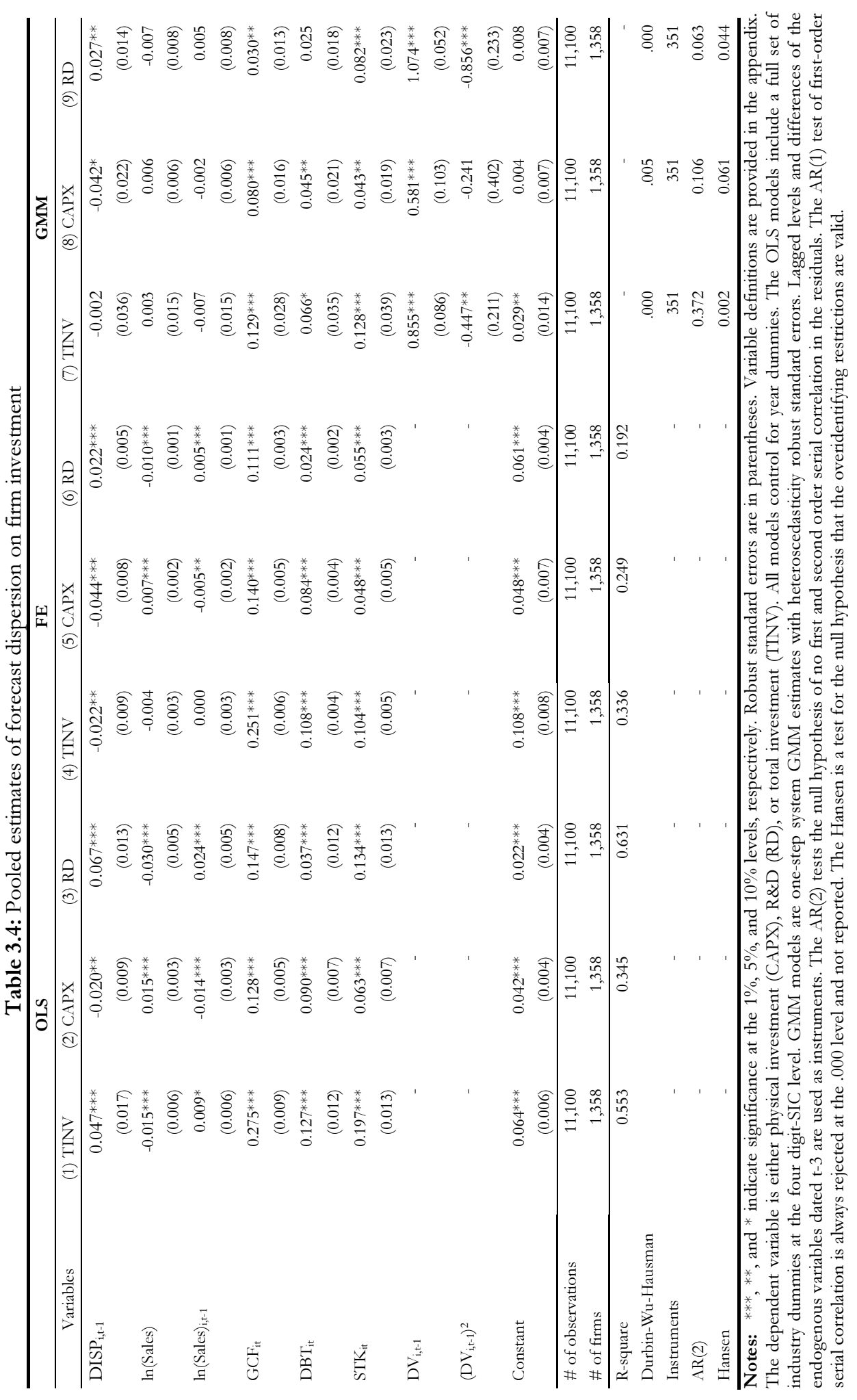




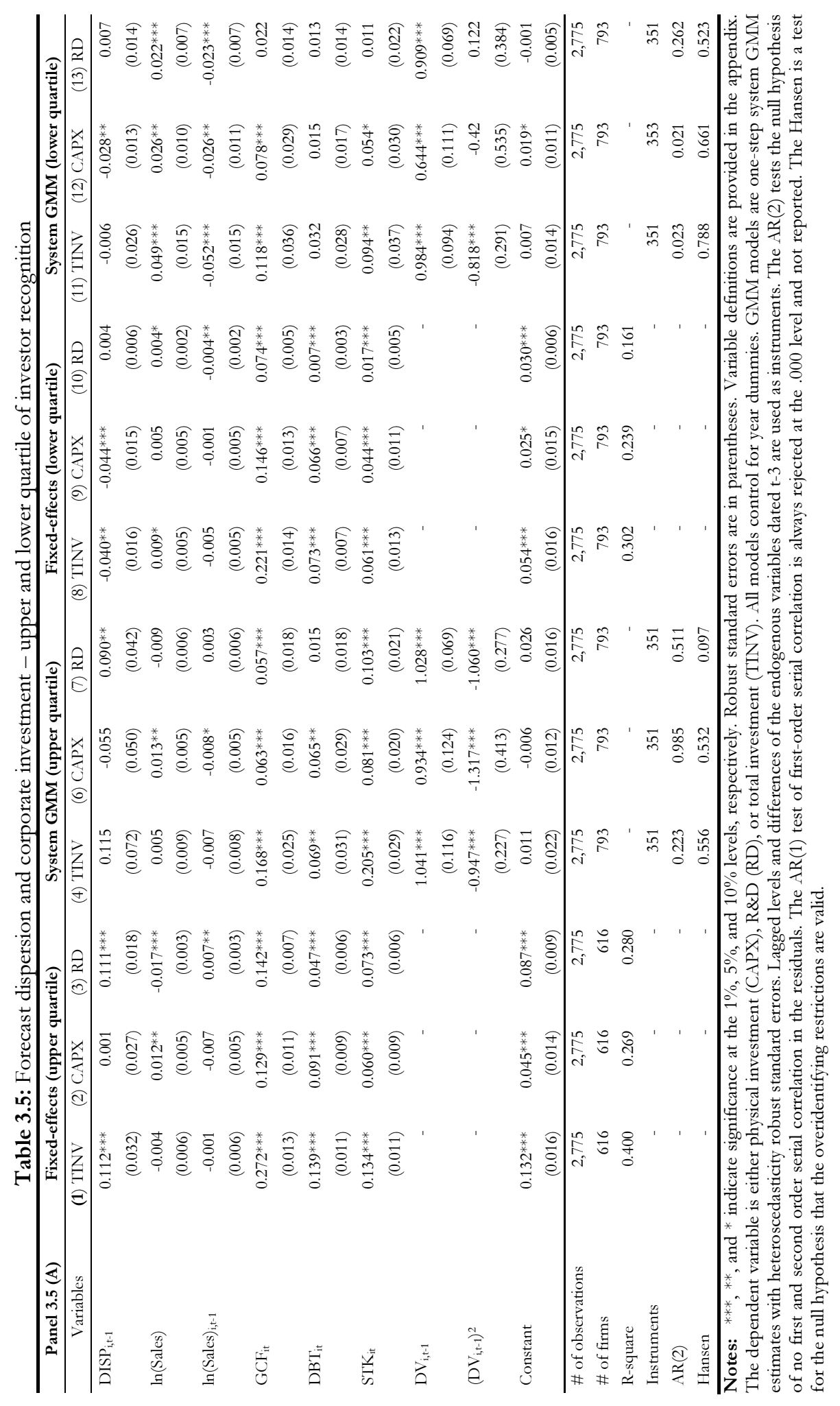




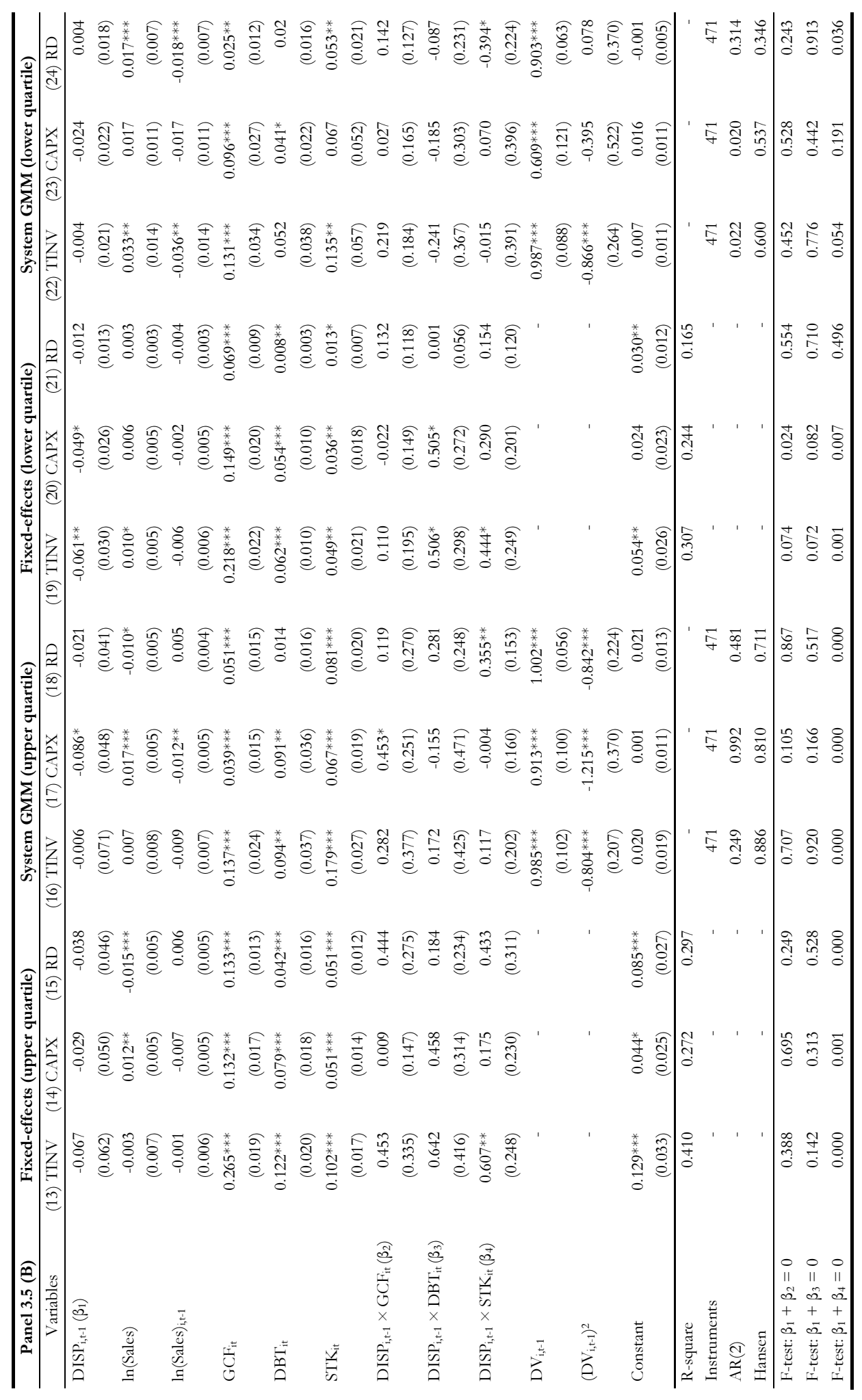




\subsubsection{Investor recognition and the sources of financing}

Hypotheses $2 \mathrm{a}$ and $2 \mathrm{~b}$ argue that forecast dispersion either increases or decreases firms' cost of external equity financing depending on the amount of investor recognition or the visibility of a firm's stock. According to hypothesis 2a, firms in the upper quartile of investor recognition should be more likely to use external (equity) financing for their investments, whereas the opposite should hold true for firms in the lower quartile of investor recognition according to hypothesis $2 \mathrm{~b}$.

Panel 3.5 (B) tests these hypotheses by including three interaction terms between the financing variables and forecast dispersion. The table also includes a set of F-tests to test whether the joint effect of forecast dispersion and the interaction terms with the three financing variables are significantly different from zero. The fixed-effects results for the aggregate investment regression in model 13 support hypothesis $2 \mathrm{a}$. The interaction term between forecast dispersion and STK is positive and significant. Thus, firms with high investor recognition tend to use external equity financing (STK) to a larger extent when analyst forecasts diverge. The F-tests at the bottom of the table strongly rejects the null hypothesis that the joint effect of forecast dispersion and STK is zero. Looking at the system GMM estimates, the interaction term between STK and forecast dispersion has the expected positive sign in the R\&D model but not in the physical investment model. These findings give partial support for hypothesis 2a. Figure 3.6 (A) plots the marginal effects of STK on R\&D for different values of forecast dispersion.

Hypothesis $2 \mathrm{~b}$ suggests that firms in the lower quartile of investor recognition use less external equity financing when forecast dispersion is high, because forecast dispersion is a measure for costly external financing for these firms. The fixed-effects estimates in model 19 do not support this hypothesis: the interaction term between STK and forecast dispersion is positive and significant. I find the expected negative association only after controlling for lagged investment and after controlling for potential endogeneity in the GMM regressions. Interestingly, this negative association is only significant in the R\&D model (model 24). Again this means that I find mixed support for hypothesis $2 \mathrm{~b}$.

Figure 3.6: Marginal effect of STK on R\&D for different values of forecast dispersion

Panel (A): Upper quartile of RESCOV Panel (B): Lower quartile of RESCOV

Figure 3.6 (B) plots the marginal effects of STK on R\&D for different values of forecast dispersion for firms with low investor recognition. The figure shows that the confidence intervals become very large for values of forecast dispersion higher than about .20. This finding suggests 
that the effect of forecast dispersion on the costs of external equity financing for firms with low investor recognition might be non-linear. I will elaborate on this idea in the robustness section.

\subsection{Robustness}

\subsubsection{Linearity of the results}

The very large confidence intervals for larger values of forecast dispersion that I find in panel (B) of figure 3.6 might suggest that the association between forecast dispersion, STK, and R\&D investment is non-linear. I assess the linearity of this relationship in table 3.6.

Table 3.6: Assessing the linearity of the stock-R\&D relationship

\begin{tabular}{|c|c|c|c|c|c|c|c|c|}
\hline \multirow{3}{*}{ Variables } & \multicolumn{4}{|c|}{ Fixed-effects (upper quartile) } & \multicolumn{4}{|c|}{ Fixed-effects (lower quartile) } \\
\hline & \multicolumn{2}{|c|}{ (1) } & \multicolumn{2}{|c|}{ (2) } & \multicolumn{2}{|c|}{ (3) } & \multicolumn{2}{|c|}{ (4) } \\
\hline & Coeff. & S.E. & Coeff. & S.E. & Coeff. & S.E. & Coeff. & S.E. \\
\hline DISP $_{i, t-1}$ & -0.020 & $(0.037)$ & -0.022 & $(0.038)$ & $-0.019 * *$ & $(0.010)$ & $-0.018^{*}$ & $(0.010)$ \\
\hline$\left(\operatorname{DISP}_{\mathrm{i}, \mathrm{t}-1}\right)^{2}$ & -0.065 & $(0.077)$ & -0.081 & $(0.078)$ & -0.002 & $(0.007)$ & 0.002 & $(0.010)$ \\
\hline $\ln ($ Sales $)$ & -0.003 & $(0.003)$ & -0.003 & $(0.003)$ & $0.006^{* * *}$ & $(0.002)$ & $0.006^{* * * *}$ & $(0.002)$ \\
\hline $\ln (\text { Sales })_{i, t-1}$ & -0.002 & $(0.003)$ & -0.003 & $(0.003)$ & $-0.006^{* * *}$ & $(0.002)$ & $-0.006^{* * *}$ & $(0.002)$ \\
\hline $\mathrm{GCF}_{\text {it }}$ & $0.036^{* *}$ & $(0.015)$ & $0.034^{* *}$ & $(0.016)$ & $0.041^{* * *}$ & $(0.010)$ & $0.040^{* * *}$ & $(0.011)$ \\
\hline$\left(\mathrm{GCF}_{\mathrm{it}}\right)^{2}$ & $0.121^{* * *}$ & $(0.026)$ & $0.124^{* * *}$ & $(0.027)$ & $0.042^{*}$ & $(0.025)$ & $0.045^{*}$ & $(0.025)$ \\
\hline $\mathrm{DBT}_{\mathrm{it}}$ & 0.008 & $(0.007)$ & 0.010 & $(0.008)$ & $0.007^{*}$ & $(0.004)$ & $0.007^{*}$ & $(0.004)$ \\
\hline$\left(\mathrm{DBT}_{\mathrm{it}}\right)^{2}$ & $0.074^{* * *}$ & $(0.012)$ & $0.068^{* * *}$ & $(0.013)$ & 0.003 & $(0.010)$ & 0.003 & $(0.010)$ \\
\hline $\mathrm{STK}_{\mathrm{it}}$ & $0.023^{* * * *}$ & $(0.007)$ & $0.022^{* * *}$ & $(0.007)$ & 0.008 & $(0.005)$ & 0.008 & $(0.005)$ \\
\hline$\left(\mathrm{STK}_{\mathrm{it}}\right)^{2}$ & $0.037^{* * *}$ & $(0.010)$ & $0.045^{* * *}$ & $(0.012)$ & $-0.028^{* *}$ & $(0.011)$ & $-0.030^{* * * *}$ & $(0.011)$ \\
\hline $\mathrm{DISP}_{\mathrm{i}, \mathrm{t}-1} \times \mathrm{GCF}_{\mathrm{it}}$ & $0.198^{* *}$ & $(0.084)$ & $0.189 * *$ & $(0.084)$ & $0.164^{* * *}$ & $(0.050)$ & $0.170^{* * *}$ & $(0.050)$ \\
\hline $\mathrm{DISP}_{\mathrm{i}, \mathrm{t}-1} \times \mathrm{DBT}_{\mathrm{it}}$ & 0.025 & $(0.162)$ & 0.095 & $(0.168)$ & -0.011 & $(0.067)$ & -0.011 & $(0.069)$ \\
\hline $\mathrm{DISP}_{\mathrm{i}, \mathrm{t}-1} \times \mathrm{STK}_{\mathrm{it}}$ & $0.242^{* * *}$ & $(0.065)$ & $0.205^{* * *}$ & $(0.069)$ & $0.193^{* * *}$ & $(0.074)$ & $0.199^{* * *}$ & $(0.074)$ \\
\hline$\left(\mathrm{DISP}_{\mathrm{i}, \mathrm{t}-1}\right)^{2} \times \mathrm{GCF}_{\mathrm{it}}$ & $4.100^{* * *}$ & $(0.478)$ & $4.255^{* * *}$ & $(0.912)$ & -0.059 & $(0.065)$ & -0.067 & $(0.077)$ \\
\hline$\left(\mathrm{DISP}_{\mathrm{i}, \mathrm{t}-1}\right)^{2} \times \mathrm{DBT}_{\mathrm{it}}$ & 0.153 & $(0.252)$ & -2.195 & $(1.658)$ & -0.004 & $(0.202)$ & -0.026 & $(0.290)$ \\
\hline$\left(\mathrm{DISP}_{\mathrm{i}, \mathrm{t}-1}\right)^{2} \times \mathrm{STK}_{\mathrm{it}}$ & $2.304^{* * *}$ & $(0.333)$ & $3.096^{* * *}$ & $(0.888)$ & $-1.275^{* *}$ & $(0.630)$ & $-1.755^{* *}$ & $(0.829)$ \\
\hline$\left(\mathrm{DISP}_{\mathrm{i}, \mathrm{t}-1}\right)^{2} \times\left(\mathrm{GCF}_{\mathrm{it}}\right)^{2}$ & & - & -0.114 & $(3.264)$ & & - & -0.331 & $(0.558)$ \\
\hline$\left(\mathrm{DISP}_{\mathrm{i}, \mathrm{t}-\mathrm{1}}\right)^{2} \times\left(\mathrm{DBT}_{\mathrm{it}}\right)^{2}$ & & - & 2.812 & $(2.272)$ & & - & 0.108 & $(0.983)$ \\
\hline$\left(\text { DISP }_{i, t-1}\right)^{2} \times\left(\text { STK }_{i t}\right)^{2}$ & & - & -1.211 & $(1.291)$ & & - & 2.367 & $(2.707)$ \\
\hline $\mathrm{DV}_{\mathrm{i}, \mathrm{t}-1}$ & $0.572 * * *$ & $(0.030)$ & $0.571^{* * *}$ & $(0.031)$ & $0.497 * * *$ & $(0.031)$ & $0.495^{* * *}$ & $(0.031)$ \\
\hline$\left(\mathrm{DV}_{\mathrm{i}, \mathrm{t}-1}\right)^{2}$ & $-0.632 * * *$ & $(0.058)$ & $-0.626 * * *$ & $(0.059)$ & $-0.656^{* * *}$ & $(0.059)$ & $-0.656^{* * *}$ & $(0.115)$ \\
\hline CONST & $0.045^{* * *}$ & $(0.009)$ & $0.046^{* * *}$ & $(0.009)$ & $0.017^{* * *}$ & $(0.009)$ & $0.017^{* * *}$ & $(0.006)$ \\
\hline \# of observations & & 2,775 & & 2,775 & & 2,775 & & 2,775 \\
\hline \# of firms & & 616 & & 616 & & 793 & & 793 \\
\hline $\mathrm{R}$-square & & 0.490 & & 0.492 & & 0.310 & & 0.310 \\
\hline
\end{tabular}

Notes: ${ }^{* * *},{ }^{* *}$, and $*$ indicate significance at the $1 \%, 5 \%$, and $10 \%$ levels, respectively. Robust standard errors are in parentheses. Variable definitions are provided in the appendix. The dependent variable is $R \& D$ investment scaled by assets.

The results in models 1 and 2 suggest that the effect of forecast dispersion on the relationship between STK is probably linear for firms with high investor recognition. Both interaction terms between STK and forecast dispersion and forecast dispersion squared are positive. Models 3 and 4 present similar regressions for firms with low investor recognition. 
Interestingly, the interaction term between forecast dispersion and STK is now positive, whereas the interaction term between STK and squared forecast dispersion is negative and significant. It appears from these regressions that forecast dispersion becomes costly for low investor recognition firms only at comparably high levels of forecast dispersion.

\subsubsection{Positive R\&D firms}

In total, 2,766 firm-year observations do not report R\&D expenses. Consequently, my findings might be affected by differences in the financing practices between R\&D reporting and non-R\&D reporting firms. Unreported regressions show that my results do not change when the non-R\&D reporting firms are excluded from the sample.

\subsection{Discussion and Conclusion}

This study examines the effect of disagreement among stock market participants on corporate investment. It contributes to a stream of literature examining the effect of analyst forecast dispersion on corporate investment (Bakke and Whited, 2010; Gilchrist, Himmelberg, and Huberman, 2005; Lyandres, 2007; Thakor and Whited, 2011). More generally, the paper provides novel insights on the effects of uncertainty - which is a main driver of analyst disagreement - on firms' abilities to use the stock market for investment financing. This paper makes the following contributions to this literature. First, the effect of disagreement among stock market participants on corporate investment differs substantially across firms that have either high or low investor recognition. Second, disagreement among stock market participants seems to affect physical investment and R\&D investment in substantially different ways. These effects may even cancel each other out. This suggests that the effects of forecast dispersion - but also the effects of other market frictions on investment should be estimated separately for R\&D and physical investment rather than estimating their effects on aggregate investment.

In more detail, the findings of this paper are the following: In line with the predictions of Miller (1977) that stock prices are likely to be overvalued when investors disagree about a firm's underlying value, I find that analyst forecast dispersion has a positive effect on corporate investment, which I measure as the sum of $\mathrm{R} \& \mathrm{D}$ investment and physical investment. However, this effect only holds for firms with high investor recognition. When I split up corporate investment into $R \& D$ and physical investments, the overvaluation effect seems to be explained entirely through the R\&D regressions. I do not find a direct effect of forecast dispersion on physical investment for firms with presumably high investor recognition.

If the positive effect of disagreement on corporate investment is due to the overvaluation of highly visible firms, the market timing hypothesis would predict that these firms exploit the overvaluation of stock prices and issue new stock. Consistent with this hypothesis, this study documents a positive interaction effect between disagreement among stock market participants and the net cash from new stock issues. Again, this effect is entirely due to R\&D. I do not find a similar effect for physical investment.

Finally, my results differ dramatically for firms with presumably low investor recognition. For these firms, the amount of disagreement among stock market participants has a negative effect on corporate investment. This time, the direct negative effect of forecast dispersion on aggregate investment is driven by the physical investment regressions. There is no significant direct effect of disagreement on $\mathrm{R} \& \mathrm{D}$ for low visibility firms. This finding may suggest that disagreement 
among stock market participants is a proxy for costly external financing for firms with low investor recognition. As R\&D is probably more costly to adjust, these firms tend to reduce their physical investments while leaving R\&D untouched. Do low visibility firms alter the sources of financing when disagreement among stock market participants is high? My expectation was that low visibility firms would refrain from using external sources of financing, as the wedge between internal and external costs of financing increases with increasing forecast dispersion. I find mixed evidence for this hypothesis. Low visibility firms with very high levels of forecast dispersion seem to use significantly less external equity for R\&D financing.

Figure 3.7 summarizes the main findings of this study. Overall, my results suggest that the relationship between disagreement among stock market participants and corporate investment is quite complex: it is influenced by specific firm characteristics, such as the amount of investor recognition, and by the nature of firms' investment expenditures. In particular, it seems to be important to differentiate $R \& D$ investments from investments into physical assets. The main difference between these types of investment is arguably the often extreme uncertainty surrounding the outcomes of R\&D investments (Hall, 2002; O'Sullivan, 2006). It might be precisely this uncertainty that can lead to the overvaluation of firm values when investor recognition is high. Obtaining a high level of investor recognition should therefore be an important task for high tech firms who seek external financing for their R\&D projects.

Figure 3.7: Summary of main findings

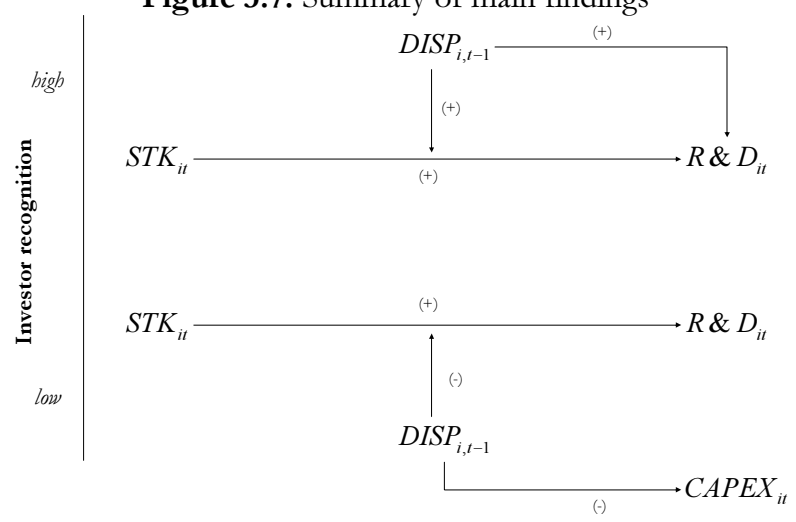

This study is not without limitations. Using analyst forecast dispersion and analyst coverage as measures for disagreement and investor recognition biases the sample towards larger and more established firms. Thus, small firms with very low investor recognition are to a large extent excluded from the sample. However, especially these firms should face high costs of external financing. Future research may therefore explore other measures of disagreement and investor recognition that do not rely on the availability of analyst data. 
Appendix 3.1: Variable definitions

\begin{tabular}{|c|c|c|}
\hline Variable & Definition & Source \\
\hline $\mathrm{TINV}_{\text {it }}$ & $\begin{array}{l}\text { Sum of capital expenditures in period } t \text { and research and development expense in period } t \\
\text { divided by the book value of assets at the beginning of period } t\end{array}$ & Compustat \\
\hline CAPX $_{\text {it }}$ & $\begin{array}{l}\text { Capital expenditures in period } t \text { divided by the book value of assets at the beginning of } \\
\text { period } t\end{array}$ & Compustat \\
\hline $\mathrm{RD}_{\text {it }}$ & $\begin{array}{l}\text { Research and development expense in period } t \text { divided by the book value of assets at the } \\
\text { beginning of period } t\end{array}$ & Compustat \\
\hline $\operatorname{Ln}($ Sale $)$ & Natural logarithm of sales per firm year. & Compustat \\
\hline $\mathrm{GCF}_{\text {it }}$ & $\begin{array}{l}\text { Gross cash flow in period } t \text { divided by the book value of total assets at the beginning of } \\
\text { period } t \text {, where gross cash flow is defined as (after-tax) income before extraordinary items } \\
\text { plus depreciation and amortization plus research and development expense }\end{array}$ & Compustat \\
\hline $\mathrm{DBT}_{\text {it }}$ & $\begin{array}{l}\text { New long-term debt in period } t \text { divided by the book value of total assets at the beginning of } \\
\text { period } t \text {, where new long-term debt is equal to long-term debt issuance minus long-term } \\
\text { debt reduction. }\end{array}$ & Compustat \\
\hline STK $_{\text {it }}$ & $\begin{array}{l}\text { Net cash raised from stock issues in period } t \text { divided by the book value of total assets at the } \\
\text { beginning of period } t \text {, where net cash from stock issues is equal to the sale of common and } \\
\text { preferred stock minus the purchase of common and preferred stock }\end{array}$ & Compustat \\
\hline $\ln \left(\mathrm{NAF}_{\mathrm{it}}\right)$ & Natural logarithm of the number of analysts following a firm's stock in period $t$ & $I / B / E / S$ \\
\hline $\ln \left(T A_{i t}\right)$ & Natural logarithm of total assets & Compustat \\
\hline RESCOV $_{\text {it }}$ & $\begin{array}{l}\text { Residual from annual regressions of analyst coverage on firm size and a set of industry } \\
\text { dummies }\end{array}$ & $\begin{array}{l}\text { Compustat and } \\
I / B / E / S\end{array}$ \\
\hline $\mathrm{DISP}_{\mathrm{i}, \mathrm{t}-1}$ & $\begin{array}{l}\text { Standard deviation of sell-side analysts' one year ahead earnings forecasts in period } t-1 \text { scaled } \\
\text { by total assets in period } t-1\end{array}$ & $\begin{array}{l}\text { Compustat and } \\
I / B / E / S\end{array}$ \\
\hline
\end{tabular}




\title{
Chapter 4
}

\section{UNCERTAINTY AND THE MARKET VALUE OF EXPLORATORY AND EXPLOITATIVE ALLIANCE PORTFOLIOS ${ }_{s+}$}

\begin{abstract}
This study contributes to the literature studying the stock market valuation of alliance portfolios - i.e., the number of alliances that a firm operates at a given point in time. The position of this paper is that alliance portfolios contribute to firm value by enabling firms to access and to internalize external knowledge about new markets and/or new technologies. Using the hedonic regression approach, this study establishes a positive effect of exploratory $R \& D$ alliances but not of exploitative commercial alliances on firm value. This study also stresses the importance of considering the size of a firm's exploratory R\&D alliance portfolio when assessing the market value of alliances. Larger exploratory alliance portfolios have stronger effects on firm value. Firms with only one exploratory R\&D alliance do not receive higher market valuations than firms with no exploratory $R \& D$ alliance. Finally, this paper suggests that the market value of exploratory alliances increases with the uncertainty among stock market participants. These findings might be consistent with the view that exploratory R\&D alliances provide signals to market participants about the value of a firm's R\&D activities. These signals become more important as uncertainty, which I measure by parameter risk and fundamental volatility, increase. My findings also hold in a diff-in-diff setting treating the burst of the late 1990's major technology bubble as an exogenous shock.
\end{abstract}

\subsection{Introduction}

The last decades have seen a substantial increase in the number of high technology firms in the United States (Bates, Kahle and Stulz, 2009; Hall, 1993b). This development can be ascribed to a high proportion of high tech IPO's in the 1980s and 1990s - in particular in industries such as computers, electronic components, communication equipment, and instruments. Especially within these high tech industries, firms have also started to engage in a growing number of alliances (Hagedoorn, 2002; Lavie, 2007; Goerzen and Beamish, 2005). For instance, Merck, an American pharmaceuticals company, reported in 2009 that $63 \%$ of its sales were attributable to alliance related activities including some of the firm's biggest blockbusters.

Alliances offer several advantages, especially within rapidly changing high tech environments (Hagedoorn, 2002). From a learning perspective, alliances increase the firms' awareness of new technologies and market opportunities and facilitate the transfer of information and tacit knowledge (Gomes-Casseres, Hagedoorn and Jaffe, 2006; Koka and Prescott, 2002; Koza and Lewin, 1998; Powell, Koput and Smith-Doerr, 1996; Rowley, Behrens and Krackhardt, 2000;

${ }^{54}$ I appreciate feedback received from Antonio della Malva, Bronwyn Hall, John Hagedoorn, Cédric Schneider, and seminar participants at a KU Leuven/ZEW workshop. 
Uzzi, 1996). From a resource-based perspective (Barney, 1991; Wernerfelt, 1984), alliances grant access to the partners' specialized assets such as distribution networks, R\&D facilities, technologies, or brand names (Colombo, Grilli, and Piva, 2006; Lavie, 2007). Alliances also enable firms to combine these resources and competencies in order to develop new products and services (Ahuja, 2000; Hagedoorn, 1993; Lavie, 2007). In this context, a key advantage of alliances over hierarchical organizations is flexibility, as alliances allow firms to access diverse knowledge bases and to use the partners' specialized resources without the need for large irreversible investments (Hoffmann, 2007).

For a number of reasons firms might also benefit from entering into multiple alliances simultaneously. Ahuja (2000), Koka and Prescott (2002), and Powell et al. (1996) argue, for instance, that the size of a firm's alliance portfolio increases the amount and the diversity of information to which the firm has access. ${ }^{55}$ In particular when knowledge is widely dispersed among different actors, the alliance network, rather than the hierarchy becomes the locus of learning and innovation (Arora and Gambardella, 1990; Powell et al., 1996). Rowley et al. (2000) argue that alliance portfolios also enable firms to triangulate novel information. Hence, firms with comparably large alliance portfolios might not only be superior in knowledge acquisition but also in the processing, evaluation, and exploitation of this novel information.

In the light of these potential benefits, understanding the implications of alliance portfolios on firm performance has become a critical task for alliance researchers and practitioners alike (Goerzen and Beamish, 2005). Several authors consider alliance portfolios to be key strategic resources that contribute to the competitive advantage of firms (Lavie, 2007; Powell et al., 1996; Rowley et al., 2000; Uzzi, 1996). These studies suggest that alliance portfolios contribute to a firm's long term profitability. Assuming that stock prices reflect all publicly available information at a given point in time, the expected future cash flows due to alliances should be reflected in a firm's current stock market value.

Surprisingly, there are relatively few studies that measure the contribution of alliance portfolios to the market value of firms. While there is substantial evidence for a positive effect of individual alliances on firm value, the effects of alliance portfolios are not well understood (Lavie, 2007). In fact, the few existing studies on the association between alliance portfolios and a firm's stock market value give remarkably inconsistent results, especially when it comes to the direct effect of alliance portfolio size on the stock market value of firms. In a study on the US software industry, Lavie (2007) documents a negative and sporadically significant effect of alliance portfolio size on the annual growth in market value. In contrast, Lavie, Kang and Rosenkopf (2011) find a consistently positive and significant effect of alliance portfolio size on market value, even though the focal industry and the time frame of the two studies are identical.

This study contributes to the literature on the stock-market valuation of alliance portfolios in three ways. First, this study differentiates alliance portfolios according to their scope, by examining the separate effects of exploratory $R \& D$ alliance portfolios and exploitative commercial alliance portfolios on the stock market value of firms. Previous research at the individual alliance level shows that this differentiation matters when analyzing the stock market reactions to alliances (Chan et al., 1997; Das, Sen, and Sengupta, 1998; Koh and Venkatraman, 1991; Merchant and Schendel, 2000). Second, this study empirically aligns the research on the stock market valuation of alliance portfolios with the extant literature on the valuation of other

55 Following Powell et al. (1996) and Lavie (2007), I define alliance portfolios as the total number of direct collaborative ties that a firm operates simultaneously at a given point in time. 
intangibles and knowledge assets, such as $\mathrm{R} \& \mathrm{D}$, patents, or trademarks. This literature employs the 'hedonic regression approach' in order to assess the relationship between intangible assets and firm value (Cockburn and Griliches, 1988; Griliches, 1981; Hall, 1993a; Hall, Jaffe, and Trajtenberg, 2005). Finally, this paper is the first to consider the moderating effects of firm-level uncertainty on the relationship between alliance portfolios and the stock market value of firms.

Using a novel panel dataset of high tech and medium tech firms listed at US stock exchanges between 1998 and 2006, this study corroborates the findings from the research at the individual alliance level that in particular exploratory technology alliances contribute to firm value. Interestingly, the effect of exploratory $\mathrm{R} \& \mathrm{D}$ alliances on firm value increase with exploratory R\&D alliance portfolio size. Finally, employing three measures for firm-level uncertainty about future expected returns, this study suggest that exploratory $R \& D$ alliance portfolios tend to become more valuable as uncertainty increases. Diff-in-Diff estimates using the burst of the late 1990 's technology bubble as an exogenous shock to uncertainty suggest that this latter effect is causal in that higher levels of uncertainty surrounding firms' future returns lead to an increase in the stock market valuation of exploratory alliance portfolios.

\subsection{Hypotheses}

\subsubsection{Alliance portfolios versus individual alliance announcements}

A relatively large body of literature investigates the stock market reactions to individual alliance announcements (Anand and Khanna, 2000a; Chan et al., 1997; Das, Sen, and Sengupta, 1998; Kale, Dyer and Singh, 2002; Koh and Venkatraman, 1991; Swaminathan and Moorman, 2009). These studies usually document positive abnormal returns to alliance announcements, even though these abnormal returns tend to be small and are sometimes only marginally significant. In recent decades large firms typically engage in multiple simultaneous alliances with different partners (Gulati, 1998; Lavie, 2007). In particular in high tech industries, where knowledge is crucial but widely dispersed among individual actors, firms become more and more embedded in dense alliance networks with suppliers, customers, competitors, and institutions such as universities and research organizations (Cloodt, Hagedoorn and Roijakkers, 2010; Powell et al., 1996; Roijakkers and Hagedoorn, 2006). Regarding these developments, researchers and practitioners alike have come to argue that the economic performance of firms does not so much depend upon any single alliance but rather on the orchestration of a larger number of alliances in alliance portfolios (Hoffmann, 2005, 2007; Lavie, 2007; Steinhilber, 2008).

Within such alliance portfolios, the outcomes of individual alliances are interdependent and can thus not be regarded as 'discrete events' (Lavie, 2007; Vassolo et al., 2004). Interdependencies in alliances portfolios exist for a number of reasons. It is, for instance, possible that firms redeploy information, capabilities, or best practices from a particular alliance across the alliances in their alliance portfolio. For this reason, especially firms who form a large number of alliances and by that accumulate experience in the management of these organizational forms, tend to benefit more from alliance formation than other, less experienced firms (Anand and Khanna, 2000a; Vassolo et al., 2004). Individual alliances might also share common resources or facilities such as dedicated alliance functions (Kale, Dyer, and Singh, 2002; Koka and Prescott, 2002; Powell et al., 1996). Finally, it is possible that firms form multiple alliances for attaining just one 
particular business goal. Steve Steinhilber, Vice President of strategic alliances at Cisco states, for example:

“At Cisco, we take a portfolio approach. We start by making sure we understand our business objectives in the technology space where we are considering a build-buypartner strategy. We then lay out the scope and number of relationships we need to achieve our business objectives"

(Steinhilber, 2008:103).

Event studies focusing on the stock market reactions to individual alliance announcement are not well suited for taking these interdependencies within alliance portfolios into account. Some researchers therefore claim that the findings of the event study literature regarding the stock market valuation of alliances might be misleading or biased. Further, it is also not clear whether the conclusions derived from the event study literature transfer easily to the alliance portfolio level (Hoffmann, 2005; Koka and Prescott, 2002; Lavie, 2007). ${ }^{56}$ A first goal of this paper is therefore to provide new evidence on the effects of alliance portfolios on the stock market value of firms.

\subsubsection{Exploratory alliances vs. exploitative alliances}

Research at the individual alliance level suggests that the effect of alliances on firm value depends critically on the task that the alliances perform. Several studies find that announcements of exploratory $\mathrm{R} \& \mathrm{D}$ alliances are followed by positive and significant abnormal stock returns, whereas exploitative commercial alliances tend to create weaker or no abnormal returns (Das et al., 1998 Koh and Venkatraman, 1991; Merchant and Schendel, 2000). It is therefore important to analyze the market valuation effects of exploitative alliance portfolios and exploratory alliance portfolios separately.

In the following, I will briefly line out the differences between exploitative and exploratory alliances. My main assumption is that both types of alliances create value by granting access to novel information or valuable knowledge, which contributes to a firm's knowledge stock. A knowledge stock is essentially a repository of knowledge and information, which a firm uses develop new products and services. It is a major determinant of the firm's growth opportunities and of its future profitability. A relatively large body of literature shows that the knowledge stock correlates positively with a firm's market value as approximated by Tobin's q (Cockburn and Griliches, 1988; Czarnitzki, Hall, and Oriani, 2006; Griliches, 1981, 1990: Hall, 1993a, 1993b; Hall et al., 2005). Differentiating between exploitative alliances and exploratory alliances in a market value context matters as the type of knowledge that firms obtain from each of the two alliance types differs quite dramatically. I will shortly elaborate on this point below.

Exploitative commercial alliances focus on downstream value chain activities such as manufacturing, marketing, distribution, or supply (Das et al., 1998; Swaminathan and Moorman,

\footnotetext{
${ }^{56}$ On the contrary, researchers analyzing the effects of alliance portfolios on firm value or performance face problems that are absent in the event study research. In particular, the construction of alliance portfolios requires several strong assumptions, for instance, about the duration of alliances, which is typically unobservable to the researcher.
} 
2009: 53). Important objectives of these alliances are related to cost savings and to overcoming resource constraints (Colombo et al., 2006). According to Swaminathan and Moorman (2009: 53), exploitative commercial can create value for a focal firm by enabling the firm to outsource certain activities that are peripheral to its core competencies. Further, the firm may benefit from exploitative alliances by accessing distribution or customer networks of their partners. With regard to learning, exploitative alliances grant access to important knowledge about customer preferences or market characteristics.

Overall, the relationship between exploitative alliances and firm value is quite ambiguous. Das et al. (1998) posit that investors may perceive these types of alliances as signs of weakness and limited growth opportunities. Swaminathan and Moorman (2009: 53) argue that the effects of exploitative alliances may differ across industries. This may explain why relatively few studies find significant abnormal returns to the announcement of exploitative alliances. In their study, Swaminathan and Moorman find evidence for positive abnormal stock returns to the announcement of marketing alliances for a sample of 250 alliance announcements in the US software industry. These findings are in line with the view that exploitative alliances contribute to a firm's knowledge stock. Hence, my first hypothesis reads as follows:

H1: There will be a positive relationship between a firm's exploitative alliance portfolio and firm value.

Exploratory R\&D alliances focus on the discovery of novel business opportunities and on the transfer of tacit knowledge and fine-grained information among firms (Colombo et al., 2006; Koza and Lewin, 1998; Rowley et al., 2000). Clearly, these alliance types are important instruments for organizational learning. Further, the importance of exploratory alliances has increased considerably in the last three to four decades, especially in high tech sectors (Hagedoorn, 2002; Mowery, 2009). In the time after the Second World War, most industries in the United States but also in other industrialized economies were dominated by few large and highly vertically integrated companies (Chandler, 1990). These 'industrial enterprises' used to be at the forefront of scientific and technological progress and used to perform the entire continuum from basic research to more applied development tasks in-house in large centralized $R \& D$ facilities. Increased international competition and increasing speed and costs of innovation have put substantial pressure on these firms (Mowery, 2009). Critical scientific and technological knowledge and capabilities are nowadays much more dispersed among different economic actors. Some researchers therefore posit that the network rather than the individual firm has become the locus of innovative activity and learning (Powell et al., 1996). As the Economist (2007) puts it:

"Modern technology firms are much less vertically integrated. They use networks of outsourced suppliers and assemblers, which has lead to the splintering of research divisions. Even though big American firms still spend billions of dollars on R\&D, none has any intention of filling the shoes left empty by Bell Labs or Xerox PARC."

In rapidly changing high tech industries, the number of exploratory alliances that a firm maintains is an indicator for the firm's embeddedness in the core innovative activities of the industry (Koka and Prescott, 2002). According to Powell et al. (1996) exploratory R\&D alliances are 'the admission ticket' to an information network that is crucial for staying abreast with 
scientific and technological developments. The effects of exploratory alliances on learning should thus be pivotal.

Indeed, a number of empirical studies show that exploratory R\&D alliances and alliance portfolios promote knowledge flows across firms as measured by patents and patent citations (Gomes-Casseres, Hagedoorn, and Jaffe, 2006; Mowery, Oxley, and Silverman, 1996; Frankort et al., 2012). Based on a sample of 132 US biotech firms, Deeds and Hill (1996) establish, for example, that the number of a firms technology related alliances has a positive effect on the rate of new product development and the number of patents granted to a firm. Ahuja (2000) confirms these findings for a sample of 97 international chemical firms. He finds that the number of direct technology ties has a positive impact on firms' successive patenting rate. Exploratory alliance portfolios may also have a direct effect on firm profitability. Colombo et al. (2009) document, for instance, that the number of technology related alliances maintained by a sample of 265 technology start-ups significantly enhances these firms' productivity. Consistent with these studies I posit that exploratory R\&D alliance portfolios are increasingly important means for organizational learning and knowledge acquisition. ${ }^{57}$ Hence:

H2: There will be a positive relationship between a firm's exploratory R\&D alliance portfolios and firm value.

\subsubsection{Uncertainty and the market value of exploratory alliance portfolios}

The previous section posits that firms benefit from alliances and alliance portfolios through the access to and through the acquisition of information and knowledge about markets and/or new technologies. Alliances therefore contribute to a firm's knowledge stock, which explains the positive relationship between alliances and firm value. However, there is another mechanism through which exploratory $\mathrm{R} \& \mathrm{D}$ alliances can potentially affect the market value of firms: the signalling of information about the value of firms' R\&D activities (Gulati, 1998; Stuart, 2000).

R\&D differs from other types of corporate investment, in that firms have strong incentives to keep their information about R\&D secret (Arrow, 1962; Hall, 2002). For this reason, R\&D intensive firms tend to be plagued by information asymmetries between managers inside the firm and outside investors (Aboody and Lev, 2000). Information asymmetries about the value of R\&D projects may lead to an increase in the cost of external financing for innovative firms and eventually to a funding gap for innovative projects (Hall, 2002).

Exploratory $R \& D$ alliances can provide informative signals about the quality of $R \& D$ projects. Stuart (2000) suggests that a firm is more likely to form an exploratory R\&D alliance with another firm, if the firm possesses leading edge technologies or has shown to be a skilled innovator. Thus, firms with strong innovative capabilities provide the most viable opportunities to learn new routines and new know-how, making them the most valuable alliance partners. Furthermore, the selection of R\&D alliance partners is preceded by a costly and time consuming screening process (Stuart, 2000: 793). Consequently, the formation of an exploratory R\&D alliance that involves the screening of $R \& D$ projects through the alliance partner can reduce the

\footnotetext{
${ }^{57}$ In a comment on Hall (1993b), Mansfield points out that research assessing the market value of a firm's knowledge stock should consider the fact that firms' R\&D projects are increasingly organized in alliances.
} 
information asymmetries between external investors and managers ${ }^{58}$. The signalling properties of exploratory R\&D alliances might even become stronger with increasing alliance portfolio size. Thus, a firm that is active in many exploratory $R \& D$ alliances at the same time can signal that it is at the heart of an innovation network (Powell et al., 1996).

Whereas it is fairly accepted in the literature that exploratory R\&D alliances carry signalling value to external investors, the conditions underlying the variation in the value of alliance signals have not been studied extensively. Gulati (1998: 301) posits that the signalling properties of status that alliances convey should be particularly valuable in uncertain environments. Uncertainty may therefore be an important factor affecting the signalling value of exploratory $R \& D$ alliances.

According to Johnson (2004) equity market actors' overall perceptions of uncertainty about firms' future returns or firms' current market value is dividable into two components. The first component captures the volatility of fundamentals or the firm's fundamental risk. The second component, which Johnson refers to as parameter risk, is purely determined by the information setting surrounding a firm. Whereas market actors perceive the information about a firm's underlying value as unfamiliar, complex, or opaque when parameter risk is high, information about firm value is perceived as rather predictable, simple, or transparent when parameter risk is low (Johnson, 2004). When parameter risk or fundamental risk about a firm's value is high, investors are likely to place a higher value on the signals that exploratory $\mathrm{R} \& \mathrm{D}$ alliances convey. This is intuitive. If there is no uncertainty about a firm's underlying value, there is no reason for investors to react to signals in the first place. This leads to my final set of hypotheses:

H3a: The positive relationship between exploratory R\&D alliance portfolios and firm value will increase as parameter risk increases.

H3b: The positive relationship between exploratory R\&D alliance portfolios and firm value will increase as fundamental risk increases.

\subsection{Data}

\subsubsection{Sample construction}

The starting point for the construction of the dataset is the Thomson SDC Platinum alliance and joint venture database (Anand and Khanna, 2000b; Schilling, 2008). From this database I take the entire set of alliances and joint ventures for the years 1998 to 2006. I confine the analysis to industries in which alliances are frequent and form a fundamental part of the incumbent firms' business strategies (Anand and Khanna, 2000a). The sample comprises the following industries: chemicals and allied products (SIC 28), manufacturing (SIC 35), electronic and other electrical equipment and components (SIC 36), transportation equipment (SIC 37), instruments and related products (SIC 38), and software (SIC 737). My sample covers firms that are predominately active in high tech sectors. ${ }^{59}$

Two of my three measures for firm-level uncertainty are based on sell-side analysts' earnings forecasts. I obtain analyst data from the Institutional Brokers' Estimate System (I/B/E/S).

\footnotetext{
${ }^{58}$ Nicholson, Danzon, and McCullogh (2003) find evidence for this type of signalling effect in the case of young biotechnology companies. Their findings suggest that these firms benefit from alliances with established pharmaceutical firms because these alliances send out positives signals to venture capital and stock market investors. ${ }^{59}$ See Brown et al. (2009) for definition of high tech sectors.
} 
I/B/E/S provides earnings per share forecast data issued by sell-side analysts from most US brokerage firms (Ljungqvist, Malloy and Marston, 2009). I/B/E/S forecast data is available in two formats: The summary dataset provides aggregated forecast data per month and includes summary measures, such as mean, median, and standard deviation of all earnings forecasts filed by analysts, as well as the number of analysts following a firm in each month. The detailed data file provides data at the analyst level and allows tracking individual analysts' behavior. Diether et al. (2002) find that the aggregate statistics from the summary data file closely match those computed from the detailed history file.

There is some concern about the accuracy of the forecast data, because I/B/E/S makes ex post adjustments to forecasts in order to produce smooth time series (Sadka and Scherbina, 2007; Diether, Malloy and Scherbina, 2002). For these reasons, I follow Diether et al. (2002) and Sadka and Scherbina (2007) and use the unadjusted summary data file for my analysis. I/B/E/S provides analyst forecast data for various time periods, ranging from one-year-ahead earnings forecasts to five-year-ahead earnings forecasts. In this paper, I focus on one-year-ahead forecasts. The main reason for this choice is that the number of analysts issuing earnings forecasts for this period is considerably larger than that of longer time horizons (see also Bond and Cummins, 2004). In order to make forecast dispersion a reasonable proxy for analyst disagreement, firmyear observations for which less than four analysts' have filed earnings forecasts with $\mathrm{I} / \mathrm{B} / \mathrm{E} / \mathrm{S}$ are excluded from the sample (Zhang, 2006). Ro reduce the effect of outliers, I exclude observations for which forecast dispersion is larger than one.

To be included in the sample, firms must have information on (daily) stock prices and stock listings. I obtain this information from the Centre of Research in Security Prices (CRSP). The matching of the CRSP and I/B/E/S databases inevitably leads to a loss of observations, because many firms (in particular small firms) that are included in CRSP are not included in the I/B/E/S database (Diether et al., 2002). I drop firms that are listed 'over the counter' (OTC), because these firms have potentially inferior information environments. ${ }^{60}$ Data on patent applications and patent citations for the years 1976 to 2007 comes from the United States Patent and Trademark Office (USPTO). Finally, I obtain accounting data and data on various firm characteristics from Compustat. The final sample used in this paper excludes firms with less than two observations with consecutive non-missing information. This leads to an unbalanced panel of 390 publicly traded firms with 1,733 firm-year observations.

Panel (A) of table 4.1 shows how these observations are distributed among industries. The majority of the observations come from chemicals and allied products $(\sim 31 \%)$, software $(\sim 20 \%)$, and electronics and electrical equipment $(\sim 19 \%)$. Panel $(B)$ of table 4.1 documents a fairly even distribution of the observations over time. Finally, panel (C) of table 4.1 shows the distribution of the observations among stock-exchanges. The vast majority of the firms in my sample are listed at NASDAQ $(\sim 55 \%)$ and NYSE $(\sim 44 \%)$. Less than $1 \%$ of all observations are listed at AMEX. ${ }^{61}$

\footnotetext{
${ }^{60}$ Hail and Leuz (2009) show, for instance, that OTC listings require a less rigorous information disclosure than listings at the NYSE, AMEX, or NASDAQ.

${ }^{61}$ Only one firm in my sample, an American pharmaceuticals company, is listed at AMEX. I decide to keep this firm in the sample, because it does not affect any of the results reported below.
} 


\subsubsection{Dependent variable}

The dependent variable in this paper is Tobin's q - a measure for the divergence of a firm's market value relative to the book value of the firm's assets (Hall, 1993a). I measure Tobin's as:

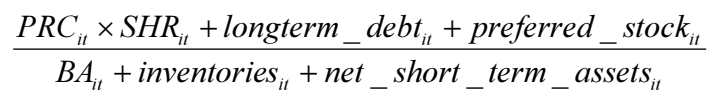

where $P R C_{i t}$ is a firm's end of the year stock price, $S H R_{i t}$ is the number of shares outstanding and $B A_{i t}$ is the book value of a firm's assets. A large number of empirical papers study the market value of various classes of intangible assets (in particular $R \& D$ and patents) by analyzing the effects of these assets on Tobin's q (e.g., Cockburn and Griliches, 1988; Hall, 1993a; Hall and Oriani, 2006; Hall et al., 2005; Toivanen, Stoneman, and Bosworth, 2002). The idea behind these studies is intuitive: as the value of a firm includes many tangible and intangible assets, it is possible to learn something about the value of these assets by “ ... looking at the wedge between the market value and the book value of the firm” (Hall, 1993c: 2). A value of Tobin's q above unity implies that the firm's market value of a firm's assets is higher than its book value. Assuming some form of market efficiency, the market value of a firm equals the discounted future cash flows that the firm derives from its assets.

Table 4.1: Distribution of the observations

\begin{tabular}{|c|c|c|c|}
\hline Industry & \# Obs. & $\%$ of Obs. & $\begin{array}{c}\text { Cum. } \\
\%\end{array}$ \\
\hline \multicolumn{4}{|c|}{ Panel (A): Number of observations by industry } \\
\hline Chemicals and allied products (SIC 28) & 532 & 30.70 & 30.70 \\
\hline Manufacturing (SIC 35) & 249 & 14.37 & 45.07 \\
\hline Electronic and other electrical equipment (SIC 36) & 319 & 18.41 & 63.47 \\
\hline Transportation equipment (SIC 37) & 103 & 5.94 & 69.42 \\
\hline Instruments and related products (SIC 38) & 182 & 10.50 & 79.92 \\
\hline Software (SIC 737) & 348 & 20.08 & 100.00 \\
\hline \multicolumn{4}{|c|}{ Panel (B): Number of observations by year } \\
\hline 1998 & 209 & 12.06 & 12.06 \\
\hline 1999 & 243 & 14.02 & 26.08 \\
\hline 2000 & 204 & 11.77 & 37.85 \\
\hline 2001 & 199 & 11.48 & 49.34 \\
\hline 2002 & 178 & 10.27 & 59.61 \\
\hline 2003 & 169 & 9.75 & 69.36 \\
\hline 2004 & 181 & 10.44 & 79.80 \\
\hline 2005 & 196 & 11.31 & 91.11 \\
\hline 2006 & 154 & 8.89 & 100.00 \\
\hline \multicolumn{4}{|c|}{ Panel (C): Number of observations by stock exchange } \\
\hline New York Stock Exchange (NYSE) & 775 & 44.72 & 44.72 \\
\hline American Stock Exchange (AMEX) & 6 & 0.35 & 45.07 \\
\hline NASDAQ & 952 & 54.93 & 100.00 \\
\hline Total & 1,733 & 100.00 & \\
\hline
\end{tabular}

\subsubsection{Measuring exploratory and exploitative alliance portfolios}

The SDC database only sporadically reports the termination dates of alliances. As a consequence, the construction of the alliance portfolios requires an assumption about the duration of alliances. In line with prior research, I assume that alliances are terminated after three 
years. Thus, I define alliance portfolios as the total number of alliances announced by a firm over a three year's period. ${ }^{62}$ To differentiate exploratory R\&D alliances from exploitative commercial alliance portfolios, I follow Rothaermel (2001) and Lavie and Rosenkopf (2006) and use the information from the SDC activity description. The activity description indicates the value chain activities that are covered by an alliance (e.g. R\&D, marketing, licensing, supply, manufacturing). I delete all alliances for which the activity description is missing and classify the remaining alliances that focus solely on $\mathrm{R} \& \mathrm{D}$ as exploration and alliances that focus on marketing, manufacturing, supply, or licensing as exploitation (Park et al., 2002). These alliances focus more on downstream value chain activities (Das et al., 1998). In a number of cases SDC reports multiple value chain activities for one alliance (e.g. $R \& D$ and licensing). In my sample, less than $20 \%$ of the alliances cover more than one purpose. Following Lavie and Rosenkopf (2006), I consider alliances that entail R\&D elements in combination with other value chain elements to be part of the exploration portfolio.

Figure 4.1 depicts the recoded alliance portfolio variables for exploratory alliance and exploitative portfolios. Panel (A) shows that the recoded exploratory alliance portfolio variable is zero for 840 observations and equals one for 452 observations. For 331 observations that have between two and five exploratory alliances, the variable takes a value of two and for 60 observations with an exploratory alliance portfolio between six and nine it equals three. Finally, for 56 observations with an alliance portfolio equal to or larger than ten, the variable takes on a value of four. I perform a similar coding exercise for exploitative alliance portfolios in panel (B). Note that the recoding of the alliance portfolio variables only serves to enhance the credibility of the results, which might be affected by outliers in the alliance portfolio distribution. Note, however, that my results are almost identical when using the raw alliance portfolio measures in my analysis.

Figure 4.1: Classification of alliance portfolios

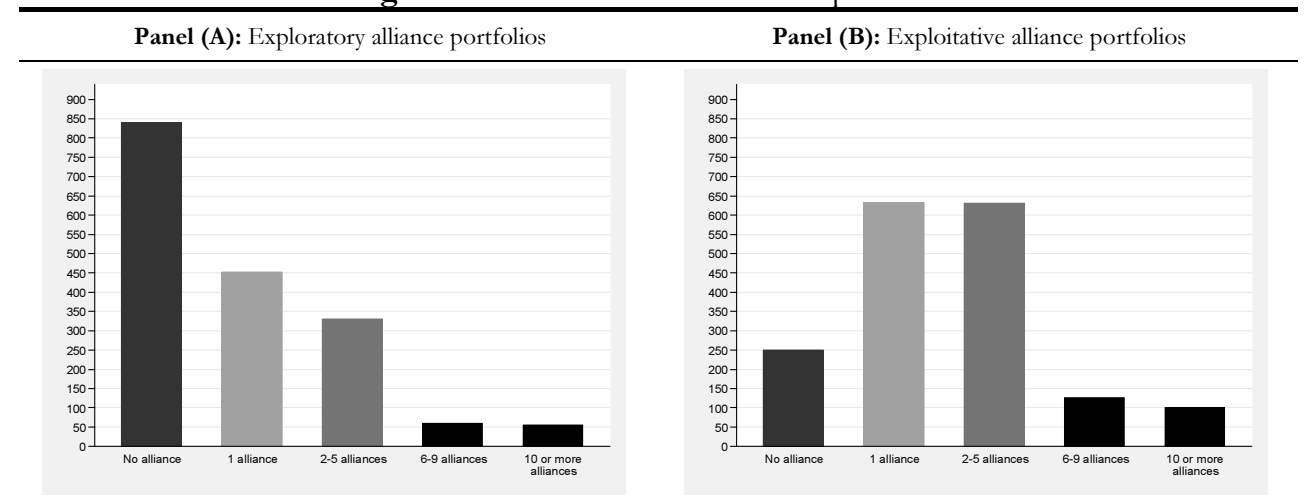

Notes: As alliance portfolio size is very skewed, I group firms' alliance portfolios into five categories based on the number of alliances that have been in announced in year $t-2$ to $\mathrm{t}$ (source: SDC Platinum).

\subsubsection{Measuring uncertainty about firm value}

I construct three measures for investors' perceived uncertainty about a firm's underlying value, which capture both fundamental riks and parameter risk. My first proxy for parameter risk

\footnotetext{
${ }^{62}$ Lavie (2007) and Schilling and Phelps (2007) have made a similar assumption about the duration of alliances and point out that this assumption is rather conservative, given the fact that some alliances may last much longer.
} 
is the dispersion in sell-side analysts' earnings forecasts (DISP). According to Johnson (2004: 1960), forecast dispersion is "... likely to be a manifestation of non-systematic risk relating to the unobservability of a firm's underlying value." ${ }_{3}$

Barron and Stuerke (1998) present some empirical evidence for the appropriateness of forecast dispersion as a measure for uncertainty about a firm's future economic performance. They argue that uncertainty increases investors' demand for additional information and find that investors' information demand after earnings announcements is indeed higher when a firm faces strong forecast dispersion. Based on these findings, they conclude that forecast dispersion is a useful measure of uncertainty. A study by Olsen and Troughton (2000) comes to a similar conclusion. These researchers conduct a survey among institutional analysts and other professional money managers and find a strong positive correlation between forecast dispersion and perceptions of uncertainty about future performance. Finally, Anderson et al. (2005) establish that forecast dispersion is a priced risk factor in traditional asset pricing models. I measure forecast dispersion as the standard deviation of analysts' earnings forecasts scaled by analysts' median earnings per share forecast (EPS). Elton, Gruber and Gultekin (1984) show that forecasts made closer to the end of a forecasting period include more firm-specific information and are less affected by macro and/or industry wide effects. For this reason, I use monthly forecast data as close as possible, but preceding the announcement date of actual earnings (Barth et al., 2001; Mansi et al., 2009; Thomas, 2002).

The second measure of parameter risk is the median forecast error (MFE). MFE is related to forecast dispersion and is measured as the difference between the mean of the analysts' earnings estimates and the 'actual' earnings reported by the firm. In other words, the MFE is a measure for the accuracy or precision of analysts' forecasts (Lang and Lundholm, 1996; Thomas, 2002). A high MFE suggests that a firm's future earnings are difficult to predict - which one would expect if parameter risk is high. I compute the MFE as the absolute difference of actual earnings per share (ACT) and the median earnings per share forecast reported by $\mathrm{I} / \mathrm{B} / \mathrm{E} / \mathrm{S}$ scaled by share price $(\mathrm{P})$ :

$$
M F E_{i, t}=\left|A C T_{i t}-E P S_{i t}\right| / P_{i t}
$$

Finally, my measure for fundamental risk is based on the idiosyncratic volatility of stock returns. I refer to this measure as firm-specific risk (FSR) in the following. I construct FSR using daily stock returns and two Fama and French (1993) risk factors. The advantage of using stock market data for measuring risk is that stock prices, in principle, include all factors in a firm's environment that investors perceive to be important (Gilchrist et al., 2010). Further, whereas the time horizon of analyst earnings forecasts is limited, stock returns include all information about future returns for an indefinite period of time. Similar to Ang et al. (2009) and Fu (2009: 26), I estimate firm-specific risk from the following model:

$$
\left(r_{i t_{d}}-r_{t_{d}}^{f}\right)=\alpha_{i}+\beta_{i}^{M}\left(r_{t_{d}}^{M}-r_{t_{d}}^{f}\right)+\beta_{i}^{S M B} S M B_{t_{d}}+\beta_{i}^{H M L} H M L_{t_{d}}+u_{i t_{d}},
$$

\footnotetext{
${ }^{63}$ Note that forecast dispersion does not proxy for the risk or uncertainty perceived by each individual analyst. In fact, all analysts could agree on a common 'mean' forecast, while each being uncertain about a firm's future performance.
} 
where $i$ indexes firms, $t_{d}$ indexes trading days in year $t$. In equation (1), $r_{i}$ denotes the firm's daily stock return, $r$ is the one-month treasury bill rate (i.e., the risk-free rate), $r^{M}$ is the valueweighted return on the market as a whole, $S M B$ is the difference between the return on a portfolio of small stocks and the return on a portfolio of large stocks, and HML is the difference between the return of a portfolio of high book-to-market stocks and the return on the portfolio of low book-to-market stocks. Note that I estimate equation (1) separately for each firm year in our sample. I then define FSR as follows:

$$
F S R_{i t}=\sqrt{\frac{1}{N-1} \sum_{n=1}^{N}\left(\hat{u}_{i t_{d}}-\hat{\bar{u}}_{i t}\right)^{2}},
$$

where $\hat{u}_{i t_{d}}$ is the OLS residual from equation (4.3) and $\hat{\bar{u}}_{i t}$ is the mean of this residual in year $t$.

\subsubsection{Control variables}

I control for unobserved heterogeneity across firms by including the five-year pre-sample mean of the $\log$ of Tobin's $q$ in all regressions (Czarnitzki, Hussinger, and Leten, 2011: 16). This pre-sample estimator has the advantage that it does not rely on the strict exogeneity of regressors. Even though the estimator was originally designed for count data models (Blundell et al., 1999), findings by Czarnitzki and Dhaene (2011) suggest that the method also provides consistent and efficient results for least square regressions.

The remaining model specification closely follows the hedonic market value literature. First, I include the natural logarithm of sales. I control for other intangible assets that might be correlated to a firm's knowledge stock. These are (1) R\&D investment, (2) patents, and (3) patent citations. I calculate R\&D stocks using a perpetual inventory method adopting the standard assumptions of a 15\% annual depreciation rate of R\&D for all firms in my sample (Hall, 1990; Hall, Jaffe and Trajtenberg, 2005; Oriani and Sobrero, 2008). The R\&D data used to construct the R\&D stock go back to 1976 , so that a correction for initial conditions is not necessary. I divide the R\&D stock by the book value of total assets of firm $i$ in year $t$. Only few firms in my data never report $R \& D$ expenditures. For these 67 observations is set the $R \& D$ stock to zero. I construct patent stocks and forward citation stocks using the same perpetual inventory method.

The patent data used in this study also goes back to the year 1976. Following prior research, I choose a cascading structure and divide a firm's patent stock by its R\&D stock and the forward citation stock by the patent stock (e.g., Hall et al., 2005). Finally, I construct a set of year dummies and industry dummies at the three-digit SIC level to control for macroeconomic and industry specific effects. All regressions include a dummy variables for the stock exchange at which a firm's shares are listed.

\subsection{Hedonic market value regressions}

A factor that differentiates most intangible assets from tangible assets is the absence of organized and competitive markets at which these assets can be traded (Griliches, 1995; Hall, 2000; Lev, 2001). The absence of markets - where prices are determined through supply and demand - and the resulting unobservability of market prices for intangibles necessitate researchers to use alternative methods for the valuation of intangible assets. One stream of 
literature employs the hedonic regression approach for this purpose (Cockburn and Griliches, 1988; Hall, 1993a, 1993b; Hall et al., 2005; Hall and Oriani, 2006). Researchers following this tradition assume that a firm's overall market value can be expressed in terms of bundles of tangible and intangible assets. Under the assumption that stock markets are efficient, the value that financial markets assign to these assets is equal to the discounted value of their corresponding future cash flows. Thus, it is possible to infer the value of intangible assets from their impact on the firm's market value (Griliches, 1981). With $A$ standing for physical assets and $K$ standing for the knowledge stock (or intangible assets), the market value of firm $i$ in year $t$ can be written as:

$$
V_{i t}\left(A_{i t}, K_{i t}\right)=q\left(A_{i t}+\gamma K_{i t}\right)^{\sigma}
$$

Assuming constant returns to scale $(\sigma=1)$, it is possible to rewrite equation 4.1 in a logarithmic form:

$$
\log (Q)_{i t}=\log \frac{V_{i t}}{A_{i t}}=\log q+\log \left(1+\gamma \frac{K_{i t}}{A_{i t}}\right)
$$

The left hand side of equation 4.6 is now the log of Tobin's q. The shadow value of the ratio of the firm's knowledge stock (or intangibles) to physical assets is represented by $\gamma$. This parameter captures investors' expectations about the contribution of a firm's knowledge stock relative to physical assets to the firm's discounted future profits. My empirical analysis uses several measures to capture $K$.

\subsection{Results}

\subsubsection{Descriptive statistics and correlations}

Table 4.2 shows that the average firm in my sample has slightly more than three exploitative alliances and about 1.5 exploratory alliances in its alliance portfolio. Thus, the firms in my sample are involved in substantially more exploitative than exploratory alliances. ${ }^{64}$ About $3 \%$ of the firms in my sample do not report R\&D expenditures and roughly $11 \%$ of the firms do not have patents. Table 4.3 gives bivariate correlations for the key variables used in this study. Interestingly, the correlation between the recoded exploratory alliance portfolio variable and Tobin's $q$ is much stronger than the correlation between recoded exploitative alliance portfolios and Tobin's q. Also note that the correlation among exploratory and exploitative alliance portfolios is relatively high. This finding is consistent with prior research, which finds that firms usually tend to engage in both types of alliances at the same time (Rowley et al., 2000). Exploratory alliance portfolios also positively correlate with $R \& D$, whereas the correlation of exploitative alliance portfolios and $\mathrm{R} \& \mathrm{D}$ is negative.

\footnotetext{
${ }^{64}$ Of the alliances included in my sample, roughly $15 \%$ are joint ventures, whereas the vast majority is contractual agreements. Excluding the joint ventures from my sample does not affect any of my results. All results are robust to controlling for the share of joint ventures in a firm's alliance portfolio in the hedonic regressions.
} 


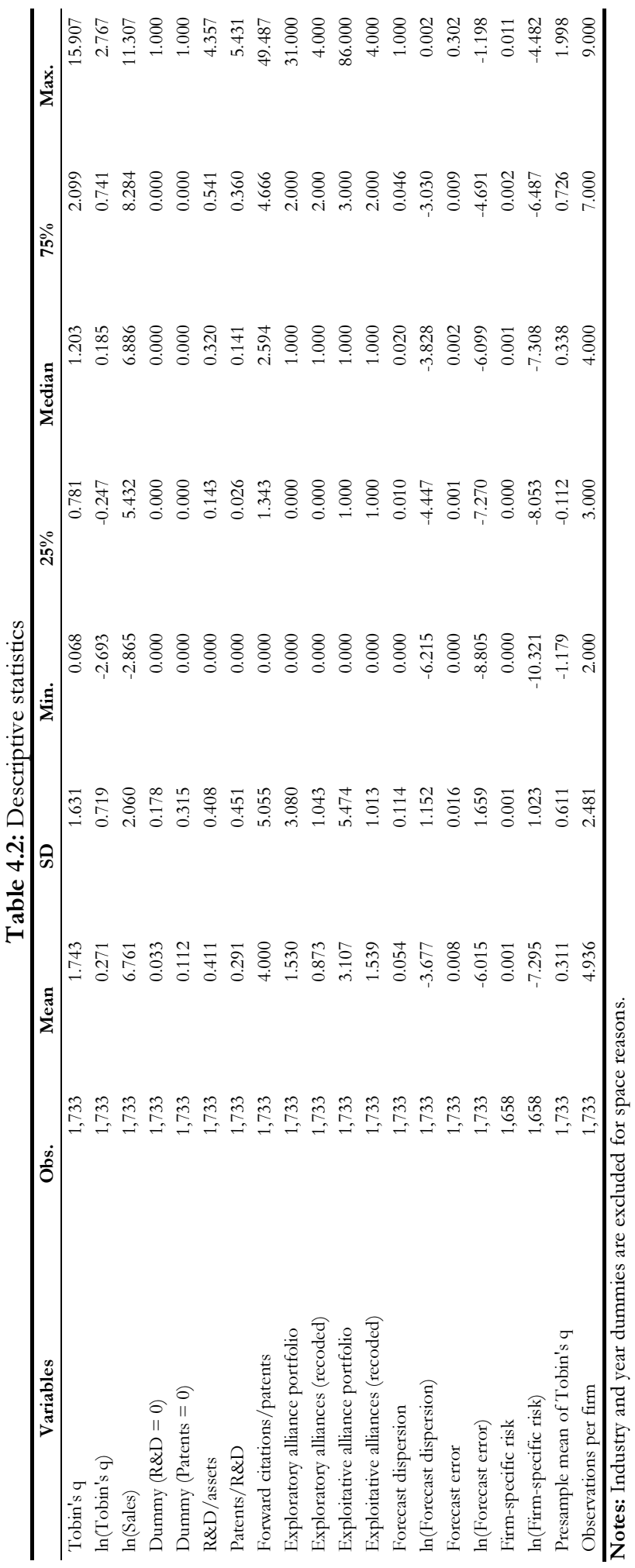




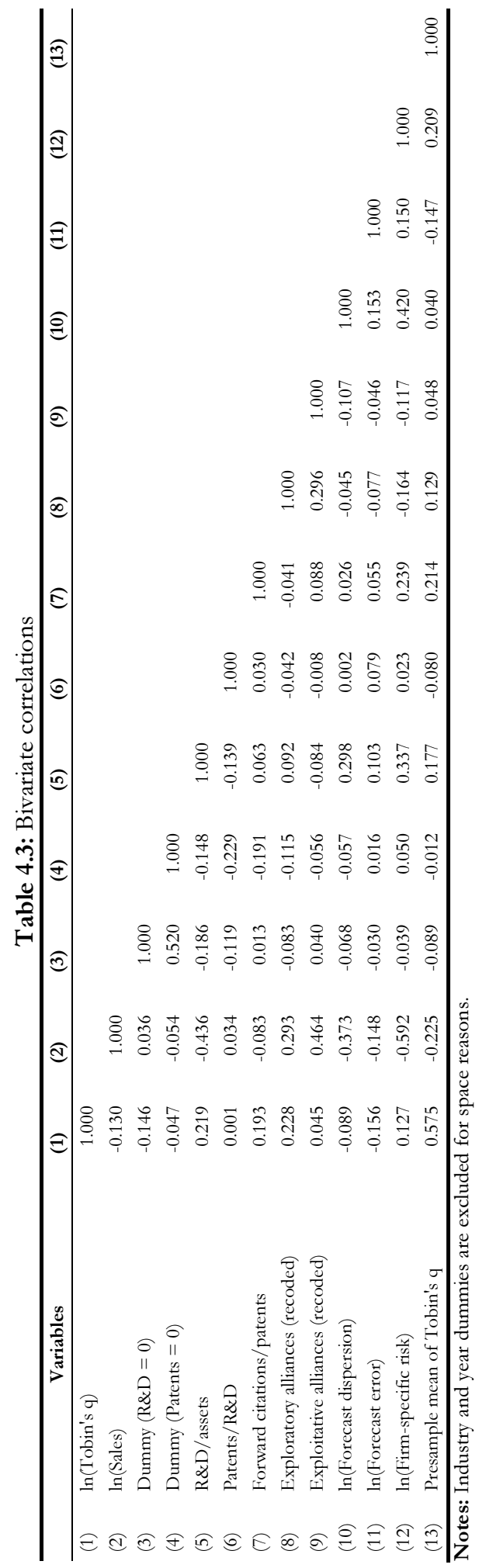


Table 4.4: The effects of alliance portfolios on Tobin's g

\begin{tabular}{|c|c|c|c|c|c|}
\hline \multirow[t]{2}{*}{ Variables } & \multicolumn{5}{|c|}{ DV: $\ln$ (Tobin's q) } \\
\hline & $(1)$ & (2) & (3) & (4) & (5) \\
\hline \multirow[t]{2}{*}{ Presample mean of Tobin's q } & $0.510^{* * *}$ & $0.508^{* * *}$ & $0.523^{* * *}$ & $0.512^{* * *}$ & $0.511^{\text {**** }}$ \\
\hline & $(0.031)$ & $(0.030)$ & $(0.031)$ & $(0.031)$ & $(0.030)$ \\
\hline \multirow[t]{2}{*}{$\ln$ (Sales) } & $0.052^{* * *}$ & $0.031^{* * *}$ & - & $0.054^{* * *}$ & $0.035^{* * *}$ \\
\hline & $(0.009)$ & $(0.011)$ & & $(0.011)$ & $(0.012)$ \\
\hline \multirow[t]{2}{*}{ Dummy $(\mathrm{R} \& \mathrm{D}=0)$} & $-0.468^{* * *}$ & $-0.473^{* * *}$ & $-0.466^{* * *}$ & $-0.465^{* * *}$ & $-0.465^{* * *}$ \\
\hline & $(0.085)$ & $(0.083)$ & $(0.084)$ & $(0.085)$ & $(0.084)$ \\
\hline \multirow[t]{2}{*}{ Dummy (Patents $=0$ ) } & $0.125^{*}$ & $0.136^{* *}$ & 0.096 & $0.123^{*}$ & $0.132 * *$ \\
\hline & $(0.064)$ & $(0.063)$ & $(0.064)$ & $(0.064)$ & $(0.064)$ \\
\hline \multirow[t]{2}{*}{$\mathrm{R} \& \mathrm{D} /$ assets } & $0.180^{* * *}$ & $0.158^{* * * *}$ & $0.126^{* *}$ & $0.182^{* * *}$ & $0.162^{* * *}$ \\
\hline & $(0.053)$ & $(0.052)$ & $(0.050)$ & $(0.054)$ & $(0.052)$ \\
\hline \multirow[t]{2}{*}{ Patents/R\&D } & $0.086^{* *}$ & $0.079^{* *}$ & $0.061^{*}$ & $0.086^{* *}$ & $0.079 * *$ \\
\hline & $(0.036)$ & $(0.036)$ & $(0.035)$ & $(0.036)$ & $(0.036)$ \\
\hline \multirow[t]{2}{*}{ Forward citations/patents } & $0.010^{* *}$ & $0.010^{* *}$ & $0.009^{* *}$ & $0.010^{* *}$ & $0.010^{* *}$ \\
\hline & $(0.005)$ & $(0.005)$ & $(0.005)$ & $(0.005)$ & $(0.005)$ \\
\hline \multirow[t]{2}{*}{ Exploitative alliances (rec.) } & - & -0.006 & $0.032^{* *}$ & - & -0.016 \\
\hline & & $(0.017)$ & $(0.015)$ & & $(0.017)$ \\
\hline \multirow[t]{2}{*}{ Exploratory alliances (rec.) } & - & - & - & $0.071 * * *$ & $0.073^{* * *}$ \\
\hline & & & & $(0.016)$ & $(0.016)$ \\
\hline \multirow[t]{2}{*}{ Constant } & $-0.398 * * *$ & $-0.265^{* *}$ & -0.064 & $-0.398^{* * *}$ & $-0.260^{* *}$ \\
\hline & $(0.101)$ & $(0.109)$ & $(0.077)$ & $(0.101)$ & $(0.109)$ \\
\hline Observations & 1,733 & 1,733 & 1739 & 1,733 & 1,733 \\
\hline R-squared & 0.473 & 0.480 & 0.464 & 0.473 & 0.480 \\
\hline
\end{tabular}

Notes: $* * * * *$, and $*$ indicate significance at the $1 \%, .5 \%$, and $10 \%$ levels, respectively. All models include a full set of year dummies, industry dummies at the three-digit SIC level, and a dummy for whether the firm is listed at the NASDAQ or not. White robust standard errors are presented in parentheses.

The correlation between exploitative alliance portfolios and average forward citations per patent is positive, which may suggest that firms with many exploitative alliances have more mature technologies. The correlations between the three uncertainty measures are all positive. Especially the correlation between firm-specific risk and analyst forecast dispersion is high. The correlations between the three risk measures and the alliance portfolio variables are consistently negative. The same holds true for the average number of forward citations received by a firm's patent stock. This may suggest that alliances indeed contain some kind of information reducing the uncertainty about a firm's future returns.

\subsubsection{Market value estimations}

Table 4.4 gives the basic market value estimates for the recoded exploitative and exploratory alliance portfolios. Model 1 gives the results of a baseline specification only including the control variables. Following prior literature, the equation includes measures for $R \& D$, patents, and forward citations (Hall et al., 2005). Consistent with this literature, R\&D, patents, and forward citations all have positive effects on Tobin's q. The coefficient of the pre-sample mean of Tobin's q is positive and significant as well, which underlines the importance of controlling for unobserved heterogeneity across firms. I add the recoded exploitative alliance portfolio in model 2. Surprisingly, the effect of this variable on Tobin's q is insignificant. Hypothesis 1 is therefore 
clearly rejected. However, even though exploitative alliance portfolios have no significant effect on Tobin's q, the inclusion of the variable reduces the coefficient estimate of sales quite substantially.

Table 4.5: Alliance portfolios, Tobin's q, and the effects of firm-specific risk and uncertainty

\begin{tabular}{|c|c|c|c|c|c|c|c|}
\hline \multirow[t]{2}{*}{ Variables } & \multicolumn{7}{|c|}{ DV: $\ln$ (Tobin's q) } \\
\hline & (1) & (2) & (3) & (4) & (5) & (6) & (7) \\
\hline \multirow[t]{2}{*}{ Presample mean of Tobin's q } & $0.491^{* * *}$ & $0.494^{* * * *}$ & $0.481^{* * *}$ & $0.484 * * *$ & $0.511^{* * *}$ & $0.514^{* * *}$ & $0.474 * * *$ \\
\hline & $(0.030)$ & $(0.030)$ & $(0.031)$ & (0.031) & $(0.031)$ & (0.031) & (0.031) \\
\hline \multirow[t]{2}{*}{$\ln$ (Sales) } & $0.021^{*}$ & $0.024^{* *}$ & $0.033^{* * *}$ & $0.034 * * *$ & 0.016 & 0.018 & 0.015 \\
\hline & $(0.012)$ & $(0.012)$ & $(0.012)$ & $(0.012)$ & $(0.013)$ & $(0.013)$ & $(0.013)$ \\
\hline \multirow[t]{2}{*}{ Dummy $(\mathrm{R} \& \mathrm{D}=0)$} & -0.459 *** & $-0.473^{* * *}$ & $-0.505^{* * *}$ & $-0.502^{* * *}$ & $-0.502^{* * *}$ & $-0.517^{* * *}$ & $-0.545^{* * *}$ \\
\hline & $(0.082)$ & $(0.081)$ & $(0.083)$ & $(0.083)$ & $(0.084)$ & $(0.084)$ & $(0.082)$ \\
\hline \multirow[t]{2}{*}{ Dummy (Patents = 0) } & $0.119^{*}$ & $0.130 * *$ & $0.151^{* *}$ & $0.155^{* *}$ & $0.155^{* *}$ & $0.171^{* * *}$ & $0.187^{* * *}$ \\
\hline & $(0.062)$ & $(0.062)$ & $(0.063)$ & $(0.063)$ & $(0.065)$ & $(0.065)$ & $(0.063)$ \\
\hline \multirow[t]{2}{*}{$\mathrm{R} \& \mathrm{D} /$ assets } & $0.190^{* * *}$ & $0.187^{* * *}$ & $0.182^{* * *}$ & $0.183^{* * *}$ & $0.153^{* * * *}$ & $0.158^{* * * *}$ & $0.194 * * *$ \\
\hline & $(0.055)$ & $(0.054)$ & $(0.053)$ & $(0.053)$ & $(0.051)$ & $(0.051)$ & $(0.053)$ \\
\hline \multirow[t]{2}{*}{ Patents/R\&D } & $0.087^{* *}$ & $0.083^{* *}$ & $0.106^{* * *}$ & $0.108^{* * *}$ & $0.084^{* *}$ & $0.080^{* *}$ & $0.114^{* * *}$ \\
\hline & $(0.035)$ & $(0.036)$ & $(0.036)$ & $(0.036)$ & $(0.036)$ & $(0.036)$ & $(0.036)$ \\
\hline \multirow[t]{2}{*}{ Forward citations/patents } & $0.010^{* *}$ & $0.011 * *$ & $0.011^{* *}$ & $0.011^{* *}$ & $0.011^{* *}$ & $0.011^{* *}$ & $0.011^{* *}$ \\
\hline & $(0.004)$ & $(0.004)$ & $(0.005)$ & $(0.005)$ & $(0.005)$ & $(0.005)$ & $(0.005)$ \\
\hline \multirow[t]{2}{*}{ Exploitative alliances (recoded) } & -0.012 & -0.09 & -0.015 & 0.031 & -0.011 & -0.025 & -0.008 \\
\hline & $(0.017)$ & $(0.056)$ & $(0.017)$ & $(0.052)$ & $(0.017)$ & $(0.124)$ & $(0.122)$ \\
\hline \multirow[t]{2}{*}{ Exploratory alliances (recoded) } & $0.075^{* * *}$ & $0.175^{* * *}$ & $0.073^{* * *}$ & $0.166^{* * *}$ & $0.058^{* * *}$ & $0.345^{* * *}$ & $0.454 * * *$ \\
\hline & $(0.016)$ & $(0.046)$ & $(0.016)$ & $(0.049)$ & $(0.016)$ & $(0.100)$ & $(0.102)$ \\
\hline \multirow[t]{2}{*}{$\ln (\mathrm{DISP})$} & $-0.088^{* * *}$ & $-0.078^{* * *}$ & - & - & - & - & $-0.049^{* *}$ \\
\hline & (0.013) & $(0.024)$ & & & & & $(0.025)$ \\
\hline \multirow[t]{2}{*}{ Exploitative alliances (recoded) $* \ln ($ DISP) } & - & -0.021 & - & - & - & - & -0.019 \\
\hline & & $(0.013)$ & & & & & $(0.014)$ \\
\hline \multirow[t]{2}{*}{ Exploratory alliances (recoded) $* \ln ($ DISP) } & - & $0.027^{* *}$ & - & - & - & - & 0.004 \\
\hline & & $(0.011)$ & & & & & $(0.012)$ \\
\hline \multirow[t]{2}{*}{$\ln (\mathrm{FE})$} & - & - & $-0.050^{* * *}$ & $-0.075^{* * *}$ & - & - & $-0.072^{* * *}$ \\
\hline & & & $(0.009)$ & $(0.015)$ & & & $(0.015)$ \\
\hline \multirow[t]{2}{*}{ Exploitative alliances (recoded) $* \ln (\mathrm{FE})$} & - & - & - & 0.007 & - & - & 0.011 \\
\hline & & & & $(0.008)$ & & & $(0.008)$ \\
\hline \multirow[t]{2}{*}{ Exploratory alliances (recoded) $* \ln (\mathrm{FE})$} & - & - & - & $0.015^{* *}$ & - & - & 0.008 \\
\hline & & & & $(0.007)$ & & & $(0.008)$ \\
\hline \multirow[t]{2}{*}{$\ln (\mathrm{FSR})$} & - & - & - & - & $-0.131 * * *$ & $-0.162^{* * *}$ & $-0.120^{* * *}$ \\
\hline & & & & & $(0.025)$ & $(0.034)$ & $(0.036)$ \\
\hline \multirow[t]{2}{*}{ Exploitative alliances (recoded) $* \ln (\mathrm{FSR})$} & - & - & - & - & - & -0.003 & -0.001 \\
\hline & & & & & & $(0.016)$ & $(0.016)$ \\
\hline \multirow[t]{2}{*}{ Exploratory alliances (recoded) $* \ln (\mathrm{FSR})$} & - & - & - & - & - & $0.039^{* * *}$ & $0.044^{* * *}$ \\
\hline & & & & & & $(0.013)$ & $(0.014)$ \\
\hline \multirow[t]{2}{*}{ Constant } & $-0.532^{* * *}$ & $-0.529 * * *$ & $-0.567 * * *$ & $-0.735^{* * *}$ & $-1.139 * * *$ & $-1.402^{* * *}$ & $-1.744 * * *$ \\
\hline & $(0.116)$ & $(0.138)$ & $(0.118)$ & $(0.142)$ & $(0.198)$ & $(0.261)$ & $(0.269)$ \\
\hline Observations & 1733 & 1733 & 1733 & 1733 & 1658 & 1658 & 1657 \\
\hline R-squared & 0.495 & 0.498 & 0.491 & 0.493 & 0.484 & 0.487 & 0.511 \\
\hline
\end{tabular}

Notes: $* * *, * *$, and $*$ indicate significance at the $1 \%, .5 \%$, and $10 \%$ levels, respectively. All models include a full set of year dummies, industry dummies at the three-digit SIC level, and a dummy for whether the firm is listed at the NASDAQ or not. White robust standard errors are presented in parentheses.

Model 3 is similar to model 2 but excludes sales from the regression. Interestingly, exploitative alliance portfolios now have the expected positive effect. What does this finding 
imply? Assuming that sales proxies for the demand for a firm's products, it might show that exploitative alliances in the way they are defined in this study are not so much informative about organizational learning - as I have stated in hypothesis 1 - but probably about the way in which firms cater to demand for their products. I add the recoded exploratory alliance portfolio variable in model 4. As expected, the coefficient of this variable is positive and significant supporting hypothesis 2 . Finally, model 5 gives the results of a model containing both alliance portfolio measures. The effect of exploratory $\mathrm{R} \& \mathrm{D}$ alliances remains significant and positive in this specification.

\subsubsection{Uncertainty and the market value of exploratory R\&D alliances}

Table 4.5 includes my measures of parameter risk and fundamental risk and the interaction terms of these variables with the alliance portfolio measures. The effects in models 1 to 6 are remarkably similar. Thus, all three uncertainty measures have negative effects on Tobin's q, whereas the interaction terms with exploratory $R \& D$ alliances are positive and significant. Model 7 gives the results of a full model. Note that the interaction terms of the two parameter risk variables turn insignificant. These results are consistent with hypothesis $3 \mathrm{~b}$, whereas hypothesis $3 \mathrm{a}$ is rejected. Figure 4.2 uses the estimates in model 7 to show the marginal effects of exploratory R\&D alliances on Tobin's q over the distribution of firm-specific risk. At least for exploratory alliances, the results in model 1 of table 4.6 suggest that the size of a firm's alliance portfolio has important valuation effects. The baseline category in model 1 is firms with no exploratory R\&D alliances. Surprisingly, the dummy for firms with one exploratory R\&D alliance is insignificant. These results suggest that exploratory $R \& D$ alliances only have a positive effect on firm value for firms that have more than one of these alliances. The larger a firm's exploratory $\mathrm{R} \& \mathrm{D}$ alliance portfolio, the larger its effect on firm value becomes.

Figure 4.2: Marginal effect of exploratory alliances on Tobin's q for different values of firm-specific risk

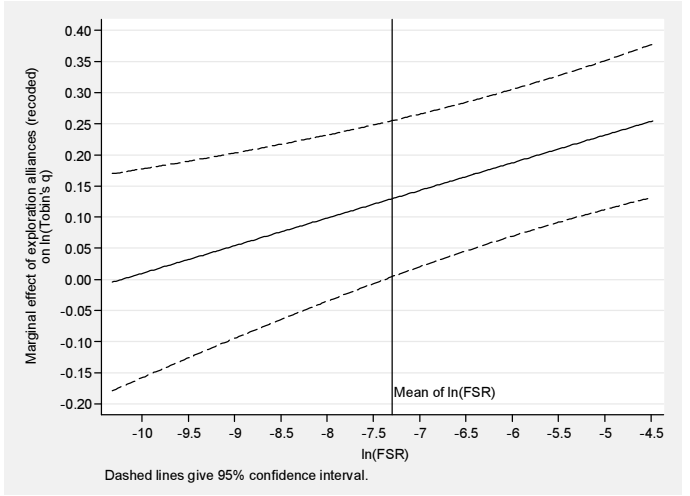




\subsection{Robustness}

4.6.1. Exploring the shape of the valuation effects

In order to explore the shape of the valuation effects, I run regressions including sets of dummy variables for each alliance portfolio category described in figure 4.1. Is it just the fact that a firm has alliances or not or is it important to consider the size of a firm's alliance portfolio to assess the market valuation of alliances? Model 1 in table 4.6 presents the regression results. Two results are worth mentioning here. First, firms that have only one exploratory $R \& D$ alliance do not experience higher market valuations relative to firms with no such alliances. Second, the effect of exploratory R\&D alliances on Tobin's q increases with alliance portfolio size.

Table 4.6: Exploring the shape of the valuation effects

\begin{tabular}{|c|c|c|c|c|}
\hline \multirow[t]{2}{*}{ Variables } & \multicolumn{2}{|c|}{ Exploratory alliances } & \multicolumn{2}{|c|}{ Exploitative alliances } \\
\hline & Model 1 & Model 2 & Model 3 & Model 4 \\
\hline \multirow[t]{2}{*}{$\ln (\mathrm{FSR})$} & $-0.131 * * *$ & $-0.184^{* * *}$ & $-0.131 * * *$ & -0.033 \\
\hline & $(0.025)$ & $(0.030)$ & $(0.025)$ & $(0.045)$ \\
\hline \multirow[t]{2}{*}{1 Alliance } & 0.021 & $0.647^{* *}$ & $-0.076^{*}$ & $-1.071 * * *$ \\
\hline & $(0.034)$ & $(0.278)$ & $(0.044)$ & $(0.345)$ \\
\hline \multirow[t]{2}{*}{ 2-5 Alliances } & $0.090^{* *}$ & $0.787^{* * *}$ & $-0.137^{* * *}$ & $-1.010^{* * *}$ \\
\hline & $(0.039)$ & $(0.270)$ & $(0.046)$ & $(0.358)$ \\
\hline \multirow[t]{2}{*}{ 6-9 Alliances } & $0.224^{* * *}$ & $1.265^{* *}$ & 0.053 & -0.052 \\
\hline & $(0.074)$ & $(0.550)$ & $(0.067)$ & $(0.459)$ \\
\hline \multirow[t]{2}{*}{10 or more Alliances } & $0.269^{* * *}$ & $1.547^{* *}$ & 0.044 & -0.197 \\
\hline & $(0.083)$ & $(0.670)$ & $(0.083)$ & $(0.614)$ \\
\hline \multirow[t]{2}{*}{1 Alliance $\times \ln (\mathrm{FSR})$} & - & $0.088^{* *}$ & - & $-0.139 * * *$ \\
\hline & & $(0.037)$ & & $(0.046)$ \\
\hline \multirow[t]{2}{*}{ 2-5 Alliances $\times \ln (\mathrm{FSR})$} & - & $0.097^{* * * *}$ & - & $-0.121 * *$ \\
\hline & & $(0.035)$ & & $(0.047)$ \\
\hline \multirow[t]{2}{*}{ 6-9 Alliances $\times \ln (\mathrm{FSR})$} & - & $0.139^{* *}$ & - & -0.018 \\
\hline & & $(0.066)$ & & $(0.059)$ \\
\hline \multirow[t]{2}{*}{10 or more Alliances $\times \ln (\mathrm{FSR})$} & - & $0.167^{* *}$ & - & -0.035 \\
\hline & & $(0.079)$ & & $(0.077)$ \\
\hline \multirow[t]{2}{*}{ Constant } & $-1.118^{* * *}$ & $-1.532^{* * *}$ & $-1.140^{* * *}$ & -0.443 \\
\hline & $(0.199)$ & $(0.235)$ & $(0.198)$ & $(0.340)$ \\
\hline Observations & 1,658 & 1,658 & 1,658 & 1,658 \\
\hline R-squared & 0.484 & 0.489 & 0.487 & 0.492 \\
\hline
\end{tabular}

Notes: ${ }^{* * *}, * *$, and $*$ indicate significance at the $1 \%, .5 \%$, and $10 \%$ levels, respectively. Heteroscedasticity robust standard errors are clustered at the firm level. All models include a full set of year dummies, 27 industry dummies at the three-digit SIC level, and all independent variables that are included in table 4.4. These variables are not displayed for space reasons.

Model 2 includes interaction terms between the exploratory R\&D portfolio dummies and FSR. The coefficients of all three interaction terms are positive and significant. Interestingly, the positive effect of FSR on the market value of exploratory alliances also seems to increase with alliance portfolio size. These findings are probably consistent with the interpretation that a firm's embeddedness in $\mathrm{R} \& \mathrm{D}$ alliance networks gives strong signals about the quality of a firm's innovative projects. Models 3 and 4 include dummies for the size of firms' exploitative alliance portfolios and interaction terms with FSR. Interestingly, firms with few exploitative alliances seem to experience lower market valuations relative to firms that have no such alliances. Model 4 
suggests that these effects become even more negative as FSR increases. These findings may be consistent with the Das et al. (1998), who argue that investors perceive exploitative alliances as signals of weakness.

4.6.2. The valuation of exploratory alliances and the burst of the late 1990's technology bubble

The position of this paper is that uncertainty leads to an increase in the market valuation of exploratory R\&D alliances, because the signalling value of exploratory alliances increases with the volatility of a firm's fundamentals. So far, I have used measures for parameter risk and fundamental risk as proxies for uncertainty.

However, my sample also includes an event that probably caused a 'natural' increase in uncertainty for many firms: the burst of the major technology bubble (MTB) in March 2000 (Perez, 2008). This exogenous shock provides a suitable laboratory, to assess how exogenous changes in idiosyncratic risk affect the market valuation of exploratory alliances. In the time immediately following this shock, investors' perceived uncertainty about firm value was immense, especially for high tech firms listed at NASDAQ. In the spirit of hypothesis $3 \mathrm{a}$ and $3 \mathrm{~b}$, I would therefore expect that the value of exploratory $R \& D$ alliances will increase in the period immediately following the bubble's burst (i.e., in the years 2000 and 2001). Further, this effect should be more pronounced for firms listed at the NASDAQ.

Table 4.7: Exploratory alliances and market value: Diff-in-Diff estimates

\begin{tabular}{|c|c|c|c|c|c|c|}
\hline \multirow[t]{2}{*}{ Variables } & \multicolumn{3}{|c|}{ OLS } & \multicolumn{3}{|c|}{ Fixed-Effects } \\
\hline & (1) & (2) & (3) & (4) & (5) & (6) \\
\hline \multirow[t]{2}{*}{ Bubble } & $-0.160^{* * *}$ & $-0.162^{* * *}$ & $-0.139 * *$ & $-0.102^{* *}$ & -0.067 & -0.021 \\
\hline & $(0.048)$ & $(0.053)$ & $(0.055)$ & $(0.044)$ & $(0.045)$ & $(0.048)$ \\
\hline \multirow[t]{2}{*}{ Nasdaq } & 0.169 & 0.168 & 0.175 & - & - & - \\
\hline & $(0.126)$ & $(0.127)$ & $(0.127)$ & & & \\
\hline \multirow[t]{2}{*}{ Bubble $\times$ Exploratory all. (rec.) } & $0.083^{* * *}$ & $0.083^{* * *}$ & $0.060^{* *}$ & $0.069^{* * *}$ & $0.067^{* * *}$ & 0.019 \\
\hline & $(0.027)$ & $(0.027)$ & $(0.030)$ & $(0.021)$ & $(0.021)$ & $(0.023)$ \\
\hline \multirow[t]{2}{*}{ Nasdaq $\times$ Exploratory all. (rec.) } & $0.055^{* *}$ & $0.055^{* *}$ & 0.039 & $0.078^{*}$ & $0.071^{*}$ & 0.048 \\
\hline & $(0.026)$ & $(0.026)$ & $(0.029)$ & $(0.043)$ & $(0.043)$ & $(0.043)$ \\
\hline \multirow[t]{2}{*}{ Nasdaq $\times$ Bubble } & - & 0.003 & -0.039 & - & -0.058 & $-0.137 * *$ \\
\hline & & $(0.055)$ & $(0.070)$ & & $(0.045)$ & (0.056) \\
\hline \multirow[t]{2}{*}{ Nasdaq $\times$ Bubble $\times$ Exploratory all. (rec.) } & - & - & 0.049 & - & - & $0.094^{* *}$ \\
\hline & & & $(0.056)$ & & & $(0.042)$ \\
\hline \multirow[t]{2}{*}{ Constant } & $-0.527^{* * *}$ & $-0.527^{* * * *}$ & $-0.531 * * *$ & 0.396 & 0.403 & 0.389 \\
\hline & $(0.164)$ & $(0.164)$ & $(0.164)$ & $(0.258)$ & $(0.259)$ & $(0.258)$ \\
\hline $\mathrm{N}$ & 1733 & 1733 & 1733 & 1733 & 1733 & 1733 \\
\hline $\mathrm{r} 2$ & 0.471 & 0.471 & 0.471 & 0.194 & 0.195 & 0.197 \\
\hline
\end{tabular}

Notes: $* * *, * *$, and $*$ indicate significance at the $1 \%, .5 \%$, and $10 \%$ levels, respectively. Heteroscedasticity robust standard errors are clustered at the firm level. The OLS models include a full set of year dummies, 27 industry dummies at the three-digit SIC level, and all independent variables that are included in table 4.4. The fixed-effects estimates exclude time-invariant regressors.

I use a difference-in-difference approach to compare the market valuation of exploratory alliances in the years immediately following the bubble burst to the years before and after this event. The OLS and fixed-effects estimates in table 4.7 suggest that the market valuation of exploratory alliances was indeed higher in the two years after the bubble burst relative to the remaining years in my sample. Next, I condition on whether a firm is listed at the NASDAQ or 
not. ${ }^{65}$ Whereas the OLS estimates of this diff-in-diff-in-diff estimator turn out to be insignificant, the fixed-effects estimates are significant and positive and are consistent with my expectations.

4.6.3. Fundamental risk and the market value of $R \& D$, patents, and forward citations

My findings suggest that the market valuation of exploratory $\mathrm{R} \& \mathrm{D}$ alliances increases with the volatility of fundamentals. I argue that this effect occurs, as the signals that exploratory R\&D alliances convey become more valuable to investors as the amount of uncertainty surrounding firms' future returns increases. By that, I implicitly assume that the market value of other innovation related assets that do not possess such signalling characteristics should be unaffected or may even decline as uncertainty increases. The results in table 4.8 support this idea. Whereas the market value of $R \& D$ decreases with increasing uncertainty, the market value of forward citations to patents - which are also informative about the quality of a firm's inventions (Trajtenberg, 1990) - increases.

Table 4.8: Fundamental risk and the market value of other intangibles

\begin{tabular}{|c|c|c|c|}
\hline \multirow[t]{2}{*}{ Variables } & \multicolumn{3}{|c|}{ DV: $\ln$ (Tobin's q) } \\
\hline & (1) & (2) & (3) \\
\hline \multirow{2}{*}{$\mathrm{R} \& \mathrm{D} /$ assets } & $0.537^{* *}$ & $0.521^{*}$ & $0.610^{* *}$ \\
\hline & $(0.266)$ & $(0.269)$ & $(0.263)$ \\
\hline \multirow[t]{2}{*}{ Patents/R\&D } & $0.081^{* *}$ & 0.159 & 0.187 \\
\hline & $(0.036)$ & $(0.239)$ & $(0.237)$ \\
\hline \multirow[t]{2}{*}{ Forward citations/patents } & $0.012^{* *}$ & $0.012^{* *}$ & $0.073^{* * *}$ \\
\hline & $(0.005)$ & $(0.005)$ & $(0.024)$ \\
\hline \multirow[t]{2}{*}{ Exploitative alliances (recoded) } & $0.361^{* * *}$ & $0.363^{* * *}$ & $0.400^{* * *}$ \\
\hline & $(0.101)$ & $(0.102)$ & (0.104) \\
\hline \multirow[t]{2}{*}{ Exploratory alliances (recoded) } & -0.023 & -0.022 & -0.047 \\
\hline & $(0.126)$ & $(0.126)$ & $(0.127)$ \\
\hline \multirow[t]{2}{*}{$\ln (\mathrm{FSR})$} & $-0.125^{* * *}$ & $-0.130^{* * * *}$ & $-0.164^{* * *}$ \\
\hline & $(0.037)$ & $(0.039)$ & $(0.040)$ \\
\hline \multirow[t]{2}{*}{ Exploitative alliances $($ recoded $) \times \ln (\mathrm{FSR})$} & -0.003 & -0.003 & -0.006 \\
\hline & $(0.016)$ & $(0.016)$ & $(0.016)$ \\
\hline \multirow[t]{2}{*}{ Exploratory alliances $($ recoded $) \times \ln (\mathrm{FSR})$} & $0.041 * * *$ & $0.042^{* * * *}$ & $0.046^{* * *}$ \\
\hline & $(0.013)$ & $(0.013)$ & $(0.013)$ \\
\hline \multirow[t]{2}{*}{ (R\&D/assets) $\times \ln (\mathrm{FSR})$} & $-0.108 * * *$ & $-0.106^{* * *}$ & $-0.119 * * *$ \\
\hline & $(0.040)$ & $(0.040)$ & $(0.039)$ \\
\hline \multirow[t]{2}{*}{ (Patents $/$ R\&D) $\times \ln (\mathrm{FSR})$} & - & 0.011 & 0.016 \\
\hline & & $(0.033)$ & $(0.033)$ \\
\hline \multirow[t]{2}{*}{ (Forward citations $/$ patents $) \times \ln ($ FSR $)$} & - & - & $0.009^{* * *}$ \\
\hline & & & $(0.003)$ \\
\hline \multirow[t]{2}{*}{ Constant } & $-1.128^{* * *}$ & $-1.157^{* * *}$ & $-1.380^{* * *}$ \\
\hline & $(0.275)$ & $(0.290)$ & $(0.295)$ \\
\hline Observations & 1658 & 1658 & 1658 \\
\hline R-squared & 0.489 & 0.489 & 0.493 \\
\hline
\end{tabular}

Notes: $* * *, * *$, and $*$ indicate significance at the $1 \%, .5 \%$, and $10 \%$ levels, respectively. Heteroscedasticity robust standard errors are clustered at the firm level. The OLS models include a full set of year dummies, 27 industry dummies at the three-digit SIC level, and all independent variables that are included in table 4.4.

\footnotetext{
${ }^{65}$ Remember that the firms in my sample are either listed at the NASDAQ or the NYSE and to a very small extent at the AMEX.
} 


\subsection{Discussion and conclusion}

This paper analyzes the effects of exploitative commercial alliances and exploratory R\&D alliance portfolios on the stock market value of firms. In doing so, this paper contributes to the alliance literature in several ways. By using hedonic market value regressions, this paper aligns the research on the stock market valuation of alliance portfolios with that on the market valuation of other types of intangible assets such as patents and R\&D (Cockburn and Griliches, 1988; Hall, 1993a; Hall et al., 2005; Hall et al., 2007).

In line with the research at the individual alliance level (Chan et al., 1997; Das et al., 1998; Koh and Venkatraman, 1991; Merchant and Schendel; 2000), the results of this paper suggest that portfolios of exploratory $\mathrm{R} \& \mathrm{D}$ alliances and portfolios of exploitative commercial alliances differ quite dramatically in how they affect the market value of firms. First, the effects of exploratory $\mathrm{R} \& \mathrm{D}$ alliances tend to be substantially larger compared to the effects of exploitative commercial alliances. This result is consistent with the view that exploratory $\mathrm{R} \& \mathrm{D}$ alliances focus on the access to and the acquisition of valuable knowledge. By that, these alliances contribute to firms' knowledge stocks. In contrast, exploitative alliances often focus on cost economizing and short-term gains (Park et al., 2002). My results may also hint towards the possibility that exploitative alliances are informative about the ways in which firms cater to the demand for their products and services. This interpretation may explain why the coefficient of exploitative alliances becomes insignificant once I control for sales in the hedonic market value regressions.

Interestingly, the positive effect of exploratory alliances on market value is larger for firms that have many exploratory alliances, whereas firms having only one exploratory $R \& D$ alliance do not receive higher market valuations relative to firms that have no such alliances. This finding is probably consistent with the alliance literature showing the importance of 'alliance experience' for the market valuation of alliances (Anand and Khanna, 2000a). Firms with larger alliance portfolios are also more likely to have accumulated alliance experience over the past.

Finally, the most intriguing finding of this paper relates to the moderating effect of uncertainty. My hypothesis was that the market value of exploratory $\mathrm{R} \& \mathrm{D}$ alliances would increase with investors' perceived uncertainty about future returns. Exploratory R\&D alliances provide signals about the value of firms' R\&D activities, which may become more valuable to investors as uncertainty increases. In my empirical analysis, I tried to capture two components of uncertainty: parameter risk and fundamental risk. I used two proxies derived from analyst forecasts to measure parameter risk. My measure for fundamental risk is based on the idiosyncratic volatility of stock prices. My findings reveal that the value of exploratory alliances increases in particular with fundamental risk.

Besides signalling, other explanations may be consistent with my results. Thus, alliances might be an important way for firms to access resources. In particular, it is well known that R\&D alliances tend to be more valuable in rapidly changing environments, because alliances enable firms to access new knowledge and valuable resources quickly and without the need to make large irreversible investments (Hagedoorn, 2002). In other words, my results may simply reflect unobserved heterogeneity across firms. However, unobserved heterogeneity is unlikely to drive my results for a number of reasons. First, I control for unobserved heterogeneity by including the presample mean of Tobin's $q$ in my regressions. ${ }^{66}$ Further, the finding that the market value

${ }^{66}$ Note that my findings also hold in traditional fixed-effects regressions. 
of exploratory alliances increases after the burst of the 1990's technology bubble in particular for NASDASQ firms is, I believe, more consistent with a signalling story than with a resource access story. 
Appendix 4.1: Tabulation of alliance portfolio size

\begin{tabular}{|c|c|c|c|c|c|}
\hline $\begin{array}{c}\text { Exploratory } \\
\text { alliance portfolio } \\
\text { size }\end{array}$ & Freq. & $\%$ & $\begin{array}{c}\text { Exploitative } \\
\text { alliance portfolio } \\
\text { size } \\
\end{array}$ & Freq. & $\%$ \\
\hline 0 & 837 & $48.30 \%$ & 0 & 248 & $14.31 \%$ \\
\hline 1 & 449 & $25.91 \%$ & 1 & 629 & $36.30 \%$ \\
\hline 2 & 175 & $10.10 \%$ & 2 & 285 & $16.45 \%$ \\
\hline 3 & 78 & $4.50 \%$ & 3 & 175 & $10.10 \%$ \\
\hline 4 & 44 & $2.54 \%$ & 4 & 108 & $6.23 \%$ \\
\hline 5 & 34 & $1.96 \%$ & 5 & 62 & $3.58 \%$ \\
\hline 6 & 16 & $0.92 \%$ & 6 & 46 & $2.65 \%$ \\
\hline 7 & 16 & $0.92 \%$ & 7 & 39 & $2.25 \%$ \\
\hline 8 & 12 & $0.69 \%$ & 8 & 22 & $1.27 \%$ \\
\hline 9 & 16 & $0.92 \%$ & 9 & 19 & $1.10 \%$ \\
\hline 10 & 10 & $0.58 \%$ & 10 & 13 & $0.75 \%$ \\
\hline 11 & 8 & $0.46 \%$ & 11 & 9 & $0.52 \%$ \\
\hline 12 & 7 & $0.40 \%$ & 12 & 6 & $0.35 \%$ \\
\hline 13 & 2 & $0.12 \%$ & 13 & 5 & $0.29 \%$ \\
\hline 14 & 9 & $0.52 \%$ & 14 & 6 & $0.35 \%$ \\
\hline 15 & 4 & $0.23 \%$ & 15 & 4 & $0.23 \%$ \\
\hline 16 & 3 & $0.17 \%$ & 16 & 4 & $0.23 \%$ \\
\hline 17 & 1 & $0.06 \%$ & 17 & 7 & $0.40 \%$ \\
\hline 18 & 1 & $0.06 \%$ & 18 & 3 & $0.17 \%$ \\
\hline 19 & 2 & $0.12 \%$ & 19 & 5 & $0.29 \%$ \\
\hline 20 & 1 & $0.06 \%$ & 20 & 2 & $0.12 \%$ \\
\hline 21 & 2 & $0.12 \%$ & 21 & 5 & $0.29 \%$ \\
\hline 22 & 1 & $0.06 \%$ & 22 & 3 & $0.17 \%$ \\
\hline 25 & 1 & $0.06 \%$ & 23 & 4 & $0.23 \%$ \\
\hline 26 & 1 & $0.06 \%$ & 24 & 1 & $0.06 \%$ \\
\hline 27 & 1 & $0.06 \%$ & 26 & 4 & $0.23 \%$ \\
\hline 29 & 1 & $0.06 \%$ & 27 & 2 & $0.12 \%$ \\
\hline 31 & 1 & $0.06 \%$ & 28 & 2 & $0.12 \%$ \\
\hline - & - & - & 30 & 1 & $0.06 \%$ \\
\hline - & - & - & 31 & 1 & $0.06 \%$ \\
\hline - & - & - & 32 & 1 & $0.06 \%$ \\
\hline - & - & - & 33 & 2 & $0.12 \%$ \\
\hline - & - & - & 35 & 1 & $0.06 \%$ \\
\hline - & - & - & 36 & 1 & $0.06 \%$ \\
\hline - & - & - & 38 & 1 & $0.06 \%$ \\
\hline - & - & - & 39 & 1 & $0.06 \%$ \\
\hline - & - & - & 43 & 1 & $0.06 \%$ \\
\hline - & - & - & 45 & 1 & $0.06 \%$ \\
\hline - & - & - & 46 & 1 & $0.06 \%$ \\
\hline - & - & - & 49 & 1 & $0.06 \%$ \\
\hline - & - & - & 66 & 1 & $0.06 \%$ \\
\hline - & - & - & 86 & 1 & $0.06 \%$ \\
\hline Total & 1,733 & $100.00 \%$ & Total & 1,733 & $100.00 \%$ \\
\hline
\end{tabular}

Notes: Alliance portfolio size is the number of exploratory or exploitative alliances that have been in announced in year $t-2$ to $\mathrm{t}$ (source: SDC Platinum). 


\section{Chapter 5}

\section{WHEN DOES THE MARKET PERCEIVE ALLIANCES TO BE (NOT) RISKY? EVIDENCE FROM ALLIANCE PORTFOLIOS AROUND THE BURST OF THE LATE 1990’S TECHNOLOGY BUBBLE}

What is the effect of alliances on firm-specific risk? Existing literature offers at least two answers on this question. On the one hand, alliances are often said to be inherently risky as they involve the cooperation of otherwise independent firms and leave room for opportunistic behavior and appropriation hazards. On the other hand, alliances are also frequently portrayed as instruments for reducing or sharing business risk, in particular the risk that stems from rapid technological change. Even though not mutually exclusive, these views lead to an interesting paradox. To manage their business risks, firms engage in organizational forms that are themselves extraordinarily risky. Also from a managerial perspective, should a firm become highly connected to enjoy risk-sharing benefits or should it refrain from alliances to avoid the potentially high risk that these organizations entail? In this paper, we study the effects of alliance portfolios on firmspecific risk, i.e. the risk that is unique to each firm. Our findings suggest that that the relationship between alliance portfolios and firm-specific risk is complex and depends on the size of firms' alliance portfolios as well as on a variety of alliance portfolio characteristics. Most intriguingly, however, we find that our results are not stable over time but change substantially in the aftermath of an exogenous shock, which lead to a persistent increase in environmental uncertainty or systematic risk.

\subsection{Introduction}

Interfirm alliances have gradually increased in importance over the last decades and are now a cornerstone of firms' competitive strategies across many industries (Gulati, 1998; Mowery, Oxley, and Silverman, 1996; Hagedoorn, 2002). ${ }^{68}$ Regarding this 'explosion in alliances' (Dyer and Singh, 1998), scholars have become interested in understanding the effects of alliances on firm performance (Hagedoorn and Schakenraad, 1994; Sampson, 2007). Within this stream of literature, several studies examine the stock market valuation of alliances. This research shows

\footnotetext{
${ }^{67}$ This chapter is based on joint work with John Hagedoorn. We thank seminar participants at Maastricht University, KU Leuven, the Centre for European Economic Research (ZEW) in Mannheim, Harvard Business School, and participants at the $3^{\text {rd }}$ Asia-Pacific Innovation Conference at Seoul National University, Korea, for helpful comments 68 Among others, Lavie (2007) presents evidence for the growing importance of alliances. In a study on the U.S. software industry, he finds that the percentage of firms that engage in alliances increased from 32\% in 1990 to $95 \%$ in 2001. Roijakkers and Hagedoorn (2006) find consistent patterns for the pharmaceutical biotech sector.
} 
that the average abnormal returns to alliance announcements are positive, suggesting that alliances contribute to firm value (Anand and Khanna, 2000a; Chan et al., 1997; Das, Sen, and Sengupta, 1998; Koh and Venkatraman, 1991; Merchant and Schendel, 2000; Kumar, 2010). While the event study literature focuses on the market valuation of individual alliances, a different body of literature argues that a firm's alliances are often interdependent and thus should not be treated as discrete events (Hoffmann, 2007; Lavie, 2007; Vassolo, Anand, and Folta, 2004). Nevertheless, this research at the alliance portfolio level - where an alliance portfolio comprises the total number of alliance ties that a firm maintains at a given point in time - broadly confirms the findings of the event study literature that alliance portfolios affect firm value. However, extant research also suggests that the effects of alliance portfolios are contingent upon the structure of the firms' alliance portfolios as well as upon the characteristics of the partners (Hoffmann, 2007; Lavie, 2007; Lavie and Miller, 2008 Goerzen, 2007; Stuart, 2000).

Even though there seems to be a consensus in the literature that alliances and alliance portfolios affect investors' perceptions about firm value, few studies analyze whether or how alliances alter the riskiness that investors attach to firms' future returns. This is surprising, above all because alliance researchers typically stress that interfirm cooperations are inherently instable and risky (Parkhe, 1993; Reuer, Zollo, and Singh, 2002) and that the rate of alliance failure tends to be high (Dhanaraj and Beamish, 2004; Kogut, 1989; Park and Russo, 1996; Reuer and Zollo, 2005). Some researchers even posit that success is the exception rather than the rule in alliances (Park and Ungson, 2001). We would therefore expect strong effects of alliances and alliance portfolios on the riskiness of firms' future returns. Other researchers point out that an important motive for alliance formation is the sharing and management of risk and uncertainty especially with regard to R\&D and the development of new products and technologies (Das and Teng, 1996; Hagedoorn, 1993, 2002). This literature might even suggest a negative effect of alliances and alliance portfolios on firm-specific risk. Bamford, Gomes-Casseres, and Robinson (2003: 36) argue that these conflicting views in the literature lead to an 'unpleasant' paradox: “... to manage the business risk they face, companies are choosing an organizational strategy that is itself notoriously risky. (...). In a sense, alliance strategies enable firms to buy protection from business risk only by taking on additional relationship risks." From a pure risk perspective, the effects of alliances and alliance portfolios are ambiguous. Should a firm become highly connected to enjoy risk-sharing benefits or should it refrain from alliances to avoid the potentially high costs resulting from increased exposure to relational risk?

The few studies that investigate this topic empirically tend to be rather small-scale event studies that examine the volatility of stock returns around the date of the alliance announcements. Das, Sen, and Sengupta (1998) examine the stock market reactions to 119 alliance announcements between 1987 and 1991. They find that investor uncertainty measured through the variance in stock returns increases significantly after the announcement of marketing alliances whereas the effect of technology alliances is weakly negative. Arend (2004) analyzes the stock market reactions to the announcements of 96 alliances in the US computing industry during the years 1984 to 1994. Contrary to his expectations, he finds a positive effect of alliance-firm fit which he defines as the proximity of the focal firm and the alliance in their markets, products, operations, and technologies - on the volatility of stock returns. That study also suggests that volatility declines when alliances take the form of equity joint ventures and when the primary function of an alliance relates to setting of industry standards. Finally, Bayona, Corredor and Santamaría (2006) examine 69 announcements of technology alliances of 13 Spanish 'new 
economy' firms in the period 1997 to 2002 . Their paper suggests a positive effect of alliances on the abnormal volatility of stock returns during a five-day event window.

We develop our theory along two primary lines of reasoning. On the one hand, we argue that alliances impose high risks on the partnering firms. This risk stems from the hybrid nature of alliances between hierarchies and markets (Williamson, 1985, 1991) and has been described as relational risk (Das and Teng, 1996, 1998). Alliances are prone to relational risk for mainly two reasons. First, there is the risk that a partner does not fully commit to the alliance and behaves opportunistically. Second, the potential for unintended knowledge leakage (appropriation hazards), tends to be high in alliances. On the other hand, alliances seem to be more frequent in rapidly changing environments in which uncertainty and risk are abundant. Important motives for the formation of alliances are the reduction of uncertainty and risk in technology development (Hagedoorn, 1993, 2002). Alliances can also enhance the legitimacy of firms (Stuart, 2000). Especially firms that form 'intensive alliances' that involve joint research and development (R\&D) or equity are often subject to extensive screenings through their alliance partners (Kumar and Park, 2012; Stuart, 2000). Alliances may therefore serve as signals for unobserved firm quality and hence should reduce firm-specific risk (Stuart, 2000: 794).

This paper differs from previous research in several ways. First, the unit of analysis in this paper is the firm and its alliance portfolio rather than the individual alliance. This set up accounts for the fact that interdependencies among individual alliances within alliance portfolios may have important effects on the way in which each individual alliance affects a firm's aggregate performance and risk (Vassolo, Anand, and Folta, 2004). It also reflects the findings of previous alliance research that the alliance portfolio is the preferable unit of analysis to study the effects of alliances on firm performance (Hoffmann, 2005, 2007; Lavie, 2007). Second, the panel structure of our data allows us to account for unobserved heterogeneity across firms. More importantly, it also enables us to examine how the effect of alliance portfolios on firm-specific risk changes in times of a major exogenous shock in the environment - the burst of the technology bubble in 2000. From that date on until the end of 2002, stock prices in the US literally collapsed and a large number of high tech firms faced binding financing constraints or financial distress. Many of these firms were even forced out of business. The study of macro shocks to uncertainty is interesting in the context of this paper, because such events influence the costs and benefits of managing business relations (Bergh and Lawless, 1998; Hill and Hoskisson, 1987; Jones and Hill, 1988). We use the burst of the technology bubble as a natural experiment to assess how the effects of alliance portfolio size and several alliance portfolio characteristics on firm-specific risk change in times of increased environmental uncertainty. ${ }^{69}$

The main findings of our study can be summarized as follows: Consistent with the event study literature (Bayona et al., 2006) we find that alliance portfolios have a positive and significant effect on firm-specific risk, which we approximate by a measure based on the variance in firms' daily stock returns. However, we also find that firm-specific risk decreases with the share of joint ventures and with the share of exploratory R\&D alliances in a firm's alliance

\footnotetext{
${ }^{69}$ The focus of our paper on shocks or fluctuations in environmental uncertainty deserves some clarification at this point. Environmental uncertainty might be permanently high in some sectors of the economy, for instance, due to rapid technological change (Hagedoorn, 2002). However, in this study, we focus on the effects of persistent shocks to environmental uncertainty, which disrupt the status quo within an industry sector or within the economy as a whole. In other words, we focus on an increase in systematic risk, which is common to all firms in the economy. Our understanding of such 'uncertainty shocks' is consistent with studies by Gilchrist, Sim, and Zakrajšek (2010) and Bloom (2009).
} 
portfolio. The latter finding suggests that exploratory $R \& D$ alliances are useful means for managing the risk associated with the development of new technologies (Hagedoorn, 1993). Our most interesting findings concern the temporal stability of our results. We find that the positive effect of alliance portfolio size on firm-specific risk increases significantly in the period after the burst of the technology bubble. Further the negative effect of the share of exploratory R\&D alliances in firms' alliance portfolios turns positive in the immediate post-bubble period. Finally, our findings suggest that the negative effect of the share of joint ventures in firms' alliance portfolios seems to be much stronger in the post-bubble period. We interpret this finding as evidence that the administrative mechanisms that joint ventures provide become particularly relevant in times of pronounced environmental uncertainty, which demands a coordinated response from all alliance partners (Williamson, 1991: 278).

\subsection{Alliances and firm-specific risk}

An alliance is an organizational structure that enables cooperation between firms that themselves remain separately owned (Bamford, et al., 2003: 37). Researchers typically find that the success rate of alliances is rather moderate to low with roughly half of the alliances failing to reach their intended goals (Kogut, 1989; Parkhe, 1993; Park and Russo, 1996; Porter, 1987; Reuer and Zollo, 2005). Surveys among alliance managers give comparable results (De Man, 2005: 318). Consequently, there seems to be a consensus in the literature that alliances are fraught with risk (Kale, Dyer, and Singh, 2002; Park and Ungson, 2001). Research on the internationalization strategies of firms also presents some evidence that alliances are less stable and more risky than alternative, vertically integrated organizational forms such as wholly owned subsidiaries (Dhanaraj and Beamish, 2004; Gomes-Casseres, 1987; Makino et al., 2007). This surplus of instability arises because alliances do not provide comparable control and coordination mechanisms as hierarchies and because the incentives of alliance partners might not always be well aligned (Oxley, 1997; Rowley, Behrens, and Krackhardt, 2000: 371; Williamson, 1985, 1991)..$^{70}$

To be more specific, the literature on alliances presents several explanations for the high risk connected to inter-firm alliances. Several researchers posit that alliances are prone to relational risk, which refers to the risk that a partner does not fully commit to the joint efforts in the alliance. In other words, relations risk captures the uncertainty about a partner's future behavior and the risk that an alliance partner does not cooperate in the expected manner (Das and Teng, 1996; Parkhe, 1993: 794). Relational risk arises because alliances require otherwise independent firms to cooperate and compete at the same time. Through cooperative behavior, the alliance partners can achieve common benefits, whereas competitive behavior leads to private benefits that are unique to each firm. Due to this hybrid nature of cooperation and competition, alliances face a high probability of experiencing opportunistic behavior where at least one firm exploits its alliance partner and strives for short-term private benefits (Gulati, 1995; Khanna, Gulati, and Nohria, 1998; Nooteboom et al., 1997; Williamson, 1991). Williamson (1985: 47) defines opportunistic behavior as self-interest seeking behavior of strategic nature in order to redirect profits from vulnerable partners. Opportunism can come about in many forms, such as '... lying, stealing,

\footnotetext{
${ }^{70}$ Steensma et al. (2000: 953) state, for instance, that alliances are “... inherently risky and unstable because of the dual control of the relationship, the intrinsic incentive to cheat, and the uncertainty about the partner and its changing goals."
} 
cheating, and calculated efforts to mislead, disguise, obfuscate, or otherwise confuse.' Opportunistic behavior reduces the perception of commitment, trust, and harmony, creates uncertainty about performance, and can lead to delays or project failures. A lack of commitment and trust also reduces the incentives to make relationship specific investments, which are often necessary to develop complementary resources and competencies. Finally, the anticipation of opportunistic behavior leads to high transaction costs, especially due to high ex ante negotiation costs and high ex post monitoring costs (Das and Teng, 1996; Nooteboom et al., 1997: 318; Parkhe, 1993).

A related type of risk is appropriation risk (Oxley, 1997; Teece, 1986). Alliances are vulnerable to appropriation hazards, due to incomplete contracts and because it is impossible to fully monitor and control the behavior of alliance partners (Oxley, 1997: 392). Appropriation risk also stems from the unique trading characteristics of information (Arrow, 1971), which might 'spill over' in an uncontrollable way to the partnering firm (Oxley, 1997). This type of risk is particularly high when the capabilities that a focal firm contributes to an alliance are tacit, when these capabilities are at the core of a focal firm's competitive advantage, and when the alliance partner has a strong intention to learn (Hamel, 1991; Mowery et al., 1996). When a firm expects this unintended leakage of knowledge it might be less willing to cooperate, which again leads to a higher risk of alliance failure (Larsson et al., 1998; Park and Ungson, 2001).71

Finally, another source of risk in alliances is performance risk (Das and Teng, 1996; Ring and van de Ven, 1992). Performance risk refers to the probability that an alliance does not achieve its objectives, even though the alliance partners have the best intentions to cooperate and strive towards achieving common benefits. In other words, performance risk takes optimal cooperation for granted and incorporates all kinds of hazards that are exogenous to the cooperation itself. Whereas relational risk refers to the uncertainties arising from suboptimal cooperation, performance risk refers to adverse effects that stem form firm incompetencies and market uncertainty (Das and Teng, 1998: 27). For instance, alliances can fail because of excessive coordination costs and high managerial complexity (Killing, 1988; Park and Ungson). To put it differently, alliances can fail because of partners' bounded rationality or a lack of managerial resources and competencies.

There is some evidence that complexity is higher when alliances are asymmetric with regard to the partnering firms (Harrigan, 1988; Oxley, 1997). Asymmetries between partners can reside at different levels, for instance, the partnering firms' knowledge bases, their organizational cultures, or other firm characteristics such as size or age. Specialized and distinct knowledge bases induce managerial complexity as the alliance partners may lack the information or information processing capacities that are needed for coordinating the activities within an alliance successfully. Asymmetries can also result from differences in national or organizational cultures, which can lead to coordination problems (Park and Ungson, 2001: 44).72 Performance risk might

\footnotetext{
${ }^{71}$ Note that Park and Ungson (2001) group the risks imposed by opportunism and appropriation hazards into one category, which they refer to as inter-firm rivalry. Similarly, Das and Teng (1996: 831) interpret appropriation hazards as a special form of relational risk. Yet, whereas unintended knowledge leakage might be more likely when a partner acts opportunistically it is not a necessary condition (Norman, 2001: 179). Thus, a partner may simply exploit opportunities to learn that arise during 'the normal course' of cooperation within an alliance. For this reason, we prefer to discuss these two sources of risk in alliances separately.

72 Whereas performance risk and relational risk are independent dimensions of risk, there may be some feedback, especially from performance risk to relational risk (Das and Teng, 1998: 25). For instance, asymmetries between
} 
also vary with respect to the task that an alliance performs. For instance, performance risk tends to be high in $\mathrm{R} \& \mathrm{D}$ alliances because the outcomes of $\mathrm{R} \& \mathrm{D}$ are by definition highly uncertain (Das and Teng, 1996; Ring and van de Ven, 1992).

\subsubsection{An alliance portfolio perspective on firm-specific risk}

The above suggests that alliances are inherently risky due to factors that are intrinsic to this organizational form. In the words of Das and Teng (1998: 26), "as opportunistic behavior is present only in cooperative strategies, relational risk is a direct concomitant of participating in strategic alliances. If a firm stays away from strategic alliances, it would not be subject to relational risk." Whereas the above suggests a positive effect of alliances on firm-specific risk, we do not expect to find this effect for firms that form alliances sporadically. In other words, when alliances are not an integral part of a firm's competitive strategy, we do not expect that they have an impact on firm-specific risk, because they are at best marginally relevant for a firm's future performance. However, all else equal, we posit the larger the number of alliances that a firm manages simultaneously at a given point in time, the more central will be the role of these alliances for a firm's overall business strategy. This is akin to Hoffmann (2007: 834), who states that the "number of alliances determines the quantity (volume) of information and resources that a firm can access and acquire by virtue of its alliances." Especially when alliances are at the center of firms' competitive strategies and when firms form alliances frequently for a variety of purposes, the high relational risk that these organizations entail should become particularly relevant.

A related stream of literature on firm diversification (Jones and Hill, 1988; Hill and Hoskisson, 1987) also provides other reasons for why it is probably more adequate to look at the alliance portfolio as a whole rather than on the individual alliance tie in the context of this paper. Hill and Hoskisson (1987: 336) demonstrate that the complexity of managing a diversified firm and the information processing requirements of managers are functions of the number of subunits that a firm has and of the interdependence or connectedness of these subunits among each other. Firms with a larger number of interdependent subunits are particularly complex to manage and require firms to make substantial investments into performance monitoring and resource coordination (Jones and Hill, 1988: 164).

Similar mechanisms are at work when firms form large alliance portfolios. Stuart (1998: 676) argues, for instance, that negotiating alliance terms and conditions, monitoring partner behavior, and resolving conflicts in alliances requires a high level of managerial attention. As firms may experience opportunistic behavior and appropriation hazards in each alliance in which they are active, the potential for conflict also increase with increasing alliance portfolio size (Singh and Mitchell, 1996; Stuart, 1998). It is for these reasons that Stuart (1998) posits there is an upper limit to the number of alliances that a firm can manage efficiently at the same time. Similarly, Kale, Dyer, and Singh (2002: 752), point out that as alliance portfolio size increases, it becomes more difficult to manage and to monitor the performance of each alliance and to understand whether there is potential conflict or overlap between individual alliances or between different alliance partners. Regarding these interdependencies among individual alliances within alliance

alliance partners can culminate in hold-up problems and asymmetric dependencies, which cause a high vulnerability to partner opportunism (Hagedoorn and Hesen, 2009). 
portfolios, practitioners have compared the management of alliance portfolios to playing a game of 'three-dimensional chess', where any action taken in one alliance can impact the performance of other alliances (Steinhilber, 2008). In the light of these arguments, we submit the following hypothesis:

H1: Alliance portfolio size has a positive effect on firm-specific risk.

5.2.2. Alliance portfolio characteristics and firm-specific risk

\subsubsection{The share of competitor alliances}

Appropriation hazards should be particularly high in alliances with direct competitors (Das and Teng, 2000; Krishnan, Martin, and Noorderhaven, 2006; Oxley and Sampson, 2004). Further, competitors might have stronger incentives to exploit valuable knowledge and capabilities at the expense of their partners leading to considerable relational risk. Appropriation hazards tend to be high as competitors operate in similar industries the overlap between these firms' resources and capabilities tends to be larger (Mowery et al., 1996). Hence, competitors are more likely to possess the absorptive capacity that is necessary to identify valuable information within a partner firm. For the same reason, the likelihood that a partner is able to absorb proprietary knowledge is also pronounced (Krishnan et al., 2006; Park and Russo, 1996). Also note that it might be especially risky to lose proprietary knowledge to direct competitors, because a focal firm's ability to create unique value for customers is diminished when competitors duplicate its knowledge and skills (Norman, 2001: 178). Due to the high relational risk, alliances with direct competitors are more likely to experience misunderstandings, conflicts, and low levels of trust. Firms might also be less willing to share resources, especially knowledge, which increases the risk of alliance failure (Krishnan et al., 2006). Indeed, Park and Russo (1996) find that alliances with direct competitors are significantly more likely to fail. They conclude that these alliances are substantially more risky than alliances with non-competing firms.

At the alliance portfolio level, Lavie (2007) argues that portfolios comprising a larger share of alliances with direct competitors face a high risk of opportunistic behavior and disputes. His study shows that the share of competitor alliances in a firm's alliance portfolio has a negative effect on firm value, especially when the bargaining position of a focal firm is relatively weak in comparison to the firm's alliance partners. Thus, the amount of conflict and relational risk should increase as the share of alliances with direct competitors in a firm's alliance portfolio increases. In the light of these findings, we argue that all else equal, firm-specific risk will increase with the share of competitor alliances in a firm's alliance portfolio. Hence:

H2: The share of competitor alliances in a firm's alliance portfolio has a positive effect on firm-specific risk.

\subsubsection{The share of joint ventures}

The alliance literature proposes several mechanisms through which firms can mitigate the relational risk inherent in alliances. One mechanism relates to the choice of the governance 
structure (Nooteboom et al., 1997: 317; Oxley, 1997; Williamson, 1991). ${ }^{73}$ Even though alliances encompass a variety of agreement types and contractual forms, at a very basic level they can be grouped into two categories (Gulati, 1995: 88; Hagedoorn and Narula, 1996: 265). On the one hand there are several forms of contractual agreements such as licensing and distribution agreements, technology exchange agreements, or joint R\&D pacts. These alliances are often short-term, highly flexible, project based cooperations (Hagedoorn, 1990, 1993; Nooteboom et al., 1997).

On the other hand, there are alliances that involve the sharing of equity through joint ventures that involve the creation of a separate legal entity and which are jointly owned and operated by at least two sponsoring firms. Joint ventures are different from contractual agreements, in that they entail some important characteristics of hierarchies (Osborn and Baughn, 1990; Gomes-Casseres, Hagedoorn, and Jaffe, 2006). For instance, many joint ventures have their own headquarters, board of directors, chief executive officers (CEO), and staff (Gulati, 1995: 95). The profits and losses of the venture are usually shared in proportion to the sponsors' equity stakes (Boone and Ivanov, 2012; Hagedoorn, 1990: 20).

According to Williamson (1991) the distinguishing feature of hierarchical organizations is the opportunity of reaching decisions through fiat, which enables parties to appeal disputes or conflicts to the hierarchy for a resolution. In the words of Williamson (1991: 276): “ ... firms can and do exercise fiat that markets cannot." Due to their quasi-hierarchical nature, joint ventures mitigate some of the relational risk inherent in alliances (Das and Teng, 1996; Gulati, 1995; Pisano and Teece, 1989; Ring and van de Ven, 1992). For instance, joint ventures reduce the incentives of firms to act opportunistically, as the returns that the sponsoring firms incur form a joint venture are based on the venture as a whole. Thus, the incentives of the sponsoring firms are more closely aligned in joint ventures as compared to contractual agreements. ${ }^{74}$ This feature becomes particularly important in the case of unexpected external events, which may affect the sponsoring firms in dissimilar ways further aggravating incentive and monitoring problems (Oxley, 1997: 393). Hold-up problems between alliance partners are also less frequent in joint ventures relative to contractual agreements (Boone and Ivanov, 2012: 553). Compared to contractual agreements, joint ventures tend to be more directly linked to the senior management of the sponsoring firms, also providing superior control and monitoring mechanisms for the alliance (Oxley, 1997). Overall, a joint venture provides a structure that enables firms to control relational risk, which may lead to 'smoother' cooperation (Das and Teng, 1996: 835).

Joint ventures might also benefit investors from an 'information perspective.' Investors perceive firms' future returns to be more risky when they have little information or when the information is of low quality (Epstein and Schneider, 2008). Whereas firms are not obliged to disclose any information on contractual agreements, they need to disclose at least some information about joint ventures. ${ }^{75}$ In other words, firm disclosure tends to be more forthcoming

\footnotetext{
${ }^{73}$ We acknowledge that the existence of trust between the partnering firms - which might accumulate through repeated cooperations - is an alternative mechanism (Gulati, 1995; Nooteboom et al., 1997; Zaheer, McEvily, and Perrone, 1998). We leave it to future research to address the question whether inter-organizational trust alters the relationship between alliance portfolios and firm-specific risk.

${ }^{74}$ Kumar (2010: 50) shows that the abnormal returns to joint venture announcements are positively correlated for the sponsoring firms. These results suggest that, on average, joint ventures tend to be positive sum games, in which cooperative behavior and common benefits dominate competitive behavior and private benefits.

${ }^{75}$ In most cases, the sponsoring firms have to report their stakes in the joint venture by using the equity method of accounting, which requires the parent companies to report their share of the joint venture's net assets and net income in their financial reports. Whereas there are financial disclosure regulations for joint ventures, no such
} 
to investors with regard to joint ventures as compared to contractual agreements. Further, as joint ventures are 'strong ties' that typically require close and long-term cooperation between the sponsoring firms (Contractor and Lorange, 1988; Rowley et al., 2000) firms have incentives to systematically evaluate the quality of the alliance partner. For this reason, the formation of a joint venture provides signals about a firm's growth opportunities to investors (Kumar and Park, 2012). In line with the findings by Arend (2004) at the individual alliance level, we argue that firm-specific risk declines with the share of joint ventures in a firm's alliance portfolio. Thus:

H3: The share of joint ventures in a firm's alliance portfolio has a negative effect on firm-specific risk.

\subsubsection{The share of exploratory Re D alliances}

Firms enter into alliances for a variety of motives. However, according to Koza and Lewin (1998) any alliance can be thought of as being primarily focused on either exploration or exploitation. In this paper, we assume that exploratory alliances cover the early stages of the value chain. In particular, these alliances undertake some form of joint research and development $(\mathrm{R} \& \mathrm{D})$. These alliances involve the search for new knowledge, the experimentation with unfamiliar technologies, and the creation of products with uncertain future demands (Koza and Lewin, 1998; Lavie and Rosenkopf, 2006). Whereas exploratory R\&D alliances tend to create value in the short-term (Chan et al., 1997; Das et al., 1998; Merchant and Schendel, 2000), the financial returns to these alliances tend to occur in the distant future and are often difficult to predict (Contractor and Lorange, 1988; Rowley et al., 2000). Exploitative alliances mainly focus on downstream activities, such as joint manufacturing, marketing, or distribution. The financial returns to these alliances tend to occur closer in time and are also easier to predict (Koza and Lewin, 1998; Rothaermel, 2001).

We argue in the following that the effects of exploratory $\mathrm{R} \& \mathrm{D}$ alliances and exploitative commercial alliances on firm-specific risk are likely to differ. Before doing so, however, it is helpful to briefly recapitulate some of the motives for why firms form exploratory R\&D alliances. Among the more important reasons for the formation of exploratory $R \& D$ alliances is the reduction of risk and uncertainty inherent in the development of new products or technologies (Hagedoorn, 1993: 378; Rosenkopf and Schilling, 2007).76

Exploratory R\&D alliances can reduce the risks and uncertainties associated with $R \& D$ in at least two ways. First, these alliances allow firms to monitor the evolution of different technologies, without requiring them to make large irreversible investments (Hagedoorn, 1993).The argument here is the following. The future development of technologies and the success of R\&D projects are inherently uncertain and difficult to predict (Mansfield et al., 1977; Nelson and Winter, 1982). Uncertainty implies that a firm is unable to assess how a particular technology or a technological field will develop in the future or which technology in a set of alternative technologies with equal probabilities of success will turn out to be dominant. In other words, firms' can essentially select among a potentially infinite variety of R\&D projects without

requirements exist for contractual agreements. The financial information of these alliances is aggregated into the financial reports of the parent companies and is largely unobservable to investors.

${ }^{76}$ For a more comprehensive review of firms' motives to form R\&D alliances see Hagedoorn (1993). 
knowing the probability by which any of these projects will lead to a successful product (Hagedoorn, 1993; Nelson and Winter, 1982). Due to their bounded rationality, firms develop $R \& D$ strategies to choose among alternative $R \& D$ projects on the basis of simplified models of reality. Due to their routinized character, firms alter or abandon an R\&D strategy only under duress (Cyert and March, 1963; Nelson and Winter, 1982).

Obviously there is no guarantee that a firm's R\&D strategy is 'correct' and that it will create the desired results. Here, exploratory $R \& D$ alliances are an important means for reducing technological uncertainty, as these alliances enable firms to learn about other firms' interpretation of the environment and about relevant developments in different technologies (Ahuja, 2000; Hagedoorn, 1993; Mowery et al., 1996). There is considerable support for the view that exploratory $\mathrm{R} \& \mathrm{D}$ alliance portfolios are important instruments for information gathering and learning about new technologies. Powell et al. (1996) submit that exploratory R\&D alliances are the entry ticket to an information network. They show that a central position in such a network is an important determinant of firm performance. Consistently, Ahuja (2000) finds that a larger portfolio of exploratory R\&D alliances enhances a firm's innovative performance as measured by patents. A recent paper by Frankort, Hagedoorn, and Letterie (2011) suggests that firms are probably more successful in reducing technological uncertainty when they form multiple simultaneous R\&D alliances..$^{77}$ Hoffmann (2007: 834) and Koka and Prescott (2002) posit that the number of alliances that firms maintain is a proxy for the amount of information that a firm can access through its alliances. These findings suggest that especially firms with large portfolios of exploratory R\&D alliances are in a good position to monitor the development of new technologies, which should have a negative effect on firm-specific risk.

A second important motive for the formation of exploratory R\&D alliances relates to the rising costs and speed and the increasingly inter-sectoral nature of new product development and technological change. In the light of these developments, exploratory R\&D alliances allow firms to take on projects that would be too risky for each individual firm or projects that would go beyond the capabilities and resources of each alliance partner alone (Hagedoorn, 1993; Sampson, 2004). Further, alliances also have the advantage that firms do not have to develop relevant resources themselves, which might be a lengthy and expensive undertaking (Sampson, 2004). Finally, exploratory R\&D alliances may also serve as signals for firm quality. Stuart (2000) argues, for instance, that R\&D alliances are 'access relationships.' Firms will only form exploratory R\&D alliances with other firms that have leading edge technologies or that are skilled innovators. Hence, the fact that a firm participates in an exploratory R\&D alliance might serve as a positive signal to investors, reducing investors' perceptions of firm-specific risk.

The above suggests that certain elements of exploratory R\&D alliances work to offset the relatively high relational risk that these alliances entail. However, this counterbalancing effect is likely to be weaker in exploitative commercial alliances. In fact, Das et al. (1998: 29) argue that investors may even perceive exploitative commercial alliances as a sign of weakness. Their study documents significant abnormal returns to the announcements of exploratory R\&D alliances but not to the announcement of exploitative commercial alliances. Further, consistent with our hypothesis, these authors find that the announcement of exploitative marketing alliances leads to

\footnotetext{
${ }^{77}$ Frankort et al. (2011) find a positive relationship with decreasing marginal effects between R\&D alliance portfolio size and the inflows of technological knowledge, which they measure by patent citations.
} 
a significant increase in the variance of a firm's stock returns, whereas the effect of exploratory $\mathrm{R} \& \mathrm{D}$ alliances is negative but insignificant. Based on these findings, we argue:

H4: The share of exploratory R\&D alliances in a firm's alliance portfolio has a negative effect on firm-specific risk.

\subsection{Uncertainty shocks and the effects of alliance portfolios on firm-specific risk}

Environmental uncertainty refers to the extent to which the future state of the environment can be accurately predicted or anticipated (Lawrence and Lorsch, 1967). An increase in environmental uncertainty reduces a firm's ability anticipate the future for two reasons. On the one hand, environmental uncertainty leads to an increase in complexity, i.e., in the number of factors in a firm's external environment that must be taken into account. On the other hand, environmental uncertainty also refers to the dynamics of these factors. This latter dimension of environmental uncertainty has two components. First, it describes how rapidly external factors that are relevant for decision making processes within firms change over time. Second, it also encompasses the frequency with which decision makers need to consider new and different factors increases together with environmental uncertainty (Duncan, 1972: 316).

We expect that a shock or a persistent increase in environmental uncertainty alters the effects of both alliance portfolios and alliance portfolio characteristics on firm-specific risk. We follow the transaction cost literature when we argue that increases in environmental uncertainty reduce a firm's ability to manage its alliances efficiently. In addition, we submit that a focal firm's partners are more likely to file for bankruptcy or to experience financial distress in the aftermath of uncertainty shocks. This risk of a partner's bankruptcy or financial distress is certainly exogenous to the cooperation but it is likely to be harmful for a focal firm. Hence, the performance risk of alliances should also increase after a shock to environmental uncertainty. We will briefly elaborate on these two perspectives in the following.

\subsubsection{Shocks to environmental uncertainty and relational risk}

Williamson $(1985,1991)$ posits that highly consequential disturbances in the environment require firms to make timely responses in order to adapt to the new environment. In alliances, such timely adaptations tend to be difficult to achieve and tend to involve considerably higher coordination costs compared to hierarchical organizations (Das and Teng, 1996: 838). On the one hand, disturbances often require the adaptation and renegotiation of incomplete contracts, which creates scope for opportunistic behavior. According to Williamson, whereas cooperation is the rule, self-interested bargaining of the opportunistic kind is the exception and it is more likely to occur in response to 'outlier disturbances' that alter firms' perceptions with regard to the benefits and costs of cooperative or competitive behavior (Oxley, 1997; Williamson, 2005: 8). Opportunistic behavior may become particularly problematic if the shock affects the alliance partners in dissimilar ways, leaving one partner more vulnerable than the other. ${ }^{78}$

\footnotetext{
$78 \mathrm{~A}$ study by Lerner et al. (2003) suggests that relational risk changes in response to changing conditions in the external environment. The study suggests that in periods where stock market financing is costly, small biotech firms tend to be more likely to finance R\&D projects through alliances with larger cooperations. Moreover, they document that during such periods, the biotech firms seem to assign the bulk of the control rights to the larger
} 
On the other hand, the search for a coordinated response to highly consequential disturbances frequently leads to conflicts and maladaptations to the new environment as independent parties may read and react to the oftentimes ambiguous and difficult to interpret signals in different ways, even though their intention is to achieve a timely and compatible combined response (Williamson, 1991). Consequently, alliance partners are more likely to disagree about how an adequate response should look like, which leads to high coordination costs and a high potential for conflicts. Alliances offer few mechanisms to deal with such disputes. Therefore, Williamson predicts that when disturbances or shocks in the environment are highly consequential, “... the hybrid mode supported by arbitration and excuse doctrine incurs added costs and comes under added strain” (Williamson, 1991: 271-273).

\subsubsection{Shocks to environmental uncertainty and performance risk}

Shocks to environmental uncertainty typically lead to financial market imperfections and to an increase in firms' external financing premiums, i.e., the spread between the cost of internal and external financing (Fazzari et al., 1988). Industry or economy wide uncertainty shocks are tend to be accompanied by a steep drop in stock prices, which increases the costs of external equity financing Due to the elevated bankruptcy risk, banks become more likely to demand higher interest rates (Bernake et al., 1999; Bloom, 2009; Gilchrist et al., 2010). Consequently, the probability that firms face binding financing constraints or financial distress increases considerably. In a recent study, Gilchrist et al. (2010) find, for instance that uncertainty shocks lead to an increase in firms' costs of external financing and to a drop in investment levels and output. They conclude that uncertainty shocks have significant adverse consequences for the real economy. This conclusion is also supported by the findings of Bloom (2009).

In the following, we assume that a focal firm's alliance partners are more likely to face financial distress or bankruptcy in the aftermath of major uncertainty shock (Bloom, 2009; Gilchrist et al., 2010). Financial distress or bankruptcy of a partner can affect a focal firm in two ways. On the one hand, a financially distressed partner will be less able to contribute to the successful completion of an alliance. On the other hand, firms that form an alliance exchange some of their assets or make relationship-specific investments that cannot be (fully) recovered outside the relationship. The interdependencies and switching costs that follow from such investments make firms vulnerable to the default of their alliance partners. Thus, when a shock hits a focal firm's alliance partner, the firm itself will be affected by the shock to the extent that its non-recoverable investments are lost. Because such shocks are clearly exogenous to the cooperation itself, we argue that major shocks in environmental uncertainty increase the performance risk of alliances.

Several studies examine how the bankruptcy or financial distress of a focal firms' alliance partner affects the focal firm itself. Singh and Mitchell (1996) find that when a focal firm's alliance partner shuts down in response to an exogenous industry shock, the focal firm itself faces an increased risk of dissolution in the future. Hence, they argue that the performance of a focal firm critically depends on the performance of its alliance partners. This dependency should

corporations, which demonstrates that the larger firms exploit the vulnerability of their alliance partners in an opportunistic way. Interestingly, Lerner et al. also establish that the alliances that are formed within a period of costly external financing are significantly less successful, most likely due to inefficient allocation of ownership and control rights. 
increase with the extent to which the operations of the alliance partners are intertwined through interorganizational routines. A nascent stream of literature in corporate finance also examines how financial distress or bankruptcy of alliance partners affect a focal firm (Boone and Ivanov, 2012; Hertzel et al., 2008). Hertzel et al. (2008) analyze how financial distress and bankruptcy filings of firms affect the market value of these firms' customers and suppliers. They find that bankruptcy filings of buyers lead to significant negative stock price reactions for suppliers. Boone and Ivanov (2012) find that firms whose alliance partners file bankruptcy experience negative stock price reactions and a decline in profit margins and real investment levels in the two years after the bankruptcy event. They conclude that the non-bankrupt party can experience substantial operating difficulties and negative valuation effects from the failure of their alliance partners.

The above suggests that both the relational risk and the performance risk of alliances increase in the aftermath of major shocks in environmental uncertainty. On the one hand, transaction cost economists posit that disturbances in the environment increase the threat of opportunistic behavior and the potential for conflicts among alliance partners. On the other hand, the dissolution of an alliance partner may increase the performance risk of an alliance and by that a focal firm's own fundamental risk (Singh and Mitchell, 1996; Tomkins, 2001: 162). Hence, shocks to environmental uncertainty should lead to an increase in the positive effect of alliances on firm specific risk. Note that our paper focuses on exogenous shocks in the environment that affect all firms in one way or the other. Consequently, the riskiness of each alliance that a firm maintains at a certain point in time with different alliance partners is likely to increase. Hence, firm-specific risk is likely to increase in particular for firms with large alliance portfolios. This leads to the following hypothesis:

H5: The positive effect of alliance portfolio size on firm-specific risk increases during the aftermath of a major shock to environmental uncertainty.

A shock in environmental uncertainty should have a larger impact on horizontal alliances with direct competitors. Such alliances are typically closer to the focal firm's core business (Dussauge et al., 2000; Krishnan et al., 2006). Hence, frictions related to the cooperation within these alliances should have more significant effects on the performance of a focal firm. Consistent with this line of reasoning, Boone and Ivanov (2012) find that bankruptcies from alliance partners that share the same two-digit SIC class have a strong negative effect on the valuation of a focal firm. Due to their close relatedness to a firm's core business, alliance portfolios that comprise a large share of alliances with a focal firm's direct competitors may become particularly risky in the aftermath of an uncertainty shock. Hence, we propose:

H6: The positive effect of the share of competitor alliances in a firm's alliance portfolio on firm-specific risk increases during the aftermath of a major shock in environmental uncertainty.

Transaction costs economists point out that the governance structure of alliances influences firms' abilities to deal with uncertainty and unexpected events (Williamson, 1991). Oxley (1997: 393) argues that, compared to contractual alliances, the shared equity of joint ventures and their additional monitoring rights and administrative controls make joint ventures more responsive to large disturbances in the external environment. Gulati (1995) posits that the administrative hierarchy of joint ventures helps to address contingencies as they arise. Boone and Ivanov (2012: 
565) find that the parties to contractual agreements experience negative share price effects and negative effects on their operating performance when their alliance partners file for bankruptcy. They do not find evidence for such effects in the case of joint ventures. In the light of this finding, they argue that the clear legal and operational separation of the joint venture from its sponsoring firms can help to isolate the healthier partner from negative spillover effects that arise from a partner's bankruptcy. In other words, joint ventures should mitigate relational risk especially when there is an increase in environmental uncertainty. Moreover, the value of joint ventures as signals for unobserved firm quality might be particularly high in times of high uncertainty in the environment. For these reasons, we expect that firms that have a high share of joint ventures in their alliance portfolios will be better equipped to deal with major shocks in environmental uncertainty. This leads to the following hypothesis:

H7: The negative effect of the share of joint ventures in a firm's alliance portfolio on firm-specific risk increases (becomes more negative) during the aftermath of a major shock in environmental uncertainty.

Finally, a shock in environmental uncertainty may also diminish the efficacy of exploratory $\mathrm{R} \& \mathrm{D}$ alliances in reducing firm-specific risk. On the one hand, we argue above that exploratory $R \& D$ alliances reduce firm-specific risk by enabling a focal firm to observe its partners' $R \& D$ strategies. In the aftermath of an uncertainty shock, partners' R\&D strategies are probably much more difficult to understand, as the diversity and complexity of the information that decision makers need to absorb increases dramatically. For instance, a major uncertainty shock may lead some firms to alter their R\&D expenditures or to pause or discontinue certain R\&D projects. In the aftermath of a shock, decision makers both within and outside a firm will be exposed to a large number of conflicting and frequently changing signals. Consistent with Lawrence and Lorsch (1967), such disruptions of the status quo will impair the ability of decision makers to accurately forecast the technological developments within an industry or within the economy as a whole. In other words, the usefulness of technology alliances as means for gathering information and knowledge is probably lower in the aftermath of a major uncertainty shock.

On the other hand, the above suggests that firms often form exploratory $\mathrm{R} \& \mathrm{D}$ alliances to share the risks and costs associated to new product development. If a focal firm's alliance partners face financial distress or bankruptcy, the firm needs to decide whether it continues a certain R\&D project or not, whether it searches for a new alliance partner, or whether it internalizes the entire $\mathrm{R} \& \mathrm{D}$ project. The latter choice will inevitably lead to an increase in the firm's own fundamental risk. However, searching for a new alliance partner can also lead to substantial reorganization costs and delays. Both arguments suggest that exploratory $R \& D$ alliances should have a less negative effect on a firm's performance risk in the aftermath of an uncertainty shock. For this reason, we expect that especially firms whose alliance portfolios comprise a share of exploratory $R \& D$ alliances should face higher firm-specific risk in the aftermath of a shock to environmental uncertainty. Consequently, our final hypothesis reads as follows:

H8: The negative effect of the share of exploratory R\&D alliances in a firm's alliance portfolio on firm-specific risk decreases (becomes less negative) during the aftermath of a major shock in environmental uncertainty. 


\subsection{Method}

\subsubsection{Data and variables}

We collected data for the years 1997 to 2006 from a variety of sources. First, information on alliances was obtained from the SDC Platinum database (Anand and Khanna, 2000b; Schilling, 2009). We retrieved data on stock prices from the Centre of Research in Security Prices (CRSP) daily stock price database. We also obtained daily Fama and French (1993) factors from Kenneth French's homepage. All accounting variables and data on several firm characteristics come from Compustat. Finally, data on analyst coverage come from the Institutional Brokers' Estimate System $(\mathrm{I} / \mathrm{B} / \mathrm{E} / \mathrm{S})$.

We restrict our analysis to medium- and high tech industries in which alliances are common and form an important part of the incumbents' business models (Hagedoorn, 2002; Rosenkopf and Schilling, 2007). The firms in our sample have their primary activity in SIC 28 (Chemicals and Allied Products), SIC 35 (Industrial and Commercial Machinery and Computer Equipment), SIC 36 (Electronics and Electrical Equipment), SIC 38 (Measuring, Analyzing, and Controlling Instruments, Photonics, Medical and Optical Goods), SIC 48 (Communications), and SIC 73 (Business Services). ${ }^{79}$ We impose some more restrictions on this basic sample. First, we require each firm to have at least three consecutive years of complete data, in order to allow for first differencing and the inclusion of firm fixed effects.

Table 5.1: Annual distribution of observations across industries

\begin{tabular}{|c|c|c|c|c|c|c|c|c|}
\hline Year & SIC 28 & SIC 35 & SIC 36 & SIC 38 & SIC 48 & SIC 73 & Total & $\%$ \\
\hline 1997 & 49 & 52 & 55 & 35 & 12 & 75 & 278 & $6.47 \%$ \\
\hline 1998 & 62 & 58 & 75 & 50 & 19 & 95 & 359 & $8.36 \%$ \\
\hline 1999 & 69 & 69 & 84 & 58 & 26 & 114 & 420 & $9.78 \%$ \\
\hline 2000 & 69 & 65 & 86 & 45 & 29 & 135 & 429 & $9.99 \%$ \\
\hline 2001 & 74 & 59 & 76 & 38 & 25 & 123 & 395 & $9.19 \%$ \\
\hline 2002 & 77 & 54 & 79 & 40 & 24 & 127 & 401 & $9.33 \%$ \\
\hline 2003 & 82 & 47 & 77 & 44 & 27 & 112 & 389 & $9.05 \%$ \\
\hline 2004 & 90 & 56 & 76 & 47 & 27 & 124 & 420 & $9.78 \%$ \\
\hline 2005 & 86 & 49 & 77 & 46 & 25 & 117 & 400 & $9.31 \%$ \\
\hline 2006 & 76 & 41 & 72 & 47 & 21 & 102 & 359 & $8.36 \%$ \\
\hline Total & 734 & 550 & 757 & 450 & 235 & 1,124 & 3,850 & - \\
\hline$\%$ & $19.06 \%$ & $14.29 \%$ & $19.66 \%$ & $11.69 \%$ & $6.10 \%$ & $29.19 \%$ & 100.00 & - \\
\hline
\end{tabular}

Notes: The sample comprises medium and high technology firms with their main activity in SIC 28: Chemicals and Allied Products, SIC 35: Industrial and Commercial Machinery and Computer Equipment, SIC 36: Electronics and Electrical Equipment, SIC 38: Measuring, Analyzing, and Controlling Instruments, Photonics, Medical and Optical Goods, SIC 48: Communications, SIC 73: Business Services.

Second, to make sure that the firms in our sample were not subject to major disruptions of their operations, we only include firms with the maximum number of daily returns available for each firm year. Our final sample is an unbalanced panel with 3,850 observations related to 696 firms. The shares of these firms are traded at the NYSE (43\%) or NASDAQ (57\%). About $88 \%$ of the

\footnotetext{
${ }^{79}$ We select the industries based on the information in the SDC Platinum data base. Prior research suggests that the SDC industry classification is very accurate (Anand \& Khanna, 2000b; Schilling, 2009). In a few cases, the primary SIC code assigned by SDC changes within firms over time. In these cases, we compared the SDC data to the primary SIC codes from Compustat and made corrections when necessary.
} 
firms in our sample are headquartered in the United States. The remaining firms are mostly large multinational companies (MNCs) from Europe or Japan. Table 5.1 gives an overview of the distribution of the observations across time and industries.

\subsubsection{Dependent variable}

Firm-specific or idiosyncratic risk is the risk about future returns that is unique to a firm (Rosenberg and McKibben, 1973). Idiosyncratic risk also relates to unexpected variation in firms' future returns (Miller, 1992; Das and Teng, 1998). We use daily stock returns and two Fama and French (1993) risk factors for which we also have daily data to construct our measure of timevarying firm-specific risk. The advantage of using stock market data for constructing our risk measure is that stock prices, in principle, include all factors in a firm's environment that investors perceive to be important (Gilchrist et al., 2010). Similar to Ang et al. (2009) and Fu (2009: 26), we estimate firm-specific risk from the following model:

$$
\left(r_{i_{d}}-r_{t_{d}}^{f}\right)=\alpha_{i}+\beta_{i}^{M}\left(r_{t_{d}}^{M}-r_{t_{d}}^{f}\right)+\beta_{i}^{S M B} S M B_{t_{d}}+\beta_{i}^{H M L} H M L_{t_{d}}+u_{i_{d}},
$$

where $i$ indexes firms, $t_{d}$ indexes trading days in year $t$. In equation (1), $r_{i}$ denotes the firm's daily stock return, $r$ is the one-month treasury bill rate (i.e., the risk-free rate), $r^{M}$ is the valueweighted return on the market as a whole, $S M B$ is the difference between the return on a portfolio of small stocks and the return on a portfolio of large stocks, and HML is the difference between the return of a portfolio of high book-to-market stocks and the return on the portfolio of low book-to-market stocks..$^{80}$ Note that we estimate equation (1) separately for each firm year in our sample. In a second step, we define idiosyncratic risk as follows:

$$
\sigma_{i t}=\sqrt{\frac{1}{N-1} \sum_{n=1}^{N}\left(\hat{u}_{i t_{d}}-\hat{\bar{u}}_{i t}\right)^{2}}
$$

where $\hat{u}_{i t_{d}}$ is the OLS residual from equation (1) and $\hat{\bar{u}}_{i t}$ is the mean of this residual in year $t$. In other words, oit is a measure for the time-varying equity volatility for firm $i$, which accounts for common risk factors that have been shown to drive differences in expected returns across firms (Gilchrist et al., 2010: 4). In our analysis, we use the natural logarithm of oit as a proxy for firm-specific risk.

\subsubsection{Independent variables}

Alliance portfolio size: Following Lavie (2007), Schilling and Phelps (2007), and Srivastava and Gnyawali (2011) we measure alliance portfolio size as the three-year cumulative number of alliances per firm. As our alliance data goes back to 1995, all alliance portfolios comprise information from three firm years. ${ }^{81}$ Between 1995 and 2006, SDC reports 19,211 alliances for

\footnotetext{
${ }^{80}$ For details, see http://mba.tuck.dartmouth.edu/pages/faculty/ken.french/Data_Library/f-f_factors.html.

${ }^{81}$ Strategic alliances are typically designed to last several years or until the alliance partners reached a specified goal. Ideally, we would construct firms' alliance portfolios based on the actual duration of the alliances in our sample. This is difficult, however, as the SDC data base and also other alliance data bases report termination dates for only a small minority of alliances. In line with prior literature (Lavie, 2007; Stuart, 2000), we find that about 65\% of the alliances
} 
which we are able to identify at least one partner in Compustat. ${ }^{82}$ This number declines substantially due to our focus on high- and medium-tech firms that are listed at major US stock exchanges. Within this time frame, the 696 firms that we include in our final sample formed 7,323 alliances of which 2,612 (35\%) involve some form of joint R\&D and 1,117 (15\%) are joint ventures. We use this subset of alliances to construct the firms' alliance portfolios. ${ }^{83}$

Share of competitor alliances: We assume that alliance partners are direct competitors when their primary operations fall into the same four-digit SIC class (Mowery et al., 1996; Oxley and Sampson, 2004; Park and Russo, 1996). We generate a variable that equals 1 when a firm's SIC code matches that of its alliance partner. In alliances with more than two partners, this variable is the share of alliance partners with the same SIC code. We aggregate this measure to the alliance portfolio level by taking its average over a firm's portfolio of alliances. This measure is similar to what Frankort et al. (2011) and Lavie (2007) call the amount of bilateral competition in a firm's alliance portfolio. The measure is bounded by 0 and 1 . A value closer to one implies that a firm has a higher share of alliances with competitors.

Share of joint ventures: We define this variable as a firm's share of joint ventures as reported by SDC relative to the total number of alliances in the firm's alliance portfolio (Frankort et al., 2011; Lavie, 2007: 1201). This variable also ranges from 0 to 1 . A value closer to 1 indicates a higher share of joint ventures.

Share of R\&D alliances: We classify all alliances as either exploration or exploitation. We use the SDC activity description for the classification of the alliances into the two categories (Boone and Ivanov, 2012; Rothaermel, 2001; Lavie and Rosenkopf, 2006). In a first step, we classify all alliances that focus on joint technology development as exploratory R\&D alliances. We code alliances with the single purposes of marketing, manufacturing, supply, licensing, and technology transfer as exploitative commercial alliances. By this procedure, we are able to classify more than $80 \%$ of the alliances in our sample into one of the two categories. The remaining $20 \%$ of the alliances undertake two or more value chain activities (e.g., R\&D and licensing). Following Lavie and Rosenkopf (2006), we assign 0.5 points to all multi-purpose alliances that include R\&D. We code all multi-purpose alliances that do not include R\&D as exploitative marketing alliances. Again, this variable is bounded by 0 and 1 . A higher value corresponds to a larger share of $R \& D$ alliances.

\footnotetext{
in our sample for which we do have duration data are terminated between the third and fifth year after their announcement. We used Lexis-Nexis and other public source to manually search for termination dates for the remaining alliances in our sample. While we were able to find termination dates for some alliances, most firms do not make public announcements about the termination of alliances. Our results are robust to alternative assumptions about alliance duration such as four and five year durations. Zaheer and Hernandez (2011) use the SDC data and assume five year durations of alliances, for instance.

82 We use the CUSIP identifier to match the SDC data to Compustat. We find that these identifiers are mostly accurate in SDC. A problem is that CUSIPs may change over time and that SDC does not always seem to correct for this. For instance, in SDC the CUSIP of ASM International NV is 'N07045' in 1999 but changes to '007914' in 2003. While such changes concern a small minority of alliances, we use a name matching algorithm (see Blasnik, 2007) to match on the propensity that the firm names in SDC and Compustat are the same. We cannot match on precise names, because the firm names in the datasets differ. We check the results of this matching procedure extensively to ensure that no matching errors occurred.

${ }^{83}$ Note that the share of joint ventures is even smaller within the sample of R\&D alliances. In total, only $290(11 \%)$ of the alliances involving $R \& D$ were joint ventures.
} 


\subsubsection{Control variables}

Following Lavie (2007), we control for portfolio internationalization, which captures the percentage of foreign partners in a firm's alliance portfolio. Alliances with foreign partners might be riskier due to cultural differences, diverse educational backgrounds, or distance (Hagedoorn, Cloodt, and van Kranenburg, 2005; Mowery et al., 1996). Hence, we expect a positive effect of this variable on firm-specific risk. We also control for the average number of agreements per alliance. Alliances that comprise more than one value chain activity (e.g., R\&D, manufacturing, marketing, supply) call for more extensive sharing of knowledge and coordination. Further, the number of contact points increases in such alliances making it more difficult to control knowledge flows (Oxley and Sampson, 2004). Again we expect a positive effect of this measure on firm-specific risk.

We also control for a rich set of firm characteristics to ensure the robustness of our results. First, we control for firm size by including the natural logarithm of total assets. We expect this variable to have a negative effect on firm-specific risk (Ang et al., 2009). We control for R\&D intensity measured as the ratio of $\mathrm{R} \& \mathrm{D}$ expenditures to total assets. As the returns to $\mathrm{R} \& \mathrm{D}$ tend to be risky we expect a positive effect of this variable on firm-specific risk (Mazzucato and Tancioni, 2008). We also include the natural logarithm of Tobin's $q$, which we compute as the ratio of market value of assets divided by book value of assets to control for a firm's investment opportunities (Kaplan and Zingales, 1997). Firms' with a higher Tobin's q ratio should face less firm-specific risk. Lerner and Merges (1998) and Lerner et al. (2003) argue that firms that face frictions in raising equity or debt capital should be more likely to form alliances. We control for potential financing constraints by the ratio of gross cash flow to assets, which we define as after tax income before extraordinary items plus depreciation and amortization plus research and development expenses. We expect a negative effect of this measure on firm-specific risk. We compute a dummy variable for analyst coverage, which equals one if at least one analyst follows a firm in a certain year according to I/B/E/S. Firms that have analyst coverage should face less firm-specific risk. Finally, young firms might face higher firm-specific risk than more mature firms. We create a dummy variable, which is equal to one if a firm is young, i.e. the difference between a focal year and the year of a firm's first appearance in Compustat is less than 10 years. This variable is also used by Brown et al. (2009).

\subsubsection{The late 1990 s technology bubble}

Our theory predicts that uncertainty shocks in the external environment moderate the effect of alliance portfolio size and the three alliance portfolio characteristics on firm-specific risk. We argue that the burst of the high tech bubble in March 2000 represents a suitable laboratory for testing these hypotheses. Studies in the field of corporate investment find that in the run-up period to the bubble, which began somewhere between 1995 and 1998 (see DeLong and Magin, 2006 for a discussion), many firms - notably also firms outside the high tech sectors experienced extraordinarily high stock market valuations enabling these firms to raise external capital at very low costs (Campello and Graham, 2012). For instance, in the period from early 1998 to February 2000, firms in the internet sector earned over 1000\% returns on their public equity (Ofek and Richardson, 2003: 1113). Figure 5.1 graphs the development of the NASDAQ and the NYSE indices over our sample period. Panel A shows that in particular the prices for 
NASDAQ stocks increased substantially in the time before 2000. Panel B shows a comparable but less dramatic pattern for NYSE stocks.

We assume that in the post-bubble period, firms across many industries faced substantial uncertainty and high costs of external financing. These assumptions are realistic as many high tech firms delisted their shares from NASDAQ in this post-bubble period (Griffin et al., 2011: 1264). Evidence from the IPO market also suggests that stock market financing became less attractive in the post-bubble period. Perez (2009) and Schwert (2002) document that the number of high tech IPOs increased rapidly in the run-up period to the bubble and peaked in 1999. In contrast, IPO activity literally collapsed in the post-bubble period. Park and Mezias (2005: 990) show that the average number of IPOs per month on NASDAQ declined significantly after the burst of the technology bubble. Hertzel et al. (2008) and Boone and Ivanov (2012) find that the number of bankruptcies peaked in the years 2000 to 2003. Consistently, Park and Mezias (2005) document a significant increase in the number of monthly bankruptcy filings of NASDAQ firms after the February $2000 .{ }^{84}$

Our method is related to two recent studies by Hong et al. (2011) and Campello and Graham (2012), who use the internet bubble as a natural experiment to study the effects of the stock market bubble on firms' cost external financing and investment. However, whereas these studies focus on the boom period prior to the bursts of the bubble - assuming that firms faced low cost of external financing in this time - we focus on the post-bubble period. Our bubble indicator is a binary variable which takes the value one when an observation falls into the years 2000 to 2002 and which is zero otherwise.

Figure 5.1: Development of stock price indices over the sample period

Figure 5.1: Panel (A): Development of NASDAQ index

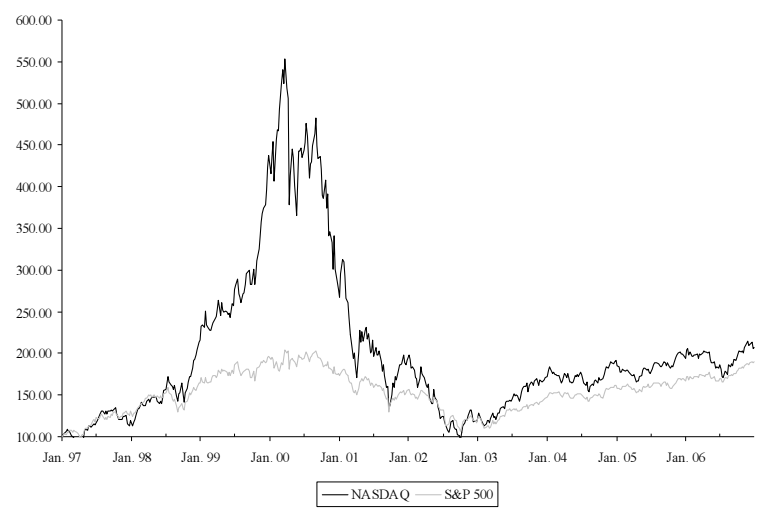

${ }^{84}$ This finding is consistent with the more general insights be Allen and Gale (2000), who argue that the number of firm bankruptcies typically increases in the aftermath of stock market bubbles. 


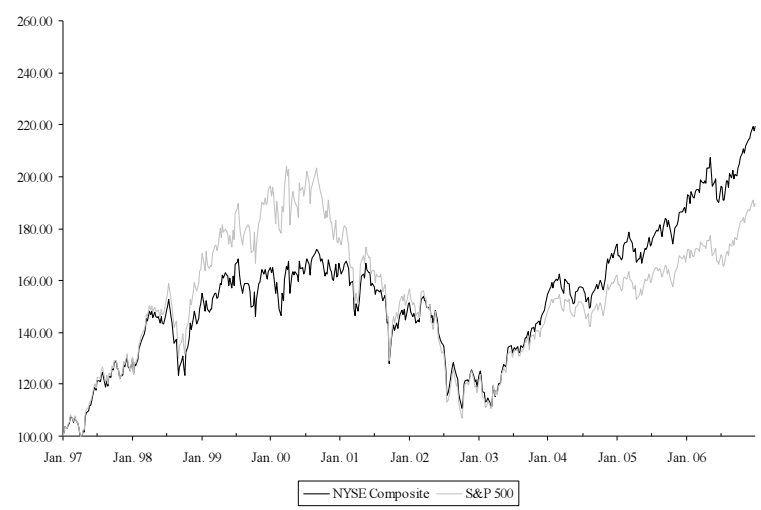

Source: Thomson One-Banker, Datastream

We assume that in the post-bubble period, firms across many industries faced substantial uncertainty and high costs of external financing. These assumptions are realistic as many high tech firms delisted their shares from NASDAQ in this post-bubble period (Griffin et al., 2011: 1264). Evidence from the IPO market also suggests that stock market financing became less attractive in the post-bubble period. Perez (2009) and Schwert (2002) document that the number of high tech IPOs increased rapidly in the run-up period to the bubble and peaked in 1999. In contrast, IPO activity literally collapsed in the post-bubble period. Park and Mezias (2005: 990) show that the average number of IPOs per month on NASDAQ declined significantly after the burst of the technology bubble. Hertzel et al. (2008) and Boone and Ivanov (2012) find that the number of bankruptcies peaked in the years 2000 to 2003. Consistently, Park and Mezias (2005) document a significant increase in the number of monthly bankruptcy filings of NASDAQ firms after the February $2000 .{ }^{85}$

Our method is related to two recent studies by Hong et al. (2011) and Campello and Graham (2012), who use the internet bubble as a natural experiment to study the effects of the stock market bubble on firms' cost external financing and investment. However, whereas these studies focus on the boom period prior to the bursts of the bubble - assuming that firms faced low cost of external financing in this time - we focus on the post-bubble period. Our bubble indicator is a binary variable which takes the value one when an observation falls into the years 2000 to 2002 and which is zero otherwise.

\subsubsection{Descriptive statistics and correlations}

Table 5.2 presents descriptive statistics for the main variables used in this study. The average alliance portfolio size is 5.4 with a median of 2 . As the variable is skewed, we use its natural logarithm in our empirical analysis. The share of competitor alliances, joint ventures, and R\&D alliances are all rather low, which is consistent with previous literature (Frankort et al., 2012; Gomes-Casseres et al., 2006; Lavie, 2007). We also regressed firm-specific risk on a set of year dummies. Figure 5.2 plots the coefficients from these regressions for each 2-digit industry. These

\footnotetext{
85 This finding is consistent with the more general insights be Allen and Gale (2000), who argue that the number of firm bankruptcies typically increases in the aftermath of stock market bubbles.
} 
coefficients can be interpreted as the percentage change in aggregate firm-specific risk per industry relative to the baseline category. The figure is large consistent with the findings in Gilchrist et al. (2010: 5). Thus, after a period of stability, aggregate firm risk increased substantially towards the end of the in the 1990s and peaked in 2000 in all industries that are included in our sample. In most sectors (except SIC 38) it dropped below its 1992 level in 2003.

5.2: Summary statistics

\begin{tabular}{lrrrrrr}
\hline \multicolumn{1}{c}{ Variables } & \# of obs. & \multicolumn{1}{c}{ Mean } & \multicolumn{1}{c}{ SD } & \multicolumn{1}{c}{ Min } & Median & Max \\
\hline Firm-specific risk & 3,850 & 0.012 & 0.014 & 0.000 & 0.007 & 0.189 \\
ln(Firm-specific risk) & 3,850 & -4.900 & 1.035 & -8.019 & -4.897 & -1.664 \\
Alliance portfolio size & 3,850 & 5.424 & 10.539 & 1.000 & 2.000 & 166.000 \\
In(Alliance portfolio size) & 3,850 & 1.009 & 1.014 & 0.000 & 0.693 & 5.112 \\
Share of competitor alliances & 3,850 & 0.102 & 0.256 & 0.000 & 0.000 & 1.000 \\
Share of joint ventures & 3,850 & 0.136 & 0.276 & 0.000 & 0.000 & 1.000 \\
Share of R\&D alliances & 3,850 & 0.201 & 0.265 & 0.000 & 0.071 & 1.000 \\
Portfolio internationalization & 3,850 & 0.434 & 0.443 & 0.000 & 0.333 & 1.000 \\
Agreements per alliance & 3,850 & 1.435 & 0.731 & 1.000 & 1.000 & 6.000 \\
Total assets (in '000 USD) & 3,850 & 8196.471 & 22150.430 & 11.632 & 1102.132 & 270717.40 \\
ln(Total assets) & 3,850 & 7.183 & 1.918 & 2.454 & 7.005 & 12.509 \\
R\&D/assets & 3,850 & 0.091 & 0.101 & 0.000 & 0.070 & 1.744 \\
Tobin's q & 3,850 & 2.783 & 2.487 & 0.329 & 1.999 & 29.497 \\
Ln(Tobin's q) & 3,850 & 0.797 & 0.618 & -1.111 & 0.693 & 3.384 \\
Gross cash flow/assets & 3,850 & 0.136 & 0.160 & -1.970 & 0.134 & 1.452 \\
Analyst coverage (D) & 3,850 & 0.919 & 0.273 & 0.000 & 1.000 & 1.000 \\
Young firm (D) & 3,850 & 0.383 & 0.486 & 0.000 & 0.000 & 1.000 \\
NASDAQ (D) & 3,850 & 0.574 & 0.495 & 0.000 & 1.000 & 1.000 \\
Bubble indicator (D) & 3,850 & 0.318 & 0.466 & 0.000 & 0.000 & 1.000 \\
\hline
\end{tabular}

Figure 5.3: Aggregate risk by year and industry

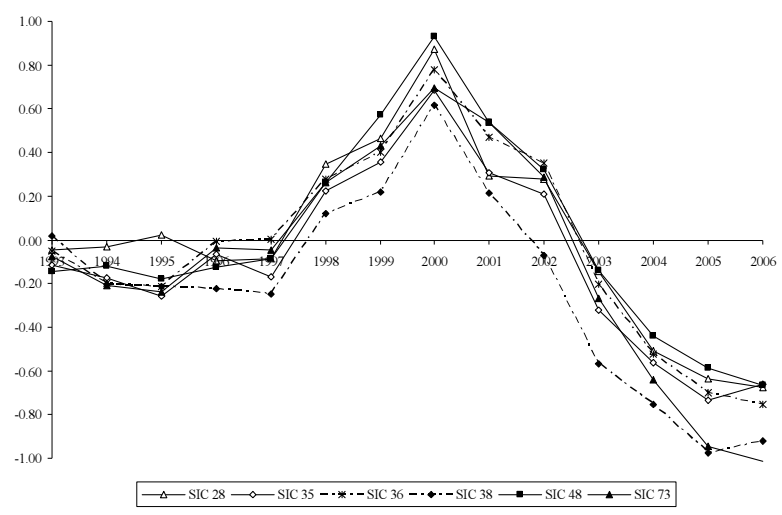

Notes: For this figure, we regress the log of firm-specific risk on sets of year dummies for the six 2-digit SIC industries included in our sample. The base year is 1992 . The coefficients can be interpreted as percentage changes in aggregate firm-specific risk relative to the base category. All regressions include firm-fixed effects. 


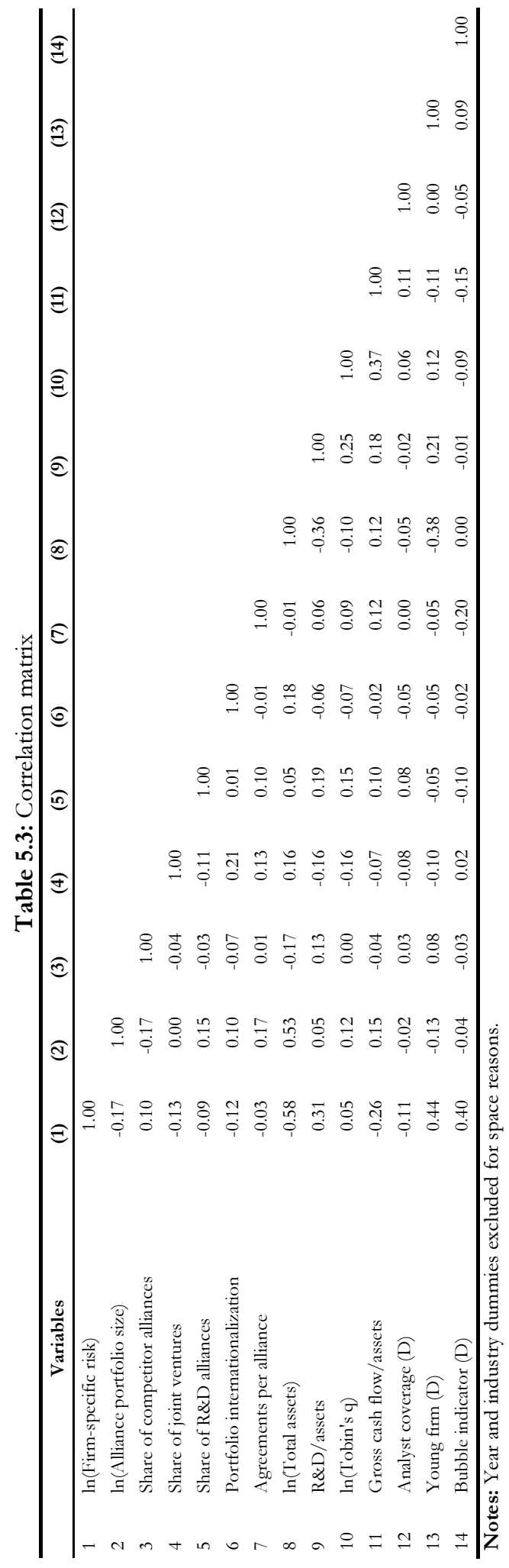


Table 5.3 presents bivariate correlations for the key variables used in this study. Most of the correlations between the independent variables are moderate to low. ${ }^{86}$ Nevertheless, we present variance inflation factors (VIFs) below each of our regressions. The VIFs are always well below the critical value of ten. Consequently, multicollinearity is no concern in our data.

\subsection{Results}

\subsubsection{Specification}

Our theory predicts that shocks to environmental uncertainty alter the relationship between firms' alliance portfolios and firm-specific risk. Our theory predicts that shocks to environmental uncertainty affect the relationship between firms' alliance portfolios and firm-specific risk. Thus, we are interested in how the effect of alliance portfolios on firm-specific risk changes within firms over time. Our theory therefore calls for the use of fixed-effects estimators. We also performed several specification tests, which suggest that we need to control for unobserved firm effects. In a model similar to that in column 1 of table 5.4, we find that a Breusch-Pagan Lagrangian multiplier test rejects the null hypothesis of no significant differences across firms $\left[\chi^{2}(1)=1178.15 ;\right.$ p. $\left.<.001\right]$. Further, a Hausman test strongly rejects the null hypothesis that the coefficients of fixed- and random effects estimators are similar $\left[\chi^{2}(21)=\right.$ 80.43; p. < .000]. Finally, we also performed Wooldridge (2002) tests to assess the need to correct for serial correlation in the residuals. The null hypothesis of no first-order serial correlation was rejected at the .000 level. This finding is consistent with other literature, which finds that firm-specific risk tends to be fairly persistent over time (Gilchrist et al., 2010). In our analysis, we therefore use fixed-effects estimators that allow for first-order serial correlation in the residuals (Baltagi and Wu, 1999; Hsiao, 2003). We report the estimated serial correlation coefficient $\varrho$ below the regression output in each column. Due to the Cochrane-Orcutt method that we use for the AR(1) transformation, we have to drop the first period of observation. Hence, the number of usable observations is $3,154 .{ }^{87}$

\subsubsection{Main findings}

Table 5.4 presents our main findings. Looking at the control variables in column (1), we see that portfolio internationalization and the young firm dummy have a positive effect on firm-specific risk. In contrast, we observe negative effects of firm size, cash flow, Tobin's q, and the dummy for analyst coverage. The effect of R\&D intensity is positive but insignificant. Consistent with hypothesis 1 , the effect of alliance portfolio size on firm-specific risk is positive and significant.

\footnotetext{
${ }^{86}$ Only the correlation between alliance portfolio size and firm size is high. This is not surprising, as large firms are far more likely to form alliances (Hagedoorn and Schakenraad, 1994: 299). We therefore ran all regressions including and excluding firm size. Our results do not change.

${ }^{87}$ In unreported regressions we also used standard fixed-effects estimators that do not account for serial correlation in the residuals. Further, we experimented with panel estimators that rely on the Prais and Winston (1954) transformation to eliminate serial correlation. In contrast to the Cochrane-Orcutt estimators, these estimators do not drop the first time period. All estimators yield fairly consistent results. The output of these regressions is available from the authors upon request.
} 
The coefficient estimates imply that an increase in alliance portfolio size by one percent increases firm-specific risk by roughly $.042 \%$. Next, we turn to the alliance portfolio characteristics to test hypotheses 2 to 4 . The share of competitor alliances has a positive but insignificant effect. We therefore cannot reject the null hypothesis in favor of hypothesis 2 . In contrast, the effects of the share of joint ventures and the share of $R \& D$ alliances are both negative and significant. Hence, we accept hypotheses 3 and 4 .

In column (2), we add an interaction term between our bubble indicator and alliance portfolio size. Note that we cannot identify the direct effect of the bubble indicator, as our regressions include year fixed effects. Similar to Hong et al. (2011), we therefore drop the bubble indicator form the regressions. ${ }^{88}$ The estimation results show that the interaction term between the bubble indicator and alliance portfolio size is positive and significant. Further, note that the coefficient of alliance portfolio size turns insignificant once we include the interaction term. Thus, consistent with hypothesis 5 , we find that the effect of alliance portfolio size on firm-specific risk is stronger in times of high environmental uncertainty.

Column (3) adds an interaction term between the share of competitor alliances and the bubble indicator. Here, we expected a positive sign of the interaction term because alliances with direct competitors are often more closely related to a firm's core activities and frictions in these alliances should have larger effects on firm-specific risk. While the interaction term is indeed positive, it is insignificant. We therefore reject hypothesis 6 .

Hypothesis 7 predicts that the negative effect of the share of joint ventures in a firm's alliance portfolio on firm-specific risk increases during the aftermath of a major shock in environmental uncertainty. Consistent with this hypothesis, we find that the interaction term between the bubble indicator and the share of joint ventures in column (4) is negative and significant, whereas the direct effect of the share of joint ventures becomes insignificant.

Our final hypothesis states the negative effect of the share of exploratory R\&D alliances in a firm's alliance portfolio on firm-specific risk decreases during the aftermath of a major shock in environmental uncertainty. The results in column (5) fully support this hypothesis. Whereas the coefficient of the share of exploratory $R \& D$ alliances remains negative and significant, its interaction term with the bubble indicator is positive and significant. Finally, column (6) includes all three alliance portfolio characteristics. Here the interaction term between the share of competitor alliances and the bubble indicator turns negative but is still insignificant. The interaction term between the bubble indicator and the share of exploratory $\mathrm{R} \& \mathrm{D}$ alliances becomes somewhat weaker but is still significant.

\subsection{Robustness}

\subsubsection{Interactions with year dummies}

To assess the robustness of our results, we choose a more flexible specification and allow the effects of our four alliance portfolio measures to change in each year, by interacting each variable with a set of year dummies. The year dummies should capture shocks to uncertainty that are common to all firms.

\footnotetext{
${ }^{88}$ Note, however, that our results are similar when we exclude the year dummies.
} 
Table 5.4: The effects of alliance portfolios on firm-specific risk

\begin{tabular}{|c|c|c|c|c|c|c|}
\hline DV: $\ln$ (Firm-specific risk) & (1) & (2) & (3) & (4) & (5) & (6) \\
\hline \multirow[t]{2}{*}{$\ln$ (Alliance portfolio size) } & $.042^{* *}$ & .028 & $.040^{* *}$ & $.042^{* *}$ & $.040^{* *}$ & $.042^{* *}$ \\
\hline & $(.019)$ & $(.020)$ & $(.019)$ & $(.019)$ & $(.019)$ & $(.019)$ \\
\hline \multirow[t]{2}{*}{ Share competitor alliances } & .029 & .025 & -.008 & -.013 & -.006 & -.010 \\
\hline & $(.051)$ & $(.051)$ & $(.049)$ & $(.047)$ & $(.047)$ & $(.049)$ \\
\hline \multirow[t]{2}{*}{ Share joint ventures } & $-.105^{*}$ & $-.107^{* *}$ & $-.105^{*}$ & -.006 & $-.107^{* *}$ & -.012 \\
\hline & $(.054)$ & $(.054)$ & $(.054)$ & $(.060)$ & $(.054)$ & $(.060)$ \\
\hline \multirow[t]{2}{*}{ Share R\&D alliances } & $-.124^{* *}$ & $-.127 * *$ & $-.127^{* *}$ & $-.128^{* *}$ & $-.179 * * *$ & $-.173^{* * *}$ \\
\hline & $(.055)$ & $(.055)$ & $(.055)$ & $(.055)$ & $(.060)$ & $(.060)$ \\
\hline \multirow[t]{2}{*}{ Bubblea $^{*} \ln ($ Alliance portfolio size $)$} & - & $.036^{* *}$ & - & - & - & - \\
\hline & & $(.018)$ & & & & \\
\hline \multirow[t]{2}{*}{ Bubblea $^{a}$ Share competitor alliances } & 一 & - & .002 & 一 & - & -.003 \\
\hline & & & $(.073)$ & & & $(.073)$ \\
\hline \multirow[t]{2}{*}{ Bubble ${ }^{a} *$ Share joint ventures } & - & - & - & $-.249^{* * *}$ & - & $-.238^{* * *}$ \\
\hline & & & & $(.068)$ & & $(.068)$ \\
\hline \multirow[t]{2}{*}{ Bubble $^{a} *$ Share R\&D alliances } & - & - & 一 & - & $.169^{* *}$ & $.146^{*}$ \\
\hline & & & & & $(.074)$ & $(.075)$ \\
\hline \multirow[t]{2}{*}{ Portfolio internationalization } & $.043^{*}$ & $.043 *$ & $.043 *$ & .041 & .041 & .039 \\
\hline & $(.026)$ & $(.026)$ & $(.026)$ & $(.026)$ & $(.026)$ & $(.026)$ \\
\hline \multirow[t]{2}{*}{ Agreements per alliance } & -.019 & -.019 & -.017 & -.023 & -.018 & -.023 \\
\hline & $(.025)$ & $(.025)$ & $(.025)$ & $(.025)$ & $(.025)$ & $(.025)$ \\
\hline \multirow[t]{2}{*}{$\ln$ (Total assets) } & $-.147 * * *$ & $-.148^{* * *}$ & $-.148^{* * * *}$ & $-.146^{* * *}$ & $-.149 * * *$ & $-.147^{* * *}$ \\
\hline & $(.029)$ & $(.029)$ & $(.029)$ & $(.029)$ & $(.029)$ & $(.029)$ \\
\hline \multirow[t]{2}{*}{$\mathrm{R} \& \mathrm{D} /$ assets } & .225 & .224 & .227 & .196 & .246 & .210 \\
\hline & $(.172)$ & $(.172)$ & $(.172)$ & $(.172)$ & $(.172)$ & $(.172)$ \\
\hline \multirow[t]{2}{*}{ Ln(Tobin's q) } & $-.073^{* * *}$ & $-.074 * * *$ & $-.073 * * *$ & $-.069^{* * *}$ & $-.076^{* * *}$ & $-.071^{* * *}$ \\
\hline & $(.024)$ & $(.024)$ & $(.024)$ & $(.024)$ & $(.024)$ & (.024) \\
\hline \multirow[t]{2}{*}{ Cash flow/assets } & $-.389^{* * * *}$ & $-.389 * * *$ & $-.390 * * *$ & $-.377 * * *$ & $-.385^{* * * *}$ & $-.374^{* * * *}$ \\
\hline & $(.086)$ & $(.086)$ & $(.086)$ & $(.085)$ & $(.086)$ & (.085) \\
\hline \multirow[t]{2}{*}{ Analyst coverage (D) } & $-.162^{* * *}$ & $-.165^{* * *}$ & $-.162^{* * *}$ & $-.158^{* * *}$ & $-.164^{* * * *}$ & $-.161 * * *$ \\
\hline & $(.057)$ & $(.057)$ & $(.057)$ & $(.057)$ & $(.057)$ & $(.057)$ \\
\hline \multirow[t]{2}{*}{ Young firm (D) } & $.090^{* *}$ & $.093^{* *}$ & $.090^{* *}$ & $.090^{* *}$ & $.095^{* *}$ & $.094^{* *}$ \\
\hline & $(.039)$ & $(.039)$ & $(.039)$ & $(.039)$ & $(.039)$ & $(.039)$ \\
\hline \multirow[t]{2}{*}{ Constant } & $-.152^{*}$ & -.126 & $-.160^{*}$ & $-.178^{* *}$ & $-.155^{*}$ & $-.173^{* *}$ \\
\hline & $(.085)$ & $(.086)$ & $(.085)$ & $(.085)$ & $(.085)$ & $(.086)$ \\
\hline Time fixed-effects & Yes & Yes & Yes & Yes & Yes & Yes \\
\hline Firm fixed-effects & Yes & Yes & Yes & Yes & Yes & Yes \\
\hline \# of observations & 3,154 & 3,154 & 3,154 & 3,154 & 3,154 & 3,154 \\
\hline \# of firms & 696 & 696 & 696 & 696 & 696 & 690 \\
\hline Variance inflation factor (VIF) & 2.27 & 2.36 & 2.26 & 2.30 & 2.31 & 2.34 \\
\hline 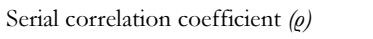 & .375 & .374 & .375 & .375 & .375 & .371 \\
\hline R-squared & .744 & .744 & .744 & .745 & .744 & .745 \\
\hline
\end{tabular}

Notes: ${ }^{* * *}(* *, *)$ indicate a significance level of $1 \%(5 \%, 10 \%)$. The sample comprises six two-digit SIC industry classes. The dependent variable is the natural logarithm of firm-specific risk, which we obtain from annual Fama-French (1993) three-factor models. Year dummies are excluded for space reasons. Standard errors are corrected for first-order serial correlation. a The Bubble indicator is a dummy variable for the post-bubble period 2000 to 2002 . Since the models include year fixed-effects, this variable is not uniquely identified and thus dropped from the regressions. 
Table 5.5: The effects of alliance portfolios on firm-specific risk

\begin{tabular}{|c|c|c|c|c|}
\hline DV: $\ln$ (Firm-specific risk) & (1) APS & (2) COMP & (3) JV & (4) $\mathrm{RD}$ \\
\hline \multirow[t]{2}{*}{$\ln$ (Alliance portfolio size) } & $.039^{*}$ & $.042^{* *}$ & $.041^{* *}$ & $.041^{* *}$ \\
\hline & $(.021)$ & $(.019)$ & $(.019)$ & $(.019)$ \\
\hline \multirow[t]{2}{*}{ Share competitor alliances } & -.010 & -.098 & -.014 & -.006 \\
\hline & $(.047)$ & $(.094)$ & $(.047)$ & $(.047)$ \\
\hline \multirow[t]{2}{*}{ Share joint ventures } & $-.111 * *$ & $-.108^{* *}$ & .095 & $-.106^{*}$ \\
\hline & $(.054)$ & $(.054)$ & $(.112)$ & $(.054)$ \\
\hline \multirow[t]{2}{*}{ Share R\&D alliances } & $-.134^{* *}$ & $-.126^{* *}$ & $-.131^{* *}$ & $-.193^{*}$ \\
\hline & $(.055)$ & $(.055)$ & $(.055)$ & $(.100)$ \\
\hline \multirow[t]{2}{*}{ Portfolio variable * 1997} & -.023 & -.448 & .371 & .556 \\
\hline & $(.018)$ & $(.524)$ & $(.463)$ & $(.507)$ \\
\hline \multirow[t]{2}{*}{ Portfolio variable $* 1998$} & -.012 & .125 & -.043 & .209 \\
\hline & $(.008)$ & $(.196)$ & $(.195)$ & $(.206)$ \\
\hline \multirow[t]{2}{*}{ Portfolio variable * 1999} & -.005 & .061 & -.152 & -.017 \\
\hline & $(.003)$ & $(.159)$ & $(.148)$ & $(.154)$ \\
\hline \multirow[t]{2}{*}{ Portfolio variable $* 2000$} & -.002 & .059 & $-.330^{* *}$ & $.425^{* * *}$ \\
\hline & $(.003)$ & $(.151)$ & $(.142)$ & $(.149)$ \\
\hline \multirow[t]{2}{*}{ Portfolio variable $* 2001$} & .001 & .191 & $-.455^{* * *}$ & .144 \\
\hline & $(.003)$ & $(.144)$ & $(.139)$ & $(.144)$ \\
\hline \multirow[t]{2}{*}{ Portfolio variable $* 2002$} & $.006^{*}$ & .024 & $-.363^{* * * *}$ & .054 \\
\hline & $(.004)$ & $(.129)$ & $(.139)$ & $(.128)$ \\
\hline \multirow[t]{2}{*}{ Portfolio variable * 2003} & $.009^{* *}$ & .108 & -.117 & .013 \\
\hline & $(.004)$ & $(.128)$ & $(.141)$ & $(.125)$ \\
\hline \multirow[t]{2}{*}{ Portfolio variable $* 2004$} & .003 & .176 & .022 & -.025 \\
\hline & $(.004)$ & $(.115)$ & $(.137)$ & $(.114)$ \\
\hline \multirow[t]{2}{*}{ Portfolio variable $* 2005$} & -.005 & .075 & -.103 & .12 \\
\hline & $(.004)$ & $(.104)$ & $(.113)$ & $(.101)$ \\
\hline \multirow[t]{2}{*}{ Portfolio internationalization } & $.046^{*}$ & $.043^{*}$ & $.043 *$ & .038 \\
\hline & $(.026)$ & $(.026)$ & $(.026)$ & $(.026)$ \\
\hline \multirow[t]{2}{*}{ Agreements per alliance } & -.019 & -.016 & -.022 & -.020 \\
\hline & $(.025)$ & $(.026)$ & $(.026)$ & $(.026)$ \\
\hline \multirow[t]{2}{*}{$\ln$ (Total assets) } & $-.146^{* * *}$ & $-.149^{* * *}$ & $-.143 * * *$ & $-.148^{* * *}$ \\
\hline & $(.029)$ & $(.029)$ & $(.029)$ & $(.029)$ \\
\hline \multirow[t]{2}{*}{$\mathrm{R} \& \mathrm{D} /$ assets } & .241 & .230 & .190 & .256 \\
\hline & $(.172)$ & $(.172)$ & $(.173)$ & (.173) \\
\hline \multirow[t]{2}{*}{$\ln ($ Tobin's q) } & $-.069 * * *$ & $-.073^{* * *}$ & $-.073^{* * *}$ & $-.078^{* * *}$ \\
\hline & $(.024)$ & $(.024)$ & $(.024)$ & $(.024)$ \\
\hline \multirow[t]{2}{*}{ Cash flow/assets } & $-.386^{* * *}$ & $-.385^{* * * *}$ & $-.373 * * *$ & $-.392^{* * *}$ \\
\hline & $(.086)$ & $(.086)$ & $(.086)$ & $(.086)$ \\
\hline \multirow[t]{2}{*}{ Analyst coverage (D) } & $-.155^{* * *}$ & $-.162^{* * * *}$ & $-.160^{* * * *}$ & $-.165^{* * *}$ \\
\hline & $(.057)$ & $(.057)$ & $(.057)$ & $(.057)$ \\
\hline \multirow[t]{2}{*}{ Young firm (D) } & $.092^{* *}$ & $.085^{* *}$ & $.088^{* *}$ & $.097^{* *}$ \\
\hline & $(.039)$ & $(.039)$ & $(.039)$ & $(.039)$ \\
\hline \multirow[t]{2}{*}{ Constant } & $-.185^{* *}$ & $-.172^{* *}$ & $-.186^{* *}$ & $-.142 *$ \\
\hline & $(.086)$ & $(.086)$ & $(.087)$ & $(.085)$ \\
\hline Time fixed-effects & Yes & Yes & Yes & Yes \\
\hline Firm fixed-effects & Yes & Yes & Yes & Yes \\
\hline 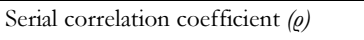 & .373 & .376 & .370 & .376 \\
\hline R-squared & .745 & .745 & .746 & .746 \\
\hline
\end{tabular}

Notes: $\quad * * *(* *, *)$ indicate a significance level of $1 \%(5 \%, 10 \%)$. The sample comprises six two-digit SIC industry classes. Standard errors are corrected for first-order serial correlation. 
Table 5.5 presents the coefficient estimates from these regressions. The reference year is 2006. Column (1) shows that the interaction terms between alliance portfolio size and the year dummies is first negative but moves towards zero in following periods. Thus, during the run-up period to the bubble, the positive effect of alliance portfolio size on firm-specific risk was apparently weaker. The effect turns positive in 2001 and is significant in the years 2002 and 2003. This finding might support the results from Boone and Ivanov (2012), who find that the bankruptcy filing of alliance partners (where bankruptcy is an extreme form of financial distress) affects a focal firm's performance in the two years after the bankruptcy event. In Column (2) we present interaction terms between the year dummies and the share of competitor alliances. Supporting our findings in the above, we find no clear pattern for this variable. Column (3) gives interaction terms for the share of joint ventures. Here, we find that the interactions of this variable with the years 2000 to 2002 are significant and negative. Finally, Column (4) includes the interaction terms between the year dummies and the share of exploratory $\mathrm{R} \& \mathrm{D}$ alliances. Our estimates reveal a strong positive effect in 2000 , which declines gradually in the following years. Figure 5.3 plots the coefficient estimates of the interaction terms.

Figure 5.4: Coefficient estimates alliance portfolios and firm-specific risk

\begin{tabular}{ccc}
\hline Panel (A): Alliance portfolio size & Panel (C): Share of joint ventures \\
\hline & & \\
0.0200 \\
0.0150 \\
0.0100 \\
0.0050 \\
0.0000
\end{tabular}

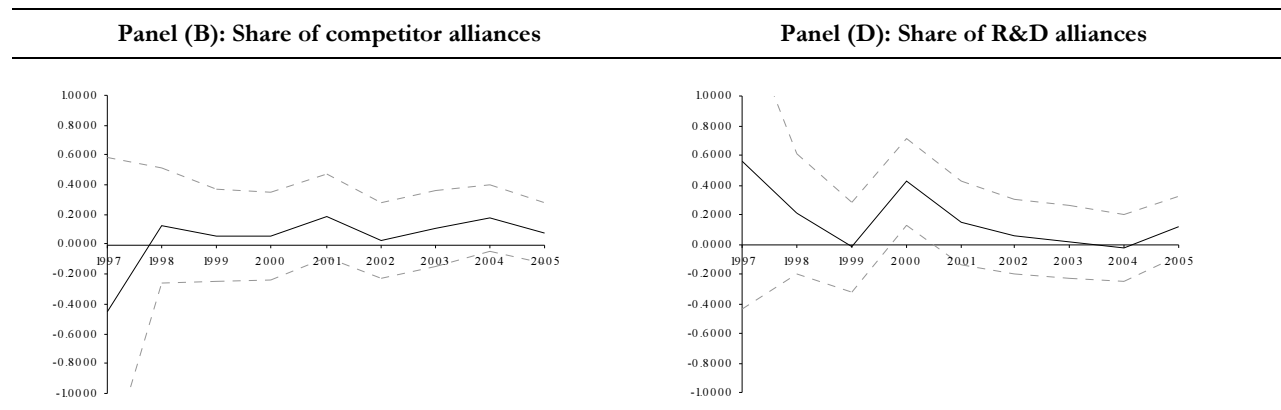

Notes: These figures plot the coefficient estimates and confidence intervals for interaction terms between the four alliance portfolio variables and dummies for the years 1997 to 2005 . The dependent variable is the natural logarithm of firm-specific risk. The dashed lines give $95 \%$ confidence intervals.

5.6.2. Fixing the alliance portfolio variables at their initial conditions

It is possible that our results are affected by changes in firm and alliance portfolio characteristics over time. As an additional robustness test, we hold the alliance portfolio variables constant at their initial values in 1997. Further, we restrict our sample to firms with consecutive 
non-missing data between 1997 and at least 2003 - the first year outside our bubble period. This restricted dataset contains information on 118 firms for which we have a minimum of 7 years of consecutive non-missing data. ${ }^{89}$ We interact the initial alliance portfolio measures with the bubble indicator. As these variables are time invariant and the technology bubble has no cross-sectional variation, these variables cannot be identified when year and firm-fixed effects are included. The coefficients of interest are the interaction terms between the initial alliance portfolio measures and the bubble indicator. These coefficients show how the effects of our initial alliance portfolio measures differ during the bubble period compared to the rest of the sample. Table 5.6 shows the diff-in-diff regression results for all four alliance portfolio measures. These results are broadly consistent with our main findings. Surprisingly, however, the interaction term between the initial share of competitor alliances and the bubble indicator is negative and significant. This finding suggests that the effect of competitor alliances on firm-specific risk has, in fact declined during the bubble period.

\subsubsection{Accounting for the correlation between alliance portfolio size and firm size}

Alliance portfolio size strongly correlates with firm size. Moreover, it might also be important to adjust alliance portfolio size for industry effects (Hagedoorn, 2002). With this in mind, we compute an alternative measure for alliance portfolio size, by extracting the residuals from the following regressions that we run for each year:

$$
\ln (A P S)_{i}=\alpha+\beta_{1} \ln (T A)_{i}+\sum_{j=1}^{J} \delta_{j i}(I N D)_{j i}+\varepsilon_{i},
$$

where APS is alliance portfolio size, TA is the book value of total assets, and IND is a set of industry dummies at the two-digit SIC level. The resulting measure of 'residual alliance portfolio size' is highly correlated with our standard measure of alliance portfolio size (.78) but by construction unrelated to firm size. Appendix 2 plots residual alliance portfolio size against firmspecific risk. In line with our expectations, firm-specific risk increases with residual alliance portfolio size. Nevertheless, the relationship seems to be rather flat at higher levels of residual alliance portfolio size. For values of residual alliance portfolio size above 1.5 - a value above the $95^{\text {th }}$ percentile in our data - the relationship may even become negative. Unreported regressions show that our results are robust to using residual analyst coverage in our analysis. Due to potential non-linearity, we also include a squared term of residual analyst coverage. This variable turns out to be negative and insignificant in our regressions, whereas the linear term does not change.

\subsubsection{Testing for potential biases in the alliance data}

A daunting problem for many studies in the empirical alliance research relates to the availability of reliable alliance data. Researchers have, for instance, reported several biases in the SDC alliance data, which we also use in this study.

\footnotetext{
${ }^{89}$ Appendix 5.1 gives an overview about the firms included in this sample.
} 
Table 5.6: The effects of (initial) alliance portfolios on firm-specific risk

\begin{tabular}{|c|c|c|c|c|}
\hline DV: $\ln ($ Firm-specific risk) & (1) & (2) & (3) & (4) \\
\hline Bubble $^{\mathrm{a} *} \ln (\text { Alliance portfolio size })^{\mathrm{b}}$ & $\begin{array}{l}.051^{* *} \\
(.026)\end{array}$ & - & - & - \\
\hline Bubble $^{a *}$ Share competitor alliances ${ }^{b}$ & - & $\begin{array}{r}-.385^{* *} \\
(.186)\end{array}$ & - & - \\
\hline Bubble $^{\mathrm{a} *}$ Share joint ventures ${ }^{\mathrm{b}}$ & - & - & $\begin{array}{r}-.295^{* * *} \\
(.109)\end{array}$ & - \\
\hline Bubble $^{\mathrm{a}} *$ Share R\&D alliances ${ }^{\mathrm{b}}$ & - & - & - & $\begin{array}{r}.421^{* * *} \\
(.152)\end{array}$ \\
\hline $\ln$ (Total assets) & $\begin{array}{c}-.107^{*} \\
(.060)\end{array}$ & $\begin{array}{c}-.104^{*} \\
(.060)\end{array}$ & $\begin{array}{c}-.116^{*} \\
(.060)\end{array}$ & $\begin{array}{c}-.116^{*} \\
(.060)\end{array}$ \\
\hline $\mathrm{R} \& \mathrm{D} /$ assets & $\begin{array}{r}.473 \\
(.402)\end{array}$ & $\begin{array}{r}.514 \\
(.402)\end{array}$ & $\begin{array}{r}.517 \\
(.401)\end{array}$ & $\begin{array}{r}.631 \\
(.403)\end{array}$ \\
\hline $\ln ($ Tobin's q) & $\begin{array}{r}-.122^{* *} \\
(.049)\end{array}$ & $\begin{array}{r}-.119 \text { ** } \\
(.049)\end{array}$ & $\begin{array}{r}-.110^{* *} \\
(.049)\end{array}$ & $\begin{array}{r}-.117^{* *} \\
(.049)\end{array}$ \\
\hline Cash flow/assets & $\begin{array}{r}-.548^{* *} \\
(.242)\end{array}$ & $\begin{array}{r}-.548^{* *} \\
(.242)\end{array}$ & $\begin{array}{r}-.565^{* *} \\
(.242)\end{array}$ & $\begin{array}{r}-.583^{* *} \\
(.242)\end{array}$ \\
\hline Young firm (D) & $\begin{array}{r}.103 \\
(.080)\end{array}$ & $\begin{array}{r}.101 \\
(.080)\end{array}$ & $\begin{array}{r}.095 \\
(.079)\end{array}$ & $\begin{array}{r}.097 \\
(.079)\end{array}$ \\
\hline Constant & $\begin{array}{r}-.014 \\
(.217) \\
\end{array}$ & $\begin{array}{r}-.059 \\
(.218) \\
\end{array}$ & $\begin{array}{r}-.078 \\
(.217) \\
\end{array}$ & $\begin{array}{r}-.089 \\
(.217) \\
\end{array}$ \\
\hline Time fixed-effects & Yes & Yes & Yes & Yes \\
\hline Firm fixed-effects & Yes & Yes & Yes & Yes \\
\hline \# of observations & 965 & 965 & 965 & 965 \\
\hline \# of firms & 118 & 118 & 118 & 118 \\
\hline Serial correlation coefficient $(\varrho)$ & .413 & .415 & .415 & .414 \\
\hline R-squared & .670 & .670 & .671 & .671 \\
\hline
\end{tabular}

Notes: ${ }^{* *}(* *, *)$ indicate a significance level of $1 \%(5 \%, 10 \%)$. All firms are observed in 1997 and have complete consecutive data until at least 2003. The dependent variable is the natural logarithm of firm-specific risk, which we obtain from annual Fama-French (1993) three-factor models. Year dummies are excluded for space reasons. Standard errors are corrected for first-order serial correlation. Note that all firms in this sub-sample have analyst coverage. Hence we drop the analyst coverage dummy from the regressions.

a The Bubble indicator is a dummy variable for the post-bubble period 2000 to 2002. Since the models include year fixed-effects, this variable is not uniquely identified and thus dropped from the regressions.

${ }^{\mathrm{b}}$ For this analysis, the alliance portfolio measures are held constant at their initial conditions in 1997. As these variables do not vary over time, they cannot be identified.

Kale, Dyer, and Singh (2002) discuss three main biases of this data. First, SDC does not cover the entire universe of alliances, as firms may not always disclose their alliances publicly. Second, the database reports alliance announcements rather than 'real' alliances. However, some of the alliances that are reported by SDC never have surpassed the announcement stage, so that cooperation between firms never occurred. Likewise, some firms may announce to form alliances but never really commit to them. Such problems are not unique to the SDC database. Schilling (2009) shows that in fact none of the existing alliance databases is complete. Further, the overlap between the existing databases tends to be rather low. The results of empirical work on alliances - including our own - are therefore potentially affected by the noisiness of the underlying alliance data. 
Schilling (2009) points out that one way to assess the robustness of empirical alliance research is to replicate analyses based on alternative alliance databases. This is what we do in the following. For this purpose, we take a subset of alliances from the MERIT-CATI database, which is maintained at Maastricht University (for details on this database see Hagedoorn, 2002). One major difference between the SDC Platinum database and the CATI database is the focus of the latter on R\&D agreements. This specialization essentially limits the applicability of the CATI data to hypotheses 4 and 8 in the context of our study.

We first briefly compare the content of the two databases. Unfortunately, the datasets differ substantially in their structure. This makes it nearly impossible to write an algorithm to match the content of these databases automatically. To keep the workload manageable, we focus on a subset of 2,615 information technology alliances reported in CATI between1995 and 2006. The information technology sector includes computers, telecom, semiconductors, industrial automation, and software (Hagedoorn, 2002). We manually compare the alliances in CATI to those reported by SDC. We are able to identify roughly 14\% (357 alliances) of the CATI alliances in the SDC data..$^{90}$ Regarding the 696 firms in our main sample, $498 \mathrm{R} \& \mathrm{D}$ alliances are reported in the CATI database but do not occur in SDC. ${ }^{11}$ This number would probably be much larger if our CATI data would also include alliances from the pharmaceutical sector. However, our experiment shows that the alliance data that we use in this study is clearly incomplete.

The question remains whether the noisiness of the alliance data represents a problem for empirical work on alliances. Schilling (2009) argues that this might not necessarily be the case. She finds that most alliance databases follow roughly similar patterns and yield comparable results in empirical applications. We follow her lead and reconstruct our dataset using only the CATI data. Otherwise, we follow the same methodology as described above for constructing our sample. Because the starting point for building our dataset is now the universe of firms that are included in CATI - which only reports R\&D agreements - our sample is smaller compared to that used in our main analysis. The CATI-sample comprises 838 observations related to 138 firms for which we have at least three years of consecutive non-missing data. On average, the firms in this sample have about six R\&D alliances with a median of two. Our theory predicts a negative effect of R\&D alliance portfolio size on firm specific risk. Further, the interaction term between this variable and the bubble indicator should be positive. We present fixed-effects regressions in table 5.7. The results broadly support our expectations and provide further confidence for our results.

\subsection{Discussion and conclusion}

The argument that alliances are inherently risky and instable is not new. In fact, many papers have found evidence for the instability of alliances (Reuer and Zollo, 2005) and for high termination rates (Makino et al., 2007; Reuer et al., 2002). However, few studies analyze how alliances affect firm-specific risk as perceived by stock market investors. The few empirical

\footnotetext{
90 This number is substantially smaller compared to the finding of Schilling (2007) who finds $26 \%$ of a random sample of alliances from the MERIT-CATI database in the SDC data.

${ }^{91}$ It is not clear how these differences in the two databases arise. Note, however, that the alliances that are reported in CATI but not in SDC often involve large European firms such as Erickson, France Telecom; Nokia, or STMicroelectronics. This finding is consistent with Schilling (2007), who shows that the two databases differ in their geographic scope.
} 
studies that exist suggest that alliances have an effect on firm-specific risk, even though the direction of this effect may differ according to alliance characteristics. For instance, these studies suggest the effects of joint ventures on firm-specific risk are different compared to contractual agreements (Arend, 2004). Similarly, the effects of commercial alliances on firm-specific risk are probably different from the effects of R\&D alliances (Das et al., 1998).

Table 5.7: Using the MERIT-CATI database to construct R\&D alliance portfolio size

\begin{tabular}{|c|c|c|}
\hline DV: $\ln$ (Firm-specific risk) & (1) & (2) \\
\hline \multirow[t]{2}{*}{$\ln (\mathrm{R} \& \mathrm{D}$ alliance portfolio size $)$} & $-.144 * *$ & $-.152 * *$ \\
\hline & $(.073)$ & $(.072)$ \\
\hline \multirow[t]{2}{*}{ Bubble $^{\mathrm{a} *} \ln (\mathrm{R} \& \mathrm{D}$ alliance portfolio size $)$} & - & $.040^{*}$ \\
\hline & & $(.023)$ \\
\hline \multirow[t]{2}{*}{$\ln$ (Total assets) } & $-.283^{* * *}$ & $-.278^{* * *}$ \\
\hline & $(.055)$ & $(.055)$ \\
\hline \multirow[t]{2}{*}{$\mathrm{R} \& \mathrm{D} /$ assets } & -.039 & -.015 \\
\hline & $(.371)$ & $(.370)$ \\
\hline \multirow[t]{2}{*}{$\ln ($ Tobin's q) } & $-.582^{* * *}$ & $-.578^{* * *}$ \\
\hline & (.196) & $(.196)$ \\
\hline \multirow[t]{2}{*}{ Cash flow/assets } & $-.085^{*}$ & $-.084^{*}$ \\
\hline & $(.046)$ & $(.046)$ \\
\hline \multirow[t]{2}{*}{ Analyst coverage (D) } & -.085 & -.089 \\
\hline & $(.102)$ & $(.101)$ \\
\hline \multirow[t]{2}{*}{ Young firm (D) } & -.028 & -.026 \\
\hline & $(.079)$ & $(.079)$ \\
\hline \multirow[t]{2}{*}{ Constant } & $-4.775^{* * *}$ & $-4.799 * * *$ \\
\hline & $(.431)$ & $(.432)$ \\
\hline Time fixed-effects & Yes & Yes \\
\hline Firm fixed-effects & Yes & Yes \\
\hline \# of observations & 838 & 838 \\
\hline \# of firms & 130 & 130 \\
\hline R-squared & .712 & .713 \\
\hline
\end{tabular}

Notes: $* * *(* *, *)$ indicate a significance level of $1 \%(5 \%, 10 \%)$. The sample comprises six two-digit SIC industry classes. The dependent variable is the natural logarithm of firm-specific risk, which we obtain from annual Fama-French (1993) three-factor models. Year dummies are excluded for space reasons. Standard errors are corrected for first-order serial correlation.

a The Bubble indicator is a dummy variable for the post-bubble period 2000 to 2002. Since the models include year fixed-effects, this variable is not uniquely identified and thus dropped from the regressions.

A first goal of this paper is to validate these existing findings based on a large sample of firms from various medium- and high tech industries. We argue that it is useful in this context to shift the unit of analysis to the level of the firm and its alliance portfolio, which comprises the total number of direct alliance ties in which a firm is active at a given point in time. The alliance portfolio perspective has become increasingly popular in recent alliance research, in particular because researchers start to understand that there are important interdependencies among the individual alliances that a firm maintains simultaneously at a certain point in time. In other words, it is not adequate to model alliances as separate discrete events (Hoffmann, 2007; Lavie, 2007; Wassmer and Dussauge, 2011). In this study, an alliance portfolio perspective is taken because with the relevance of alliances for a firm's overall competitive strategy most likely increases with the number of alliances that a firm operates at a given point in time. Further, important 
interdependencies exist in alliance portfolios, which may affect the riskiness of a firm's overall alliance strategy.

Our empirical findings are broadly consistent with our expectations. Further, they also help to reconcile a paradox in the alliance literature (Bamford et al., 2003). On the one hand several researchers posit that firms build large alliance portfolios to hedge the risk related to each individual alliance (George et al., 2001). Others argue that an important motive for the formation of technology alliances is the sharing of the risk and uncertainty of new technology development (Hagedoorn, 1993). In other words, these studies suggest a negative effect of alliance portfolios on firm-specific risk. On the other hand, it is typically argued in the literature that alliances are inherently risky and that unintended terminations are frequent (Das and Teng, 1998; Makino et al., 2007). These latter studies point towards a positive effect of alliances on firm-specific risk. Consistent with prior literature (Das et al., 1998), our study suggests that one way to reconcile this paradox is to separate alliances according to their purpose. Thus, we find that portfolios of exploratory $R \& D$ alliances have a negative effect on firm-specific risk, whereas the effect of exploitative commercial alliances is positive. In line with Arend (2004) we also find that it is important to differentiate alliances with respect to their governance structures. Joint ventures appear to be less risky than contractual agreements.

The most important contribution of this study is our finding that the effects of alliance portfolios and alliance portfolio characteristics on firm-specific risk are not stable over time. We use the burst of the technology bubble in 2000 as a natural experiment. We argue that this event lead to an increase in environmental uncertainty, which had an immediate impact on the operations of many high tech firms (e.g., on their costs of external financing, the likelihood of experiencing financial distress, or the likelihood of bankruptcy). Our main prediction is that this shock to environmental uncertainty alters the effects of alliance portfolios on firm-specific risk, either because environmental uncertainty affects the likelihood of opportunistic behavior (Luo, 2007; Williamson, 1991) or because environmental uncertainty increases the probability that a firm's alliance partners face financial distress (Boone and Ivanov, 2012).

Our empirical findings strongly support this basic prediction. The positive effect of alliance portfolio size on firm-specific risk increases significantly in the two years after the burst of the technology bubble. In contrast, the negative effect of joint ventures - which is also reported by Arend (2004) - seems to be entirely driven by the particularities of the post-bubble period. Thus, we find strong negative effects of the share of joint ventures on firm-specific risk in the three years from 2000 to 2002. This finding seems to support the predictions of transaction cost economists, who argue that the hierarchical elements and governance mechanisms that joint ventures provide become particularly relevant in times of influential disturbances in the environment (Williamson, 1991). Finally, we find that the negative effect of exploratory R\&D alliances on firm-specific risk becomes significantly more positive in the immediate post-bubble period. This finding also holds in an alternative sample based on the MERIT-CATI alliance database.

Even though our empirical findings are very robust, this study is certainly not without limitations. The most important limitation relates to our alliance data. Whereas we try to validate some of our results by using data form two different alliance databases, we are not able to solve all problems that are inherent in the alliance data. In particular the fact that we do not observe the termination dates of the alliances in our sample creates a bias in our alliance portfolio measures. There is unfortunately little we can do about this. Most firms do not announce the 
termination of their alliances publicly. Further, the large number of alliances that we used for constructing the portfolio measures makes it impractical to search termination dates in industry reports, trade journals, or related publications even if this data would be reported. The best that we can do is therefore to make an informed guess about the duration of the alliances in our sample. Similar simplifying assumptions have been made by other researchers (Boone and Ivanov, 2012; Schilling and Phelps, 2007; Stuart, 2000).

One important aspect that we have not touched upon in this paper concerns the potential effect of alliance experience on firm-specific risk. In particular, a broad stream of literature suggests that firms learn how to form and manage alliances through prior experience (Anand and Khanna, 2000a; Gulati, 1995). Firms might also develop high levels of trust through repeated collaborations with a specific firm. The development of trust might serve as a mechanism, through which firms can limit the threat of opportunistic behavior of alliance partners (Gulati, 1995; Nooteboom et al., 1997; Zaheer et al., 1998). Consequently, our theory would predict that trust reduces the positive effect of alliances on firm-specific risk. Further, recent research suggests that value creation and risk in alliances and alliance portfolios depend not only on alliance characteristics, but also on the characteristics of the partnering firms (Kumar, 2010; Lavie, 2007; Stuart, 2000). We do not address these two questions in this study. However, we do believe that these are promising areas for future research. Future research may also test whether the findings that we describe in this paper are transferable to other uncertainty shocks, such as the recent banking crisis.

Finally, we argue throughout this paper that the moderating effect of shocks in environmental uncertainty on firm-specific risk may occur for two reasons. First, such shocks may increase the likelihood that partners act opportunistically; second they should increase the likelihood that alliance partners face financial distress or bankruptcy. If an external shock hits a firm that is part of an alliance network the adverse effects that the shock has on this particular firm may spread by contagion to other members of the network. It is difficult to assess which of these explanations drives our results. In fact, it is possible that both mechanisms operate simultaneously. Much more fine-grained data at the transaction level is needed for understanding the intricacies of this question. 


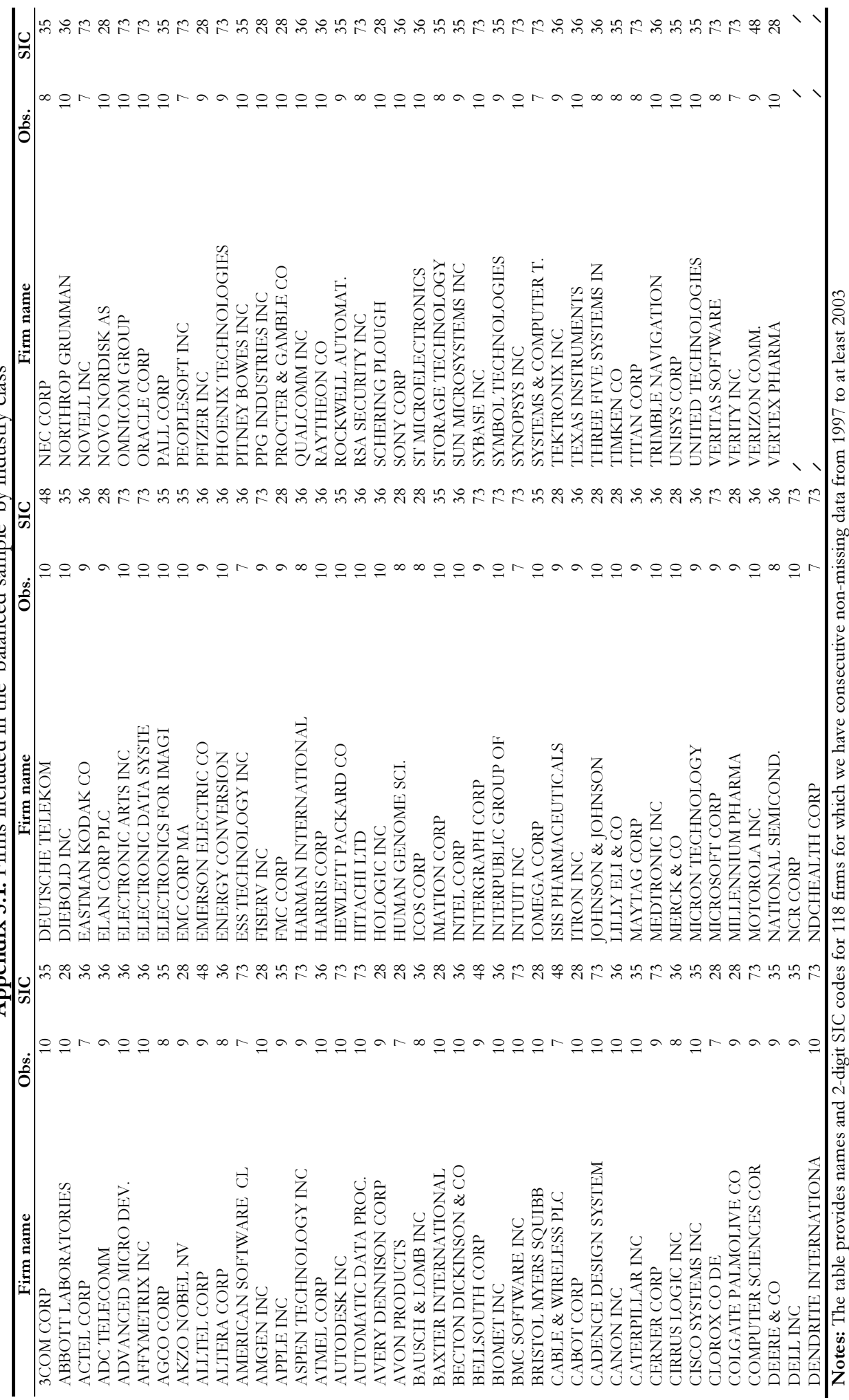


Appendix 5.2: Residual alliance portfolio size and firm-specific risk

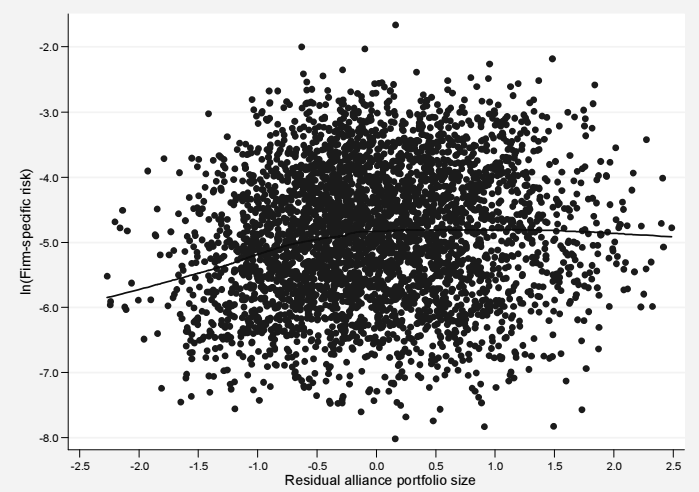

Notes: This figure plots the values for residual alliance portfolio size against the natural logarithm of firm-specific risk. The solid line shows locally weighted regression of $\ln$ (firm-specific risk) on residual alliance portfolio size obtained by the 'lowess' command in STATA 


\section{Chapter 6}

\section{Discussion and Conclusion}

\subsection{Summary of main findings}

This dissertation started from the observation that the nature of the firm has changed in recent decades. Two of these changes are of particular importance in the context. First, the way that firms obtain a competitive advantage over their competitors has probably changed over time. Unique physical and financial assets used to be the main source of sustained competitive advantage for the industrial enterprise that emerged in the last quarter of the $19^{\text {th }}$ century. For the modern enterprise, the importance of physical assets has tended to decline, whereas the importance of intangible assets - especially the importance of knowledge - has increased (Brown et al., 2009; Rajan and Zingales, 2000). Firms can only benefit from knowledge when this knowledge is specialized (see Demsetz, 1988). Among other factors, specialization in knowledge has lead to a disintegration of the industrial enterprise. The modern enterprise is much more focused on a rather narrow set of core competencies. Second, loose forms of interfirm cooperation and alliances have regained importance and have become a popular alternative to vertical integration. Alliances also enable firms to manage the increasing risks and costs associated with innovation and rapid technological change.

In this dissertation, I posit that not only the nature of the firm has changed but also the ways in which firms interact with their environment. For instance, the industrial enterprise primarily used internal equity for the financing of $\mathrm{R} \& \mathrm{D}$ projects, because the high uncertainty about $\mathrm{R} \& \mathrm{D}$ outcomes and potentially severe information asymmetries made it costly to finance $R \& D$ through external sources. In contrast, the modern enterprise may have become more likely to use external equity financing for the financing of R\&D (Brown et al., 2009; Brown and Petersen, 2009). Few studies examine the contextual factors at the firm-level that influence the stock market valuation of $R \& D$ assets and firms' abilities to use the stock market for $R \& D$ financing. Moreover, few - if any - empirical studies investigate the relationship between alliances and firmspecific risk, even though the management of risk is among the more important motivations for the formation of alliances (Hagedoorn, 1993).

The position of this dissertation is that $\mathrm{R} \& \mathrm{D}$ investments differ from other investments primarily through the amount of uncertainty surrounding future returns. It seeks answers to some of the following questions: Can firms influence the degree to which stock market participants perceive R\&D assets to be uncertain? Do differences in firm-level uncertainty matter for understanding the stock market valuation of $R \& D$ assets ( $R \& D$ spending and $R \& D$ alliances)? What is the role of alliances and alliance portfolios in managing investor perceptions of risk and 
uncertainty? Against this background, the aim of this dissertation was to provide answers for the following research questions:

- All else equal, do investors perceive the future returns of $R \& D$ intensive firms to be more uncertain compared to less $\mathrm{R} \& \mathrm{D}$ intensive firms?

- (How) can firms influence the extent to which investors perceive the returns to their R\&D projects as uncertain?

- How do investor perceptions of uncertainty affect (1) the stock market value of a firm's knowledge capital, and (2) a firm's ability to use the stock market for R\&D financing?

- Do alliance portfolios contribute to a firm's knowledge capital as measured by the stock market?

- Do investor perceptions of uncertainty moderate the relationship between alliance portfolios and the stock market value of firms?

- What is the relationship between alliances and investors' perceptions of firm-specific risk?

Each of the four empirical studies in this dissertation provides novel insights to one or more of these research questions. In chapter 2, I investigated whether and how R\&D investments which I measured as the ratio of a firm's R\&D stock to assets - affect the dispersion in sell-side analysts' earnings forecasts, which is a measure for the 'true' uncertainty surrounding a firm's future economic performance (research question I). Based on a panel of 299 manufacturing firms listed at the New York Stock exchange and the Nasdaq between 1997 and 2006, the study found a positive effect of $\mathrm{R} \& \mathrm{D}$ intensity on forecast dispersion. The paper also examined the effects of patents on firm-level uncertainty. I argued that patents might provide information about the quality of a firm's R\&D projects and should therefore reduce stock market participants' perceptions of uncertainty (research question II). Indeed, the empirical results revealed that patents reduced the positive effect of $R \& D$ on analyst forecast dispersion. This effect seems to be limited to patents of high quality, as measured by the number of forward citations, non-patent references, the number of claims, whether or not the patent was part of triadic patent family, and whether or not the patent has been renewed. Finally, chapter 2 documented a negative effect of forecast dispersion on the stock market value of $\mathrm{R} \& \mathrm{D}$, but not on the stock market value of patents (research question III). A potential reason could be that investors discount the future returns to $R \& D$ at a higher rate, because the returns to these investments are highly uncertain. Patents, in turn, are may be a measure for (intermediate) innovation outputs. As the information in patents is more certain there I do not find evidence for an uncertainty or ambiguity discount (Epstein and Schneider, 2008) for patents.

Chapter 3 examined the effects of forecast dispersion on corporate investment (research question III). Recent studies on this topic have yielded largely inconclusive results (Bakke and Whited, 2001; Gilchrist et al., 2005; Lyandres, 2007; Thakor and Whited, 2011). While some of the previous studies assume that forecast dispersion is a measure of costly external financing, others argue that forecast dispersion is a measure for the overvaluation of a firm's stock price. I drew from two seminal papers by Miller (1977) and Merton (1986) and argued that the 
relationship between forecast dispersion and a firm's cost of external financing is likely to be more complex.

Whether forecast dispersion leads to an over- or undervaluation of stock prices depends on the specific type of investment and on the amount of investor recognition to which a stock is exposed. I defined investor recognition as the residual from a regression of analyst coverage on firm size. Using a large panel of US manufacturing firms that were publicly traded between 1983 and 2006, I found a positive effect of forecast dispersion on corporate investment (i.e. the sum of R\&D and physical investment) but only for firms with high investor recognition. Auxiliary regressions revealed that this positive effect only held for R\&D but not for physical investment.

Chapter 3 also examined how firms' preferences for different types of financing changed in response to changes forecast dispersion. I found a positive and significant interaction term between forecast dispersion and a proxy for the issuance of new stock (the net cash from new stock issues). Again, this effect was entirely explained by changes in R\&D investment and only held for firms with high investor recognition. These findings may suggest that market participants overvalue the returns to firms' R\&D projects. Firms seem to issue new equity to exploit the overvaluation of stock prices.

These results differed quite dramatically for firms in the bottom quartile of investor recognition. For these firms, the study documented an overall negative effect of forecast dispersion on corporate investment. Interestingly, this effect was only driven by physical and not by $R \& D$. This latter finding might suggest that R\&D is more costly to adjust and firms do not alter R\&D expenditures in response to increases in the costs of external financing. Additional analyses using dynamic panel estimators revealed that the interaction effect between R\&D and new stock issuance was negative. Financially less visible firms were thus less likely to use external equity for the financing of $R \& D$ when forecast dispersion was high. Overall, the results of this chapter were consistent with the claim of Lazonick (2006), that there are certain types of firms who might be able to use the stock market for R\&D financing. These seem to be highly visible firms with strong (but uncertain) growth opportunities.

Chapter 4 and 5 examined stock market participants' perceptions about alliance portfolios. In chapter 4, I employed the hedonic regression approach (Griliches, 1981, 1990; Hall, 1990; Hall et al., 2005) to assess the market value of firms' alliance portfolios (research question III and V). The study found a positive effect of exploratory alliance portfolios on the stock market value of firms. The market value of exploratory alliance portfolios was found to be increasing with measures of firm-specific risk or uncertainty. These results are consistent with the view that exploratory R\&D alliances provide signals to market participants about the quality of a firm's knowledge assets. These signals become more valuable as firm-specific risk and uncertainty increase.

Chapter 5 explored the relationship between alliance portfolios and firm-specific risk (research question VI). I argued that alliance portfolios can affect firm-specific risk in at least two ways. On the one hand alliances enable firms to manage business risk and the high costs of R\&D. This suggests a positive relationship between alliances and firm-specific risk. On the other hand alliances are inherently risky due to factors inherent in this organizational form. In theory, alliance portfolios may therefore increase or decrease firm-specific risk. Others have referred to the relationship between alliances and risk as an 'unpleasant paradox' in the literature (Bamford et al., 2003: 36). To manage their business risks, firms engage in organizational forms which are inherently risk themselves. The results of chapter 5 portrayed a complex relationship between alliance portfolios and firm specific risk. Whereas firms with larger alliance portfolios seemed to 
face higher idiosyncratic risk, the study found negative effects of the share of joint ventures and of the share of exploratory R\&D alliances in firms' alliance portfolios on firm-specific risk. Interestingly, the study also found evidence that the riskiness of alliance portfolios increased substantially in the aftermath of the burst of the technology bubble in March 2000. This finding might imply that alliance portfolios are a conduit through which risk can spread among firms.

\subsection{Implications}

This dissertation has several implications for researchers and for managers interested in the relationship between innovation, interfirm cooperations, and the stock market. For researchers, this dissertation suggests to be more open and responsive towards other disciplines. Researchers in the field of financial economics and innovation economics have, for instance, developed approaches to study the market value of knowledge or the effects of financing constraints on corporate (R\&D) investment (Brown et al., 2009; Griliches, 1981, 1990; Hall et al., 2005; Himmelberg and Petersen, 1994). Yet, it is astonishing to me, how limited the interest in interfirm alliances in these disciplines actually is. In his comment on Hall (1993b: 331), Edwin Mansfield points exactly towards this 'blind spot' in the literature on the stock market valuation of knowledge assets. He states that in recent decades“... increased reliance has been put on cooperative $\mathrm{R} \& \mathrm{D}$ and strategic alliances, which also have tended to reduce the significance of the size of individual firms' R\&D expenditures." Recognizing the importance of alliances would certainly open a variety of new questions for researchers in the above mentioned disciplines. However, the same kind of ignorance seems to exist in much of the alliance research. For instance, there are well established models to study the stock market valuation of knowledge assets or intangibles. However, researchers interested in the stock market valuation of alliances and alliance portfolios often use rather ad hoc research designs, which makes it difficult to compare the results of this literature with the findings that have been made in related disciplines.

The results of this dissertation further indicate that firms are able to influence market participants' perceptions regarding the value of $R \& D$ and alliances. Chapter 2 showed that certain characteristics of patents can reduce market participants' perceptions of uncertainty about the outcomes of R\&D. Firms might use patents and exploratory alliances as signals about the quality of their R\&D projects (see e.g., Long, 2002; Gulati, 2000). The fact that perceptions of uncertainty (forecast dispersion) have a negative effect on stock market valuation of $R \& D$ suggests that firms might benefit from additional disclosure about these activities (Aboody and Lev, 2000; Johnson, 2004). Interestingly, the patent system might be an alternative to voluntary disclosure about R\&D, which some researchers would like to see extended (Lev, 2001).

Compared to voluntary disclosure, patents have the advantage that they receive at least some 'external validation' through patent examiners. Further, in contrast to voluntary disclosure, patent protection is costly to establish and to maintain. Due to these reasons, the information entailed in patents might be more credible compared to voluntary disclosed information about R\&D.

Finally, it seems that a firm's ability to use the stock market for $R \& D$ financing depends crucially on the extent to which a firm is able to create investor recognition. When investor recognition is high, the forecast dispersion or disagreement among stock market participants might be an indicator of 'buzz' or an atmosphere of excitement in the stock markets. It seems that such excitement is due to the future growth opportunities that $\mathrm{R} \& \mathrm{D}$ investments may create but also due to the inherent uncertainty of R\&D. Firms may use these periods of excitement to 
issue equity - an option that firms with low investor recognition do not have. It is not clear what these developments mean from a social perspective and this question is also beyond the scope of this dissertation.

\subsection{Limitations and suggestions for future research}

A problem potentially affecting all studies in this dissertation is that of unobserved heterogeneity and/or omitted variables that influence the dependent variable as well as one or more independent variables. In chapter 2 it might be possible that certain unobserved firmattributes influence the nature of a firm's patent portfolios. It is possible that such omitted variables - such as managerial quality - rather than high quality patents per se affect analyst forecast dispersion. The relationship between alliance portfolios and a firm's stock market, which I investigate in chapter 4, may be subject to similar concerns. If such omitted variables are constant over time, standard fixed-effects estimators may suffice to eliminate these concerns. In this dissertation, as with so many studies in the field of innovation research, the use of fixedeffects estimators is a two-sided sword, however. Most of the key variables employed in the individual papers do not vary too much within firms over time. Due to the within-transformation of the fixed-effects estimator, which subtracts the within firm-sample mean of each variable, fixed-effects estimates tend to be imprecise and unstable when there is little variation in the timeseries. The use of standard fixed-effects estimators is further complicated by the presence of serial correlation in the residuals. In essence, serial correlation can lead to biased standard errors and inefficient estimates. The best I can do about these concerns is to be careful in selecting the right estimator for each study. Where possible, I used pre-sample information to control for unobserved heterogeneity across firms. I also used panel GMM-estimators that account for the potential endogeneity of variables. In almost all studies, my results hold across a variety of estimators and are very robust, which is - as I believe - a comforting sign.

A further limitation concerns the relationship between analyst forecast and the timing of the returns to innovation. Most of the analyst forecast data available in $\mathrm{I} / \mathrm{B} / \mathrm{E} / \mathrm{S}$ are one-year-ahead earnings forecasts. Whereas longer-term forecasts, such as three or five-year earnings forecasts are available for some firms, using this type of data causes a quite dramatic drop in sample size. For this reason I used the one-year-ahead earnings forecasts in chapters 2, 3, and 4. This choice might be problematic, as the outcomes of $R \& D$ investments but also those of $R \& D$ alliances typically take several years to materialize. Current year investments in $R \& D$ projects should therefore not affect one-year-ahead earnings forecasts. While this concern might be quite relevant - especially in chapter 2 - this view also neglects the cumulative nature of R\&D projects in specific and technological developments in general (see Lazonick, 2007). It is unlikely that a firm's $R \& D$ expenditures in year $t$ are unrelated to those in year $t-2, t-3$, etc. R\&D expenditures are investments into a knowledge stock. This knowledge stock takes time to accumulate. I used data on $\mathrm{R} \& \mathrm{D}$ stocks rather than $\mathrm{R} \& \mathrm{D}$ flow to account for the cumulative nature of technology development. These stock measures should provide a roughly adequate measure for the overall $\mathrm{R} \& \mathrm{D}$ intensity of a firm. However, the set-up of my study makes it difficult to interpret the results as changes within firms over time and is more consistent with differences between firms. Future research should study whether within-firm changes in $\mathrm{R} \& \mathrm{D}$ and patents over time cause within-firm changes in market participants' perceptions of uncertainty. 
Another potential limitation relates to the selection of the sample. All studies employ data from a rather selective set of high tech firms, which are all listed at major US stock exchanges. Most chapters employ data from a relatively short time period (10 years), which includes a major disruption in the form of the burst of the technology bubble. Only chapter 3 uses data for a longer time period (1983 to 2006). In three studies I require firms to be covered by financial analysts, which biases my sample towards larger firms. Due to these limitations of the data, it would be interesting to see whether the results of this dissertation hold in different settings, e.g., different countries, or different time periods. Is the overvaluation effect of $\mathrm{R} \& \mathrm{D}$, for which chapter 3 provides some evidence, unique to the US?

There are other questions, which clearly require a longer panel of firms. For instance, has the effect of patents on analyst forecast dispersion changed over time or around certain events or legislative changes? In chapter 5, I found that alliance portfolios became more risky in the aftermath of the burst of the technology bubble. Can we observe similar patterns in the aftermath of other crises, such as the more recent banking crisis? One of the most interesting questions to study in future research is how external shocks affect alliance networks.

In more general terms, future research should spend more effort on examining the risks inherent in cooperative strategies. There are some studies like Afuah (2000), Boone and Ivanov, 2012, or Mitchell and Singh (1996) which study the effects of an alliance partner's failure on a focal firm's performance. However, compared to the literature examining the benefits of alliances and networks, this is a very small and disconnected field of research.

Finally, an assumption I made in this dissertation is that increasing R\&D and the trend towards alliances are caused by similar forces. However, I mostly do not explore the interactions that may exist between $\mathrm{R} \& \mathrm{D}$ and alliances. For instance, chapter 4 examines whether $\mathrm{R} \& \mathrm{D}$ alliances contribute to a firm's knowledge stock as measured by a firm's stock market value. Even though this hypothesis is supported, I do not further investigate potential interactions between $\mathrm{R} \& \mathrm{D}$ and alliances. In chapters 4 and 5 , I posit that R\&D alliances might be positive signals about the quality of a firm's R\&D projects. This was also suggested by Stuart (2000). Future research might therefore examine the interactions between $R \& D$ alliances and corporate $R \& D$ spending, both in a market value context and in an investment setting. ${ }^{92}$ On the one hand, one may ask whether firms can use strategic alliances as a means to alleviate financing constraints in a setting equal to chapter 3 . On the other hand, $R \& D$ alliances seem to mitigate investors' perceived uncertainty about $R \& D$ outcomes. Hence, $R \& D$ alliances might positively moderate the relationship between $R \& D$ and a firm's stock market value.

\footnotetext{
${ }^{92}$ Preliminary analyses indeed suggest that this interaction effect is positive.
} 


\section{Nederlandse samenvatting}

In het begin van dit proefschrift is geobserveerd dat het karakter van bedrijven in de laatste decennia is veranderd. Twee van deze veranderingen zijn van specifiek belang in deze context. Een eerste mogelijke verandering is de manier waarop bedrijven concurrentievoordeel behalen ten opzichte van hun concurrenten. Voor de industriële onderneming die ontstond in het laatste kwart van de 19e eeuw waren unieke materiële en financiele activa de belangrijkste bron van duurzaam concurrentievoordeel. Voor de moderne onderneming echter, is het belang van materiële activa gedaald, terwijl het belang van immateriele activa - voornamelijk het belang van kennis - is toegenomen (Brown et al., 2009; Rajan en Zingales, 2000). Bedrijven kunnen slechts dan van kennis profiteren wanneer deze kennis is gespecialiseerd (zie Demsetz, 1988). Naast andere factoren, heeft de specialisatie van kennis geleid tot de disintegratie van de industriële onderneming. De moderne onderneming is meer gericht op een kleine groep van kerncompetenties. Een tweede verandering in de aard van bedrijven, is dat losse vormen van samenwerken en allianties tussen bedrijven belangrijker zijn geworden en zijn uitgegroeid tot een populair alternatief voor verticale integratie. Allianties stellen ondernemingen ook in staat om de toenemende risico's en kosten die verband houden met innovatie en snelle technologische veranderingen te beperken.

In dit proefschrift stel ik dat niet alleen het karakter van bedrijven is veranderd, maar ook de manier waarop bedrijven omgaan met hun omgeving. Bijvoorbeeld, de industriële onderneming maakte voornamelijk gebruik van intern eigen vermogen om R\&D projecten te financieren, omdat de grote onzekerheid over de resultaten en de mogelijke ernstige asymmetrische informatie, financiering door externe bronnen duur maakte. Daarentegen is het voor de moderne onderneming eenvoudiger geworden om voor de financiering van $R \& D$ gebruik te maken van externe bronnen (Brown et al., 2009; Brown en Petersen, 2009). Er zijn slechts enige studies die de contextuele factoren in bedrijven onderzoeken die de beurswaarde van R\&D activa en de mogelijkheden van de bedrijven om de beurs te gebruiken voor het financieren van R\&D beïnvloeden. Bovendien, zijn er weinig -misschien wel geen - emprisische studies die de relatie tussen allianties en bedrijfsspecifiek risico onderzoeken, ondanks dat het beheer van risico's een van de belangrijkste drijfveren is voor de vorming van allianties (Hagedoorn, 1993).

De stelling van dit proefschrift is dat $R \& D$ investeringen voornamelijk verschillen van andere investeringen in de mate van onzekerheid wat betreft het toekomstige rendement. Het antwoord op een aantal van de volgende vragen wordt gezocht: Kunnen bedrijven de mate van onzekerheid van $\mathrm{R} \& \mathrm{D}$ activa die deelnemers van de aandelenmarkt ervaren, beïnvloeden? Zijn verschillen in bedrijfsspecifieke onzekerheid van belang bij het begrijpen van de beurswaarde van $R \& D$ activa (R\&D uitgaven en R\&D allianties)? Wat is de rol van allianties en alliantie portfolio's bij het managen van de perceptie van risico en onzekerheid van de investeerder? Met dit als basis, is het doel van dit proefschrift het beantwoorden van de volgende onderzoeksvragen:

- Vinden investeerders, ceteris paribus, de toekomstige rendementen van R\&D intensieve bedrijven onzekerder ten opzichte van bedrijven die minder R\&D intensief zijn?

- Kunnen bedrijven de mate waarin investeerders het rendement van de R\&D projecten als onzeker ervaren, beïnvloeden. Zo ja, hoe? 
- Hoe kan de perceptie van onzekerheid bij de investeerder (1) de beurswaarde van het kennis kapitaal van een bedrijf en (2) de mogelijkheid van een bedrijf om de beurs te gebruiken om R\&D te financieren, beïnvloeden?

- Dragen alliantie portfolio's bij aan het kennis kapitaal van een bedrijf zoals gemeten door de beurs?

- Beïnvloeden de percepties van onzekerheid bij investeerders de relatie tussen alliantie portfolio's en de beurswaarde van bedrijven?

- Wat is de relatie tussen allianties en de perceptie van bedrijfsspecifiek risico bij investeerders?

Elk van de vier empirische studies in dit proefschrift verschaft nieuwe inzichten in een of meer van deze onderzoeksvragen. In hoofdstuk 2 , heb ik onderzocht of en hoe R\&D investeringen invloed hebben op de winstprognose variatie van analisten aan de verkoopkant. Deze variatie is een maat voor de 'echte' onzekerheid wat betreft de toekomstige economische prestaties van een bedrijf (onderzoeksvraag I). Op basis van een panel van 299 productiebedrijven, tussen 1997 en 2006 genoteerd aan de New York Stock Exchange en de Nasdaq, is in deze studie een positief effect gevonden van R\&D intensiteit op de prognose variatie. In het artikel zijn ook de effecten van patenten op bedrijfsspecifieke onzekerheid onderzocht. Ik stelde dat patenten informatie over de kwaliteit van de $R \& D$ projecten van een bedrijf zouden verschaffen en daardoor zouden patenten de perceptie van onzekerheid bij investeerders verminderen (onderzoeksvraag II). Uit de empirische resultaten bleek inderdaad, dat patenten het positieve effect van R\&D op prognose variatie van analisten verminderen. Dit effect lijkt beperkt tot patenten van hoge kwaliteit, gemeten door het aantal forward citaties, non-patent referenties, het aantal claims, of het patent deel was van een triadic patent familie en of het patentrecht was vernieuwd. Tot slot wordt in hoofdstuk 2 beschreven dat de prognose variatie een negatief effect heeft op de beurswaarde van R\&D, maar niet op de beurswaarde van patenten (onderzoeksvraag III). Een mogelijke reden hiervoor zou kunnen zijn dat investeerders de toekomstige rendementen van $R \& D$ tegen een hogere rente verdisconteren, omdat het rendement op deze investeringen hoogst onzeker zijn. Patenten op hun beurt, kunnen weer een maat zijn voor (tussentijdse) innovatie output. Aangezien de informatie in patenten zekerder is, heb ik geen bewijs kunnen vinden voor een onzekerheid of ambiguiteit verdiscontering (Epstein en Schneider, 2008) van patenten.

In hoofdstuk 3 worden de effecten van de prognose variatie op de bedrijfsinvesteringen onderzocht (onderzoeksvraag III). Recente studies over dit onderwerp hebben grotendeels geen overeenstemmende resultaten opgeleverd (Bakke en Whited, 2001; Gilchrist et al., 2005; Lyandres, 2007; Thakor en Whited, 2011). Waar sommige eerdere studies aannemen dat prognose variatie een maat is voor dure externe financiering, stellen anderen dat prognose variatie een maat is voor de overwaardering van de aandeelprijs van het bedrijf. Ik heb gebruik gemaakt van twee baanbrekende papers van Miller (1977) en Merton (1986) en stelde dat de relatie tussen prognose variatie en de kosten voor externe financiering waarschijnlijk complexer is.

Of prognose variatie leidt tot een over- of onderwaardering van aandeelkoersen is afhankelijk van het type investering en van de mate van erkenning door investeerders waaraan een aandeel wordt blootgesteld. Ik heb de erkenning door investeerders gedefinieerd als het residu uit een regressie van het aantal analisten dat een aandeel aanprijst en de grootte van bedrijven. Met gebruik van een groot panel van Amerikaanse productiebedrijven die openbaar verhandeld werden tussen 1983 en 2006, heb ik een positief effect van prognose variatie op corporate investeringen (i.e. de som van R\&D en materiële investeringen) gevonden, maar alleen voor bedrijven met een hoge waardering van investeerders. Extra, ondersteunende regressies lieten zien dat dit positieve effect alleen geldt voor R\&D en niet voor materiële investeringen. 
In hoofdstuk 3 werd ook besproken hoe de voorkeuren voor verschillende manieren van financieren veranderden in navolging van veranderingen in prognose variatie. Ik vond hierbij een positieve en significante interactie term tussen prognose variatie en een proxy voor het uitgeven van nieuwe aandelen. Ook hier kon dit effect volledig worden uitgelegd door de veranderingen in $R \& D$ investeringen en golden alleen voor bedrijven met een hoge waardering van investeerders. Deze resultaten kunnen de suggestie wekken dat deelnemers in de markt de rendementen van R\&D projecten overwaarderen.

Deze resultaten zijn vrij verschillend ten opzichte van de resultaten voor bedrijven in het laagste kwartiel van investeerder waarderingen. Voor deze bedrijven is een algemeen negatief effect van prognose variatie op corporate investeringen beschreven. Frapant is dat, dit effect slechts gedreven was door materiële investeringen en niet door R\&D. Dit resultaat zou kunnen aanduiden dat het duurder is om $\mathrm{R} \& \mathrm{D}$ aan te passen en dat bedrijven $\mathrm{R} \& \mathrm{D}$ uitgaven niet aanpassen in reactie op de kosten van externe financiering. Additionele analyses, waarbij gebruik werd gemaakt van dynamische panel estimators, lieten zien dat het interactie effect tussen R\&D en het uitgeven van nieuwe aandelen negatief is. Bedrijven die door investeerders moeilijker te observeren zijn, zijn geneigd minder gebruik te maken van externe bronnen voor het financieren van $\mathrm{R} \& \mathrm{D}$ als de prognose variatie groot is. In het algemeen zijn de resultaten in dit hoofdstuk in overeenstemming met de bewering van Lazonick (2006), dat het bepaalde soorten ondernemingen zijn die gebruik maken van de aandelenmarkt voor het financieren van R\&D. Deze ondernemingen hebben een hoge visibiliteit met sterke (maar onzekere) groeimogelijkheden.

Hoofdstuk 4 en 5 onderzochten de percepties van alliantie portfolio's bij deelnemers in de aandelenmarkt. In hoofdstuk 4 heb ik gebruik gemaakt van de hedonische regressie benadering (Griliches, 1981, 1990; Hall, 1990; Hall et al., 2005) om de marktwaarde van de alliantie portfolio van bedrijven de bepalen (onderzoeksvraag III en V). De studie vond een positief effect van verkennende alliantie portfolio's op de beurswaarde van bedrijven. De marktwaarde van deze verkennende portfolio's bleek toe te nemen met de mate van bedrijsspecifieke risico's of onzekerheid. Deze resultaten zijn consistent met de opvattingen dat verkennende R\&D allianties signalen afgeven aan marktdeelnemers over de kwaliteit van de kennis van een bedrijf. Deze signalen worden belangrijker naar mate de bedrijfsspecifieke risico's en de onzekerheid toenemen.

In hoofdstuk 5 onderzocht ik de relatie tussen de alliantie portfolio's en de bedrijfsspecifieke risico's (onderzoeksvraag VI). Ik stelde hier dat alliantie portfolio's de bedrijfsspecifieke risico's op minstens twee manieren beïnvloeden. Enerzijds stellen allianties ondernemingen in staat om bedrijfsrisico's en de hoge kosten van R\&D de beheren. Dit geeft een positieve relatie tussen allianties en bedrijfsspecifieke risico's aan. Anderzijds zijn allianties inherent risicovol door factoren die samenhangen met deze organisatievorm.

Theoretisch gezien kunnen alliantie portfolio's de bedrijfsspecifieke risico's dus vergroten en verkleinen. Anderen noemen de relatie tussen allianties en risico als een 'onaangename paradox' in de literatuur (Bamford et al., 2003: 36). Om hun bedrijfsrisico's te beheren, gaan bedrijven organisatievormen aan die inherent risicovol zijn. De resultaten van hoofdstuk 5 lieten een complexe relatie tussen alliantie portfolio's en bedrijsspecifieke risico's zien. Terwijl bedrijven met grotere alliantie portfolio's met een hoger idiosyncratisch risico geconfronteerd leken te worden, vond de studie negatieve effecten van het aandeel joint ventures en het aandeel verkennende R\&D allianties in de alliantie portfolio's van bedrijven. Interessant is dat de studie ook vond dat de risico's van alliantie portfolio's aanzienlijk zijn toegenomen in de nasleep van het uiteenspatten van de 'technology bubble' in maart 2000. Deze bevinding zou kunnen impliceren dat alliantie portfolio's een kanaal zijn waarlangs risico zich onder bedrijven kan verspreiden. 


\section{Bibliography}

A

Aboody, D., Lev, B. 2000. Information asymmetry, R\&D, and insider gains. Journal of Finance, 55(6): 2747-2766.

Afuah, A. 2000. How much do your co-opetitors' capabilities matter in the face of technological change. Strategic Management Journal, 21: 387-404.

Aghion, P., Von Reenen, J., Zingales, L. 2010. Innovation and institutional ownership. Unpublished working paper, Harvard University.

Ahuja, G. 2000. Collaboration networks, structural holes, and innovation: A longitudinal study. Administrative Science Quarterly, 45: 435-455.

Akerlof, G. 1970. The market for 'lemons': Quality, uncertainty, and the market mechanism. Quarterly Journal of Economics, 84: 488-500.

Alcácer, J., Gittelman, M., Sampat, B. 2009. Applicant and examiner citations in U.S. patents: An overview and analysis. Research Policy, 38: 415-427.

Allen, F., Gale, D. 2000. Bubbles and crises. The Economic Journal, 110: 236-255.

Almeida, H., Campello, M. 2007. Financial constraints, asset tangibility, and corporate investment. The Review of Financial Studies, 20(5): 1429-1460.

Almeida, H., Campello, M., Galvao, A.F. 2010. Measurement errors in investment equations. The Review of Financial Studies, 23(9): 3279-3328.

Almeida, H., Campello, M., Weisbach, M.S. 2004. The cash flow sensitivity of cash. The Journal of Finance, Vol. 59(4): 1777-1804.

Anand, B.N., Khanna, T. 2000a. Do firms learn to create value? The case of alliances. Strategic Management Journal, 21: 295-315.

Anand, B.N., Khanna, T. 2000b. The structure of licensing contracts. Journal of Industrial Economics, 46: 103-135.

Anderson, E.W., Ghysels, E., Juergens, J.L. 2005. Do heterogeneous beliefs matter for asset pricing? The Review of Financial Studies, 18: 875-924.

Ang, A., Hodrick. R.J., Xing, Y., Zhang, X. 2009. High idiosyncratic volatility and low returns: International and further U.S. evidence. Journal of Financial Economics, 2009: 1-23.

Anton, J.J., Yao, D.A. 2004. Little patents and big secrets: Managing intellectual property. The RAND Journal of Economics, 35: 1-22.

Arend, R.J. 2004. Volatility-based effects of shareholder value: Alliance activity in the computing industry. Journal of Management, 30: 487-508.

Arellano, M., Bond, S. 1991. Some tests of specification for panel data: Monte Carlo evidence and an application to employment equations. Review of Economic Studies, 58: 277-297.

Arellano, M., Bover, O. 1995. Another look at the instrumental variable estimation of error component models. Journal of Econometrics, 68: 29-51.

Arora, A., Gambardella, A. 1990. Complementarity and external linkages: The strategies of the large firms in biotechnology. The Journal of Industrial Economics, 38: 361-379.

Arora, A., Fosfuri, A., Gambardella, A. 2001. Markets for Technology. The Economics of Innovation and Corporate Strategy. MIT Press, Cambridge. 
Arrow, K.J. 1962. Economic welfare and the allocation of resources for invention. In. R. Nelson (ed.) The rate and direction of inventive Activity, Princeton, NJ, Princeton University Press.

Arrow, K.J. 1971. Essays in the theory of risk-bearing. Chicago: Markham.

Asker, J., Farre-Mensa, J., Ljungqvist, A. 2011. Comparing the investment behavior of public and private firms. NBER Working Paper 17394

\section{B}

Baker, M., Wurgler, J. 2002. Market timing and capital structure. The Journal of Finance, 57(1): 1-32.

Bakke, T., Whited, T.M. 2010. Which firms follow the market? Analysis of corporate investment decisions. The Review of Financial Studies, 23(5): 1941-1980.

Baltagi, B.H., Wu, P.X. 1999. Unequally spaced panel data regressions with AR(1) disturbances. Econometric Theory, 15: 814-823.

Bamford, J.D., Gomes-Casseres, B., Robinson, M.S. 2003. Mastering alliance strategy - A comprehensive guide to design, management, and organization. Jossey-Bass. San Francisco, CA.

Barney, J.B. 1991. Firm resources and sustained competitive advantage. Journal of Management, 17: 9912.

Barron, O.E., Byard, D., Kile, C., Riedl, E. 2002. High technology intangibles and analysts' forecasts. Journal of Accounting Research, 40: 289-312.

Barron, O.E., Stuerke, P.S. 1998. Dispersion in analysts' earnings forecasts as a measure of uncertainty. Journal of Accounting, Auditing \& Finance, 13: 245-270.

Barth, M.E., Kasznik, R. McNichols, M.F. 2001. Analyst coverage and intangible assets. Journal of Accounting Research, 39: 1-34.

Bates, T.W., Kahle, K.M., Stulz, R.M. 2009. Why do U.S. firms hold so much more cash than they used to? The Journal of Finance, 64: 1985-2021.

Baum, C., Schaffer, M., Stillman, S. 2003. Instrumental variables and GMM: Estimation and testing. Stata Journal 3(1): 1-31

Baumol, W.J. 2002. The Free-Market Innovation Machine. Princeton University Press.

Bayona, C., Corredor, P., Santamaría, R. 2006. Technological alliances and the market valuation of new economy firms. Technovation, 26: 369-383.

Beardsley, G., Mansfield, E. 1978. A Note on the accuracy of industrial forecasts of the profitability of new products and processes. The Journal of Business, 51: 127-135.

Bernake, B., Gertler, M., Gilchrist, S. 1999. The financial accelerator in a quantitative business cycle framework. In: Taylor, J., Woodford, M. (eds.) Handbook of Macroeconomics.

Bernstein, S. 2012. Does going public affect innovation? Unpublished working paper, Harvard University.

Bessen, J. 2008. The value of U.S. patents by owner and patent characteristics. Research Policy, 37: 932945.

Bhattacharya, S., Ritter, J.R. 1983. Innovation and communication: Signaling with partial disclosure. Review of Economic Studies, 50: 331-346.

Blasnik, M. 2007. RECLINK: Stata module to probabilistically match records. Statistical Software Components S456876, Boston College Department of Economics, revised 18 Jan 2010.

Bloom, N. 2009. The impact of uncertainty shocks. Econometrica, 77: 623-685.

Bloom, N., Van Reenen, J. 2002. Patents, real options and firm performance. The Economic Journal, 112: 97-116. 
Blundell, R., Bond, S.R. 1998. Initial conditions and moment restrictions in dynamic panel data models. Journal of Econometrics, 87: 114-143.

Blundell, R., Griffith, R., van Reenen, J. 1999. Market share, market value and innovation in a panel of British manufacturing firms. The Review of Economic Studies, 66: 529-554.

Bodnaruk, A., Ostberg, P. 2009. Does investor recognition predict returns? Journal of Financial Economics, 91: 208-226.

Boehme, R.D., Danielsen, B.R., Sorescu, S.M. (2006). Short-sale constraints, differences of opinion, and overvaluation. Journal of Financial and Quantitative Analysis, 41: 455-486.

Boehme, R.D., Danielsen, B.R., Kumar, P., Sorescu, S.M. (2009). Idiosyncratic risk and the cross-section of stock returns: Merton (1987) meets Miller (1977). Journal of Financial Markets, 12: 438-468.

Bond, S.R., Cummins, J.G. 2000. The stock market investment in the new economy: Some tangible facts and intangible fictions. Brookings Papers on Economic Activity, 1: 61-108.

Bond, S.R., Cummins, J.G. 2004. Uncertainty and investment: An empirical investigation using data on analysts' profit forecasts. Finance and Economics Discussion Series 2004-20.

Boone, A.L., Ivanov, V.I. 2012. Bankruptcy spillover effects on strategic alliance partners. Journal of Financial Economics, 103: 551-569.

Boone, J.P., Raman, K.K. 2002. Off-balance sheet R\&D assets and market liquidity. Journal of Accounting and Public Policy, 20: 97-128.

Brands, H.W. 2010. American colossus: The triumph of capitalism, 1865-1900. Anchor Books, New York.

Brealey, R.A., Myers, S.C., Allen, F. 2006. Corporate Finance. McGraw-Hill, Irwin.

Brown, J.R., Petersen, B.C. 2009. Why has the investment-cash flow sensitivity declined so sharply? Rising R\&D and equity market developments. Journal of Banking \& Finance, 33(5): 971-984.

Brown, J.R., Petersen, B.C. 2011. Cash holdings and R\&D smoothing. Journal of Corporate Finance, 17: 694-709.

Brown, J.R., Fazzari, S.M., Petersen, B.C. 2009. Financing innovation and growth: Cash flow, external equity, and the 1990s R\&D boom. The Journal of Finance, 64(1): 151-185.

C

Campello, M., Graham, J. 2007. Do stock prices influence corporate decisions? Evidence from the technology bubble. NBER Working Paper 13640.

Chan, S.H., Kensinger, J.W., Keown, A.J., Martin, J.D. 1997. Do strategic alliances create value? Journal of Financial Economics, 46: 199-221.

Chan, L.K.C., Lakonishok, J., Sougiannis, T. 2001. The Stock Market Valuation of Research and Development Expenditures. The Journal of Finance, 56: 2431-2456.

Chandler, A.D. 1990. Scale and scope: The dynamics of industrial capitalism. Belknap, Harvard.

Cloodt, M., Hagedoorn, J., Roijakkers, N. 2010. Inter-firm R\&D networks in the global software industry: An overview of major trends and patterns. Business History, 52: 120-149.

Cockburn, I., Griliches, Z. 1988. Industry effects and appropriability measures in the stock market's valuation of R\&D and patents. The American Economic Review, 78: 419-423.

Cockburn, I.M., MacGarvie, M.J. 2009. Patents, thickets and the financing of early-stage firms: Evidence from the software industry. Journal of Economics \& Management Strategy, 18: 729-773.

Cockburn, I.M., Kortum, S., Stern, S. 2003. Are all patent examiners equal? Examiners, patent characteristics, and litigation outcomes. In W.Cohen and W. Merrill (eds.), Patents in the knowledge-based Economy. Washington DC, National Academies Press. 
Cohen, L., Diether, K., Malloy, C. 2011. Misvaluing innovation. Unpublished working paper, Harvard University.

Cohen, W., Nelson, R., Walsh, J. 2000. Protecting their intellectual assets: Appropriability conditions and why U.S. firms patent (or not). NBER Working Paper 7552.

Colombo, M.G., Grilli, L., Murtinu, S., Piscitello, L., Piva, E. 2009. Effects of international R\&D alliances on performance of high tech start-ups: A longitudinal analysis. Strategic Entrepreneurship Journal, 3: 346-368.

Colombo, M.G., Grilli, L., Piva, E. 2006. In search of complementary assets: The determinants of alliance formation of high tech start-ups. Research Policy, 35: 1166-1199.

Contractor, F.J., Lorange, P. 1988. Why should firms cooperate? The strategy and economic basis for cooperative ventures. In Cooperative strategies in international business, Contractor, F.J., Lorange, P. (eds.). Lexington books. Lexington, MA

Cyert, R.M., March, J.G. 1963. A behavioral theory of the firm. Englewood Cliffs, Prentice Hall.

Czarnitzki, D., Dhaene, G. 2011. Efficient fixed-effects estimation using pre-sample means, mimeo, KU Leuven.

Czarnitzki, D.; Hall, B.H., Oriani, R. (2006). The market valuation of knowledge assets in US and European firms, in: D. Bosworth and E. Webster, The Management of Intellectual Property, Cheltenham Glos, 111-131.

Czarnitzki, D., Hussinger, K., Leten, B. 2011. The market value of blocking patent citations. Working Paper KU Leuven, March 2011.

Czarnitzki, D. Hussinger, K., Schneider, C. 2011. Wacky patents meet economic indicators. Economics Letters, 113: 131-134.

Czarnitzki, D., Toole, A. 2011. Patent protection, market uncertainty, and R\&D investment. The Review of Economics and Statistics, 93: 147-159.

D

Daniel, K., Hirshleifer, D., Theo, S.H. 2002. Investor psychology in capital markets: Evidence and policy implications. Journal of Monetary Economics, 48: 139-209.

Daniel, K., Titman, S. 2006. Market Reactions to Tangible and Intangible Information. The Journal of Finance, 61: 1605-1643.

Das, R.K., Teng, B.S. 1996. Risk types and inter-firm alliance structures. Journal of Management Studies, 33: $827-843$.

Das, S., Sen, P.K., Sengupta, S. 1998. Impact of strategic alliances on firm valuation. Academy of Management Journal, 41: 27-41.

De Rassenfosse, G., Van Pottelsberghe de la Potterie, B. 2009. A policy insight into the R\&D-patent relationship. Research Policy, 38: 779-792.

Deeds, D.L., Hill, C.W.L. 1996. Strategic alliances and the rate of new product development: An empirical study of entrepreneurial biotech firms. Journal of Business Venturing, 11: 41-55.

DeLong, J.B., Magin, K. 2006. A short note on the size of the dot-com bubble. NBER Working Paper 12011.

De Man, A. 2005. Alliance capability: A comparison of the alliance strength of European and American Companies. European Management Journal, 23: 315-323.

Demsetz, H. 1988. The theory of the firm revisited. Journal of Law, Economics, and Organization, 4: 141-161. 
Dernis, H., Khan, M. 2004. Triadic patent families methodology. STI Working Paper. Paris, Organisation for Economic Co-operation and Development.

Dhanaraj, C., Beamish, P.W. 2004. Effect of equity ownership on the survival of international joint ventures. Strategic Management Journal, 25:295-305.

Diether, K.B., Malloy, C.J., Scherbina, A. 2002. Differences in opinion and the cross section of stock returns. Journal of Finance, 57: 2113-2141.

Dosi, G. 1982. Technological paradigms and technological trajectories: A suggested interpretation of the determinants and directions of technical change. Research Policy, 11: 147-162.

Dosi, G., Nelson, R.R. 1994. An introduction to evolutionary theories in economics. Journal of Evolutionary Economics, 4: 153-172.

Doukas, J.A., Kim, C., Pantzalis, C. 2005. The two faces of analyst coverage. Financial Management, summer 2005: 99-125

Doukas, J.A., Kim, C., Pantzalis, C. 2006. Divergent opinions and the performance of value stocks. Financial Analysts Journal, 60: 55-64.

Dyer, J.H., Singh, H. 1998. The relational view: Cooperative strategy and sources of Interorganizational advantage. Academy of Management Review, 23: 660-679.

Duncan, R.B. 1972. Characteristics of organizational environments and perceived environmental uncertainty. Administrative Science Quarterly, 17: 313-327.

Dussauge, P., Garrette, B., Mitchell, W. 2000. Learning from competing partners: Outcomes and durations of scale and link alliances in Europe, North America, and Asia. Strategic Management Journal, 21: 99-126.

E

Eastwood, J.C., Nutt, S.R. 1999. Inefficiency in analysts' earnings forecasts: Systematic misreaction or systematic optimism? Journal of Finance, 54: 1777-1997.

Elliot, W.B., Van Ness, B.F., Walker, M.D, Warr, R.S. (2006). What drives the S\&P 500 inclusion effect? An analytical survey. Financial Management, 35: 31-48.

Elton, E.J., Gruber, M.J., Gultekin, M.N. 1984. Professional expectations: Accuracy and diagnosis of errors. The Journal of Financial and Quantitative Analysis, 19: 351-363.

Eberhart, A.C., Maxwell, W.F., Siddique, A.R. 2004. An Examination of Long-Term Abnormal Stock Returns and Operating Performance Following R\&D Increases. The Journal of Finance, 59: 623650 .

Epstein, L.G., Schneider, M. 2008. Ambiguity, information quality, and asset pricing. The Journal of Finance, 63: 197-228.

$\mathbf{F}$

Fama, E.F., French, K.R. 1993. Common risk factors in the returns on stocks and bonds. Journal of Financial Economics, 33: 3-56.

Fazzari, S.M., Hubbard, R.G., Petersen, B.C. 1988. Financing constraints and corporate investment. Brookings Papers on Economic Activity, 1: 141-195.

Ferreira, D., Manso, G., Silva, A.C. 2012. Incentives to innovate and the decision to go public or private. The Review of Financial Studies, forthcoming.

Fleming, L., Sorensen, O. 2004. Science as a map in technological search. Strategic Management Journal, 25: 909-928. 
Frankort, H.T.W., Hagedoorn, J., Letterie, W. (2011). R\&D partnership portfolios and the inflow of technological knowledge. Industrial and Corporate Chance. Forthcoming.

Fu, F. (2009). Idiosyncratic risk and the cross-section of expected stock returns. Journal of Financial Economics, 2009: 24-37.

$\mathbf{G}$

Gambardella, A. Harhoff, D., Verspagen, B. 2008. The value of European patents. European Management Review, 5: 69-84.

Gans, J., Hsu, D., Stern, S. 2008. The impact of uncertain intellectual property rights on the market for ideas: Evidence from Patent Grant Delays. Management Science, 54: 982-997.

George, G., Zahra, S.A., Wheatley, K.K., Khan, R. 2001. The effects of alliance portfolio characteristics and absorptive capacity on performance: A study of biotechnology firms. Journal of High technology Management Research, 12: 205-226.

Gilchrist, S., Himmelberg, C.P., Huberman, G. 2005. Do stock price bubbles influence corporate investment. Journal of Monetary Economics, 52: 805-827.

Gilchrist, S., Sim, J.W., Zakrajšek, E. 2010. Uncertainty, financial frictions, and investment dynamics. Working Paper, Boston University.

Gittelman, M. 2008. A Note on the value of patents as indicators of innovation: Implications for management research. Academy of Management Perspectives, 22: 21-27.

Goerzen, A. 2007. Alliance networks and firm performance: The impact of repeated partnerships. Strategic Management Journal, 28: 487-509.

Gomes-Casseres, B. 1987. Joint venture instability: Is it a problem? Columbia Journal of World business, Summer 1987: 97- 102.

Gomes-Casseres, B., Hagedoorn, J., Jaffe, A.B. 2006. Do alliances promote knowledge flows. Journal of Financial Economics, 80: 5-33.

Graham, J.R., Campello, M. Do stock prices influence corporate decisions? Evidence from the technology bubble. Journal of Financial Economics, Forthcoming.

Graham, J.R., Harvey, C.R., Rajgopal, S. 2005. The economic implications of corporate financial reporting. Journal of Accounting and Economics, 40, 3-73.

Grant, R.M. 1996. Toward a knowledge-based theory of the firm. Strategic Management Journal, 17: 109122.

Griffin, J.H. Harris, J.H., Shu, T., Topaloglu, S. 2011. Who drove and burst the tech bubble? The Journal of Finance, 66: 1251-1290.

Griliches, Z. 1981. Market value, R\&D, and patents. Economic Letters, 7: 183-187.

Griliches, Z. 1990. Patent statistics as economic indicators: A survey. Journal of Economic Literature, 28: 1661-1707.

Griliches, Z. 1995. R\&D and productivity: Econometric results and measurement issues. In Handbook of the economics of innovation and technological change, edited by Paul Stoneman, 52-89. Oxford, U.K. Blackwell.

Guellec, D. and van Pottelsberghe de la Potterie, B. 2008. The economics of the European patent system. Oxford University Press.

Gulati, R. 1995. Does familiarity breed trust? The Implications of repeated ties for contractual choice in alliances. The Academy of Management Journal, 38: 85-112.

Gulati, R. 1998. Alliances and networks. Strategic Management Journal, 19: 293-317. 
Güntay, L., Hackbarth, D. 2010. Corporate bond credit spreads and forecast dispersion. Journal of Banking \& Finance, 34, 2328-2345.

\section{H}

Hagedoorn, J. 1990. Organizational modes of inter-firm co-operation and technology transfer. Technovation, 10: 17-30.

Hagedoorn, J. 1993. Understanding the rationale of strategic technology partnering: Interorganizational modes of cooperation and sectoral differences. Strategic Management Journal, 14: 371-385.

Hagedoorn, J. 2002. Inter-firm R\&D partnerships: an overview of major trends and patterns 1960. Research Policy, 31: 477-492.

Hagedoorn, J., Hesen, G. 2009. Contractual complexity and the cognitive load of R\&D alliance contracts. Journal of Empirical Legal Studies, 6: 818-847.

Hagedoorn, J. Narula, R. 1996. Choosing organizational modes of strategic technology partnering: International and sectoral differences. Journal of International Business Studies, 27: 265-284.

Hagedoorn, J., Schakenraad, J. 1994. The effect of strategic technology alliances on company performance. Strategic Management Journal, 15: 291-311.

Hall, B.H. 1993a. The stock market valuation of R\&D investment during the 1980s. American Economic Review, 83, 259-264.

Hall, B.H. 1993b. Industrial research during the 1980s: Did the rate of return fall? Brookings Papers on Economic Activity. Microeconomics, 2: 289-344.

Hall, B.H. 1993c. The value of intangible corporate assets: an empirical study of the components of Tobin's q. University of California, Berkley Working Paper No. 93-207.

Hall, B.H. 2000. Innovation and market value. In Productivity, innovation and economic performance, Mason, B.R., O’Mahoney, M. (eds). Cambridge University Press: Cambridge, UK, 177-198.

Hall, B.H. 2002. The financing of research and development. Oxford Review of Economic Policy, 18(1), 35-51.

Hall, B.H. 2005. Measuring the returns to R\&D: The depreciation problem. Annales d'Economie et de Statistique, 79-80: 341-381.

Hall, B.H., Griliches, Z., Hausman, J.A. 1986. Patents and R\&D: Is there a lag? International Economic Review, 27: 265-284.

Hall, B.H., Jaffe, A.B., Trajtenberg, M. 2005. Market value and patent citations. The R\&D Journal of Economics, 36: 16-38.

Hall, B.H., Oriani, R. 2006. Does the market value R\&D investments by European firms? Evidence from a panel of manufacturing firms in France, Germany, and Italy. International Journal of Industrial Organization, 24: 971-993.

Hall, B.H., Mairesse, J., Mohnen, P. 2009. Measuring the returns to R\&D. NBER Working Paper No. 15622.

Hall, B.H., Thoma, G., Torrisi, S. 2007. The market value of patents and R\&D: Evidence from European firms. NBER Working Paper, August 2007.

Hamel. G. 1991. Competition for competence and interpartner learning within international strategic alliances. Strategic Management Journal, 12: 83-103.

Harhoff, D., Narin, F., Scherer, F.M., Vopel, K. 1999. Citation frequency and the value of patented inventions. The Review of Economics and Statistics, 81: 511-515.

Harhoff, D., Reitzig, M. 2004. Determinants of opposition against EPO patent grants - The case of biotechnology and pharmaceuticals. International Journal of Industrial Organization, 22: 443-480. 
Harhoff, D, Scherer, F.M. 2000. Technology policy for a world of skew-distributed outcomes. Research Policy, 29: 559-566.

Harhoff, D., Scherer, F.M., Vopel, K. 2003. Citations, family size, opposition and the value of patent rights. Research Policy, 32: 1343-1363.

Harrigan, K.R. 1988. Joint ventures and competitive strategy. Strategic Management Journal, 9: 141-158.

Häussler, C., Harhoff, D., Mueller, E. 2010. To be financed or not - The role of patents for venture capital financing. Unpublished Working Paper, May 18 ${ }^{\text {th }}, 2010$.

Hail, L., Leuz, C. 2009. Costs of capital effects and changes in growth expectations around U.S. crosslistings. Journal of Financial Economics, 93: 428-454.

Healy PM, Palepu KG. 2001. Information asymmetry, corporate disclosure, and the capital markets: a review of the empirical disclosure literature. Journal of Accounting and Economics, 31: 405-44.

Hegde, D., Sampat, B. 2009. Examiner citations, applicant citations, and the private value of patents. Economics Letters, 105: 287-289.

Hertzel, M.G., Li, Z. Officer, M.S., Rodgers, K.J. (2008). Inter-firm linkages and the wealth effects of financial distress along the supply chain. Journal of Financial Economics, 87: 374-387.

Hill, C.W.L., Hoskisson, R.E. 1987. Strategy and structure in the multiproduct firm. The Academy of Management Review, 12: 331-341.

Himmelberg, C.P., Petersen, B.C. 1994. R\&D and internal finance: A panel study of small firms in high tech industries. The Review of Economics and Statistics, 76: 38-51.

Hirschey, M., Richardson, V.J. 2004. Are scientific indicators of patent quality useful to investors? Journal of Empirical Finance, 11: 91-107.

Hitt, M.A., Dacin, M.T., Levitas, E. 2000. Partner selection in emerging and developed market contexts: Resource-based and organizational learning perspectives. The Academy of Management Journal, 43: 449-467.

Hoffmann, W.H. 2005. How to manage a portfolio of alliances. Long Range Planning, 38: 121-143.

Hoffmann, W.H. 2007. Strategies for managing a portfolio of alliances. Strategic Management Journal, 28 : 827-856.

Holtz-Eakin, D., Newey, W., Rosen, H.S. 1988. Estimating vector autoregressions with panel data. Econometrica, 56, 1371-1395.

Hong, H., Kubik, J.D. 2003. Analyzing the analysts: career concerns and biased earnings forecasts. The Journal of Finance, 58: 313-349.

Hong, H., Kubik, J.D., Scheinkman, J.A. 2011. Financial constraints on corporate goodness. NBER Working Paper. Available from SSRN at: http://ssrn.com/abstract=1734164.

Hou, K., Moskowitz, T.J. 2005. Market frictions. Price delay, and the cross-section of expected returns. The Review of Financial Studies, 18(3): 981-1020.

Hsu, D., Ziedonis, R. 2007. Appropriability, proximity, routines and innovation. Paper to be presented at DRUID Summer Conference 2007.

\section{I}

Inkpen, A.C. 1996. Creating knowledge through cooperation. California Management Review, 39: 123140.

\section{J}

Jaffe, A.B. 2004. The U.S. Patent system in transition: Policy innovation and the innovation process. Research Policy, 29: 531-557. 
Jaffe, A.B., Lerner, J. 2004. Innovation and its discontents. Princeton, NJ, Princeton University Press.

Johnson, T.C. 2004. Forecast Dispersion and the Cross Section of Expected Returns. Journal of Finance, 59: 1957-1978.

Jones, G.R., Hill, C.W.L. 1088. Transaction cost analysis of strategy-structure choice. Strategic Management Journal, 9: 159-172.

\section{$\mathbf{K}$}

Kale, P., Dyer, J.H., Singh, H. 2002. Alliance capability, stock market response, and long-term alliance success: the role of the alliance function. Strategic Management Journal, 23: 747-767.

Kaplan, S.N., Zingales, L. 1997. Do Investment Cash Flow Sensitivities Provide Useful Measures of Financing Constraints? The Quarterly Journal of Economics, February: 169-215.

Khanna, T., Gulati, R., Nohria, N. 1998. The dynamics of learning alliances: Competition, cooperation, and relative scope. Strategic Management Journal, 19: 193-210.

Killing, P.J. 1988. Understanding alliances: The role of task and organizational complexity. In Cooperative strategies in international business, Contractor, F.J., Lorange, P. (eds.). Lexington books. Lexington, $\mathrm{MA}$

Kim, J., Marschke, G. 2004. Accounting for the recent surge in US patenting: Changes in R\&D expenditures, patent yields, and the high tech sector. Economics of Innovation and New Technology, 13: 674-692.

King, M.R., Segal, D. 2009. The long-term effects of cross-listing, investor recognition, and ownership structure on valuation. Review of Financial Studies, 22: 2393-2421.

Kogut, B. 1989. The stability of joint ventures. Reciprocity and competitive rivalry. Journal of Industrial Economics, 38: 183-198.

Kogut, B., Zander, U. 1992. Knowledge of the firm, combinative capabilities, and the replication of technology. Organization Science, 3: 383-397.

Koh, J., Venkatraman, N. 1991. Joint venture formations and stock market reactions: An assessment in the information technology sector. Academy of Management Journal, 34: 869-892.

Koka, B.R., Prescott, J.E. 2002. Strategic alliances as social capital: A multidimensional view. Strategic Management Journal, 23: 795-816.

Kortum, S., Lerner, J. 1999. What is Behind the Recent Surge in Patenting? Research Policy 28, 1-22.

Kothari, S.P., Laguerre, T.E., Leone, A.J. 2002. Capitalization versus expensing: Evidence on the uncertainty of future earnings from capital expenditures versus $R \& D$ outlays. Review of Accounting Studies, 7: 355-382.

Koza, M.P., Lewin, A.Y. 1998. The co-evolution of strategic alliances. Organization Science, 9: 255-264.

Knight, F. 1921/2006. Risk, uncertainty and profit. Dover Publications: Mineola, NY (Original work published in 1921 by Houghton Mifflin: Boston).

Krishnan, R., Martin, X., Noorderhaven, N.G. 2006. When does trust matter for alliance performance? The Academy of Management Journal, 49: 894-917.

Kumar, M.V.S. 2010. Are joint ventures positive sum games? The relative effects of cooperative and noncooperative behavior. Strategic Management Journal, 32: 32-54.

Kumar, S., Park, J.C. 2012. Partner characteristics, information asymmetry, and the signaling effects of joint ventures. Managerial and Decision Economics, 33: 127-145.

Kumar, P., Sorescu, S.M., Boehme, R.D., Danielsen, B.R. 2008. Estimation risk, information, and the conditional CAPM: Theory and evidence. The Review of Financial Studies, 21: 1037-1075. 
$\mathbf{L}$

Lanjouw, J.O., Schankerman, M. 2001. Characteristics of patent litigation: A window on competition. The RAND Journal of Economics, 32: 129-151.

Lanjouw, J.O., Schankerman, M. 2004. Patent quality and research productivity: Measuring innovation with multiple indicators. The Economic Journal, 114: 441-465.

Lanjouw, J.O., Pakes, A., Putnam, J. 1996. How to count patents and value intellectual property: Uses of patent renewal and application data. NBER Working Paper No. 5741.

Larsson, R., Bengtsson, L., Henriksson, K., Sparks, J. 1998. The interorganizational leaning dilemma: Collective knowledge development in strategic alliances. Organization Science, 9: 285-305.

Lavie, D. 2007. Alliance portfolios and firm performance: A study of value creation and appropriation in the U.S. software industry. Strategic Management Journal, 28: 1187-1212.

Lavie, D., Kang, J., Rosenkopf, L. 2011. Balance within and across domains: The performance implications of exploration and exploitation in alliances. Organization Science, 22: 1517-1538.

Lavie, D., Miller, S.R. 2008. Alliance portfolio internationalization and firm performance. Organization Science, 19: 623-646.

Lavie, D., Rosenkopf, L. 2006. Balancing exploration and exploitation in alliance formation. Academy of Management Journal, 49: 797-818.

Lawrence, P.R., Lorsch, J.W. Organization and environment. Homewood, Illinois. Irwin.

Lazonick, W. 2006. The innovative firm. In Nelson, R.R., Fagerberg, J, Mowery, D.C. The Oxford Handbook of Innovation, Oxford University Press: 29-55.

Lazonick, W. 2007. The US stock market and the governance of the innovative enterprise. Industrial and Corporate Change, 16: 983-1035.

Lerner, J., Merges, R.P. (1998). The Control of Technology Alliances: An Empirical Analysis of the Biotechnology Industry. The Journal of Industrial Economics, 46: 125-156.

Lerner, J., Sorensen, M., Strömberg, P. 2011. Private equity and long-run investment: The case of innovation. The Journal of Finance, 66: 445-475.

Lerner, J., Shane, H., Tsai, A. 2003. Do equity financing cycles matter? Evidence from biotechnology alliances. Journal of Financial Economics, 67: 411-446.

Lev. B. 2001. Intangibles: Management, measurement, and reporting. Brookings Institution Press, Washington D.C.

Levinthal, D., March, J.G. 1981. A model of adaptive organizational search. Journal of Economic Behavior and Organization, 2: 307-333.

Lin, H., McNichols, M.F. 1998. Underwriting relationships, analysts' earnings forecasts and investment recommendations. Journal of Accounting and Economics, 25: 101-125.

Ljungqvist, A., Malloy, C., Marston, F. 2009. Rewriting history. Journal of Finance, 64: 1935-196.

Long, C. 2002. Patent signals. The University of Chicago Law Review, 69: 625-679.

Luo, Y. 2007. Are joint venture partners more opportunistic in more volatile environments? Strategic Management Journal, 28: 39-60.

Lyandres, E. 2007. Costly external financing, investment timing, and investment-cash flow sensitivity. Journal of Corporate Finance, 13: 959-980.

$\mathbf{M}$

Makino, S., Chan, C.M., Isobe, T., Beamish, P.W. 2007. Intended and unintended termination of international joint ventures. Strategic Management Journal, 28: 1113-1132. 
Mansfield, E., Rapoport, J., Romeo, A., Villani, E., Wagner, S., Husic, F. 1977. The production and application of new industrial technology. New York: Norton.

Mansi, S.A., Maxwell, W.F., Miller, D.P. 2011. Analyst forecast characteristics and the cost of debt. Review of Accounting Studies, 16: 116-142.

March, J.G. 1991. Exploration and exploitation in organizational learning. Organization Science, 2, $71-87$.

Mazzucato, M., Tancioni, M. 2008. Innovation and idiosyncratic risk: An industry- and firm-level analysis. Industrial and Corporate Change, 17: 779-811.

Merchant, H. and Schendel, D. 2000. How do international joint ventures create shareholder value? Strategic Management Journal, 21: 723-737.

Merges, R.P., Nelson, R.R. 1990. On the complex economics of patent scope. Columbia Law Review, 90: 839-916.

Merton, R.C. 1987. A simple model of capital market al.location with incomplete information. The Journal of Finance, 42: 483-510.

Miller, E.M. 1977. Risk, uncertainty, and divergence of opinion. The Journal of Finance, 32: 1151-1168.

Mitchell, W. 1999. Alliances: Achieving long-term value and short-term goals. Financial Times "Mastering Strategy" series, October 1999.

Mitchell, W., Singh, K. 1996. Survival of businesses using collaborative relationships to commercialize complex goods. Strategic Management Journal, 17: 169-196.

Modigliani, F., Miller, M.H. (1958). The cost of capital, corporate finance, and the theory of investment. The American Economic Review, 48: 261-297.

Moeller, S.B., Schlingemann, F.P., Stulz, R.M. 2007. How do diversity of opinion and information asymmetry affect acquirer returns? The Review of Financial Studies, 20, 2047-2078.

Mowery, D.C. 2009. Plus ca change. Industrial R\&D in the 'third industrial revolution.' Industrial and Corporate Change, 18: 1-50.

Mowery, D.C., Oxley, J.E., Silverman, B.S. 1996. Strategic alliances and interfirm knowledge transfer. Strategic Management Journal, 17: 77-91.

Myers, S.C. 1984. The capital structure puzzle. The Journal of Finance, 39: 575-592.

Myers, S.C., Majluf, N.S. 1984. Corporate financing and investment decisions when firms have information that investors do not have. Journal of Financial Economics, 13: 187-221.

$\mathbf{N}$

Narin, F., Hamilton, K.S., Olivastro, D. 1997. The increasing linkage between U.S. technology and public science. Research Policy, 26: 317-330.

Narula, R., Duysters, G. 2004. Globalization and trends in international R\&D alliances. Journal of International Management, 10: 199-218.

Nelson, R.R. 1990. Capitalism as an engine for progress. Research Policy, 19: 193-214.

Nelson, R.R. 1991. Why do firms differ and how does it matter? Strategic Management Journal, 12: 61-74.

Nelson, R.R., Winter, S.G. 1977. In search of useful theory of innovation. Research Policy, 6: 36-76.

Nelson, R.R., Winter, S.G. 1982. An evolutionary theory of economic change. Cambridge, MA: Harvard University Press.

Nicholson, S., Danzon, P.M., McCullough, J. 2003. Biotech-pharmaceutical alliances as a signal of asset and firm quality. NBER Working Paper No. 9007.

Nickell, S. 1981. Biases in dynamic models with fixed effects. Econometrica, 49: 1417-1426. 
Nooteboom, B., Berger, H., Noorderhaven, N.G. 1997. Effects of trust and governance on relational risk. Academy of Management Journal, 40: 308-338.

Norman, P.M. 2001. Protecting knowledge in strategic alliances: Resource and relational characteristics. The Journal of High Technology Management Research, 13: 177-202.

$\mathbf{O}$

OECD 2011. OECD Triadic patent families database, July 2011

OECD 2012. Main science and technology indicators: Volume 2011/2: 18-21.

Ofek, E., Richardson, M. 2003. DotCom Mania: The rise and fall of internet stock prices. The Journal of Finance, 58: 1113-1138.

Olsen, R.A., Troughton, G.H. 2000. Are risk premium anomalies caused by ambiguity? Financial Analysts Journal, 56: 24-31.

Oriani, R., Sobrero, M. 2008. Uncertainty and the market valuation of R\&D within a real options logic. Strategic Management Journal, 29: 343-361.

O’Sullivan, M. 2006. Innovation and Finance. In Nelson, R.R., Fagerberg, J, Mowery, D.C. The Oxford Handbook of Innovation, Oxford University Press: 240-265.

Oxley, J.E. 1997. Appropriability hazards and governance in strategic alliances: A transaction cost approach. Journal of Law, Economics, and Organization, 13: 387-409.

Oxley, J.E., Sampson, R.V. 2004. The scope and governance of international R\&D alliances. Strategic Management Journal, 25: 723-750.

Oxley, J.E., Sampson, R.C., Silverman, B.S. 2009. Arms race or détente? How alliance announcements change the stock market valuations of rivals. Management Science, 55: 1321-1337.

Ozcan S, Overby ML. 2008. A cognitive model of stock market reactions to multi-firm alliance announcements. Strategic Organization, 6: 435-469.

$\mathbf{P}$

Pakes, A., Schankerman, M. 1984. The rate of obsolescence of patents and research gestation lags, and the private rate of return to research resources. In: Griliches, Z. (eds.). R\&D, patents, and productivity. Chicago: University of Chicago Press.

Palmon, D., Yezegel, A. 2012. R\&D intensity and the value of analysts' recommendations. Contemporary Accounting Research, Forthcoming.

Park, N.K., Mezias, J.M. 2005. Before and after the technology sector cash: The effect of environmental munificence on stock market response to alliances of e-commerce firms. Strategic Management Journal, 26: 987-1007.

Park, S.H., Russo, M. 1996. When competition eclipses cooperation: An event history analysis of alliance failure. Management Science, 42: 875-890.

Park, S.H., Ungson, G.R. 2001. Interfirm rivalry and managerial complexity. A framework of alliance failure. Organization Science, 12: 37-53.

Parkhe, A. 1993. The structuring of strategic alliances: A game-theoretic and transaction-cost examination of interfirm cooperation. Academy of Management Journal, 36: 794-829.

Pavitt, K. 2002. Innovating routines in the business firm: What corporate tasks should they be accomplishing? Industrial and Corporate Change, 11: 117-133.

Penin, J. 2005. Patents versus ex post rewards: A new look. Research Policy, 34: 641-656.

Perez, C. 2009. The double bubble at the turn of the century: Technological roots and structural implications. Cambridge Journal of Economics, 33: 779-805. 
Pisano, G.P., Teece, D.J. 1989. Collaborative arrangements and global technology strategy: Some evidence from the telecommunications equipment industry. Research on Technological Innovation, Management and Policy, 4: 227-256.

Polanyi, M. 1966/1983. The tacit dimension. Peter Smith, Gloucester, Mass. Reprinted 1983 by arrangement with Doubleday \& Company, Inc.

Powell, W.W., Koput, K.W., Smith-Doerr, L. 1996. Interorganizational cooperation and the locus of innovation: Networks of learning in biotechnology. Administrative Science Quarterly, 41: 116145.

\section{$\mathbf{R}$}

Rajan, R.G., Zingales, L. 2000. The governance of the new enterprise. NBER Working Paper 7958.

Ravenscraft, D., Scherer, F.M. 1982. The lag structure of returns to research and development. Applied Economics, 14: 603-620.

Reitzig, M. 2004. Improving patent valuations for management purposes - Validating new indicators by analyzing application rationales. Research Policy, 33: 939-957.

Reuer, J.J., Ragozzino, R. 2006. Agency hazards and alliance portfolios, Strategic Management Journal, 27: $27-41$.

Reuer, J.J., Zollo, M. 2005. Termination outcomes of research alliances. Research Policy, 34: 101-115.

Reuer, J.J., Zollo, M., Singh, H. (2002). Post-formation dynamics in strategic alliances. Strategic Management Journal, 23: 135-151.

Ring, P.S., Van de Ven, A.H. 1992. Structuring cooperative relationships between organizations. Strategic Management Journal, 13: 483-498.

Roijakkers, N., Hagedoorn, J. 2006. Inter-firm R\&D partnering in pharmaceutical biotechnology since 1975: Trends, patterns, and networks. Research Policy, 35: 431-446.

Rosenberg, N. 1994. Exploring the black box: Technology, economics, and history. Cambridge, UK, Cambridge University Press.

Rosenberg, B., McKibben, W. 1973. The prediction of systematic and specific risk in common stocks. The Journal of Financial and Quantitative Analysis, 8: 317-333.

Rosenkopf, L., Schilling, M.A. 2007. Comparing alliance network structure across industries: Observations and Explanations. Strategic Entrepreneurship Journal, 1: 191-209.

Rothaermel, F.T. 2001. Incumbent's advantage through exploiting complementary assets via interfirm cooperation. Strategic Management Journal, 22: 687-699.

Rothaermel, F.T., Deeds, D.L. 2004. Exploration and exploitation alliances in biotechnology: A system of new product development. Strategic Management Journal, 25: 201-221.

Rowley, T., Behrens, D., Krackhardt, D. 2000. Redundant governance structures: An analysis of structural and relational embeddedness in the steel and semiconductor industries. Strategic Management Journal, 21: 369-386.

\section{S}

Sadka, R., Scherbina, A. 2007. Analyst disagreement, mispricing, and liquidity. The Journal of Finance, 62: 2367-2403.

Sampson, R.C. 2004. The costs of misaligned governance in R\&D alliances. Journal of Law, Economics and Organization, 20: 484-526.

Sampson, R.C. 2007. R\&D alliances and firm performance: The impact of technological intensity and alliance organization on innovation. Academy of Management Journal, 50: 364-386. 
Schankerman, M., Pakes, A. 1986. Estimates of the value of patent rights in European countries during the post-1950 period. Economic Journal, 97: 1-25.

Schilling, M.A. 2009. Understanding the alliance data. Strategic Management Journal, 30: 233-260.

Schilling, M.A., Phelps, C. 2007. Interfirm collaboration networks: The impact of large-scale network structure on firm innovation. Management Science, 53: 1113-1127.

Schumpeter, J. 1942/2008. Capitalism, socialism, and democracy, Harper \& Row: New York. Reprinted: First Harper Perennial Modern Thought Edition: New York.

Schwert, G.W. 2002. Stock volatility in the new millennium: How wacky is the Nasdaq? Journal of Monetary Economics, 49: 3-26.

Scotchmer, S., Green, J. 1990. Novelty and disclosure in patent law. The RAND Journal of Economics, 21: 13-146.

Serrano, C.J. 2010. The dynamics of the transfer and renewal of patents. RAND Journal of Economics, 41: 687-708.

Singh, K, Mitchell, W. 1996. Precarious collaboration: Business survival after partners shut down or form new partnerships. Strategic Management Journal, 17: 99-115.

Steensma, H.K., Marino, L., Weaver, K.M., Dickson, P.H. 2000. The influence of national culture on the formation of technology alliances by entrepreneurial firms. Academy of Management Journal, 43: 951-973.

Stein, J.C. 1988. Takeover threats and managerial myopia. Journal of Political Economy, 96:61-80.

Steinhilber, B. 2008. Strategic alliances: Three ways to make them work. Cambridge MA: Harvard Business Press.

Stuart, T.E. 1998. Network positions and propensities to collaborate: An investigation of strategic alliance formation in a high technology industry. Administrative Science Quarterly, 43: 668-698.

Stuart, T.E. 2000. Interorganizational alliances and the performance of firms: a study of growth and innovation in a high technology industry. Strategic Management Journal, 21: 791-811.

Swaminathan, V., Moorman, C. 2009. Marketing alliances, firm networks, and firm value creation. Journal of Marketing, 73: 52-69.

$\mathrm{T}$

Teece, D.J. 1986. Profiting from technological innovation: Implications for integration, collaboration, licensing, and public policy. Research Policy, 15: 285-305.

Teece, D.J. 1992. Competition, cooperation, and innovation: Organizational arrangements for regimes of rapid technological progress. Journal of Economic Behavior and Organization, 18: 1-25.

Teece. D.J. 1993. The dynamics of industrial capitalism: Perspective on Alfred Chandler's scale and scope. Journal of Economic Literature, 31:199-225.

Teece, D.J., Pisano, G., Shuen, A. 1997. Dynamic capabilities and strategic management. Strategic Management Journal, 18: 509-533.

Thakor, A.V., Whited, T.M. 2011. Shareholder-manager disagreement and corporate investment. Review of Finance, 15, 277-300.

The Economist 2007. Out of the dusty labs: The rise and fall of corporate R\&D. Print Edition 11 March 2007.

Thomas, S. 2002. Firm diversification and asymmetric information: Evidence from analysts' forecasts and earnings announcements. Journal of Financial Economics, 64: 373-397.

Toivanen, O., Stoneman, P., Bosworth, D. (2002). Innovation and the Market Value of UK Firms. Oxford Bulletin of Economics and Statistics, Vol. 64, 39-61. 
Tomkins, C. 2001. Interdependencies, trust and information in relationships, alliances and networks. Accounting, Organizations and Society, 26: 161:191.

Trajtenberg, M. 1990. A Penny for your quotes: Patent citations and the value of innovations. RAND Journal of Economics, 21, 172-187.

Trueman, B. 1994. Analyst forecasts and herding behavior. Review of Financial Studies, 7: 97-124.

V

Van Ness, B.F., Van Ness, R.A., Warr, R.S. 2001. How well do adverse selection components measure adverse selection? Financial Management, Autumn 2001: 77-98.

Vassolo, R.S., Anand, J., Folta, T.B. 2004. Non-additivity in portfolios of exploration activities: a real options-based analysis of equity alliances in biotechnology. Strategic Management Journal, 25: 1045-1061

Verrechia, R.E. 1982. The Use of Mathematical Models in Financial Accounting. Journal of Accounting Research, 20: 1-46.

Von Stamm, B. 2003. Managing innovation, design, and creativity. London Business School, Case study No. 10: The Technology Partnership. London, UK.

W

Wassmer, U., Dussauge, P. 2011. Network resource stocks and flows: How do alliance portfolios affect the value of new alliance formations? Strategic Management Journal, Forthcoming.

Wernerfelt, B. 1984. A resource-based view of the firm. Strategic Management Journal, 5: 171-180.

Whited, T.M., Wu, G. 2006. Financial constraints risk. The Review of Financial Studies, Vol. 19(2): 531559.

Williamson, O.E. 1985. The economic institutions of capitalism. Free Press: New York.

Williamson, O.E. 1991. Comparative economic organization: The analysis of discrete structural alternatives. Administrative Science Quarterly, 36: 269-296.

Williamson, O.E. 2005. The economics of governance. The American Economic Review, 92: 1-18.

\section{$\mathbf{Z}$}

Zaheer, A., Hernandez, E. 2011. The geographic scope of the MNC and its alliance portfolio: Resolving the paradox of distance. Global Strategy Journal, 1: 109:126.

Zaheer, A., McEvily, B., Perrone, V. 1998. Does trust matter? Exploring the effects of interorganizational and interpersonal trust on performance. Organization Science, 9: 141-159.

Zhang, X.F. 2006. Information uncertainty and stock returns. The Journal of Finance, 61: 105-137.

Zingales, L. 2000. In search of new foundations. The Journal of Finance, 55: 1623-1653. 


\section{Biography}

Sebastian Pacher was born on March 16, 1982 in Neuss, Germany. He holds a master's degree in international business from Maastricht University and a bachelor's degree in business administration from the University of Hertfordshire. After graduating from Maastricht University in June 2008, he joined the Department of Organization and Strategy at Maastricht University as a $\mathrm{PhD}$ candidate. During his $\mathrm{PhD}$ studies, Sebastian was a visiting researcher at the Harvard Graduate School of Arts and Sciences in Cambridge and at the University of California, Berkeley. Parts of this dissertation have been presented at various conferences and workshops, including the COST PhD workshop 2009 in La Bastide d'Anjou (France), the CISS 2010 - Competition and Innovation Summer School in Turunç/Marmaris (Turkey), the innovation seminar at the University of California at Berkeley (USA), the ZEW in Mannheim (Germany), and the third Asia-Pacific Innovation Conference at Seoul National University (South Korea). As of September 2012, Sebastian is working as a researcher at the UNU-Merit in Maastricht. 